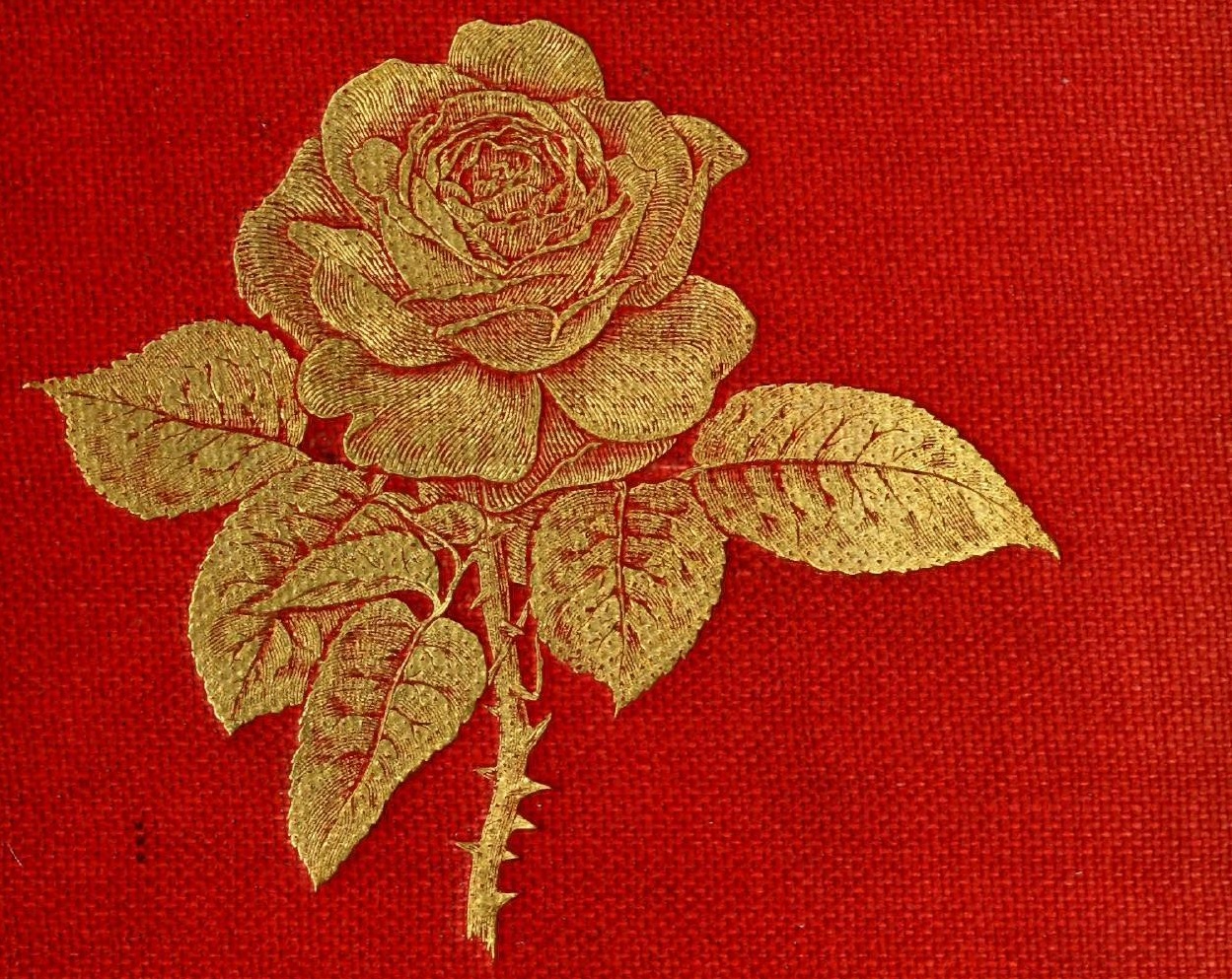

- 

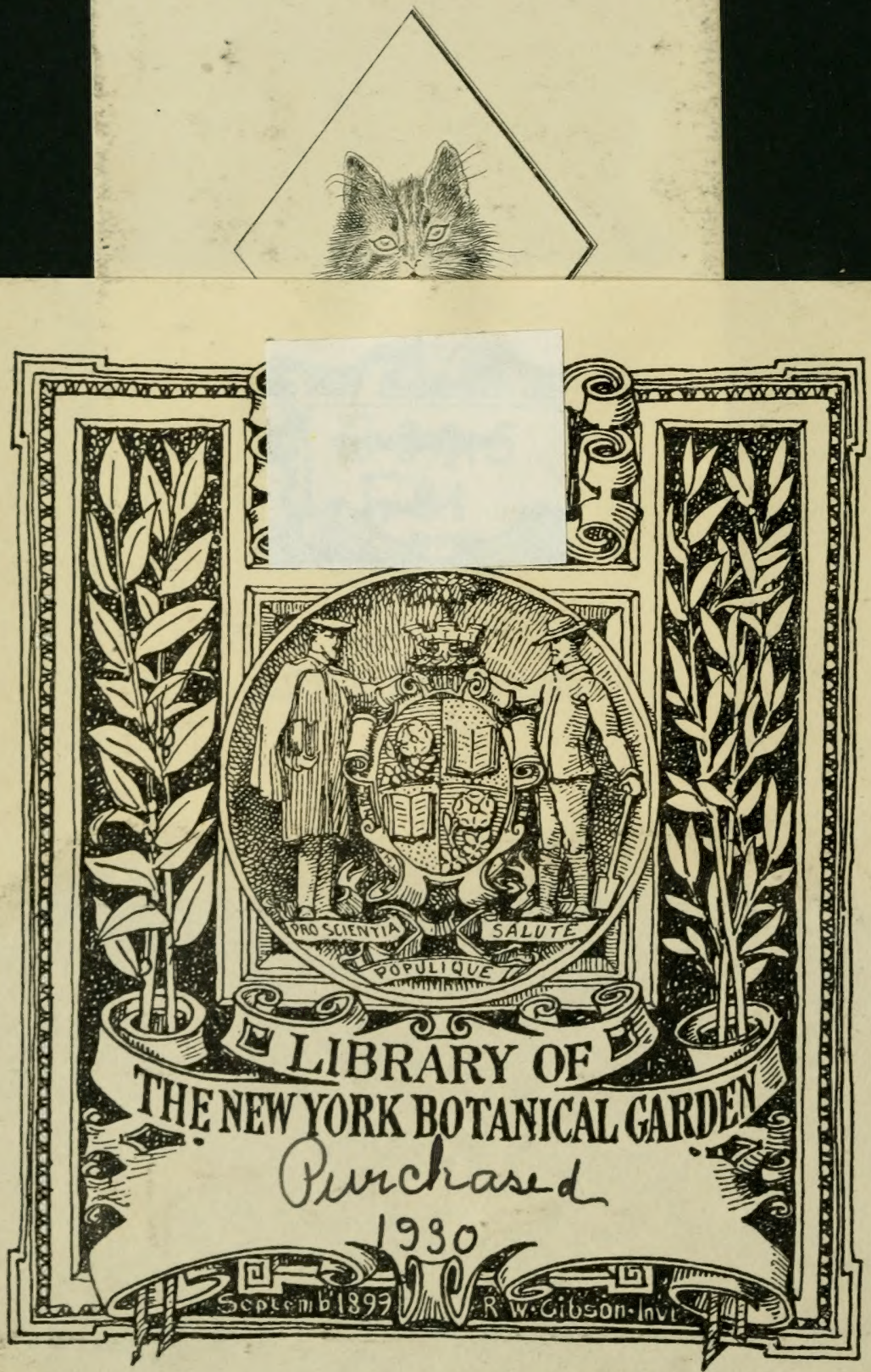

2. Hoseve
Iany 1895-

THE

\section{BOOK OF THE ROSE}

IIBRARY

NEW YORK BOTANICAL, ICARDEN 


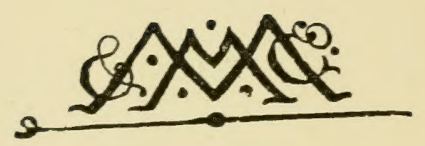





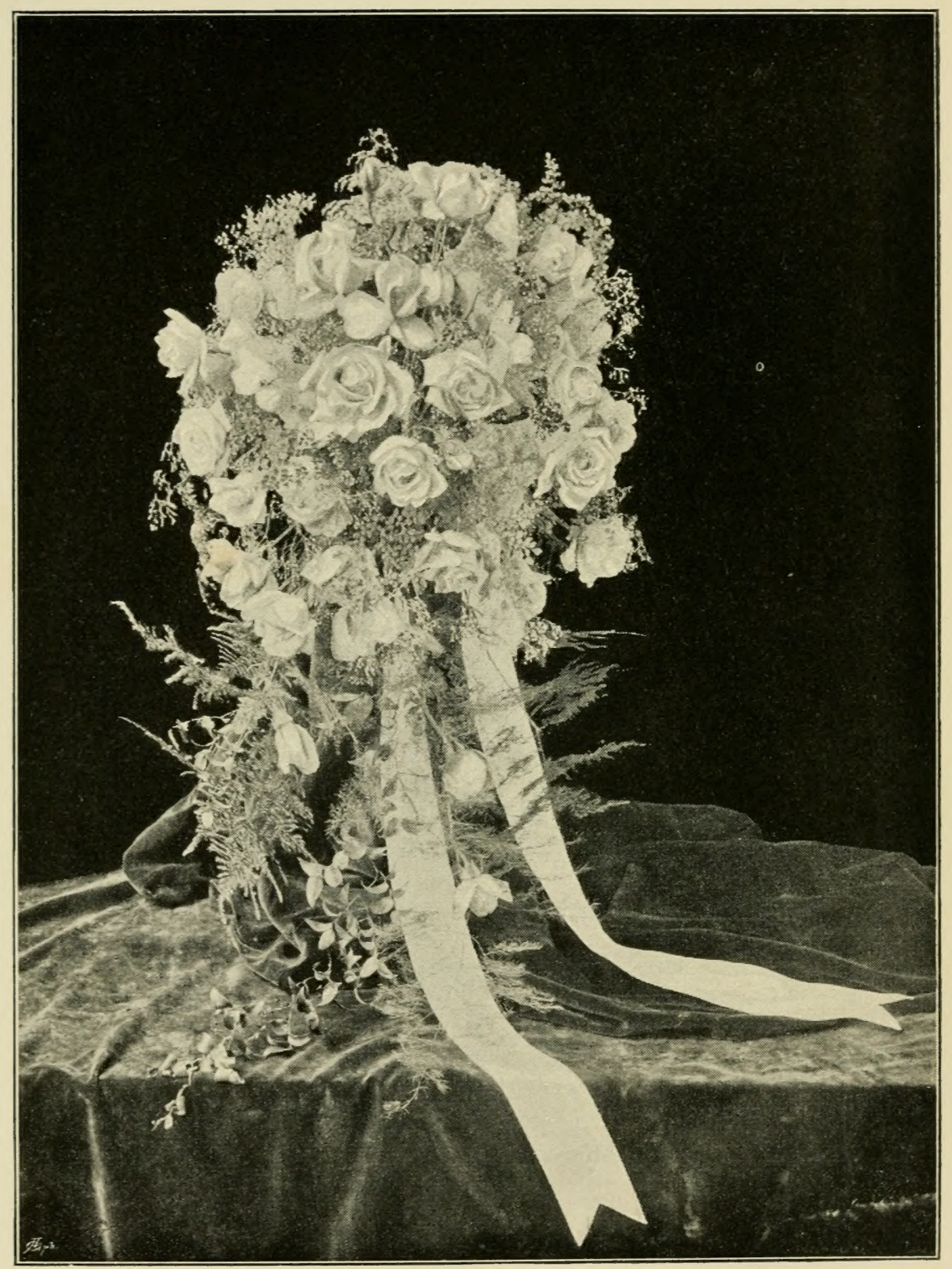

Shower Botquet, exhibited by Mrs. Orpex. Frontispiece. 
THE

\section{BOOK OF THE ROSE}

BY

REV. A. FOSTER-MeLLIAR, M.A.

RECTOR OF SPROUGHTON, SUFFOLK

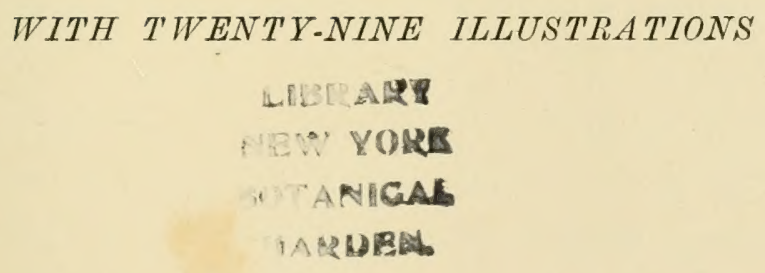

Zlonion

MACMILLAN AND CO.

AND NEW YORK

1894

The Right of Translation and Reproduction is Reserved 
Richard Clay and Sons, Limited, LONDON AND BUNGAY. 


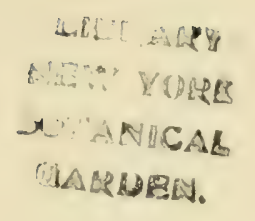

\section{PREFACE}

IT seems right to make some sort of apology, as most of my predecessors have done, for putting forth another Rose-book when there are already so many; but perhaps it is not really required, as the columns devoted to the subject every week in horticultural literature show that there is ever something fresh to be said on the different matters connected with the Rose.

My idea was, in the first place, to give, from an amateur, full details of practical culture for amateurs from the beginning to the end: and I ought to be able to do this satisfactorily even if I have not succeeded, as, under unfavourable conditions of soil and situation, I have done with my own hands every portion of the work, from raising and establishing the stocks to carrying off a champion challenge cup at the Crystal Palace. Secondly, to give such descriptions of the best known Roses as should tell of their faults and bad habits as well as of their good qualities and perfections, since I have good reason to believe a record of this sort will be welcomed. And thirdly, if possible, to make a readable as well as useful book: under no 
circunstances did I aspire to tread worthily in the footsteps of Dean Hole: yet (for to me too the worldcven the Rose world - " teems with quiet fun") I did hope to make it fairly light and amusing; but details and practical matter have proved so overwhelming as to get a mastery of the whole.

I have much kind assistance to acknowledge from various sonrces. From my old friend, Mr. Benjamin R. Cant, Ruse-grower, Colchester, and his two sons, I have had very much cordial help in many ways. Mr. Frank Cant, of Braiswick Nursery, Colchester, has freely given me useful information on the subject of Roses under Glass (Chapter X). Mr. W. D. Prior, of Myland Nurseries, in the same metropolis of Roses, has aided me in the preparation of photographs: and in the same neighbourhood, Mr. and Mrs. Orpen, of West Bergholt, have been good enough to give me opportunities of representing their skill in Rose decoration. I have also received help from Mr. A. Dickson, jun., of the Royal Nurseries, Newtownards, Ireland, in information kindly furnished as to the raising of Roses from seed. Mr. Charles Turner, of Slough, has kindly lent me a photograph of one of his giant Pot Roses.

I am indebted to Dr. Hogg; the proprietor of T'he Journal of Horticulture, for leave to republish certain matters which I have written in that paper under the nom de plume of "W. R. Raillem," especially Chapter XII, which has been thoroughly revised: and to IIr. J. Wright of that office, I am very much beholden for kind counsel and advice. For revised reproductions of 
papers of mine, which have appeared in the Tonvmel of the Royal Horticultural Society and in The Rosarian's Ycar-Book, I have to thank the Rev. W. Wilks, Sec. R.H.S., and the Rev. H. H. D'Ombrain, Hon. Sec. of the National Rose Society.

My best thanks are due to my neighbour the Rev. J. H. Hocking, Rector of Copdock, for considerable trouble in the identification of Insects, and to Mr. E. B. Lindsell, of Bearton, Hitchin, for advice and encouragement. Messrs. A. Hill Gray, J. Bateman, Ismay Fisher, and the Rev. F. R. Burnside have also kindly helped me with photographs, or in other ways.

Mr. William Paul's large work The Rose Garden has naturally been consulted, and proved of much value, especially in Chapter II., and a further comparison of ideas and methods has been made with the contents of most other Rose-books; but my own experience, which is considerable, has been throughout my principal reliance, and where my practice is at variance with the general use, reasons have been given for the procedure recommended.

Sprovghton ReCtory, September, 1894. 



\section{CONTENTS}

CHAPTER I

PAGE

INTRODUCTION

CHAPTER II

HISTORY AND CLASSIFICATION . . . . . . . . . . 6

CHAPTER III

SITUATION AND SOIL . . . . . . . . . . . . . 28

CHAPTER IV

PLANTING: WITH LAYING OUT OF THE BEDS AND PROTECTION 43

CHAPTER V

MANURES

CHAPTER VI

PRUNING .

CHAPTER VII

stocks 
CHAPTER VIII

PROPAGATION

\section{CHAPTER IX}

PESTS

CHAPTER X

ROSES UNDER GLASS

CHAPTER XI

FXHIBITING . . . . . . . . . . . 182

CHAPTER XII

MANNERS AND CUSTOMS 211

CHAPTER XIII

SELECTIONS . 309

CHAPTER XIV

CALENDAR OF OPERATIONS 321 


\section{LIST OF ILLUSTRATIONS}

TO FACE PAGE

A Shower boUQuet . . . . . . Frontispiece

MR. B. CANT'S ROSE FIELD

AYRSHIRES AS A ROSE HEDGE

25

ROSE SPRAY-POLYANTHAS

MR. A. H. GRAY'S ROSE GARDEX

A WEEPING ROSE-AYRSHIRE

96

MARÉCHAL NTEL IN GREENHOUSE

CATERPILLAR HIDDEN ON SHOOT 160

FIRST APPEARANCE OF MLDEW

STANDARD ROSE (U. BRUNNER) IN POT 176

DWARF ROSE (P. PERRAS) IN POT 181

A WINNING TWENTY-FOUR-CUP STAND . . . . . . . 208

A "DIVIDED" PoSE . . . . . . . . . , , 214 
DUKE OF WELLTACTON .

GUSTAVE PIGANEAU 237

JEAN SOUPERT

MARGUERITE BOUDET 2.54

MARIE VERDIER 256

MRS. JOHN TAATY 259

PRTYCE AKTHUR 263

ULRICH BRUNNER 269

CLEOPATRA 27

MADAME CUSIN 291

MADAME DE WATTEVILLE 292 MARÉCHAI, NIEL. 297

THE BRITE: 307

THREE BUTTONHOLES 317 


\title{
THE BOOK OF THE ROSE
}

\author{
CHAPTER I
}

\section{INTRODUCTION}

IT is a common saying that the love of flowers is universal; and it is not surprising, seeing that the tendency of the age is to subdivide occupations and interests and make men specialists in smaller branches of subjects, that certain flowers have been selected for cultivation by persons who have given all their leisure, or even the whole of their time, to the study of them. As the Rose has been entitled the queen of flowers without serious dispute for nearly twenty-five centuries, special subjects of such a queen may naturally be looked for; and they may be found among such as style themselves Rosarians, who endeavour to cultivate the Rose in such a manner as to get the finest and most beautiful blooms.

One would naturally suppose that those who study and pursue this subject might be credited with a special knowledge of it at least, if not with some authority; but, oddly enough, a certain number of writers on general horticulture are never weary of recounting the errors and absurdities of Rose-growers 
and, above all, Rose exhibitors. It is not so that I know of with other Hower's the foremost prize-taker's in chryanthemums or auriculas, for instance, are at least supposed to know as much about the things necessary for the welfare of those plants as other people; and in common life we do not find general physicians proclaiming the ignorance and absurdity of oculists, aurists and dentists in their several departments; yet the specialists of the Rose are frequently told by authorities in horticulture that their maxims and modes are erroneous and faulty.

In Mr. Robinson's most beautiful book, The English. Flower Garden, a fine example of this may be seen, the vials of his wrath being fully poured out upon the stupidities of Rose-books, and the general mistakes of Rosarians. We are a most harmless folk with no desire for recrimination, and I would only venture to point out that our aims and points of view are different. He looks upon the Rose as a decorative plant for the garden: I look upon the plant, in most cases, only as a means whereby I may obtain glorious Roses.

Noreover, though some enthusiasts may think it heretical, I do not consider the Rose preeminent as a decorative plant; several simpler flowers, much less beautiful in themselves, have, to my mind, greater value for general effect in the garden; and even the cut blooins are, I imagine, more difficult to arrange in water, for artistic decoration, than lighter, simpler and less noble flowers. A good Rose should stand in a vase by itself as a queen should; then let any other flower or combination of flowers rival her if they can. So, with all the best Roses I should not wish for or expect any general display at a distance, but come close and be content if I can find but one perfect bloom. 
For elegance in trailing blossoming beauty some of the best and most vigorous of the climbing Roses would indeed hold a high place among decorative plants; but for masses of grand colour as viewed from a distance, no Rose effect can equal that of the rhododendrons; and for unwearied continuance many ordinary bedding plants make a richer and more permanent display. No; the value of the Rose is in the glory of its individual flowers : and in these pages, at least, the idea is not the Rose for the garden, but the garden for the Rose.

I write for enthusiasts, for those who make a regular hobby of their Roses, and think of them as fondly and almost as fully in January as in June. There are not a few such, even among amateurs, in all ranks, and some of them, much handicapped perhaps by soil, situation or circumstances, still retain their ardour though not meeting with much success.

The man of business, who rises at daybreak to attend to his Roses before his day's work in the town; who is quite prepared if necessary to go out with a good lantern on a November night to seize a favourable condition of soil for planting at once some newlyarrived standards or dwarfs; and who later in the winter will turn out in the snow after dark to give some little extra protection that may be required for his beds: this is the sort of man for me, and for the Rose as well.

I remember a certain occasion when a small shooting party met for partridge-driving on a rather dismal bleak day in January. Two of the "guns," who lived some distance apart and did not meet very often, were continually drawing together and chattering away with the greatest enthusiasm; cutting little bits out of the hedge and comparing notes with so much interest that 
though both rery fond of the sport, on more than one nccasion the partridges flew by unheeded whilst they had strayed from their places. Said the host later on to one of his friends, "What on earth do you think $\mathrm{A}$ and $\mathrm{B}$, who are generally so keen, had got of such importance to talk about together? It was all about Roses !"

It has been my pleasure, for some months, to receive very nearly every day by post as much and sometimes more than a penny stamp would frank, of letters from a gentleman whom I have seldom seen and with whom I have hardly exchanged half-a-dozen sentences by word of mouth. This too during the spring and winter time, and all about Roses!

It is pretty well known that another gentleman, with a passionate love for Tea Roses, left his home in Scotland because he could not grow them there, and went searching for a place in Great Britain which should be suitable for their culture; and, having found such a spot, at very great expense laid out and prepared his grounds to form, as they undoubtedly do, the finest amateur Tea Rose garden in the country.

I may perhaps be excused for thinking that Rosegrowing as a special pursuit and a hobby is particularly adapted for country parsons. No one can deny that it is as harmless a pursuit as any that can be found, and, without the least neglecting his sacred calling if his cure be a small one, he can find many half-hours of daylight leisure among his Roses, where his parishioners will soon learn to come and look him up at once if he should be wanted. It will afford him varied interest, exercise, and work in the open air all the year round. In tilling the soil, the special work which God gave to man, he will find many a valuable lesson, which he will 
be able to tell, with authority and with much interest, to that majority of his unlearned parishioners who are themselves tillers of the soil. If there is no room in the parsonage garden, it is seldom indeed that some little piece of glebe cannot be taken in to be the pride of his heart and the focus of his midsummer hopes. And now that we are all so poor, and likely to be poorer still, there will be the more encouragement for him to do the Rose work with his own hands, and to summon the aid of his single useful man only at actual show time, for the carting of manure, or for pressure in planting.

He will thus become a real amateur, a true son of Adam, and genuine brother of the back-ache, with many thorns in his fingers and rough and hardened hands; but his Roses will be truly his own, he will have won them, and under the Creator will actually have made them himself. And not only will they seem to him brighter and purer and sweeter than any other Roses, but he will probably find, in comparison and competition, that they are better than those of his brother amateurs who do not personally attend to their plants; and it will be a great thought for him that other far richer men may have grand and glorious gardens, but that he in his humble little plot with his own hands raises some of the finest Roses in England. 


\section{CHAPTER II}

\section{HISTORY AND CLASSIFICATION}

THE Rose is well known as the emblem of England, and when we consider how often it has unhappily been in conflict with the Lilies of France, it may seem strange to find a large though decreasing proportion of our Roses endowed with French names.

Still, though so many of our favourites were raised the other side of the Channel, England is the true home of the Hybrid Perpetual Rose; and that, not only because it is more cultivated here with the minute attention which is paid to a "florist's flower," but also because the English climate is better suited to its perfect development.

Continuous sunshine is not the best weather for the blooming of H.P.s; they like two or three hot days, and then a dull, dry, cooler one. Some will not open in rainy weather, others do not mind it; but almost all this large class, so many of which were raised in sunny France, will display far more beautiful blooms on a dull and cooler day following after heat; and it may be, I think, safely said that the finest H.P. Roses in the world are grown in England.

The Rose is native to all countries in the world with 
the exception, perhaps, of Australia, a large portion of South America, and the actual tropics.

It is very extensively cultivated in Persia and Bulgaria for the manufacture of attar or otto of Roses and Rose-water, which are distilled from the petals. In Persia a variety of the Musk Rose (Rosa moschata) is used for this purpose, but it has not the real odour of musk, which is said to be found only in Salet, a Perpetual Moss Rose. In Bulgaria, the country which is the largest producer of the otto, a variety of the Damask Rose (R. damascena) is used: and experts allege that the Damask and Provence ( $R$. centifolia) Roses are the best representatives of the true inimitable odour of Rose. The modes of distillation in these Eastern countries are very primitive and imperfect, and moreover in Bulgaria there has been considerable adulteration of the valuable otto with geraniol or oil of pelargonium. Much the best otto of Roses now in the market is manufactured by modern skilled appliances in Germany, near Leipzig, where the Bulgarian variety of Damask Rose is used, and in France, near Grasse, where a strain of the Provence Rose is cultivated for the purpose. Rose-water and otto of Roses are also made in India, Turkey, and other places.

Few readers of a Rose-book will care for much research into the history of the Rose. Mr. William Paul has with much care gone deeply into that subject in his large volume The Rose Garden, and I will only touch a few points, and refer inquirer's on this subject to his fuller work.

Homer's allusions to the Rose in the Iliad and the Odyssey are, I suppose, the earliest mentions we have. Every one will be aware of Bible references, though it 
shonld be mentioned that the Rose of Jericho is generally understood to be a cruciferous plant, and all seem agreed that whatever the Rose of Sharon was it was certainly not a Rose; nevertheless Dr. Hooker enumerates seven species of Ruses which he observed in Syria. A passage in the Apocrypha (Wisdom II., 8) is interesting as mentioning the custom of crowning with Rosebuds at feasts and banquets, which we know to have prevailed in classic times.

By far the most important ancient quotation is from Sappho the Greek poetess, who was born about 600 B.c. A translation of a fragment of one of her poems is given in Mr. William Paul's book:-

" TVould Jove appoint some flower to reign

In matchless beauty on the plain,

The Rose (mankind will all agree),

The Rose the Queen of Flowers should be."

That the title of "The Queen of Flowers" is no modern assumption for the Rose, but has hardly been seriously questioned for nearly twenty-five centuries, is a little item of knowledge which every Rosarian should store by him as a weapon defence in time of need.

The immense sums spent by Cleopatra, Nero, and other luxurious persons in the time of the Romans, not only on Roses but on "Rose leaves" (petals) for strewing on the floor and the seats, is well known. And there are actually some points of culture that we may learn from the Romans. Horace speaks of growing Roses in beds, and Pliny of digging deeply for their cultivation, both of which items-growing them by themselves apart from other plants, and moving the soil to the depth of two feet-have still to be insister on in this year of grace 1894 .

During the long strange sleep of civilisation which 
in the Middle Ages followed the Fall of Rome, the culture of the Rose was probably somewhat neglected; but gradually, no doubt, as the pursuits of peace began to prevail, gardening, and with it the love of the queen of flowers, revived.

The National Rose Society gives $\mathbf{1 5 9 6}$ as the date at which it is known that the Centifolia (Provence or Cabbage) Rose, the common Moss, and the Austrian Yellow and Austrian Copper were grown. But Rose progress was very slow till about 1815, when in spite of the troublous times, Mons. Vibert, the earliest of the great French raisers, founded his nursery. The way had been prepared for him by the patronage of the Empress Josephine, who made Roses fashionable, and caused search to be made for all existing varicties for her garden at Malmaison. Mons. Laffay soon followed Mons. Vibert, and after them we have a grand array of famous French Rosarians, Jacques, Hardy, the Guillots, Lacharme, Gonod, Pernet, Ducher, Margottin, the Verdiers, Levet, Liabaud, Nabonnand and others, to whom we are still indebted for the majority of our best Roses.

Mons. Desportes in 1829 issued a catalogue containing the names of 2000 varieties, but the majority of these were no doubt worthless or not distinct, and by 1860 there were still but few Roses which we should now consider good, though we had Général Jacqueminot and Senateur Vaisse among H.P.s, and among Teas, Devoniensis, Madame Bravy, Rubens, and Souvenir d'Elise, the last still unequalled as the finest of all show Roses.

But taste, experience, and discrimination on the one hitnd, and demand on the other, were now beginning to tell, and in the next five year's (1860-65) the following 
wonderful additions from France were made of Roses which are still indispensable:-Alfred Colomb, Camille Bernardin, Charles Lefebvre, Dr. Andry, Duchesse de Morny, Duke of Wellington, Fisher Holmes, Marguerite de St. Amand, Marie Bamann, Marie Rady, Maurice Bernardin, Pierre Notting, Prince Camille de Rohan, and Xavier Olibo; and in Teas, La Boule d'Or and that wonder among roses Maréchal Niel.

About this time English raisers first began to come to the front with Roses still recognised as good, and Mr. W. Paul's Beauty of Waltham may be considered as one of the first of these, the origin of Devoniensis being a little doubtful. Messrs. Paul and Son of Cheshunt, with Mr. Rivers of Sawbridgeworth, Mr. Cranston of Hereford, Mr. Turner of Slough, and Messrs. Keynes, Williams and Co. of Salisbury followed, till Mr. Bennett of Shepperton commenced by hybridising to raise what he called "pedigree Roses," and delighted the Rose world with Her Majesty and Mrs. John Laing.

Messrs. A. Dickson and Son of Newtownards, Ireland, also took to hybridising with great and marked success, and this mode of obtaining new varieties from seed, by careful interchange of pollen, instead of trusting to chance cross-fertilisation, as had hitherto been done, is now probably being pursued by several raisers in the British Isles. More new varieties from our own country, and less from France, now pass their examinations and enter the ranks every year, but a very large proportion of our best Roses still bear, and will for many year's, their French names.

The worst of it is that some of these names must be said in full if there is to be no confusion. For instance, there are two Madane Eugene Verdiers, H.P. and Tea, as well as Mademoiselle Eugenie Verdier, H.P., besides 
Madame Victor Verdier and Victor Verdier, H.P.s. There are also two Madame Hippolyte Jamains, H.P. and Tea, besides Hippolyte Jamain, H.P. In addition to the well-known La France, there is also a Rose called La France de '89, a name which really shows some poverty of invention on the part of the raiser.

A remonstrance might not be well received; for the Rev. H. H. D'Ombrain, Hon. Sec. of the National Rose Society, tells an amusing story of the French raiser of Duke of Wellington H.P. complaining that English growers would not call his Rose aright, for it should be Duc de Wellington. This seems to me really comic, if meant seriously.

Still, as I have said, though so many of our best Roses owe their parentage to France, they are nowhere better cultivated than in the British Isles, there being a considerable export trade to America, the Colonies, Spain, and elsewhere; and nowhere are there such famous growers, both professional and amateur, who have made the Rose their special, and in some cases their sole, study. In mentioning the names of famous British growers, it is interesting to compare the list, given by Dean Hole in his charming book, of winners at the first National Rose Show in 1858 with those who are well known now in 1894. Of nurserymen, "Messrs Paul of Cheshunt, Cranston of Hereford, Cant of Colchester, and Turner of Slough" are still well-known names; but in the dozen or so of amateurs mentioned, "Fellowes" is the only name with which I am familiar as still growing and exhibiting well. Norfolk has not wanted a good florist or two of the name of Fellowes for many years.

In the very first rank at the present day among professional exhibitors are:-at Colchester the separate 
establishments of Messrs. B. R. Cant and Frank Cant, who devote themselves solely to Roses; in Hertfordshire, Messrs. Paul and Son of Cheshunt (Messrs. Wm. Paul and Son of Waltham not now exhibiting cut blooms in competition); and in Yorkshire, Messrs. Harkness and Sons of Bedale. No other nurserymen in the last twelve years have won either of the N.R.S. champion trophies, but a foremost place must be admitted to $\mathrm{Mr}$. Prince in Oxfordshire, whose specialty of Teas on the seedling briar has often won him the premier prize in that section, and to Messrs. A. Dickson and Son of Newtownards in Ireland, who show very strongly considering their distance and the difficulty of transit, and who have won the gold medal for new Roses of their own raising much oftener than any other British firm.

There are many others of high standing, a large proportion of whom probably sell as good plants as those I have mentioned. And if they have not come to the actual front yet as exhibitors, it may be that distance or climate, or a disinclination to incur the whole expense and trouble of competing in the first rank, have prevented their names being chronicled hitherto as the winners of the premier prizes.

Among amateurs, notable exhibitors have dropped out of the ranks in the last decade in Messrs. W. J. Grant, T. B. Hall, and E. R. Whitwell, while the senior knight of all, Mr. R. N. G. Baker, only exhibits occasionally; but we have still a large and increasing army of Rose-lovers, who like to tilt in honour of the queen at the Rose tournaments, and of these the best known are Mr. E. B. Lindsell of Hitchin, and Rev. J. H. Pemberton of Essex, for H.P.s, and Mr. A. H. Gray of Bath, and Rev. F. R. Burnside of Herefordshire, for Teas, 


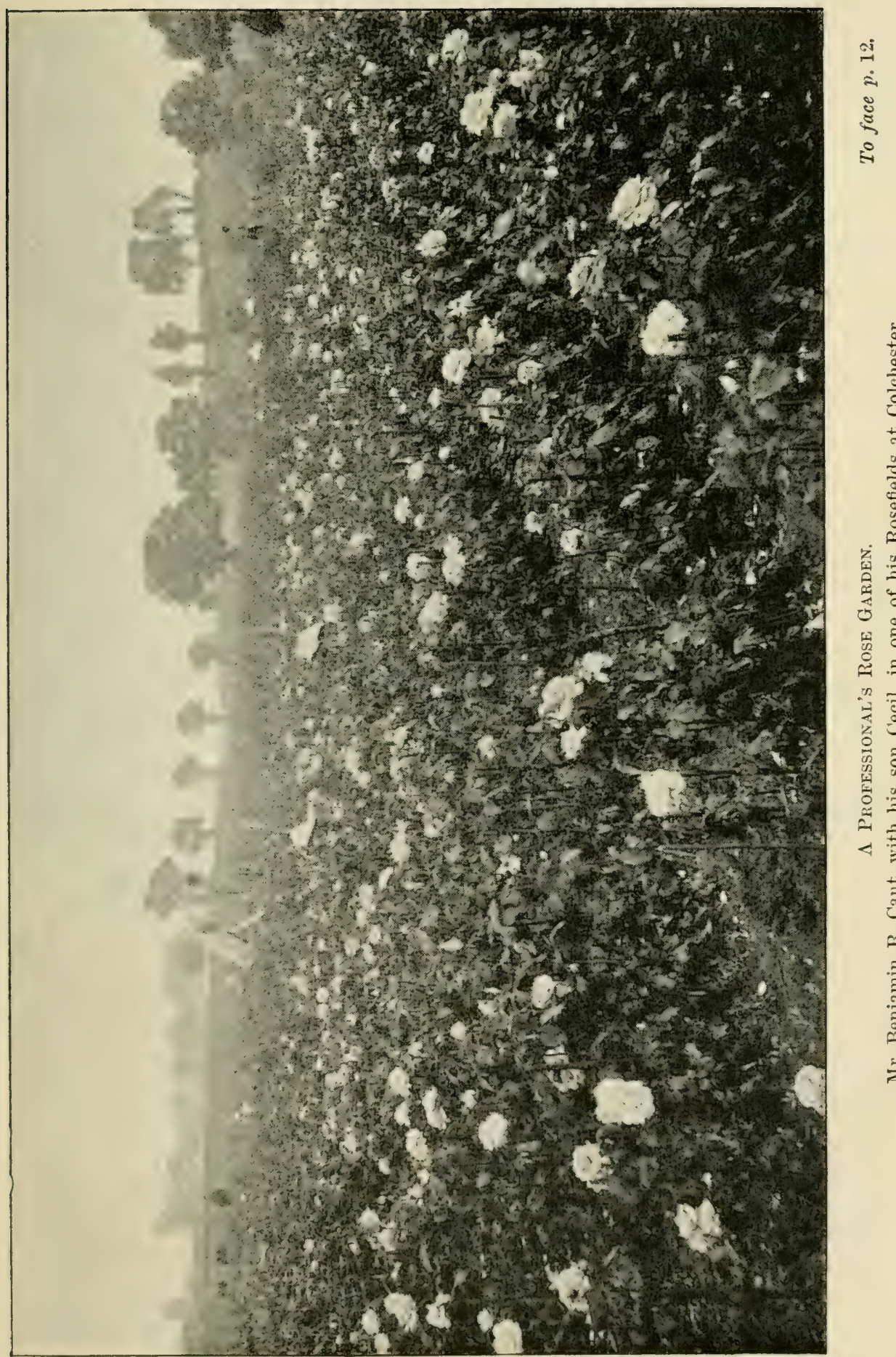



though in each division there are others treading closely on their heels, and occasionally victorious.

Classification.-In botany, the number of actual species of Roses is very great, even the wild Dog-Rose of our hedges being divided into many sub-species, as may be seen from the great variety in foliage and habit in the early growths of briar stocks in nurserymen's quarters. Of the cultivated classes, probably nine out of ten Rose-lovers will only care to know about the two great divisions as they are commonly understood: viz. Hybrid Perpetuals, including Hybrid Teas and Perpetual Bourbons, and Teas and Noisettes, with perhaps a few climbers. Comparatively few will be interested in the Austrian, Bourbon, Polyantha, Moss, and Provence races; and a still smaller number will care to investigate thoroughly the forty-one groups carefully enumerated by Mr. W. Paul in his systematic work.

Now that hybridising and crossing of groups is so largely undertaken, it seems plain that many new divisions and classes are likely to arise, and old lines of demarcation to be lost. Apart from the true climbers, and all summer or botanical varieties, Roses to the novice or spectator at Rose shows are generally divided into H.P.s and Teas, and the more these two great divisions are consolidated and made inclusive instead of being subdivided, the less confusion, to my mind, is likely to arise from crossing and hybridising.

Cultivated Roses are naturally divided into two divisions at the outset: Summer (i.e., those which only bloom once in the year), and Perpetual (i.e., those which have at least something of a second crop). It is obvious that the latter is the more valuable; the H.P.s if taken to include the Hybrid Teas and all Bourbons which are perpetual, and the Teas, with the Noisettes which are 
CHAT.

mostly crossed with them, form the bulk of the perpetual Roses, and have therefore increased immensely in culture, popularity and number of varieties, while the sorts which bloom only in the summer have naturally been neglected, though perpetual forms have now been raised among the Ayrshire, Polyantha, Scotch, and Moss classes. The H.P.s and Teas, using the terms in their widest and most inclusive sense, would thus embrace all the best Roses, that is, those which give the finest and most perfect blooms; and a large number of Rose-growers will be content with them.

The live-stock-keeper's adage, that it costs no more to keep a good animal than a bad one, may, with some reservations, be applied to Roses; and the H.P.s and Teas, in the wide sense that I have mentioned, certainly furnish the finest flowers. Still, for old associations some may cultivate the Provence (Cabbage) or York and Lancaster ; for beauty of yellow and copper shades, the Austrian; for exhibition of a pot Rose in a mass of bloom, the Hybrid Bourbon or Hybrid China; for fancy in the bud stage only, the Moss; for beauty of foliage and fruit, the Rugosa; for toys, the Pompons or Fairies; for certain forms of bouquet decoration, the Polyanthas; for sweet foliage, the Sweet-briars; and for rapid climbing, the Boursault, Evergreen, Ayrshire, or Banksians.

\section{Summer Roses}

The Provence Rose (Rosa centifolia).-The type here is the old "Cabbage" Rose, so called merely because it is full, with its petals folded like a cabbage. It is 
best grown as a bush, and requires close pruning. The original is pink, but there are other varieties of this class, white and striped.

A sub-variety of the Provence is the Pompon Rose. These are simply Roses in miniature, which should not be confounded with the Polyanthas, many of which are quite as small, or with the Lawrencianæ or Fairy Roses, which being Chinas are perpetual.

The Moss Rose is a more important sub-variety of the Provence, the Crested Rose forming a sort of link between them. This group, so well known for the moss-like covering of the calyx, has been so popular that great efforts have been made to increase the number of varieties and improve the quality of the flowers. Mr. Cranston, writing in 1855 , says that even then several hundred varieties of the Moss Rose had been raised, but though different colours, from white to crimson, have been gained, and one or two perpetual sorts have been issued, very little success in the way of actual improvement has been achieved, the common or old Moss Rose, to which the N.R.S. catalogue gives the date of 1596 , being still the best in the popular bud state. There are now so many beautiful buttonhole Teas very much superior in beauty of colour, that it seems likely that Moss Roses, which are only valuable in the bud, not of long and pointed form, and apparently incapable of improvement, will suffer somewhat from their rivalry; but many, no doubt, will still be found to cherish them from sentiment or old associations.

The Moss Roses do not do well as standards, and some of them are not very strong growers. They will grow on manetti, but are generally considered to do best on their own roots, and should be pruned hard, and highly cultivated. Some miniature Moss Roses 
have been issued, with prettily shaped rosette-like flowers, one of the best of which is Little Gem (IV. Paul and Son, 1880).

The Double Iellow Rose (R. sulphurea) is considered by some to be a form of the Provence. Fifty or sixty years ago, this ras the best yellow Rose, if it could be got to bloom ; but its "manners and customs" were so very bad, and the blooms so generally malformed or refusing to open at all, that it was pretty nearly given up as hopeless, even before Cloth of Gold appeared on the scene.

The Damast Rose (R. damascena) and The French Rose (R. gallica) are placed under one heading in the N.R.S. Catalogue, and indeed it seems rather doubtful to which of these two sections some of the old Roses belonged. These are the old pink, red, and striped Roses of our gardens, both groups having been introduced into this country at least three hundred years. The three old-fashioned striped Roses, each of which has been called York and Lancaster, are Rosa Mundi (French), which is red striped with white, and occasionally self red; Village Maid (French), which is white striped with red; and the true York and Lancaster, which is either (sometimes all on one bush) red, white, red striped with white, or white striped with red, a truly handy bush for a Vicar of Bray in the Wars of the Roses.

The Damask and French Roses are not very strong growers, producing short-jointed wood and large, showy, open flowers. They succeed as standards, but were generally grown in the bush form. Fairly close pruning is required, with care as to the shape, that the blooms be regularly placed upon the plant.

The flowers of the French Rose are but slightly 
scented when freshly gathered, but the perfume develops in the dried petals. The reverse is the case with the Damask Rose, which is principally used in the manufacture of the otto, for the scent in this case is nearly destroyed by drying

The White Rose (R. alba).-An old-fashioned class of Roses, generally grown as bushes, and still to be found by side-walks and in corners in old gardens. The majority of them are not pure white, but have a pale pink flush, very pretty in the bud, and open flat. They will grow as standards, and require rather close pruning. Félicité Parmentier (1828) and Maiden's Blush (1797) are the best known varieties.

The Hybrid China Roses are hybrids between the French or Provence, crossed slightly with the China race, and showing very little of the cross; as the Chinese are true perpetuals, and these remain as summer Roses. They are very strong growers, almost all being vigorous enough for pillars or climbing, and some sufficiently pendulous to form tal! half-weeping standards. The vigorous grower's should not be too closely pruned. Blairii No. 2 a fine climber, Chênédolé and Fulgens of brilliant colour, and Miss Ingram a well-shaped old Rose of more moderate growth, are now the best known. Madame Plantier, a very profuse bloomer, often placed in this group, scems to have in it some cross of the Noisette race.

The Hybrid Bourbons, placed under the same heading in the N.R.S. Catalogue, form a somewhat similar group, being hybrids from the French or Provence with the Bourbon race, but not having the autumnal qualities of the Bourbons. Most of them are strong enough in growth for climbing purposes, and should not be pruned too closely when thus used. But in no 
casc is the whole art of pruning more called for than in fine old standards or pot Roses of this group, where the production of a well-shaped head, thickly and regularly covered with large blooms all out at once, is sometimes a triumph of skill and training. Charles Lawson is especially noticable for its capabilitics in this way, when carefully trained as a pot Rose.

Coupe d'Hébé, of a fresh pink with a cupped shape, is a name I can never forget, as it was the first rose-a standard-I ever had of my own, about forty year's ago. Paul Ricaut is the best known crimson in this class.

The Austrian Briar (R. lutea).-These are simply wild Roses native in some parts of Europe, nearly single, and lovely in colour. The Copper, as it is called, is the form best known; it is quite single, the petals being a most beautiful shade of coppery red, with orange yellow inclined to buft on the under sides. The others, Single Yellow, Persian Yellow, and Harrisonii are also noted for their colour, being hardly surpassed in this point by any known Roses. The two last named are double though by no means full, and Harrisonii is the best grower, with a somewhat pendulous habit. They like a dry soil, will not succeed in suburban or smoky atmosphere, and all do best on their own roots, the suckers being encouraged, and taken off when rooted if required to form fiesh plants. It is best not to prune them at all, beyond cutting out dead wood; the shoots might be thinned, but there is no advantage in this with single Roses, where quantity of bloom is the thing desired; and they should not be shortened, as flower-bearing shoots often issue from the buds near the tips.

The Scotch Rose (R. spinosissima).-The "very thorny" Rose is a briar native in the north of Great 
Britain, which has become semi-double and has attained almost every shade from white to deep crimson by long cultivation and selection of the easily raised seedlings. The plant is unmistakable, for no other Rose is so thickly covered with small very sharp thorns. They are not strong in growth, and are best on their own roots, propagated by suckers, like the Austrians. Scotch Roses are generally used to form a dwarf hedge, which has a pretty effect when the little round fragrant flowers are out, but these are very soon over. One perpetual form, however, has been raisedthe Stanwell, a fair grower, very sweet, flowering freely from May to November. These Roses, as becomes natives of North Britain, are thoroughly hardy, and will flourish in the poorest soil where no other Rose will grow. No pruning, beyond cutting out dead wood, is required.

The Sweet Eriar (R. rubiginosa).-This is a native briar, growing freely wild in some parts of England, and generally where the soil is light and rather poor: The Eglantinc. as it is otherwise called, is noted for the sweet scent of the foliage, which pervades the air for a considerable distance after a shower, in spring or early summer. There have been some cultivated varieties more or less double and deeper or paler in colour than the type, and Lord Penzance has been hybridising them with the laudable view of raising a group of good Roses with sweet foliage; but though he has been most successful in colour improvement, I believe that nothing more than semi-double varieties have yet been attained.

The Ayrstire Rose (R. arvensis). This too, as its name implies, is a native species, found also throughout Europe. They have been well called running Roses, for 
the growth is extrencly long, rapid, and slender. Being very hardy and ready to grow anywhere, they are better adapted for trailing over unsightly places and ugly fences than for actual walls, which are best reserved for more valuable and tender sorts. This and the next group also form the best weeping Roses, budded on a tall standard, as the shoots are very pliable, and trail gracefully downwards in a natural manner.

Several of the Ayrshires have probably been slightly hybridised, a mark of the true sorts being that the flowers are not borne in clusters. Dundee Rambler, Ruga, and Splendens or Myrrh-seented are among the best known. The flowers are small, semi-double, and mostly white or pink. The plants are quite hardy, very rampant in growth, and most effective when allowed to ramble at will, unpruned and untrained. Madame Viviand Morel is a perpetual form.

The Evergreen liose (R. sempervirens).-This group is very much like the last, but is not a native of Great Britain; nor is it, strictly speaking, evergreen, but some foliage is generally retained through most of the winter. The flower's are produced in very large cluster's, mostly of white or light-pink colours. The plants are thoroughly hardy, as strong in growth as the Ayrshire, and useful for pillar's, arches, weeping Roses, or covering waste places, the long shoots being left unpruned. Banksixflora, Félicité Perpetue, and Rampant are perhaps the best known among them.

The Boursault Rose (R. alpina).-This is another group of strong-climbing summer Roses, with very characteristic smooth wood, not quite so pendulous in habit as the two last named. This species is a native of the Alps, thoroughly hardy, growing and blooming anywhere in large clusters of reddish flowers. The 


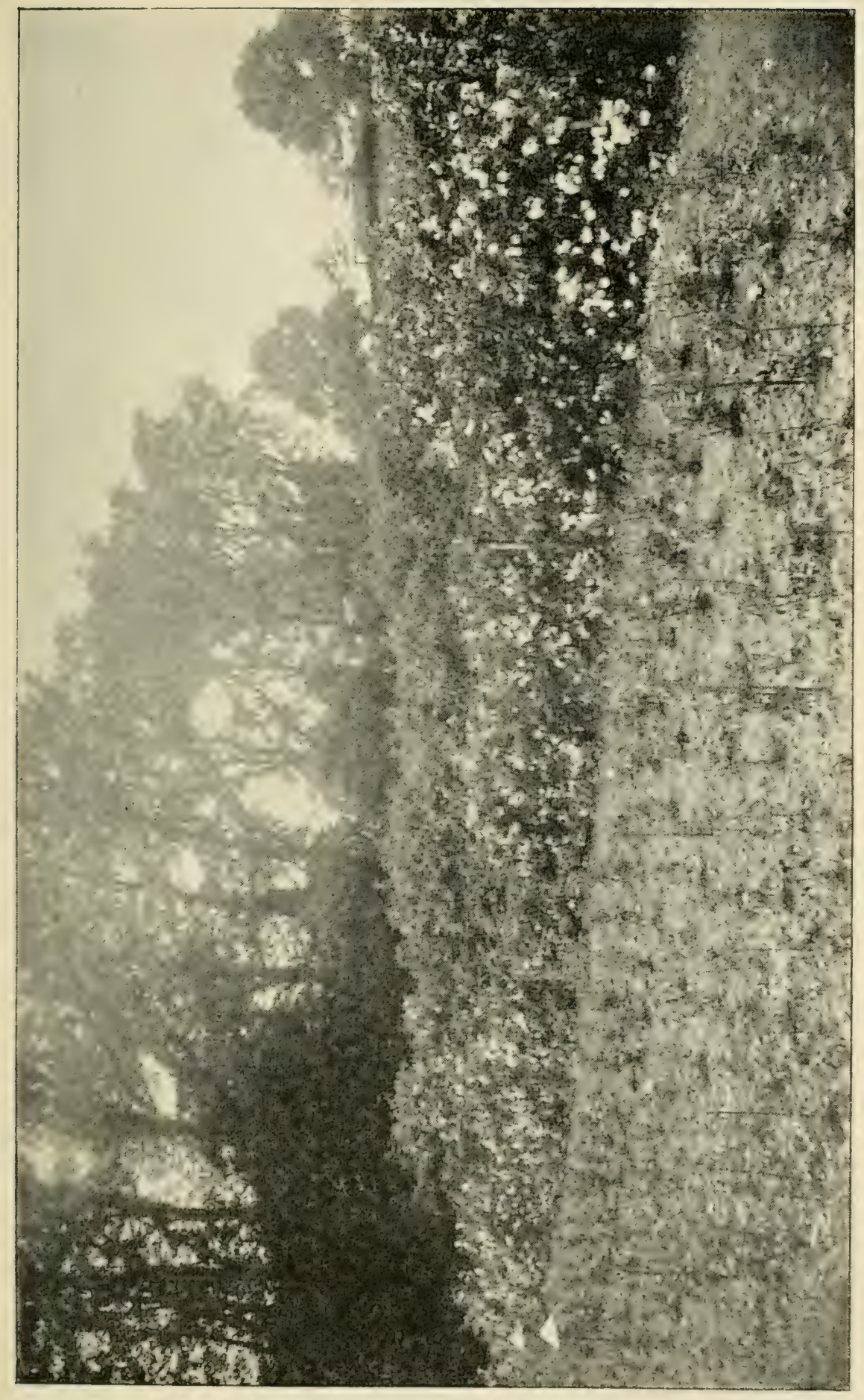

वे 

best-known varieties are Amadis or Crimson, and Gracilis.

The Bantisian liose (R. Banksix).-This is a very distinct species, said to have been introduced from China early in the century, and named after Lady Banks. The plants grow very strongly, but are not hardy, and are liable to be killed outright in severe frost, even on a south wall. There are only two varieties worth growing-the Yellow, with very small, but full, scentless flowers, produced in great abundance in clusters, and the White, with rather larger flowers, most deliciously and characteristically scented, the odour being compared to that of violets, but fewer of them. The plants, which are nearly evergreen in mild winters, should be very little pruned (see page 88); perhaps the best way is to shorten a little in the summer those shoots that have bloomed, cutting out all gross and sappy wood that is not wanted.

The Polyantha Rose (R. multiflora).--The varieties of this class, which bloom only once, are single. These are-Polyantha simplex, a great grower, now being tested as a stock for Tea Roses, and apparently with good result both as a scedling and a cutting; and P. grandiflora, similar but with much larger single Howers. To the multiflora class belongs also another Rose used as a stock for strong-growing 'Teas, De la Grifferaie, only noted for its growth and consequent root-power.

There are several other species of Roses which bloom only once, a list of the most interesting being given in the N.R.S. Catalogue. They are single in flower, and really only of value to the botanist or collector. 


\section{Autumnat Fiowering or Perpetual Roses.}

The Hybrid Perpetual Rose.-This wonderful group seems to have originated from several sources; indeed, it may no doubt be said with truth that certain strains of almost all other cultivated Roses have now been incorporated, by accident or design, into some of the members of this wide and varied class. It seems to me vain to try and trace the parentage of the most celebrated varieties. The pedigrees of most of them were absolutely unknown even to the raisers, since systematic hybridising and careful choice of seerlparents was not practised by the French Rosarians who issued our most noted sorts. Seeds were sown in immense quantities, and the cross fertilisation effected by insects or other agencies was relied on to produce the variations which ensued.

As always happens, however, according to the doctrine of evolutionists, certain marked types resulted which were not only distinct, but had also the power of impressing their characteristics upon their descendants, forming thus new groups. Victor Verdier, La France, and Baroness Rothschild are instances of these new departures, accounts of which may be found in Chapter XII.

Hybrid Teas are at present an unsatisfactory class. It is very difficult even now to draw a decided line as to where there is sufficient strain from the Teas to warrant the division; and it seems more than probable that the task will become almost impossible when the Hybrid Teas are crossed back again into the H.P.s or Teas, as they have been already in two or three instances. For this reason I have throughout 
included the so-called H.T.s among the large group of Hybrid Perpetuals, for they are both Perpetual and Hybrid.

The Bourbon Rose was introduced from the Isle of Bourbon about the year 1825. This group is noted for its sweet scent, and also for its very good autumnal qualities, the true Bourbons generally giving better blooms in the second crop. It has been quite a large class. Mr. William Paul enumerates forty-six varieties in The Rose Garden, but none of them is likely to remain or be much cultivated now, except the one celebrated sort Souvenir de la Malmaison. It seems to me highly probably that a much larger proportion of our H.P.s have some of the influence of this grand autumnal strain in their constitutions than is generally imagined; and as the two modern Bourbons, Madame Isaac Pereire and Mrs. Paul, are evidently hybrids, it appears advisable that all perpetual forms of this group also should be merged in the large class of H.P.s.

The China Rose (R. indica).-This group, truest of Perpetuals, was introduced into this country from China about the year 1789. The Common Pink, otherwise known as the Monthly Rose, always in flower, and the Crimson were imported separately about the same time; and all other varieties have resulted from these types. They are not very strong growers, do best on their own roots in a warm soil, and the flowers, weak and feeble with little or no scent, have little to recommend them beyond the one good quality in which they are unsurpassed-constant freedom of bloom, earliest, latest, and throughout the season.

Many varieties were issued in past years, but, besides the two types, Mrs. Bosanquet, of a waxy ivory tint, was generally considered the only one worth growing 
Laurette Messiny (Guillot, 1887), however, showed an improvement, a pretty buttonhole Rose, pink shaded with yellow, very free-blooming, but not a strong grower.

The Laurenceana, or Farry Rose, also introduced from China about 1810 , is simply a China Rose in miniature. These little tors are often sold in pots in the markets, and should not be confounded with the miniature pompons, which bloom only once; for the Fairy Roses are true Chinas, and if kept in health are ever in bloom. They are best perhaps in pots, but are sometimes successfully grown in rich warm soils as edgings.

The Tea Rose (R. indica odorata).-This most celebrated group, the true aristocracy of the Rose world, was also introduced from China about the year 1810. The first one was pink, and in 1824 the Yellow Tea Rose was imported.

There can be no doubt that both of these originated from the Chinese Rose, and for many years the group was known as the Tea Scented China. They are like the China group in habit, but differ from it in being tender to frost, and having the peculiar fragrance said to be like that of a newly opened tea-chest. It seems strange and suggestive that Roses with this scent should have originated in China, but scent experts deny that the odour of Tea is to be found in Tea Roses. The "manners and customs" of this lovely class will be found in Chap. XII.

The Noisette Rose originated in America, and was named after Mons. P. Noisette, who brought it to France, from which it reached this country about 1820 . It is supposed to have been an accidental cross between the Musk and the China groups: there is no doubt it had something in common with Tea Roses originally, 



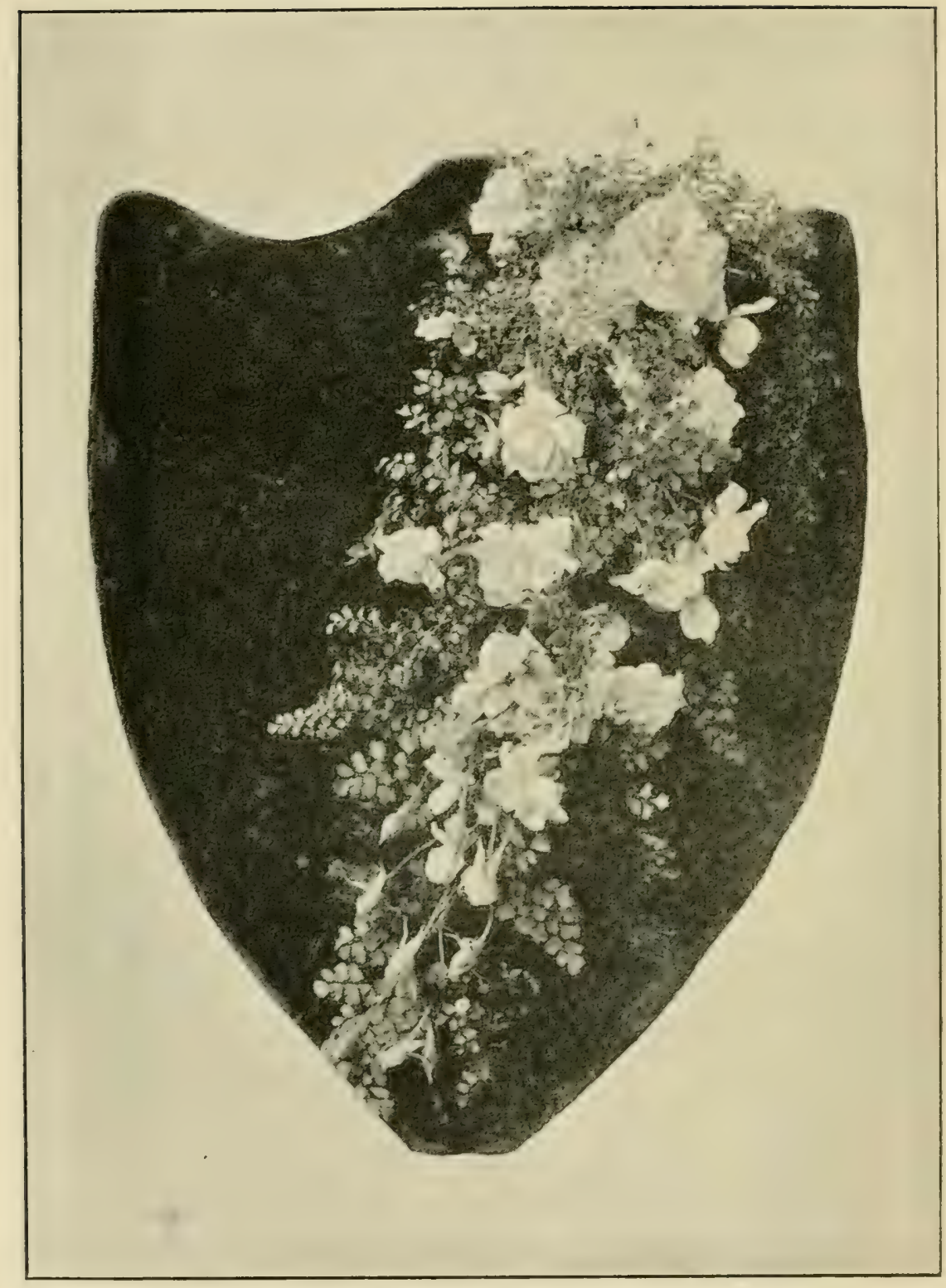

Rose Srrat, exmitited by Mrs. Orpes.

To face $p .25$. 
and the likeness was soon considerably increased by further hybridisation with the Tea Scented China. A few of our H.P.s also show a cross with this group, of which Boule de Neige is a good example. An account of the habits of this class also will be found in Chap. XII.

The Must: Rose (R. moschata).-This species is sairl to have been introduced to this country something like 300 years ago. It is a strong rambling grower, not hardy, with late-blooming clusters of single flowers, having a peculiar scent. It is a native of Persia and is said to be the sort from which the celebrated attar of Roses is manufactured in that country. The only varieties of this group which are at all well known are Madame d'Arblay and The Garland, strong climbers, which are supposed to be hybrids between the Musk Rose and some form of Rosa multiflora.

The Polyantha Rose (R. multiflora).-The perpetual forms of this group are of recent introduction, so much so that the name is not even mentioned in the sixth edition of Mr. Cranston's excellent book, published in 1877. The best are dwarf in growth, and the flowers are very small, quite tiny, but often exquisite in colour and shape, generally produced in clusters and masses, and invaluable for some of the modern forms of bouquets. Among the best known are Gloire des Polyantha, Anne Marie de Montravel, and Perle d'Or, the last named and one or two others having the true orange tint, only seen elsewhere in William Allen Richardson. The majority of the new varieties are no doubt hybrids with the H.P.s and perhaps some other classes. They are always in bloom, force well, and are sometimes used as edgings.

A new departure has been made in this class by the issue of 'Turner's Crimson Rambler, which gained the 
gold medal in 1893. This is a very strong-climbing perpetual Polyantha from Japan, the flowers being produced in great conical trusses in large abundance. It seems to be quite hardy, and promises to be a great acquisition, either for orclinary climbing purposes or for the pegging-down system of treatment.

The Macartney Pose (R. bracteata).-This species was introduced from China in 1795 by Lord Macartney. It is of vigorous growth, with bright glazed foliage, not, very hardy, and best on a warm wall. The original was single, but Marie Leonida is double, sweet-scented, and generally a mass of bloom through the season in a warm situation.

R. lucida, R. microphylla, and R. berberifolia are all somewhat similar to the last-named group-not hardy, but with shining foliage, and practically evergreen where well protected. There are double and single forms.

The Jupanese Rose (R. rugosa).-These Roses are most distinct, the thickly spined wood and foliage being very fresh and pleasing; the single flowers large and fine, and the bright-red fruit handsome and striking. The two principal varieties are the red and the white, the latter, very pure in colour, being generally the favourite. They do well on their own roots in good soil, for clumps, or a small ornamental hedge.

Other botanical varieties, all single, are $R$. macrantha a French Rose with long golden stamens; R. pomifera, with apple-shaped fruit; R. rubrifolia, with red stems and foliage: R. setigera, the Bramble-leaved Prairie Rose from the United States; and R. gigantea, from India, with white flowers five inches across. There are many others, but they are only of botanical interest. The Green Rose is a curious monstrosity of the China 
race, the so-called petals having changed into leaves, and become indistinguishable from the rest of the plant.

A sort of ill-defined division has lately arisen owing to some sorts being called "garden Roses." This term was originally applied, when H.P.s and Teas came into fashion, to the Damask, French, H.B., and H.C. Roses remaining in old-fashioned gardens. Later, it came to be used for all Roses which were not up to exhibition standard, and raisers of new varieties that were not up to the mark introduced them as "good garden Roses." The N.R.S. has now classes for the exhibition of garden Roses, and issues a definition of what may be shown under this head; but for general use, without drawing any hard and fast line around them as a class, the name is useful as representing the hardy, strong-growing, freeflowering sorts, which do not require much care, but are defective as florists' flowers. 


\section{CHAPTER III}

\section{SI'TUATION AND SOII}

Ix the choice of a situation for the cultivation of roses we must seek for a spot-

1, as little liable as may be to severe frosts ; and

2, sheltered, if possible, from violent winds, but not too near large trees or hedges.

1. It is pretty well known that most of the Tea Roses are tender, and likely to be injured or killed by severe frost. In the winter of 1890 the whole of my Maréchal Niels were absolutely killed, though they were grown in a row close to the west side of a high paling, and were well and thickly covered with bracken, with moreover nearly a foot of snow over all. The Hybrid Perpetual Roses, especially if grown as dwarfs, will generally withstand the effects of any winter; but late frosts, in May or even earlier, will seriously affect their young shoots, in severe cases (as in 1891 and 1894) blackening and killing them, and still oftener injuring or destroying the as yet invisible bud. The worst of it is that it is difficult after such a visitation to estimate at first how much damage has been done. A fortnight of genial weather may sometimes be required before we can see whether the shoot is stopped (that is, made "blind"come to an end without a bud), and even if the bud 
is still to be found apparently sound it has probably received some permanent injury or disfiguration that will render it valueless, but cannot be detected till it is too late. In such cases it will be advisable to remember that the injury is almost always worse than it appears to be at first, and that if the growth is not far advanced the sooner the damaged shoots are removed the better.

Even the native briar standard stocks, just transplanted from the hedges, will sometimes suffer; and many thousands were thus destroyed in nursery grounds in the winter of 1890-91. In one year in the eighties many of my standard H.P.s were thus destroyed, and in almost every case the injury - the frost-bite-was not to the Rose, but to the stock, black dead places, looking like actual bites, appearing in the stems. This was an exceptional case, and it does seem odd, as we rarely see a wild briar injured by frost, that the same plant should be more tender when transferred to a garden; but we must remember that standard stocks for budding have nearly all their fibrous roots cut off, and that they are generally taken from a sheltered place and planted right out in the open, much more exposed to evaporation, and are often perhaps allowed to become dry at the root in moving. It is plain, therefore, that, as frost is such an enemy to the Rose-grower, a situation should be sought where the least damage of this sort may be expected.

Frost is seldom very severe in England at the sea-side, but the salt spray and violent winds would render such a place generally undesirable, though good Roses are grown in some seaside localities. The old-fashioned saying is that "frost falls." This is of course not true in itself, but it is true in effect. Heated air, being lighter, ascends ; colder air, being heavier, descends : and it is found that frost is always most severe and danger- 
ous in low-lying places and that a covering overhead is a better protection than one at the side, because evaporation upwards towards the sky produces cold. My neighbour, a quarter of a mile off on a little hill, has always from three to five degrees less of frost than I have; and even if it were not so I believe that the same amount of frost would be more destructive to vegetation to me in a river valley than it would be to him on the upland. Valleys or low-lying ground, especially if near water, should therefore be avoided, and the uplands in all cases be preferred.

Mere height above the sea level would not, in most cases, be a matter of much moment; though on the one hand the top of a mountain would not of course be a desirable spot, and on the other a very flat plain with little height above the sea would probably be subject to severe frost: thus the flats of Cambridgeshire, which have such a slight fall to the sea, are well known as registering very low degrees of temperature. Rather high ground, not necessarily the top of a hill, with valleys in the neighbourhood for the cold air to fall to, would probably be a good situation as to comparative immunity from frost.

In dealing with situation, I do not allude to different parts of England, though it is well known that Maréchal Niel cannot be successfully grown out of doors in Yorkshire, while in sume parts of Devonshire and Cornwall even sub-tropical plants will live through the winter. I am not supposing that the Rosarian can choose his county for Rose-growing : if he could, for combination of climate and soil Herefordshire would probably make a strong bid for the pride of place, at all events for H.P.s. Teas, which depend less upon actual fatness of earth and more upon dryness in atmosphere and soil, may 
probably in favoured situations be easier grown to their best in the Eastern Counties. If a man has only his own grounds wherein to choose a spot for his Roses, let the highest spot be chosen, if it be not the actual bare cone at the top of a hill. A little height will make more difference than one would suppose; and if on a slope, let the Teas be planted at the top.

2. Exposure to strong winds is very hurtful to Roses in the flowering season, and at such a time an exhibitor will be more distressed to be awoke at night by a gale of wind than by a storm of rain. Anything that rubs or chafes against a petal will injure and spoil it; and to tie every bud up so that nothing can possibly touch it is, among a large number, almost an impossibility. But wind may, and often does, do much more harm than spoiling the blooms: the newly budded shoots of "maidens" are sure to be blown right out of the stocks as soon as they get strong and heavy, and the whole plants thus absolutely destroyed, unless they be carefully and constantly tied up to stakes; and moreover these ties must be looked to and renewed even quite up to the autumn, as a strong head is seldom safe from being blown out till it has been pruned in the following spring.

Where there are many standards, every morning after a gale will probably show several of the supporting stakes snapped off close to the ground, and the Rose plant being injured at the root by swinging in the wind. Not only must a new stake be supplied, but the old stump must be extracted without disturbing the plant; for old decaying wood has, especially in some soils, a tendency to promote the growth of a fungus which is injurious to the roots. The operation, which looks hopeless, can gencrally be satisfactorily 
performed with an old pair of garden shears, which will grip the top of the half-rotten stump, and then, by a dlownward pressure on the handles, lever it out like drawing a tooth. Again, although height is as a rule more important than shelter as a protection against frost, the drying power of the east wind in what is called a wind frost is hurtful, especially to newly planted Roses. It seems to dry the sap out of them, and if long continued may do a good deal of harm.

As strong wind is so injurious, shelter should be sought for; and that, not only on the north and east, but also on the south-west, from which the strongest winds generally come. Belts of close-growing trees or thick and high hedges will be the sort of shelter generally available, but it is most important that they be not close enough, either to shade the Roses, or for their roots to enter the beds. Buildings or walls are the best shelters, as the protection they give is real with some refricted warmth: they drop no seeds or leaves, and especially they have no robbing roots.

A place which has plenty of walls, even if most of them be low ones, offers great advantages in situation for Rose-growing. All the Teas and Noisettes can be grown to greater perfection against a wall than they can in the open, with the two disadvantages that the bloons will be too early for exhibition, and that the autumn crop will probably not be so good. 'The higher walls will be useful for the Noisettes and climbing Teas, or even for the climbing H.P.s or Hybrid Chinas; and the lower ones for the true Teas of more moderate growth, which in the Eastern or Home Counties will in ordinary seasons have first-class blooms by the first week in June. Many do not know what a beautiful Tea Rubens is, unless they have grown it on 
a wall; and some of the hot-season Teas, such as La Boule d'Or, Madame Margottin, or Madame Hippolyte Jamain, will often succeed on a wall, and even not be too early to show, in seasons when they fail in the open.

No wall should be neglected. I have grown the best of Teas on the low wall surrounding a deeply gravelled stable yard, and have won a medal with Souvenir d'Elise from this hopeless-looking place I have in such cases planted the stock against the wall and budded it there, with no preparation of the soil. The stock rooted itself firmly and strongly, and when the Rose began to grow I found that a big basin or depression in the soil round the root and plentiful supplies of liquid manure were sufficient for the production of capital growth and splendid blooms.

Apart from walls or buildings, the question of shelter is a difficult one; for it must be carefully remembered that the neighbourhood of trees, shrubs, or hedges whose roots can reach the beds, and also all actual shade, should be sedulously avoided. And, again, the situation must be quite free and open, not close and stuffy; and if no shelter whatever can be had, the finest Roses can still be grown, for the grounds of nurserymen, even those who are most successful at the shows, are absolutely open and exposed to the four winds of heaven. After all, then, it is better to be moderately high and exposed than to be too sheltered and too low, particularly if the shelter consist of growing trees or shrubs which stand too close. But, if thus unsheltered, extra and constant care must be given in the growing season to tying and supporting : the majority of the H.P.s should be grown as dwarfs, and stout bamboe stakes should support the permanent standards. 
In many cases, however, the would-be grower of Roses has no choice of a situation, but has to make the best of the ground at his disposal; and as I have to grow my own Roses in just such a situation as I have been describing as the worst of all-viz. at the bottom of a valley, near a river, hardly above the level of the water-meadows, only thirty feet above sea-level, and moreover surrounded by large trees-I can fully sympathise with any one in such a position. The disadvantages of low ground can only be surmounted by choosing the very highest you have-a little rise will tell-and by much care in protecting the Teas through the winter (see Chap. IV.). As for the big trees, if they must not be cut down, their shade and their robbing power must be utterly avoided, or success will be impossible. We may generally calculate that the roots will reach to a distance equal to the height of the tree, though some are worse robbers than others, and a specially wide berth should be given to Elms. As to the cutting through the tree-roots before they reach the beds, the labour will generally be found inadequate to the result a really deep trench, kept open, might answer in some cases, but in many it would be a serious nuisance. I have tried cutting the roots and putting tar and other things that I thought would stop them into the trench before filling it up, but without success.

The general resort of the baffled Rosarian is to take in a piece from a neighbouring field, and this is no doubt the best course to pursue; for, if the soil be good and the field an old pasture without any trees too near, it will be far better to do this at once, even at some extra cost, than to try to grow Roses to perfection in a garden without sufficient elbow-room from large trees and shrubs. 
Pure air is essential, and good Roses cannot be grown within the smoke circle of a large town; but on the border land, so to speak, of town and country, in those suburban gardens where clean or foul air may depend upon the direction of the wind, constant loving care may do a great deal to minimise the evil with a few plants. It should be remembered, in such cases, that the leaves are the lungs which are unable to respire when choked with grimy particles, and plenty of syringing, and even sponging of the leaves on the under as well as the upper surfaces, should be resorted to.

\section{SoII.}

The best soil for Roses is a strong rich deep tenacious loam, of a heavy greasy nature without being actual clay, and naturally well drained by resting, not less than two feet down, upon gravel or chalk or some other porous stratum. This will give a general description of what should be the ideal, but I do not suppose that any one can accurately appraise the value of a soil for Rose-growing by simple examination, and even chemical analysis is sometimes fallacious. The test of results is the best and most reliable, and the value of land for wheat or pasture (either of which is a good guide) is well understood by local men in any part of the country. One field will often differ very much in value from another that looks just the same; but this is all well known, as to practical results, by the farmer's and labourers on the spot, and much reliance should be placed upon their opinion, in conjunction with examination of the soil, in test holes to the depth of two or three feet at least. The best wheat land, high-rented pasture, 
a neighbourhood where the English oaks and elms grow large and the hedges are vigorous and strong; with long clean healthy shoots-such signs as these will be better guides to the seeker for a Rose soil than geological maps, which often give no indication as to the nature of the surface.

The principal soils likely to be found are clay, loam, gravel, chalk, and sand.

CLAY.-The general idea is that clay land is most suitable for Roses: but there is a very great difference in the fertility of clays, from the poor blue shale clay of the Weald of Sussex to the rich yellow unctuous butter that feeds fat the Roses of Colchester. In this matter there can be no better guide, as I have said, than the local knowledge which has been gained by generations of experience of results, and the obvious test of value is the rent or price demanded and paid.

But clay land has very much deteriorated in value for agricultural purposes of late years, more than any other, and it is not now considered, as it used to be, the best of all soils for Rose-growing: and it must be remembered that even the best of it is very difficult and troublesome to work: it cannot be meddled with at all in wet weather, and unless the surface is dry harm may be done by even treading on it. Planting in such a case is a serious trouble to the conscientious Rosarian, who is told to apply the most powdery soil to the roots of his Roses and to see that it all settles evenly and closely between the layers of fibres, if he has nothing at hand but huge sticky unbreakable clods. The precious cultivation of the hoe, keeping the surface powdery and preventing evaporation by cracks in dry weather, is a serious and difficult task. Even if the land is well drained to start with, which is absolutely necessary, the 
lower drainage of the pipes may become choked by age or neglect of attendance to the outfalls, \&c., and the upper drainage of the cultivated soil is sure to be injured if the ground be trampled on or meddled with in a thaw or at any time when the soil is wet.

If such land should be the portion of the Rosarian, every effort should be made to lighten it, and to keep its particles as separate as possible, and prevent their being squeezed together in a puddle of putty. The agriculturist seeks the aid of frost for the disintegration of clay: if the soil be thrown up roughly and as much as possible exposed to the air, it will be found on the first dry time after a thaw in fair planting condition, but even then it should be trodden as little as possible. Anything that will mechanically keep the particles apart is good for digging into actual clay: long strawy manure, leaf-mould, road-scrapings, grit, light sandy or gravelly soil, or even coal ashes will all help; but the best of all is the burnt clay itself, mixed well into the land.

The clay should be burnt as follows. A large collection should be made of all manner of vegetable refuse, weeds, and rubbish that will not easily burn, sticks and wood both green and dry, but nothing except just the kindling that will burn too quickly, Rose prunings and hedge clippings, rotten wood and old stumps, \&c. Two or three large old roots that will smoulder a long time may be placed in the middle, and the heap arranged of such a mixture of fairly inflammable and damper materials that the fire will neither go out nor break into fierce flame. In and upon and around this heap, when well on fire, should be placed the clay in quantity proportionate to the amount of fire. Constant watching will be necessary to add fresh clay when it is needed and 
to prevent the fire going out or breaking through too fiercely anywhere, the object being to char the clay black and not to burn it red. I recommend, as the best instruction possible for this as for all mechanical operations, seeing it once done by an old and experienced hand. The clay burnt red as a brick will be useful as a disintegrator at all events; but the black charred clay will also have a considerable manurial value, and it is generally agreed that there is nothing like it for improving at the same time the consistence and fertility of real solid clay.

Roses in a clay soil make long strong roots, but not many of them. It will be advisable therefore in such places to put in plants from a lighter soil, whether Roses or stocks, which would have a larger number of roots of a more fibrous nature though not so large; and it would be very desirable to have a little lighter soilleaf mould or the top soil of an old garden-to put in immediate contact with the roots. Still, if the clay land be really good and well drained, it will often repay all labour spent on it, especially in a hot and early summer; for the Dog-Rose does like heavy soil, and with a well-cultivated surface above to prevent cracking on the one hand or too great consolidation on the other, and with plenty of moisture in the cool tenacious though well-drained substance below, most of the H.P. roses may be expected to come to full perfection on this stock.

LoAm.-If there was a choice, I should select rather the best loam with a tendency to clay, what a farmer would call "strong" land. There is very great difference in the value and fertility of what in auctioneer's phrase would be "good mixed soil"; and I can only repeat that the best guide on this matter is 
local knowledge and the rent that has been paid in past years. The soil ought to be equally good for quite two feet in depth, with effective natural or artificial drainage as a sine qua non. By natural drainage I mean a subsoil of gravel, stones, sand, or chalk; and for artificial, nothing less than actual pipes should be used, laid by a competent man, with a fair fall, and outfalls not neglected, but watched, cleared, and properly attended to. In the best loam the best Roses of all sorts may and should be grown.

GRAVEL.-Soil known as gravelly is often too quickly condemned. It is considered healthy to live on, agreeable to work, and useful for many things, but too hot, poor, and dry for the cultivation of the best Roses; still, as I have had to grow most of my own in such a medium, condemned after careful examination by one of the best judges as hopeless, I can aver that there is no reason to despair of a gravel soil.

There will be some soil at least, light, dry, and powdery perhaps, but fairly fertile, on the top above the gravel, and this, probably the full depth of the spade in the garden but not so deep in the field, should be taken out and laid on one side. Though not the soil the Rose delights in, it is excellent for root formation, for the striking of cuttings, for placing next to the roots of roses, and for mixing with heavy loam or clay in the making up of the beds.

The actual gravel must then be taken clean away to the depth of two feet at least from the surface (some enthusiasts say three feet, but I do not think it necessary or even desirable), and sufficient good strong loam or actual clay procured to take its place. This is expensive, but is absolutely necessary for the growth of good H.P.s, and will last a long time. The greater part of 
this heavy loam should be placed at the bottom where the gravel was, but a little of the light soil may be mixed with it and a little of the fresh stuff added to the upper portion. How to do this will be further described in the next chapter; but it is important to notice that when the beds are thus made up of good Rose material in what is naturally a gravel soil, the advantage is gained of having such perfect natural drainage at the sides as well as at the bottoms of the beds as could not well be attained in what is by nature a good Rose soil.

Furthermore, Tea Roses may be grown to perfection on gravel soil. A large quantity of good manure should in this case take the place of the gravel at the bottom, to which a little of the heavy loam may be added, though I do not believe it to be necessary. For Teas there is no occasion to be afraid of the multitude of small stones which are natural to a gravel soil; for I believe Mr. George Paul was right when he stated in the Rosarian's Year Book that "Tea Roses like grit." The bloom of Madame Cusin which gained the medal at the Crystal Palace in 1893 as the best Tea exhibited by an amateur, and was characterised by the Secretary of the National Rose Society as "certainly never equalled in any exhibition on this side of the Channel," was grown by me in what is practically an old gravel pit where stones have been raised for the high road. The pit was refilled with the siftings and levelled, and in this soil, unaltered save by cultivation and manure, the abovementioned and other good Tea Roses have been grown.

CHaLK.-This is as hopeless as anything to grow Roses in, and on the upper chalk of down lands where it is close to the surface, and good loam probably far distant it would hardly be worth while to attempt it. But in a great deal of the chalk formation of geologists it lies 
at a considerable though varying depth, and the soil above it, of a sufficient thickness for all Rose purposes, may be gravel, sand, clay, or loam. In many of these places the chalk itself is of a clayey nature, and is then called marl, the fertilising value of which is dependent upon the proportion of clay. Poor dwellings and sheds in Suffolk used to be made of what is called "clay lump." This was marl, mixed with reeds or straw, well watered, and trodden by a wretched horse till it was thoroughly compacted, and then formed into very large bricks and left to dry but not burnt. When an old building was pulled down the "clay lumps" were considered excellent, if broken very small, for mixing with light land, and I have no doubt they were. They were thoroughly dry, and one of the great difficulties of mixing clay with other soil is overcome if it can be got so dry that it can be beaten into powder. Marl, as a mixture of clay and lime, was a good deal carted on to the light lands for agricultural purposes in times gone by, as the many old marl-pits in Suffolk testify.

Some very fertile soils may; be found on the lower chalk or marl formation, particularly on the edge of the greensand. Hitchin would be a case in point, where Mr. E. B. Lindsell has for some years grown the best amateur H.P.s, and where Messrs. Harkness and Sons have also begun to endeavour, if possible, to better even their Yorkshire fame.

SAND.-This may be considered in itself to be the worst soil of all, but where it occurs in the greensand from sandy rocks, strong loam is probably to be had within carting distance, and almost all the really sandy part being taken right away to the depth of two feet, good Teas at least might probably be grown in wellmade beds in such a place. But in sands like that to 
be found at the seaside, or as the "blowing" sands on the Norfolk and Suffolk border near Thetford, where thick belts of firs have to be planted to prevent one man's crop, and field too, being actually blown away to his neighbour, I fear the Rosarian must stifle his impulses, change his object of worship, and devote himself, according to the extent of his holding, to hyacinths or partridges. 


\section{CHAPTER IV}

\section{PLANTING : WITH LAYING OU'T OF THE BEDS AND PROTECTION}

Situation and soil being settled, we have next to lay out and prepare the beds, to plant the Roses, and to protect the delicate and tender kinds from being injured by frost.

Let it be first understood that for proper cultivation the Rose must have a place to itself. Although I sympathise with that large number of cultivators who plant Roses in mixed borders among strong herbaceous plants and even shrubs, it must be said that it is next to impossible to bring the Rose to perfection in such surroundings. When wondering much at the number of extra tall standards to be seen in nurserymen's grounds, and as to who could be found to buy them, I have been told that there is a large demand for them in some gardens for certain situations, "where a tall standard Rose would just come in "- between two huge clumps of delphinium, perhaps, or "so that it would just show nicely from behind over that bushy shrub." It must be laid down that to make the queen of flowers take a back seat is an impracticable task; she cannot stand it, but will inevitably pine away: she tolerates 
no rival near her throne, and will not show her full beauty if she has one.

Beds must be made for the Rose and the Rose alone. No : no mignonette or other annuals to " hide the bare ground," since standards need not be more than two feet high in stem, and dwarfs should be close enough together to do all the ground-hiding required. Let there be Rose beds sacred to the Rose, and let them all be grown together in the very best situation to be found; for standards dotted about singly here and there by the side of the drive or in holes on the lawn are much more difficult to manage and care for properly than if they were all together in prepared ground. It is well known that you can feed 100 people much better and cheaper in proportion than you can one person by himself. And so, if the Rose is in a big bed with many others, the food can be applied with greater economy and effect, and the roots can find in any direction the same congenial proper soil and nourishment.

Let "the small man," if he be a true Rose-lover and has a mind to grow them really well, harden his heart against all rival flowers, and go in, practically, for Roses alone. In every department of life a man must be a specialist now if he wants to succeed, and the Rose will amply repay special devoted care. There are several examples among amateur Rose-growers of singlehanded men who either unceasingly superintend or do all the work with their own hands: and most of these have not the smallest fear of meeting the best head gardeners in England in any class at the largest shows. This is by no means the fault of the great gardeners, even of such as have fifty men under them, but is simply because the Rose requires undivided care 



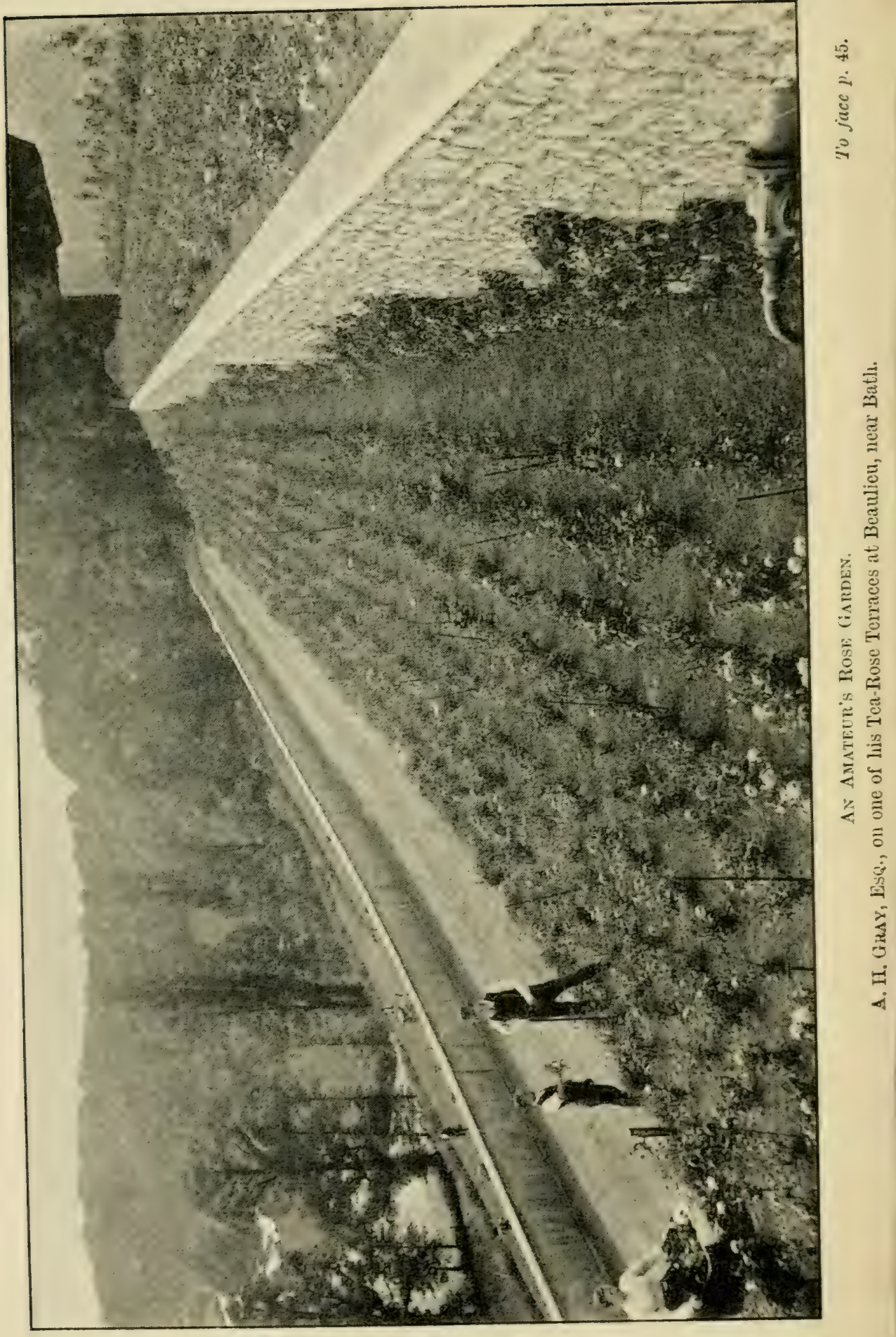


through nearly the whole of the year, and they have such a multitude of other things to attend to that they cannot compete even with a single-handed man who gives all his time to his Roses.

What, then, shall our Rosarium be like in pattern and shape and general effect? Here I fear I shall prove too practical and utilitarian for the taste of many persons. Mr. William Paul in his large work gives several carefully drawn diagrams of geometrical arrangements and of noted Rose-gardens new and old, some of them laid out quite from the landscape gardener's point of view. And Dean Hole says: "There should be beds of Roses, banks of Roses, bower's of Roses, hedges of Roses, edgings of Roses, pillars of Roses, arches of Roses, fountains of Roses, baskets of Roses, vistas and alleys of the Rose." But though these things are good and desirable, they will probably be beyond the means of most of my readers as they certainly are beyond mine. Also it must be remembered that the Rose is not like a bedding plant which will keep up continual masses of colour throughout the summer, but that the flush of flowers is not for more than a month at most, after which many sorts, even of the Teas, will be off bloom for a while and the general effect will be spoiled. Further, that for perfection of culture the best situation must be chosen, even in defiance of artistic surroundings. And lastly, I may say for myself that, given the most perfectly arranged Rosarium that ever was seen, I would leave it for a few plants in a bed in the kitchen garden with cabbages on one side and onions on the other, if there alone could be found the perfect blooms.

As to the shape of the beds, it seems evident that they should not be so wide as to necessitate treading upon the soil to reach and cut the blooms. This points 
to long and comparatively narrow beds, and when yon have them there seems no escape from actual rows, following the shape of the beds, whether straight or curved. Anything else would waste the precious room, for if the whole bed be made of the best soil and fed and manured equally, the room that will hold another plant is precious. Straight rows may be condemned as formal, and so they are, but they are thoroughly practical and economical, and undoubtedly the best for an exhibitor, who wants to be able to go over all his plants easily and expeditiously.

My own rose beds are simple parallelograms fiveand-a-half feet wide, and such beds may be as long as you like. I may wish mine were longer than they are but not wider. Longitudinally they are separated by grass paths of the same width, and there should be cross paths here and there, but not too many. Grass paths are much superior to gravel in appearance and in cost of keeping in order ; and of course if the Rose beds are made out of a meadow or pasture, the grass is simply left. These paths should not be narrower than five feet, not only for the convenience of visitors, but also for the conveyance of water or liquid manure in handcarts.

In these beds are three rows of Roses, the rows sixteen inches from each other and seventeen inches from the grass, and the strongest and tallest growers naturally in the centre row. There should be no hesitation about planting the Roses pretty close to each other, for the bed will be all prepared and fed alike, and they will not rob each other much. Beginners are apt to make a mistake in this respect, probably having young trees and shrubs in their minds; but they should remember that in the case of ordinary 
H.P.s and Teas grown in the open for the production of the finest blooms the Rose plants will not increase very much in size, for the annual pruning will prevent this. I have seen rows of standards whose distance apart might be counted by yards; there might be some excuse for wanting "to hide the soil " in such cases.

It will be found most convenient for reference and labelling, and especially if exhibiting is contemplated, to place all the plants of one variety together in a row ; and though the first idea is to dot them all about tho beds, the effect will be better if they are massed together.

Then the distance of the plants from each other in the rows should depend entirely upon the varieties; sorts that are spreading as well as tall and strong, such as Mrs. Paul, should be eighteen to twenty inches apart, while such as are upright as well as small grower's, as Lady Mary Fitzwilliam, may be within nine or ten inches of each other. Between these extremes there will be many gradations, and care should be taken at the same time neither to inconvenience the plants by crowding nor to waste the room. Some tall sorts, like François Michelon, are upright and not wide and bushy, and do not therefore require much room; while others, like Comtesse de Nadaillac, though dwarf are spreading in growth, and cover more ground in proportion. Some guide to these "manners and customs" of the varieties will be found in Chapter XII. It will be best, however, that the strong growers should be set wider apart if quantity rather than quality be aimed at, as in this case the plants will be allowed to increase in size at the annual pruning. The Gloire de Dijon race, Maréchal Niel and the Noisettes, which are pruned on a different system and require much more space, should 
not be planted in the same beds with the H.P.s and Teas.

But I am getting on too fast. We have to make up our beds after marking them out in the grass, and to do this properly everything will depend upon the nature of the soil and subsoil, instructions for dealing with which have been given in the last chapter. Whatever the soil may be, it should be moved at least two feet in depth: and, unless the soil under that should prove thoroughly porous, affording good natural drainage, the beds must be properly pipe-drained by a competent and trustworthy man. That is the first thing: without good drainage, natural or artificial, no success can be achieved. In any soil there should be perfect drainage, as cultivation depends upon it in many ways. All really worthless soil, chalk, gravel, or sand should be taken away, but long before this should have been the hunt among neighbouring farmers and landowners for good Rose material to take its place. When found and purchased, this good loam-the top spit of an old pasture if possible-ur even actual clay, should be carted to the spot while the ground is yet hard in September, for the Roses are to be planted early in November, and the soil will do well to rest and consolidate a while before planting.

Let the beds be dug out, as advised, to the depth of two clear spades at least; and let it be understood that the material is to be made up in two portions or layers, whereof the lower is to be the larger. If among grass, reserve the turf to be chopped up and mixerl into the upper portion. Next lay on one side all soil in the top spadefuls that seems fairly fertile, however light and dry; it will be useful for a thin layer in immediate contact with the roots, for mixing 
very slightly with the lower portion but more fully with the upper part, and for forming the topmost two inches of the bed. Then dig out the remainder of the depth agreed on, and see that the drainage is right. If the soil be good replace it, and if it be worthless cart it away, and fill in with the imported soil, which if it be actual clay should also have some of the lighter material worked in as thoroughly as possible. This lower portion should be about two-thirds of the whole in depth; and if manure is to be added, let it be mixed freely with this alone, and not put into the upper part. If the bed is meant for Tea Roses, heavy soil is not necessary, and a large proportion of the lower part should consist of the best manure, remembering that the more manure is added the more the beds will sink eventually as it decays.

The upper third of the bed should next be formed. If the imported material be loam, a good deal of this may be used; but if it be clay it should be added very sparingly, and as well worked in as possible with a good deal of the lighter soil and the chopped turf, the upper two inches in all cases being of soil that the hoe will pass through freely and easily. The bed is now made up, with the strongest soil and manure forming the larger lower part over the drainage, and the upper one-third of rather more friable material, getting gradually more porous towards the top, for the admission of air and warmth and the encouragement of fibrous roots. The beds should not be trodden more than can be avoided, if there be time for them to settle; it will be better if they are pressed gently from time to time, or allowed to sink naturally of themselves.

By the first or second week in November the purchased plants ought to arrive, and these should have 
been selected beforehand, if possible in the nurseryman's quarters, or at least ordered very carly, as the good plants are sure to go first. They should not be sent before November, for though you may move your own plants with care in October, they ro not stand a long: journey well before they have lost their leaves. The bundle should always be unpacked at once, unless there be strong frost: and if the frost continue, it will still be well to unpack them, remove the frozen surface from a piece of unoccupied light land, and "lay them in." This should be done with some care, seeing that the roots are not bruised or laid too closely together, that all are deeply covered with soil, and that the tops are also protected from the frost by green boughs, matting, or some such material. They should also be laid in if the weather is wet and planting cannot be proceeded with at once; it is far better to do this than to plant when the soil is sticky. Nevertheless, every effort should be made to get the planting done in November, and not to defer it till the spring; for I have often seen that fresh roots are commenced during the winter months by Roses planted in November.

Great care should be used in disentangling and untying the hearls of the Roses when unpacking, as there is still considerable danger with the "maiden" or one-year-old plants of the head being clean pulled out of the stock. Good plants will have good roots, that is, many and fibrous, rather than few, strong, and long. In " dwarf" Roses (by which term is understood all sorts cven of the most vigorous growth which are budded on the stem of the stock near the root, and not on the branches to form standards), good plants will have very little length of stem between the roots and the point where the stock was budderl, whether they be on briar or 
manetti : a perfect dwarf plant should have no "leg" at all. The wood should be ripe, firm, and hard, a fat red fleshy shoot being of no use, as it will certainly have to come off when the plant is pruned. There should be a good union between stock and scion, no failure visible in the joining, and no round knob formed by the Rose at the point of union; but it should be evident that the stock has swelled and grown in proportion to the growth of the Rose.

The roots should be pruned as soon as the Roses are unpacked, in the first place removing with a sharp knife any bruised or injured portions, and seeing that the ends of all the roots are clean cut; secondly, shortening all of extra length, especially those which are fibreless or stiff ones which go straight down; and thirdly, looking for suckers, which should be cut clean out, an easy way of distinguishing a sucker from a root being that the former gets thicker and the latter smaller the further it gets from the stem. The underground stem or main root should also be strictly examined for buds even in the most embryo stage. These should be carefully cut out, or they will certainly sooner or later form suckers.

The art of packing Roses is well understood by the best nurserymen, and some damp material is generally placed in the package around the roots. It may occasionally happen, however, owing to the parcel being delayed on the railway, that the roots have got dry or even the bark of the Roses become shrivelled. In such a case, if matters have not gone too far, it may be well to try a method of recovery recommended by Mr. Frank Cant. Lay the Roses flat in the ground and bury them completely, roots and tops, six inches deep; give the spot where they are buried a good soaking with water, 
and at the end of three days it is said that the plants will be restored to their original condition.

The very first opportunity when the soil is comparatively dry should be chosen for the planting, and one of the most important points to remember is that the roots should never be allowed to become dry; they should be kept under matting or damp leaves or soil till actually wanted, and exposed to the air as little as possible. Some recommend the dipping the roots in a pail of thick puddle composed of clay, cocoanut fibre dust, and water, as a protection from drying air; but I do not think this is necessary or advisable where there are small fibrous roots, as these get matted together and cannot be separated without some danger of injury. In spring planting, if the sun be bright, it is safest to carry the Roses in a pail of water from the place where they have been laid in during the winter to the bed where they are to be planted.

Another equally important point is that the Roses should not be planted too deeply. I consider four inches sufficient for "dwarfs": standards may be planted an inch or so deeper, and a little further apart from each other. Comparatively shallow planting, especially if the Roses are going to be cultivated and not neglected, is a great secret of success. A good piece of advice is to mark the line of soil upon the plant, and be careful not to cover it deeper than it was before: and a bad one is to plant deeper in light soil to avoid the drought. The principle of shallow planting and dependence on horizontal surface roots is well understood by gardeners in the case of fruit-trees: they will take much pains to cut the tap-roots, and will even "lift" the roots of their vines, peach, and other trees if they prove unfruitful, lay them in again nearer the surface, and encourage 
them by all means in their power to remain there. They know that the produce of tap-roots is gross wood without blossom, and that fibrous surface roots must be looked to for flowers and fruitfulness; yet some recommend the seedling briar as a stock because it roots deeper, although we surely want flowers, not gross wood alone, from the Rose as well as the fruittree.

In planting, therefore, at the depth recommended, carefully spread out the roots horizontally, equally in all directions if possible, though this cannot always be done, purchased dwarfs often having roots pointing only in one direction, which arises in soine degree from carelessness and haste in originally planting the stocks. If a separate hole be made for each plant, let it be wide enough; do not curve the roots or let them cross each other. If they naturally want to cross, or there be two or more going in the same direction, put some fairly light soil between them that they may lie in layers but always horizontally. See that the soil which is put against the roots themselves, or to cover each layer of roots, is at all events fairly fine and crumbly, if not actually dry and powdery; lift the plant by the top up and down a little with a shaking movement to settle the soil more thoroughly amongst the fibres, and remember that the whole operation of planting is done much more thoroughly and expeditiously by two men than by one. If single-handed, a short pointed stick for scratching fine soil between the fibres will often be found more handy than trowel or spade. Just fairly cover all the roots with a couple of inches of soil, tread it very lightly and carefully, and pass on to the next plant, for the rest of the soil can be added at the conclusion of the day's work. 
In planting dwarfs the point of union should be, if the stock be manetti, two inches below the surface, and one inch if the plants are budded on briar cuttings. The Rose will then throw out roots of its own, which will not only help to feed it, but being nearer the surface will also hold the plant more securely against being rocked and loosened by the wind. Now therefore may be seen the immense disadvantage of a dwarf plant which is not budded sufficiently low on the stem: either the roots must be placed too deep or the point of union must be left uncovered. Order therefore with short "legs," and "see that you get them." It should be mentioned that Mr. Prince of Oxford, who is the principal advocate and the largest user of the seedling briar, does not advocate the covering of the point of union with this stock. I have seen some of his dwarf "cutbacks" on the seedling briar which certainly were flourishing exceedingly with the point of union two inches above the surface; but with the briar cutting I have found Roses do not thrive so well if thus planted, and with the manetti it is absolutely imperative that the point of union be well covered, or the plants will assuredly die.

Standards must be securely staked at the time of planting, and it is better when the hole is made to put in the stake before any of the roots are covered, or otherwise some of the best of them may be inadvertently bruised and injured. All the plants for the day having been put in, some more soil should be added to each plant, and then tread but lightly, make the surface level, and look to the row again in a few days with a rake, filling depressions and doing away with any cracks that may appear. This will be better than treading too heavily at the time of planting. If the 
weather should continue very dry watering may be desirable; and if the plants have good green leaves on when put in, the heads should be watered at once on unpacking, and the plants well watered and syringed immediately after planting.

It is easy to imagine a beginner having some uneasy reflections after following the above instructions. "I have planted my roses only four inches deep, and trained the roots horizontally, as certainly scems right from the analogy of fruit trees and from what I know of the advantage to roots of the fertilising influences of sun, air, and the surface bacteria. But all my manure, and I gave a great quantity of valuable stuff to my Teas, has been buried from eight to twenty-four inches deep, and what is the use of all that manure there, if the roots are not to be allowed to go down to it?"

Here comes in another important principle, to illustrate which I will take as my text the soil in which hyacinths and other bulbs are grown in immense quantities in Holland for sale. This soil is extremely valuable, as the profit on the cultivation in good hands may reach quite $£ 50$ an acre. And what is it? Pure sand and nothing else for a depth of four feet or more, which no English farmer would take rent free. Yet the hyacinth must have plenty of water. We all know that in a hyacinth glass a fine plant and noble flower may be produced from the bulb with nothing but water given. We also know from this glass culture that the roots of hyacinths do go down some depth, considerably more than the height of the glass. And it should further be stated that the sand in the soil spoken of rests upon a water-bearing stratum of clayey peat, in fact the general water level of the whole country. But 
it seems almost impossible that hyacinth roots should reach down vertically for four feet or more, and quite impossible that they should start and form such a length of root without the aid of water. If, however, the water was always slightly rising up through the sand, and moreover the roots had a power of attraction almost equivalent to suction, the impossibility would vanish. And so it is. Water, or rather moisture, does rise through the soil by capillary attraction, as it will up through a sponge or piece of flannel. Just so moisture is always more or less rising up through the earth, though of course a quantity in time of rain or immediately after sinks down through it. It rises most of all when the sun shines hot and the surface is dry, and then the Rose, which likes heat and a friable air-permeated surface above and a "cool bottom" below, rejoices in the rich moisture which the roots appropriate as it rises up through the manure from below.

In thus recommending the placing of all manure at planting time beneath the horizontally lying roots, and incorporating none in the soil at their own level, it is but fair to say that I believe few Rose-growers will agree with me. I am, however, a strong believer, as the next chapter will show, in artificial and liquid manures as the best means of feeding Roses, especially if they are supplied at the outset with soil of the right texture and material. I am strongly of opinion that a great many newly planted Roses fail to thrive, because manure, generally too fresh, is placed close to the roots. It is frequently not at hand in a sufficiently decomposed state for such a position; and if it is, a great part of the manurial value has probably been lost in the decomposition. It would still be useful for forming humus 
where raw soil taken from some distance below the surface is used, but the upper portion of all soils has generally sufficient of this.

For these reasons I recommend strong rich fresh soil in preference to the addition of solid manure, and that if any be used it be placed underneath, where it may be used before it has lost its strength.

It must be borne in mind that shallow planting is of no use without cultivation, which is done by the Dutch hoe constantly at work on the surface. This causes more rapid evaporation from the actual inch or two disturbed and it soon becomes dry, but at the same time by closing the pores and filling up cracks it checks the evaporation from below, so that the moisture drawn up from beneath in the manure reaches the roots, and yet cannot escape into the air in vapour. I consider this one of the most important points in the "cultivation" of the Rose.

As to mulching for winter protection of the roots I do not believe it to be necessary, but the soil should be loose on the surface even in winter, for a friable and well-cultivated surface is a mulch as has just been seen. Very long shoots of dwarf Roses may be shortened, not too much, but only to prevent the wind getting much hold of them. This does not apply to the Noisettes, Maréchal Niel, or the Dijon race of Teas, whose long shoots must be protected and tied to some support.

If the collection is quite small, labels of as permanent a nature as possible may be used; but in large collections, especially where, for exhibition, many of a sort are grown together in rows, a book with the rows numbered and the names written in order will be found most convenient. 
But the tender and delicate Teas are to be protected from frost, and how is this best to be done?

Long manure is unsightly and unclean, and difficult to get away properly, while clean straw looks untidy and messy and is not a good protection. For a long time bracken (the common brake-fern) has been recommended by nurserymen, and good and useful it is where it can be had. If it can be procured at a reasonable price per load, a stipulation should be made that it be cut before it has got quite sere, in fact just when it begins to turn. In this case the leafy parts will adhere much longer to the skeleton stalks; but care must be taken that it be not laid before use even in small heaps, or it will be sure to heat to a certain extent and speedily rot. It should be put lightly yet thickly around and amongst the dwarf Teas and into their heads: there is no fear of its blowing away, but after a heary snow it may get beaten down a little too much, and a further supply, which should be kept in sheaves, standing in stooks, may be adderl. For standards it is a capital protection, tied tightly together at the top, and allowed to hang down all round, with a looser fastening at the bottom, as a sort of rough thatch: wheat straw may also be used in this manner, but if fir or laurel boughs be the protecting material chosen, the plant may be too top-heavy to stand a violent wind without some additional support.

For a few dwarf Teas a rude platform of crotched sticks with poles laid on them to support fir or evergreen boughs answers generally very well: in this case it would be good for the plants to remove the protection when there is no serere frost; and it may be taken as a general rule that frost to the extent of ten to twelve or even more degrees will do no harm 
in the winter, if it be not unduly prolonged or accompanied by a dry east wind.

Another material for the protection of dwarf Teas that seemed very reasonable and good at first is earth itself. To use this, the rows of plants are earthed up by a hoe, or even in large quantities by a plough, in the same manner that potatoes are treated in the spring, to the height of about six inches ; in any mode, no protection need be applied to the tops of the plants, as a great deal will necessarily be cut away in the spring pruning. But if the roots run horizontally and shallow, as they should do, there is considerable danger of injuring them in scraping up sufficient earth, and a fresh supply for the purpose from elsewhere is heary and inconvenient to move away again.

I find the cheapest, most convenient, and handy material for the protection of dwarf Teas from frost to be dead leaves, which will just have fallen and should have been gathered together in time for use. If applied thickly enough, they appear to afford ample protection against any frost and when heaped together on the beds they probably generate a small supply of heat in themselves.

They should be put a foot to eighteen inches in depth all over, around, inside, and between the plants, and I do not find that they blow away in appreciable quantity, except perhaps on the very outside, where they may be renewed. They will be beaten down and consolidated a little by snow and rain, when a fresh supply if necessary can be added.

I believe these to be the best protection: they are Nature's own covering: the bed-clothes she herself provides for the winter sleep of her tender plants, and even apples accidentally left on the ground under the 
CHAP.

fallen leaves, have been often found fresh and in good condition in the early spring. Whatever the covering be, it should not be removed till the end of March or beginning of April, when the plants are ready to be pruned, unless the quantity be so small that the covering can be very quickly replaced.

Tea Roses on walls can be easily protected by evergreen boughs hung on nails; if fir branches be used, the needles or leaves will begin to drop off in early spring: this has a good effect in exposing the plant gradually, and so hardening it off, but the needles should be swept away and not suffered to work into the soil. It must be remembered in this case and in that of standards that it is no use protecting the upper shoots if any part of the actual Rose below is left exposed. The very lowest part of the Tea Rose as budded on the briar is the important place; if that be killed the whole plant is destroyed; but if even an inch of sound wood is alive at the very bottom, though all the rest be killed, the Rose will probably grow up again as strong as ever.

In very severe frosts and on low-lying grounds there is, however, great difficulty in keeping standard Teas alive during the winter. Leaves or earth, the most efficient protectors, seem impossible of application; and as the best Tea Rose blooms are produced on standards, heavy losses are often experienced by exhibitors. Digging the standards bodily up, and, after laying them carefully in rows in the earth, covering them with boughs or soil has been tried and recommended. For the weakly growers, such as Comtesse de Nadaillac, Princess of Wales, or Cleopatra, if on strong stems, this may answer fairly well; but for the stronger sorts with large heads, such as Marie van Houtte and Anna 
Olivier, it seems a pity to lose the advantage of established plants. I have tried half-measures, with great success so far as the frost was concerned; this consisted of digging the rows of plants up, or at least loosening them, on one side only, then bending and pegging them down flat on the ground and covering them first with straw and then with earth. Though completely uninjured by severe frost, they did not do so well afterwards as I hoped they would, but it was an exceptional season, and I should try it again but that I have found a higher spot for my standard Teas, where, with due protection of their heads, they have survived severe frost without having to be moved.

Maréchal Niel is very liable to injury from frost, especially in the long strong shoots of the year, which if unhurt will produce the best blooms. As a standard in the open, where it can be efficiently protected (the plant from frost in winter and the blooms from rain in summer), it does not indeed afford such a wealth of early flowers as under glass or against a wall, but it becomes a true perpetual bloomer, and from such plants alone can Roses be cut for exhibition. In low-lying and cold situations standards should be planted at a very sharp angle, so that the heads are not more than eighteen inches or two feet at most from the ground, and wires arranged for the training of the shoots in summer horizontally and quite low. These should be unfastened at the end of November, or even earlier, and stem and shoots all pegged down as closely to the ground as possible without straining or cracking anything; the whole may then be well covered with straw or bracken, and finally with a sufficient covering of earth, well flattened with the spade; they 
will thus be "clamped," in just the same manner as mangold heaps are protected in the fields. If the plants are grown as "dwarfs" on the briar cutting or seedling, care must be taken to train the strong young shoots low and horizontally while they are yet soft, or it will be difficult to peg them down without their breaking. They should be uncovered and raised earlier than the other Teas if in a warm position, as the buds are very susceptible to the first heat of the sun.

When briars have been budded with Teas, the tiny bud, on which so much depends, is of course in danger in hard frost. An old piece of advice from Mr. Rivers was to paint it with two or three coats of collodion, which forms a white skin: I tried this for two years but cannot credit it with protection of much value. I strongly recommend for the protection of these Tea buds the little straw covers or cases in which wine-merchants send out their bottles; there can be little difficulty in obtaining these in quantity, as I believe they have no value, except for lighting fires. It should be seen that the ties are secure, especially that the one at the top is tight and sound, and then they form capital nightcaps, which are, I believe, as good protection as could be wished. In the case of dwarfs the wild briar shoots are cut close back, but the whole head not removed till the spring, as the projections hold the nightcap in position; and in the same way the budded lateral on standards is cut back only just short enough to allow the cap to pass over, when it is held quite sufficiently against the wind. The bud is thus actually thatched, and provided with what is practically a waterproof as well as a warm covering, though not impervious to air. The cases can be very readily taken off or replaced if necessary, and 
the covering increased by surrounding the dwarfs with leaves, or by putting another larger case over the other on the standards.

Any Rosarian, who has had valuable Tea-Rose plants killed in past winters, will find it a great comfort when he hears the cruel North-easter blow, or finds his sponge frozen in the morning, to know that his Rose-pets are well supplied with bed-clothes and nighteaps to keep out the frost. 


\section{CHAPTER V}

\section{MANURES}

"MaNures" may seem an unsavoury subject to those lovers of the Rose who only know of the flowers as seen in the garden or after they are cut; but to the Rosenurses, under whose constant care each shoot grows onwards to the perfect bloom, it is as important a matter as the food of a babe is to its mother. The Rose enthusiast, for whom I write, has no objection to exploring the recesses of a muck-heap-he rejoices in the discovery of a dead well of really good stuff-and wonders much how others can find any objection to the wholesome and invigorating fragrance from a big watercart full of the drainings of a cow-shed.

The Rose is said to be a gross feeder, but this does not seem a satisfactory statement, for though it will take and absorb, and "answer to treatment" as doctors say, in the reception of large quantities of strong manure, yet is it fastidious in the manner of its application. The roots of the same plant which when strong and well established will rejoice in liquid rank enough to bring the worms struggling to the surface, or even under some circumstances to kill the weeds, will, when that plant is moved in November, become sickly and 
perhaps die if they are placed in the planting in contact with fresh, raw, and insufficiently decayed manure. The roots of the Rose like to run and feed in thoroughly fertilised soil of the proper texture and quality in preference to actual manure; and this is why fresh soil, the top "spit" of an old pasture with the turf, liquid manure of different sorts, or artificial if the exact amount and proportions can be found, have more satisfactory results as a rule than any quantity of solid manure incorporated in the soil.

It may be said that the soils of many a garden are, from long manuring, thoroughly fertilised earth: and indeed the manetti stock, which seems to like this sort of ground, budded with H.P.s in a favourable situation (that is, well away from trees or shrubs or any strong vegetation), will often give very satisfactory results the first season in an old garden. But this dark old soil, very rich in humus and decayed vegetable matter, though it may be much benefited by a dressing of lime, is generally wanting in some of the -mineral constituents which the Rose requires, for though heavily manured it has probably been also heavily cropped, and the Rose likes fresh virgin soil if possible. A naturally strong, rich, rather heavy loam is what the H.P. Rose likes, as fresh and unrobbed as possible; but wonders may be done for the Teas by manure, solid, liquid, and artificial, even on a poor light soil.

Natural solid Manure.-It will be seen from the above that I do not consider solid manure to be the best form in which to give food to Roses; and in fact, all my H.P.s, and many of my Teas which have done well, have never had any natural solid manure at all. But many other good authorities may very likely be of a different opinion, and I should quite allow that 
solid manure, in the right condition and properly applied, is of great benefit to Tea Roses.

Taking first the ordinary manure made with straw from stable, cowshed, or pigstye, it is generally allowed that as the Rose likes "a cool bottom," and stable manure is "hot," and cow manure "cool," as a rule the former is the worse and the latter the better for the purpose. In clay soils stable manure would be allowable and perhaps even advisable; but, otherwise, that from cowsheds or, better still, from a yard where highly fed bullocks are kept, would be the best of all natural solid manure, the pigstye contribution ranking next in value, and the general heap from a farmyard where horses are not predominant being good enough for ordinary purposes.

The next question is, Is it to be dug into the soil, or used as a top-dressing? I never could see how manure can be dug into the ground among established Roses without bruising and disturbing the roots and bringing the manure into contact with them, unless the roots run nearly straight down, and that, as has been seen in the last chapter, is not desirable. Attempts are sometimes made to get over the difficulty by saying it is to be "forked in," or "pricked in," or "pointed in" or even "hoed in." I have never seen these operations, and should not know how to attempt them; if the manure is merely just hidden by a thin layer of earth, weeds will be encouraged and the hoe, the tool of cultivation, discouraged. If buried deeper, a fork would be a less efficient tool for the purpose than a spade, and, to do the work, would disturb the roots as much. The manure, to my mind, should be got in first where used at all, and should be sufficiently deep to be well under the 
roots as explained in the last chapter, where I have, I hope, escaped from the apparent inconsistency of urging that the roots should not run deep though the manure be beneath them.

How, satisfactorily, to apply solid manure to estabblished roses, otherwise than at the time of moving the plants, or as a top-dressing, is a problem I am unable to solve. But if it be incorporated with the soil among the roots, as is done by many good cultivators, though I am against it, we must consider what its condition should be. It should be thoroughly decomposed and "sweetened" so as to have lost its objectionable qualities to the human senses, for not till then is it suited for contact with the roots of the Rose. It is quite true that manure does lose some of its valuable constituents by rotting so far, especially if exposed to the wash of heavy showers; if the solid be preferred to the liquid, it should be protected from rain, and yet kept just damp enough to decompose thoroughly, and turned of course, as every labourer knows how, to prevent too rapid heating.

If a top-dressing be used, no confusion must be made between this and a mulch. It is not uncommon to find, in instructions on planting, one to the effect that when the job is done a coating of long manure, which may be forked in at spring time, should be laid on the top to protect the roots from the frost. In the first place it is the plant itself, not the roots, which most requires protection from frost; I have already expressed my desire to know how any manure, much less long stuff, is to be "forked" into the soil in a useful and harmless manner; and I wonder quite as much what good can be done by long straw, washed clean by the winter's snow and rains, if it is got in. A manure and a mulch 
are two different things, and should not be confounded; the former is for feeding and fertilising objects, and the latter for protection against frost, heat, or drought. Some little good may be washed out of it into the soil, but when wanted no longer it should be removed.

Well then, shall we apply our solid manure, for food during the spring and early summer, as a top-dressing ? If we do, it is plain that the roots can only feed on what is washed from it through the soil by rain or watering, and that the same advantage could be got by liquid manue alone. To this it might be answered that a long drizzling yet thorough rain would wash "the good" out of the top-dressing more gradually and with better effect than could be produced by applying liquid manure in quantity, and if the topdressing was exhausted by much rain, a new supply could take its place. This is true, but a top-dressing has its drawbacks:-not only in its unsightliness, for the enthusiast will think nothing of that-he wants the most perfect Roses and will endure anything for that object-but that, if laid on thick enough to be of any service in feeding, it hinders the beneficent influences of sun and air, brings weeds of its own and makes their extirpation troublesorne and, above all, prevents the most important cultivation of the surface during May and June by the Dutch hoe.

It should be understood that in recommending, in this and the previous chapter, no solid manure in the soil except completely under the roots, I shall be considered by many of the best and most successful cultivators to be airing a private "fad," which is not generally recognised by Rosarians. One ought, however, to state one's own convictions: and I quite believe that as a rule more harm than good is done by mixing 
ordinary manure, especially in a fresh state, with the soil immediately surrounding the roots.

A very good authority recommends that, in planting, the manure be applied in the fashion of a sandwich; that is, I take it, manure below, then soil, then the roots, then more soil, some manure over that, and the soil again at the surface. The danger here, I think, would be of either making the top layer of manure so thin as to be nearly useless, or getting the roots too deep.

Top-dressings of brewers' grains, or other compounds, are recommended by Dean Hole and other writers, but I think that some of the above disadvantages would be found connected with any one of them.

Of solid manure not made up of straw, night-soil is perhaps the most important. And as a strong believer in the earth system I am tempted here to enlarge upon the well worn theme of the folly of civilised mankind in wasting immense quantities of manure, which they spend large sums in replacing, by discharging it into the rivers where it does untold harm instead of returning it to the earth, as God commanded Moses, to the great advantage of their health, their pockets, and their gardens and fields.

Science continues to show more and more, on the one hand by the light it throws on the dissemination by water of typhoid fever and cholera, and on the other by the discovery of the purifying mission of the bacteria in the surface soil, that earth is the best receptacle for night-soil and water the worst. But after all the earth system is not practicable in large towns, and is troublesome to enforce in villages.

There is naturally great difficulty in dealing satisfactorily with night-soil as a manure for Roses, and 
often it is probably not worth the trouble when it can be dug in quickly for vegetable crops, and other good manure is procurable. Mr. William Paul, in his large work, The Rose Garden, describes a mode of using it which involves mixing with earth, burying for six months, and afterwards mixing and turning over once or twice more. This seems to require a good deal of labour, but then it must be noticed that he considers it the best of all manures for Roses on light soils, and that it has a very marked effect on the growth I can testify from an instance in my own garden. During the winter a quantity of night-soil was deeply buried near to a sweet-briar, into which I had put a bud of Maréchal Niel; and one of the shoots from that bud, being laid along a wall, reached in the course of the summer a length of 27 feet.

Manure from the fowl-house or dove-cote is good, but transitory: it should be kept from rain, and not put on in the winter.

The old custom of burying the carcasses of dead animals in vine borders is now discredited, and I should not recommend it for Roses. Bones, though most useful for the phosphates they contain, do not supply all the necessary constituents, and had better be left to the manufacturers of artificial manures.

2. Liquid Manure.-I have hinted at the advantages which $I$ conceive to belong to manure in a liquid state. (1.) In the first place, it is plain that the roots of a Rose cannot take up anything except fluids: consequently, only those parts of solid manure which are soluble can be of any use as food, and therefore liquid manure can supply everything that solids can. (2.) Secondly, the problem is by this means solved of how to get fresh food to the roots without disturbing them 
(3.) And lastly, the food can be given just when it is wanted, and withheld when it is not wanted.

1. As to the first of these points, let the beginner not only remember himself, but also diligently impress upon his assistant, that Roses drink but cannot eat. The ordinary labourer will not believe in the strength or virtue of a clear fluid-from perhaps a hazy comparison with his own beer, he distrusts anything that is not thick; and he will be careful to apply the dregs of the liquid manure cart or cask, "because that's where all the good is." It should be pointed out to him that what cannot be dissolved in water cannot be assimilated by the Rose, and he should be told not to put on the dregs, which may sometimes do harm. Of course time, chemical changes, and the power of the earth bacteria may and do eventually dissolve materials which remain solid in ordinary water; but liquid manure is as a rule for present immediate use, and therein lies one of its great advantages.

2. By liquid manure we can reach all the roots at once without disturbing them in the actual time of their most vigorous growth; and we can supply the Rose with what it wants, soil thoroughly stored with food ready cooked as it were for immediate absorption, rather than solid manure in the soil which may or may not have all the materials ready in a soluble state.

3. To obtain fine fruit, from an apple, pear or peachtree, for instance, every gardener knows that manure is wanted when the fruit is set and beginning to swell: that earlier it may induce too much wood: and that a tree which has no fruit is best without manure, as the extra nourishment is more likely to produce wood than fruit buds. Roses do not form quite an analogous case; 
for in most cases manure given early will not hinder the flowering, and a certain length and strength of stem are necessary for a good bud, but occasionally it might cause the wood to be longer than necessary and the bloom to be delayed. At all events it is when once the tiny bud is formed that the Rose most needs support; all the powers of roots and leaves are at that time devoted to the Rose itself, and then is the special opportunity for feeding with a lavish hand. Do not be afraid of making your Roses "coarse" : we can always find room for superfluous energy by less rigorous pruning in spring, or later by judicious caution or delay in disbudding.

The ordinary liquid manure which I should recommend would be the drainings after rain from cowyard or pigstye or both, but not from the stable, which is often, from being less diluted, too strong. Free access to a tank containing the drainings and stormwashings of a cow or bullock yard is well worth paying for by any Rosarian. As a rule it will not require dilution, for I have used quantities of it for years and never found it too strong for established plants, even though it may bring up and kill the earth-worms. In such a case, though, it may also kill any leaf it touches, and should be put on with care, not letting a drop fall upon the plant. In dry weather the contents of such a tank from a covered yard might possibly be too strong, and it is well to be cautious; but it is a fortunate circumstance that after rain is the best opportunity for applying liquid manure, viz., just the time when such a tank would be full and not too strong.

This should be remembered as a possible error for an assistant to make; he may be apt to think that when the ground is dry is the time for liquid manure, 
but it is not so: the drier the ground and the season the weaker the manure and the purer the water that should be given. My Tea Roses which won the Challenge Cup at the Crystal Palace in the very dry year of 1893 had no liquid manure at all that season, and were only twice watered with pure water. If in a dry time liquid manure is available, and it is desired to put it on, it would be advisable to give a thorough soaking with pure water first.

But, as I have said, it fortunately happens that liquid manure is generally to be had just when it is advisable to apply it-after a good rain.

Another mistake that may be be made is this:- "I have only got a certain amount of rich liquid, and that healthy vigorous plant does not want it, I am sure; but this poor weakly thing would certainly be the better for a dose."

This would be an error in principle as well as in fact. The principle is a Gospel one, and may be found in St. Luke xix. 24-26. It comes into Rose-growing in more than one way; notably, in pruning, that less in proportion should be cut away from strong growers than from weakly ones; in selection (for ordinary purposes, not for exhibition), that a man should cultivate most specimens of the varieties which do well with him, and not endeavour to make up the balance by growing more of those which only sometimes come good; and here, in feeding, in two ways, for not only does it pay better, as graziers and all keepers of live stock know, to encourage the healthy than to coddle and nurse the weak, but also the weak cannot use the rich food which makes the strong still stronger. Giving strong meat to babes wastes the food and also seriously injures the feeble, who must take but cannot issimilate it. 
We should never be afraid of making our plants too strong; for we can always divert the stream of sap and lessen its supply to each bud by leaving a greater number of shoots or buds on the plant at the two periods of disbudding. I have even heard of cutting the roots of La Boule d'Or in the early summer when the thick strong fleshy buds by their extra vigour seem unlikely to open properly, but should never advise it. At all erents the weakening of a shoot or plant may be easily and speedily accomplished; it is the getting up full steam that taxes all our time and energy.

In speaking of weakly plants, I do not mean the naturally "dwarf" and "moderate" growers, which if healthy and doing well according to their habit will take their full share and enjoy it, though naturally not requiring so much as the stronger growers. Comtesse de Nadaillac will require her food and answer to it in size of glorious flowers, but an extra dose will not raise her to the stature of Ulrich Brunner. I meant either an evidently unhealthy plant, or one which though fairly healthy does not from some unknown cause thrive and do as well as the others. Such a one had always better be removed than kept and nursed; try giving it away: it does not sound very generous, but removal to a different soil and situation will be either kill or cure, and experience will show many wonderful instances of the latter eventuality.

Care should also be taken that newly moved plants may have their liquid manure much weaker till they have made some strong growth with large healthy new leaves. The wrong principle, then, is the supposing that because a plant is the strongest in the bed it therefore wants the least of the liquid manure; on the contrary, it wants, because it can use, the most. 
The time for using liquid manure is May and June, especially after rain if possible; if some be given in April, be careful of the young foliage, and do not give any to "maiden" dwarfs till they have made some growth, being extra careful in this case that no drops fall on the plint itself. But will this be sufficient for a whole year's food? That would depend a good deal on the soil, and whether artificial or natural solid manures were used as well. It is not advisable to apply any in the autumn after July, as the second growth of wood is always much stronger than the first, and will not require further encouragement which might make the plants grow too late and fail to ripen properly. If we put on liquid manure in the winter, no doubt a good deal of its virtue is washed away before the roots can feed on it; but some of it will remain, and I think it is always worth doing. At that time it may be supplied much stronger and more concentrated than in the summer without fear of harm.

As to the manner of application, it may be put on by water-pot, pail or hose, or whatever is quickest, provided it soaks in. Unfortunately the surface of the soil is often such that the wash and dash close the pores of the earth, and the liquid for the moment cannot penetrate but runs off. Where much watering with liquid manure is contemplated, or under any circumstances where the natural soil is light and porous and the drainage good, it is best to have the surface of the beds below the general level of the ground; the whole can then be flooded, as it were. If, however, the beds are somewhat raised and the liquid runs off, there is nothing for it but patience; a little at a time and come back again and again to the same place.

In early spring we may sometimes find an occasion, 
in a light frost, when just the crust of the surface is sufficiently frozen to prevent the wash of the particles, and the pores remain open; at such times, on my beds, the liquid will sink in at once as through a sieve as long as you like to pour it on. Given the time, and plenty of good stuff, a large amount and depth of soil may be fertilised on such opportunities.

Two good rules for watering with liquid manure or plain water are:-Firstly, mind it is done thoroughly; be sure you give a good soaking while you are about it; remember "an inch of rain" means nearly five gallons to the square yard, and always do a little space at a time satisfactorily and fully rather than a mere wetting over a large extent.

And secondly, be sure that the surface is always stirred by the hoe as soon as possible after every soaking, whether it be the natural one of rain or the artificial one of water or liquid manure. This is most important: when the sun shines on the thoroughly soaked ground in summer it is sure to cause it to crack, often before the top is quite dry; as soon as you can work it, get just the surface dry again and as fine and powdery as possible with the hoe, for this keeps the moisture in, whereas the cracks allow it to escape.

Soap water from a laundry has some value as a liquid manure, though too much may render the land sour. And though not sufficient for Roses by itself, it is a capital thing to use mixed with other liquid which may be considered too strong. It is well in this case to be specially guarded against the dregs, a greasy scum which chokes the soil pores, and also to remember that nothing smells nastier than soapsuds which have stood for three or four days, especially in a hot sun. Amateur Inspectors of Nuisances are not always aware of this. 
The overflow water from a cesspool is very good as liquid manure, and hardly ever too strong for anything; my overflow tank is regularly emptied on my garden at night every full moon by pump and hand cart, for nothing from my house goes into the river, but all into the garden. There is some obvious inconvenience about this in the summer, and we have at that time to choose our nights with care; I do not then put it on the Rose beds, as it has sometimes to be done hastily, and more care and better light would be required. It should be understood that the contents of the overflow or second cesspool are quite as good if not better than the nightsoil itself, for the value is in the liquid. It is desirable, if possible, to have a separate tank with pumps for the contents of housemaids' slop-pails; this will be the most valuable liquid manure that comes from the house, and will generally not be so offensive but that, with choice of opportunity, it may be applied in the daytime.

Soot water is good, but would be expensive and troublesome to use in quantity; it is more useful for pot plants. The soot should be tied up in a bag and sunk in a cask or tank, and the result is a clear liquid of a wine colour, much appreciated by gardeners for mild fertilisation.

Artificial Manures.-It is not necessary to go into the discovery by the great scientists of the possibility of manufacturing by chemistry plant manures, which are called artificial not because they are not the real things but simply because they are made and compounded by art and science. It will suffice to state that those wonderful fellows the analytical chemists, who are always wanting to find out what things are made of, showed that as growing plants consist of certain soluble minerals in different proportions, so (they 
insisted) those minerals with the addition of nitrogen would, in the proper proportions, make real, though artificially made, manure. They first of all discovered the component parts of a plant by burning it and analysing the ashes, and they then said (and proved it), These are the things of which the plant is marle, and therefore with these things it can be fed. They found next that the different parts of a plant, roots, stem, leaves and flowers, often had the principal constituents in very different proportions, but this could be allowed for in considering which part of the plant is most valuable. The obvious next step was to analyse the soil too, and it was found that some of the mineral constituents of plants are practically present in sufficient quantities in nearly all soils, but that some land is deficient in one material, and some in another. A pleasing picture was then presented to the cultivator, that, with the analyses before him of his own soil and of the plant he intended to grow, it was comparatively easy to see just how much he required of each mineral constituent to feed his plants fully and perfectly.

But analysis of soil was found to be a very different thing from that of a plant; you cannot adulterate a plant or put anything into its frame which the roots will not naturally take up; thus all plants of the same species or variety would analyse alike, but very few samples of soil from the same field would agree together. The analysis is necessarily minute, and takes account of everything; the droppings of a bird or tiny animal may have rested on the spot for a while and added some fertile elements, or just that portion may have been impoverished of one or more special items by the roots of a plant or weed which is no longer present. Only a rough estimate therefore of the general fertility of a soil 
can be formed by chemical analysis of Mother Earth which receives all things, and sometimes even this estimate may be fallacious.

Nevertheless, the general value of all soils can be fairly estimated from the practical test of past results; and it is pretty well known what constituents are generally present or absent in the average soils of clay, loam, peat, chalk, gravel or sand. Besides, if all the constituents of a plant are chemically added to the soil in the right proportion, all is there which is needed; for an excess of one constituent will be inert and valueless unless all the others are present in the same proportion.

In The Rosarian's Year-Boot for 1889, edited by Rev. H. H. D'Ombrain, Secretary to the National Rose Society, there was a very interesting and valuable paper on artificial manure for Roses, by Mr. E. Tonks, B.C.L. The analysis of the ashes of the Rose are there given in a table from Wolff's Aschen Analysen, Berlin, 1871, 1880, as follows :-

\begin{tabular}{|c|c|c|c|c|c|c|c|c|c|}
\hline & 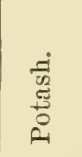 & 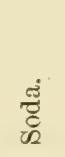 & 苞 & 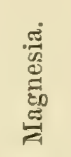 & ఏ્త & 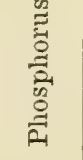 & 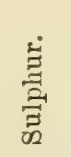 & 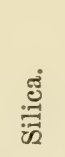 & 导 \\
\hline Roots ................... & $13 \cdot 45$ & $4 \cdot 20$ & 40.58 & $7 \cdot 15$ & $2 \cdot 86$ & $29 \cdot 14$ & 1.95 & 0.21 & $0 \cdot 21$ \\
\hline Wood .................... & $14 \cdot 25$ & 2.57 & $-51 \cdot 50$ & $7 \cdot 62$ & $4 \cdot 23$ & $10 \cdot 62$ & $2 \cdot 22$ & $4 \cdot 35$ & $2 \cdot 78$ \\
\hline Leaves .................. & $33 \cdot 13$ & 1.47 & $31 \cdot 29$ & $9 \cdot 23$ & $2 \cdot 49$ & $11 \cdot 68$ & $4 \cdot 31$ & $5 \cdot 71$ & 0.88 \\
\hline Flowers ................ & $47 \cdot 41$ & $2 \cdot 44$ & $13 \cdot 25$ & $5 \cdot 94$ & $0 \cdot 97$ & $28 \cdot 46$ & $3 \cdot 17$ & 1.52 & 0.57 \\
\hline
\end{tabular}

On reasoning from this to get a proper chemical manure for Roses, the first thing to remember is that there is one most important item not found in ash analysis, 
and that is nitrogen, for which in a chemical formula the uninitiated must look for the words "nitrate" or "ammonia." Nitrogen is the stimulant which gives life to the whole, like the spark of fire which gives such mighty power to the loaded cannon, or (to use more humble imagery) the penny in the slot which sets the whole elaborated machinery in motion. Iiere nitrates, such as nitrate of soda, show immediate and wonderful results on unexhausted land, when all the plant wants is a start; but it is like drawing a cheque upon a bank, a capital way of supplying the needful as long as the bank is replenished accordingly, but otherwise not a mode of raising money likely to be successful for long; so the nitrate makes the mineral stores (such as potash and phosphates) available if they be there, but cannot replace them. To continue using nitrates alone would be like the Irishman who, having a note from his bank that he had overdrawn his account and that they required a remittance, sent them a cheque upon themselves for the amount to make things square.

Plenty of nitrogenous matters may be found in the best of the solid and liquid natural manures recommended, but these have to be changed into nitrates by the action of the earth bacteria before they can be assimilated by the Rose, so that the stimulus is most immediate when applied in the form of nitrates. Another important point about the nitrates is that they are the very first of manurial matters to be washed ont of the ground into the drains by heary rainfall; the soil does not retain them so well as the other constituents of manure, and of course they go soonest in a porous or light soil. This points to the use of some nitrate, or good natural liquid manure which would very soon afford nitrates, in the growing season after long and 
heavy rains, when the soil is known to be well stored in other respects. Nevertheless, it should be stated that there is some little nitrogen in the rain itself, though not in ordinary water.

Certain items which are mostly present in very small quantities, soda, silica, and chlorine, are generally disregarded, as they would be present in sufficient quantities in almost all soils. Silica means flinty particles. It may seem strange to think of these as soluble, yet there is much silica in corn, straw, canes, and tall grass stems, affording the smooth surface, and the brittle sharp nature; and as Tea Roses are found to succeed in those soils which are gritty, it would be interesting to know if their ashes would show a larger proportion of silica, or whether it is only the extra drainage and consequent heat of the soil that proves favourable to them.

The very different proportions of the elements found in the roots, stems, leaves, and flowers of the Rose must, I think, be very interesting and instructive to enthusiastic cultivators. Thus nearly one half of the flowers is potash, and a quantity approaching one-third is phosphorus, and as what we aim at is flowers, we must take due notice of this, or perhaps we shall have, as we sometimes do, especially where there are taproots going down too deep, strong roots, stems and leaves without buds. But, on the other hand, due regard must be had to the right amount of vigour and strength in all parts of the plant, for we do not want it to be breaking immediately into little weak flowers all over, even if we could manage it. Lime will be noticed as predominant in the roots, more than half in the wood, and strong in the leaves, but quite low in the flowers: phosphoric acid, though weak in stem and leaves, present to a considerable amount in roots and blooms: and potash, low in 
the roots, rising gradually through stem and leaves to its maximum in the flowers. This looks as if, in the growing season, the potash is drawn by the buds from the leaves, the wood, the roots, and the soil. For the plant lives for the Rose, as the mother for her unborn babe: no sooner does the bud exist in its most embryo form on the shoot than the stem and the leaves give all their powers to it, and send fresh calls to the roots for supplies for them to pass on. This seems to point to nitrate of potash as a useful extra dressing about the end of May, if the soil has been much washed by heavy rains.

Iron is present in but small quantities, highest in the stem and lowest in the flowers. Sulphate of iron is said to give a better colour to the foliage, and in some sorts, such as Anna Olivier, to the bloom as well, but I do not place much reliance on it. In fact I have sometimes omitted the iron from the formula below, for the small quantities cause a good deal of trouble to the makers, but it should be remembered that every one of the constituents is necessar $y$, or the others are by so much rendered valueless; so perhaps it had better be included though most soils and natural manures have it in sufficient quantity.

The following is the mixture recommended by Mr. Tonks for the Rose, as deduced from the ash analysis: I have had it made up for me for years, and believe it to be excellent, not only in theory, but also in practice and fact:-

Superphosphate of lime, 12 parts.

Nitrate of potash, 10 parts.

Sulphate of magnesia, 2 parts.

Sulphate of iron, 1 part.

Sulphate of lime, 8 parts.

33 parts. 
The manure is to be applied in early spring: immediately after pruning would generally be soon enough perhaps, but February would be better. It is to be evenly scattered on the previously hoed surface, at the rate of $\frac{1}{4} \mathrm{lb}$. to the square yard, so that the Rose grower can soon calculate how much he wants. In some cases it might be difficult to procure it in small quantities, unless some manufacturer could be found to make it on speculation for such sale. If not, small Rosarians, who have difficulties with natural liquid manure, should combine to order it. A thoroughly trustworthy firm should be applied to, as the adage "see that you get it" applies very strongly to chemical manures.

A 48 flower-pot full of manure may be taken as $1 \mathrm{lb}$., which would suffice for a square marked out by a six foot rod; but, with observation and care, the "rule of thumb" will soon come in and measurement become unnecessary. It should be kept in a dry place and used fresh if possible; if caked together let it be thoroughly crushed with the back of a dry shovel. I should not advise watering it in, as no artificial watering can equal the soaking power of gentle rain. A second and lighter dressing, carefully avoiding the foliage, may sometimes be given at the end of May, if heavy rains have occurred, or nitrate of potash, the most expensive item, may be used for that purpose, as mentioned above. 


\section{CHAPTER VI}

\section{PRUNING}

Somebody came once to "see my Roses" about the middle of a backward April, and I told him they were not to be seen. But he said he had "come some distance: of course there was no bloom or even growth, but might he see the plants?" When I said there were no plants to be seen, he was incredulous and dissatisfied till I took him out to the long lines of Rosebeds. As we approached there u:c.s nothing to be seen but clean cultivated beds of soil : and it was only on close inspection that the rows of stumps or stools at their regular distances could be distinguished from the ground. Every year the whole of the plants in my beds, H.P.s and Teas alike, for the standards are elsewhere, are thus swept clear away nearly to the level of the ground, though two or three or even more inches are left of a few extra vigorous sorts.

This is pruning for exhibition; but a novice might perhaps not only ask why I thus destroyed nearly the whole of the plants I had so cherished the year before, but also go on to the wider question "Why is pruning necessary for any purpose? Why should not our Rosetrees grow as fine and large as they will?"

The answer is to be found in the manner of the 
natural growth of the Rose. By watching an unpruned Rose-tree, either wild or cultivated, it will be found that the first strong shoot flowers well the second season but gets weaker at the extremity in a year or two, and another strong shoot starts considerably lower down or even from the very base of the plant, and this soon absorbs the majority of the sap and will eventually starve the original shoot, and be itself thus starved in succession by another. A Rose in a natural state has thus every year some branches which are becoming weakened by the fresh young shoots growing out below them. This is one of the principal reasons why pruning is necessary. A Rose is not a tree to grow onwards and upwards, but a plant, which in the natural course every year or two forms fresh channels for the majority of the sap, and thus causes the branches and twigs above the new shoots to diminish in vitality. It seems better, therefore, to speak of Rose-plants than of Rose-trees, especially since standards are now less used, and so many new varieties are dwarf in their growth.

The objects of pruning are:-To maintain the life and strength equally throughout the plants, to mould and preserve their shape, and to give more vigour, colour, and substance to the flowers. Owing to the natural habit of growth before mentioned, a considerable amount of wood must be taken away annually to prevent the shoots robbing each other, and when nature is interfered with art must go a little further to make and to keep a plant of well-balanced shape. And also, even for ordinary garden purposes, a considerable amount of strength and sap must be reserved for each bloom, or, in the case of the dark H.P.s for instance, they will not show their true colours at all.

The principal art of pruning-that of forming and 
maintaining a shapely plant of well-placed shoots-has almost died out in modern out-of-door Rose culture. This is owing to the neglect now shown to the Hybrid Chinas and Hybrid Bourbons, really strong-growing varieties but only blooming once: to the waning popularity of standards where a well-balanced head is more noticeable and necessary than in a dwarf or bush plant: and to the fact that most enthusiastic Rosarians are also exhibitors, and therefore care more for perfect blooms than for well-shaped plants. When I first learnt to prune, a long time ago, H.P.s were quite new and very few in number, and there were still many large standards of summer Roses, each of which was a study in itself for the pruner's art.

First, as to the instruments required. A pruner of the old school would condemn the use of scissors, be horrified to see a shoot cut off square, and would consider the neat smooth sloping cut of a sharp knife to be the only legitimate appearance. He would also perhaps scorn the use of gloves and think he could do his work better without them; but this must be a matter of taste, for it is useless to deny that Roses have thorns, which are especially hard and sharp at pruning-time. It is well to remember that in using a knife, especially to budded Roses of one year's growth, the plant must be firmly held with the other hand, or a serious breakage is very apt to occur.

Two good knives, an oilstone, a strong pair of pruningscissors, and a mat to kneel on by the dwarf plants, will probably prove a sufficient equipment. One of the knives should have a strong blade, the other a narrower and smaller one. The hone should be carried about and not left behind, or the tearing off of a valuable branch will soon be the result of a blunted blarle. The scissors 
will be useful for very small shoots, and for bits of dead wood or anything in an awkward position, but in all such cases the cuts should afterwards be trimmed and smoothed as much as possible with a knife. A small pruning-saw is most effectual for thick pieces of dead wood, but in many instances cannot be used. Professionals will not only prune but will even bud their dwarf plants by simply stooping over them, but I confess it makes my back ache even to see them at it. For kneeling on the wet soil I have found a piece of waterproof about eighteen inches square more satisfactory and less tiring than knee-caps, but it should be borne in mind that the weight of the body will bring moisture through any alleged waterproof that has not an actual skin of indiarubber.

Next as to the time of year. Some recommend a certain amount of thinning in early autumn, to ensure the ripening of the remaining shoots. If the plants are to be but lightly pruned in the spring, this may be desirable treatment; but there is a danger of causing low dormant buds wanted for next year to push at once, the root power is probably slightly checked, and the benefit gained is very slight, if the plants are to be severely pruned.

We may commence with Roses trained on sunny walls about the middle of February, and in this case, whether nailed or tied to wires, the operation will be very similar to the pruning and laying in of a peach-tree. Begin by taking out all dead and weakly wood; then consider which shoots are required for laying in, giving preference to the ripest rather than the fattest, and steadfastly resisting the temptation to train them too close together; of the remainder for which there is no room on the wall, the gross shoots should be clean cut out and 
the medium-sized ones thinned if necessary and moderately spurred back.

A rule for all climbing Roses, but especially for Maréchal Niel, the Noisettes, and the Dijon race, is that long strong shoots of the year should not be cut back much, but either laid in at least three parts of their length or removed altngether. Unless additional height is wanted, such shoots should not be trained upright, as that is likely to lead to more wood and less bloom. The Banksian Roses need special treatment, for the flowers will not proceed from the strong shoots of the year, but from the laterals or side growths. There must accordingly not be too much pruning, but merely a thinning out of dead wood and a slight shortening of long strong shoots; the weakly-looking twigs alone will blossom. Tea Roses, not of the climbing races, which are grown on low walls may be pruned more severely if quality rather than quantity of bloom be desired.

March is the month for pruning all Roses in the open but Teas and Noisettes; and I think an amateur will not be doing wrong if he picks his days and gets through as much as he can whenever it is warm and fine. If some are pruned in the first week of the month and some in the last, bitter weather intervening, but little difference will be found in the time of flowering. It is best to leave Tea Roses in the open undisturbed in their winter's covering till April. A reckless pruner in the shape of Jack Frost has generally been before us, and often we are grateful enough if he has left us any life to cut back to. On the other hand, in early seasons like 1893, Roses which have made some growth at the top are apt to "bleed" when pruned severely, especially where old wood is cut into. In some cases the soil around the roots is kept quite damp from this cause for some days 
and the matter looks serious but does not often prove to be so: the cut heals in about a week, and the subsequent growth does not seem to be impaired.

As to the method, we will take first, as being the most complicated, the case of summer Roses, H.P.s, and other fairly strong varieties where the object is to form handsome plants for general decoration with a quantity of good blooms for cutting.

The first care will be to cut out all the dead wood, and all wood however thick and old which, as shown by the small growth made last season, is becoming weakly in comparison with the rest of the plant. Now we can study the whole and see what we have got left. Our object is to form a well-shaped head or plant, and by "well-shaped" I mean that the plant itself should be of the even globular form of a Rose. Rose petals are evenly arranged, and do not cross each other in an inward direction; such should be the shape of the plant. Bearing in mind that the top bud left of each shoot will grow first and in the direction in which it points, we should always cut back to a bud that looks outward, and take care that the centre will not be overcrowded. To get rid of a misplaced shoot it should be clean removed at the very bottom; merely cutting it hard back will only make it grow the more. It must be our endeavour each year to do away with as much old wood as possible, and in the case of strong growers to lessen the number of their shoots rather than their length. We should picture to ourselves what the plant will look like in full growth, and remember that a lover of Roses is more likely to leave too many than too few shoots. There is a saying in East Anglia "no man should hoe his own turnips." meaning that he is not likely to thin them sufficiently, but those who are used to thinning 
grapes and other garden produce will probably have got over this difficulty.

The next question is, how far, i.e. to how many buds, are the shoots to be cut back; and the answer is to be found in the golden rule of pruning, that more buds are to be left on each shoot in proportion as the plant, both as a variety and an individual, is strong, and less in proportion as it is weak. To a novice in Rose-growing it appears strange at first that we should cut away almost all there is left of a weakly-growing and precious variety, which would seem to be almost exterminated by such severity, and yet leave longer shoots on a strong sort which seems better able to stand the rough treatment; but the rule is nevertheless in strict accordance with the law of nature-Darwin's survival of the fittest-and the law of God "Whosoever hath, to him shall be given." I have elsewhere (p. 73) endeavoured to show that the same rule applies in Rose-growing to the application of liquid manure to strong and weakly plants, and to the number of each variety which should be grown by those who are not exhibitors.

A wise editor used to give as his advice to young authors in whom he had confidence, "Don't arguelay down the law"; and the counsel of a judge to judges of all sorts to give their sentences without their reasons is well known as pointing out the most useful and prudent course to pursue. But the reason for the above rule in pruning seems so clear that $I$ think it should be added. In proportion as a plant is strong in growth, from the natural habit of the variety or in a less degree from the condition of the individual, leave more buds, to perhaps six as a maximum, on each shoot; because the strong grower has the capability of supplying several buds on each shoot with a sufficiency of sap for 
good blooms, and if a due number be not allowed, the shoots will either run to wood without flower or produce coarse and ill-shaped blooms. And in proportion as a variety or plant is weakly in growth, fewer buds should be left; because the weak grower has only sufficient strength to supply sap to one or two buds on each shoot, and if more are left the power will not be sufficiently concentrated to form good blooms. The general habit of the variety should therefore be well borne in mind in determining how many buds to leave on each shoot; remembering always, with a view to the future outline of the plant, to prune to an outlooking bud, and that as a general rule the more a shoot is cut back, the longer will be the growth from the bud left at the top.

After a warm summer most of the young wood on a well-pruned and healthy plant will be found moderately ripe; but we occasionally find an extra well-ripened shoot, almost as firm and brown as the old wood, with large plump buds ready to start at the first chance. This is very valuable and plenty of space should be allowed for its development, less ripe shoots being removed to make way for it. On the other hand, we often find gross late unripened shoots, much thicker but greener, with a larger proportion of pith. These are comparatively useless, and should generally be cleanly removed. If a shoot has been injured by frost, and on cutting down to an apparently sound bud the pith appears brown instead of white, it is evident that the injury has gone farther than we supposed, and it will be better if possible to cut a little lower. If any shoot by its unusual size evidently absorbs a large proportion of the whole of the sap, it should be, according to its ripeness and the condition of the rest of the plant, either removed altogether, or left a good length and have 
other weaker shoots removed that might hinder its development.

If a plant is carefully pruned from the beginning it seldom presents many difficulties as long as it continues in health; but those which have been neglected for only one year sometimes require to be cut back sufficiently to form an entirely new framework luring the following season. A good deal may be done to remedy faults and defects by a careful examination of each plant in early May, when a thinning of the pushing buds may be practised where it is necessary. Of those growing too close together or in a wrong direction or filling up the centre, one or two may be rubbed off. But we must not be rash; if undecided, it may be prudent to adjourn the examination for a week or so, when we can still take the shoot off, but cannot put it back. It is best, when an actual shoot of an inch or more has to be removed, not to rub it out, as this leaves a deep ugly scar, but to shave it closely off with a knife.

For bedding purposes the pegging-down srstem is fairly successful with really strong-growing varieties of not too stiff habit. But it must be understood that it will not be satisfactory, unless the soil and culture be of the best, and the most free varieties in growth and bloom be selected. All must be cut away save two or three (not too many) of the strongest shoots, which are bent down and pegged over the bed. They will break and bloom all over, and in late summer other shoots will probably spring from the base, a selection of which will take the places of the old ones in the following spring.

Extra tall standards trained to form weeping Roses are beautiful objects when in bloom. It is impossible, 



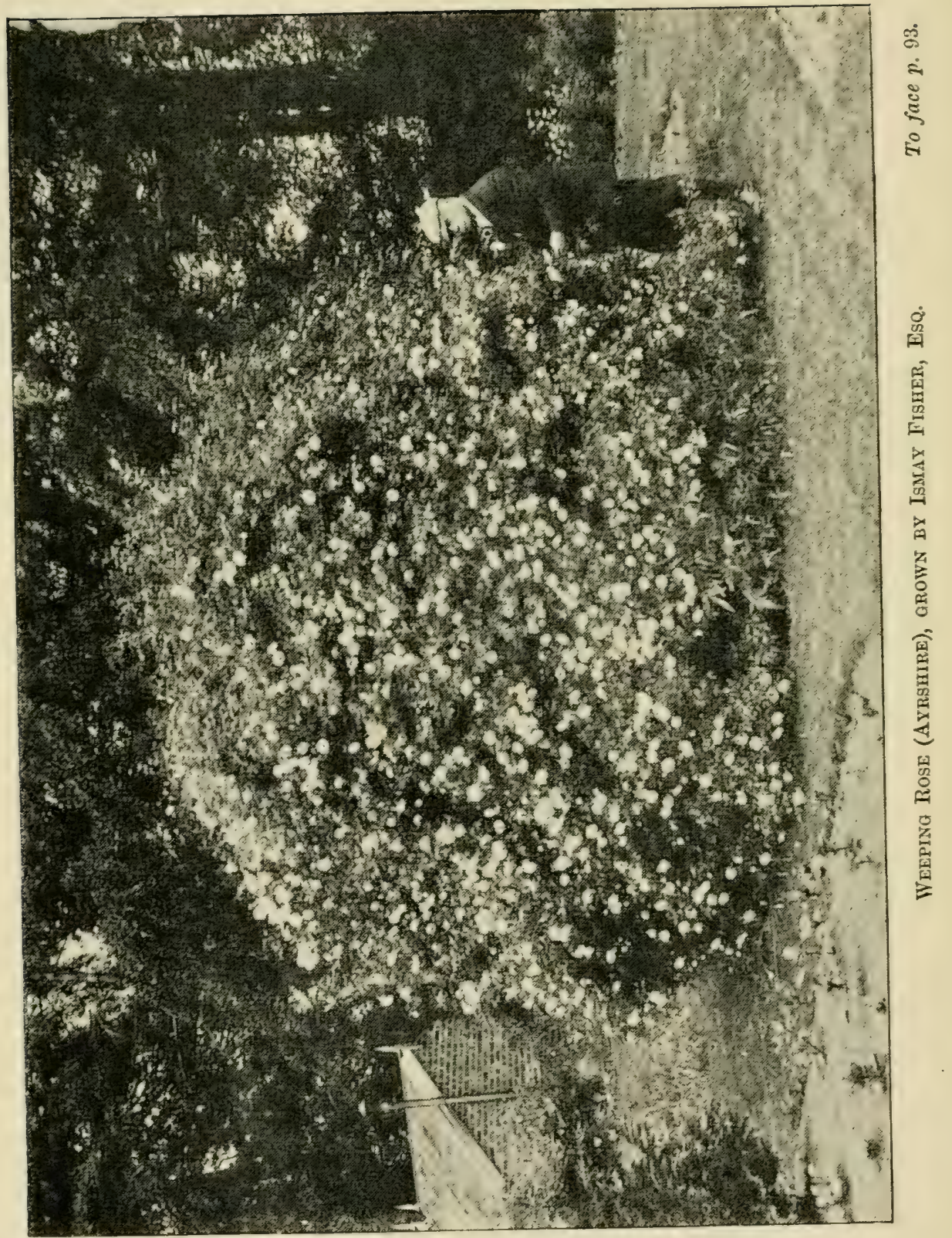


however, to make any varieties, which are not naturally of flexible or pendulous growth, take this form successfully by bending them down. The summer climbing Roses, such as the Ayrshire and evergreen classes, should therefore be used for this purpose. The heads should be vigorously pruned back the first year, or even the second if the growth is not satisfactory, and when the shoots reach the ground they should be thinned if too many and tied to some supports the proper distance apart. The pruning will afterwards consist of spurring back the blossoming laterals, or occasionally taking clean out a weakly branch and allowing another to fall down in its place.

Pruning for exhibition purposes is often quite a different matter to pruning for decoration or display. The object in this case is to get the finest possible blooms, and to attain this end the exhibitor will not care very much about the shape of his plants. If number be required, then the plants must be multiplied, as but few show flowers can be expected from each. Pruning in this case loses most of its art; only the strongest shoots will be retained, and these will be cut back very closely to two or three buds, while with weak growers in some cases not more than one bud of new wood will be retained.

The further revision of the pushing buds and young shoots, at the end of April or early in May, will in this case be an important matter, requiring much care and foresight. A good knowledge of the habit of growth and of the "manners and customs" of the different varieties will be necessary to know how many shoots should be retained, and an extra strong one however ill placed will be partoned among the weaker varietics. If injured by frost or grubs it must be decided as early 
as possible whether the damage is serious enough to warrant the removal of the whole shoot. In some cases the severe pruning will cause buds to push at once from the old wood; and among the weaker varieties, whose blooms are best on maiden plants, such buds should be encouraged; but in the case of the stronger growers, the blooms will probably be best from last year's wood. Some sorts have particularly robust and ample foliage; in this case the shoots should be left longer in the pruning, and the top buds, or those that are as far apart as possible, alone retained. Thus Madame Gabriel Luizet is strong enough to support from four to six, or even perhaps more, first-class blooms upon each plant; but as the foliage is large and full, the shoots should be left at the pruning four or five inches long, and the top ontlooking bud alone retained on each, all others being removed as fast as they appear. Varieties apt to come coarse and too full should also be left a little longer in the pruning, and have more shoots retained; but the coarseness can generally be remedied by care and discretion in gradually thinning the flowerbuds.

For ordinary and decorative purposes, Tea Roses in the open, if well fed and spared by the frost, might be pruned but little; still they should not be allowed to become leggy and scraggy, and a fair amount of pruning on the same lines as recommended for the H.P.s will tend to keep the plants in health and vigour. But in many parts of the country, particularly in low-lying districts, we often find, on removing the protecting material in April, that a considerable part of the plant has been killed during the winter; and are only thankful, as I have said, if we can find some real life to cut back to. For exhibition 
purposes the pure Teas should be in all cases pruned back as hard as the H.P.s; there is no fear of these free-flowering and most charming Roses failing to bloom.

Where Gloire de Dijon or any of its race, Maréchal Niel or any of the strong-growing Noisettes are cultivated in the open, they should be treated as mentioned above on the pruning of wall Roses. These varieties if in good health make long strong flowerless shoots late in the summer, which should be retained nearly to their full length as they will give the finest blooms. These shoots should be trained, while still soft, in as near an approach to a horizontal position as is practicable without bending them too much, and will last about two years, when they will probably become weak and should be clean removed to make way for others.

This habit of making strong flowerless growths late in the summer makes the following special treatment advisable for the training and pruning of Maréchal Niel under glass.

In a house fitted with wires up the roof as for vines let a strong maiden standard be planted, with plenty of room for extension on either side. The roots may be inside or out, but in either case ample provision must be made for the supply of abundance of rich food. The Rose should be completely cut back at the time of planting to within an inch or two of the stock. When it begins to grow, two shoots only should be selected, all others being rubbed off, and these should be trained horizontally right and left immediately under the bottoms of the wires. If still growing when they reach the end of the house or as far as it is intended to cover, train each up the end wires, and should they reach the top twist them about anywhere where room can be 
found but do not break or stop them. No pruning whatever will be necessary during the following winter, but the plant must always be highly fed. The Rose will probably bloom freely along the rods in the next spring, and as soon as the blooms are over, the upright rods (if any) must be cut quite back to the horizontal part from which all shoots must be clean removed.

We have now left, probably about April, a plant, shaped like a T, a stem with two simple horizontal arms, and this will be the whole of the permanent part of the Rose. The horizontal arms will soon begin to break in several places, and shoots must be trained under the wires about fourteen inches apart, all other buds and new shoots being rubbed off. The chosen shoots may appear weak at first, but they will gain in strength, and the autumn growth, if the plant be well nourished, will be very rapid. Probably all the shoots will not reach the top of the house this year, but they should be allowed to grow as far as they will, and to ramble anywhere where there is room when they have reached the top, till growth ceases for the winter. As soon as the buds seem inclined to break in the spring, the time being of course dependent on the amount of heat supplied, all the ties should be unfastened and the long trailing shoots most carefully let down for a few days to give the lower buds an equal chance of breaking with the upper ones. They should then be retied in their former positions, and the ends reaching further than the top of the house, for which no room can be found, may be cut off.

Almost every bud should now produce a flower-a splendid sight which may last a month. The blooms will be greatly superior to those grown out of doors in general perfection of shape, but the petals will be thinner in many cases, and the flowers less lasting. 

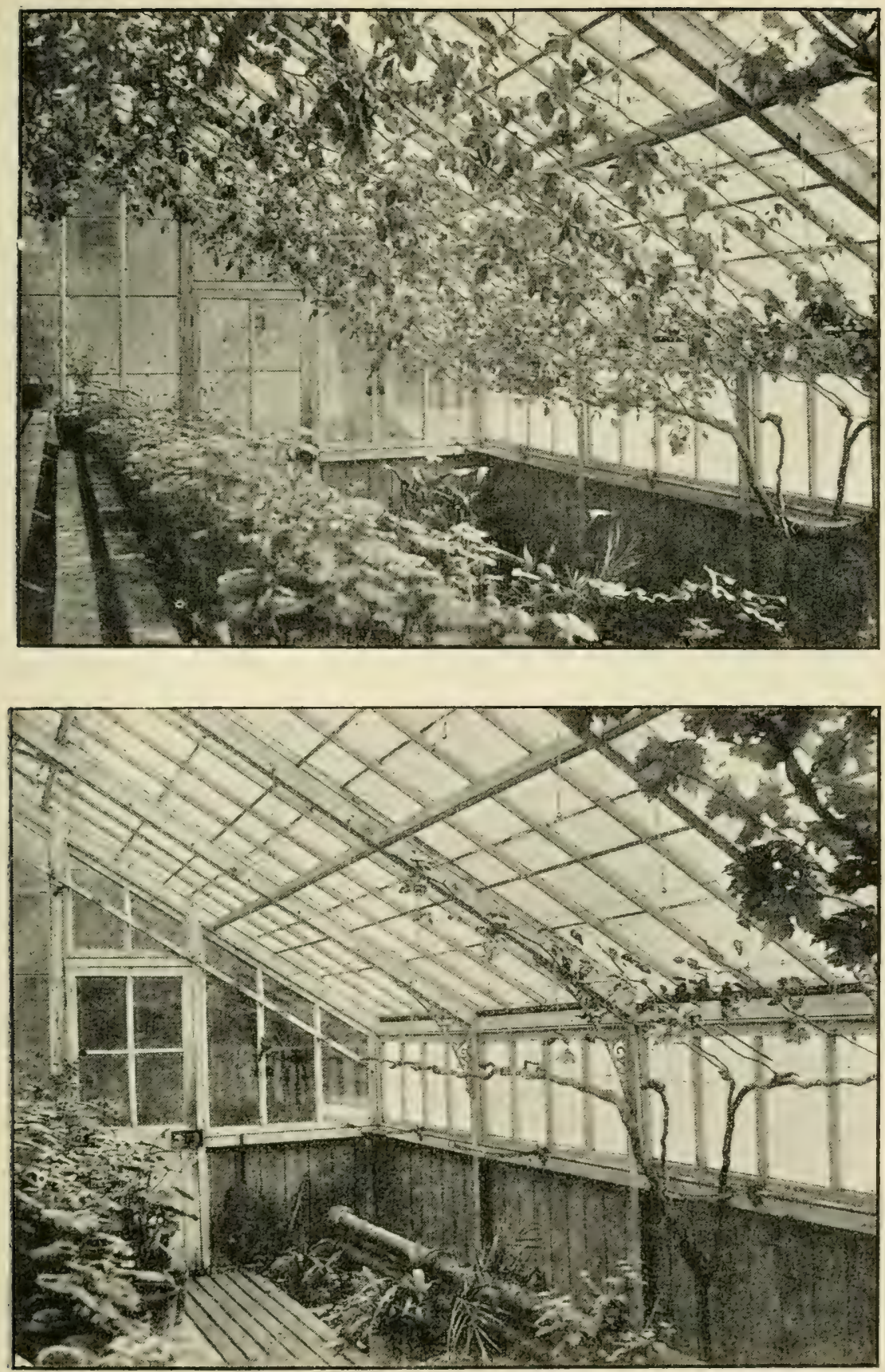

Maréchal Niel, under Glass.

To face $p .96$.

The upper plate represents the plant in full bloom, with about 300 fine roses on it, April 4th, 1894.

The lower one shows the same plant on April 27th in the same year, the whole of the upright rods, with the exception of two or three small portions, still bearing anexpanded buds, having been cut back to the horizontal permanent arms. 

They should be cut before they are expanded, for, alone of Roses, Maréchal Niel improves in colour after being placed in water. Great care should be taken in the spring growing season to avoid cold draughts, as the foliage is very tender and susceptible of mildew. As the blooms are cut or wither, the upright rods should be gradually shortened till the whole is clean removed back to the main horizontal arms at the bottom of the house. The check to the plant will be lessened by the gradual removal of the shoots, and fresh growth will soon start to be trained up during the summer and autumn in their place as before.

This is a simple, systematic, and regular method, which I have found to answer extremely well. It may be objected that all autumnal bloom is lost by it, but we ought not to want Roses under glass when there are plenty out of doors. I know of no system which will so well provide for the utilisation of the strong autumnal growth; and the blooms from these strong shoots are far superior to any that can be gathered from older wood or weak laterals.

As the cultivation of Maréchal Niel under glass by this method should result in the production of a large number of fine Roses all at once, and there will probably be a desire to send some away to friends by post or rail, this seems a good place to say something as to the packing and carriage of Rose blooms in general. For sending large quantities by rail the method that professionals have learnt by experience had better be followed: in a shallow box the Roses, gathered quite dry, should be laid flat in rows as closely together as possible, and all the same way: the ends of the shoots are wrapped in a mass of strips of some slightly absorbent paper well wetted, - a much cleaner material than 
moss,-and the whole made as tight as possible and covered with clean paper.

Roses often travel badly by post, the reason being that, if packed as above in an oblong box, the parcel is often carried perpendicularly in the postman's basket, and the Roses standing on their heads will all work down to one end and bruise the most tender and beautiful parts, the tips of the petals. For choice specimens, or at any time for small quantities, I would recommend that each actual flower be carefully wrapped in soft tissue paper, with a little cotton wool at the bloom end of the package, and much greater security by post can be attained by tying the stems in some simple manner to the bottom of the box to prevent shifting. It is no use sending away full-blown Roses: they should in all cases be undeveloped and scarcely past the bud stage, and another noteworthy and important preparation for a successful journey consists in placing the flowers in water for two or three hours before packing.

Many of the H.P. Roses grown out of doors will require a considerable thinning of the flower buds, not only for exhibition, but in order to get presentable blooms. The majority of the crimson H.P.s, such as Madame Victor Verdier, form great clusters of buds at the end of the strong shoots, and the result will be most unsatisfactory if they are all allowed to remain. The centre bud will open first or try to do so, but it will be so hampered by want of room and so robbed of its nutriment by its many companions as to fall very far short of what it might have been. It is generally not cut, as its stem is too short unless the other buds are cut unopened, so it withers and spoils the appearance of the "truss" just when two or three of the other poor things come out even 
smaller than the first one; and so the whole life of the shoot is a failure-it has not produced one Rose worthy of the name, and yet it and the plant have been exhausted by flower formation more than if the buds had been properly thinned to one or two and a glorious bloom had been obtained and cut.

Those who grow Roses merely to enjoy their beauty without any thought of exhibiting them will find that this thinning of the buds makes an immense difference to the quality and beauty of their blooms, and will give them, in the case of many varieties, really fine flowers instead of a mere mass, wherein are some dead, some overblown, some not out, and all poor. I can never pass such a great head of buds in a neighbour's garden without my fingers instinctively longing to be at them, and ease the struggling competing crowd.

It should be remembered that the production of fruit, flowers, or even flower buds, has just the opposite effect upon the constitution of a plant to that which is given by the growth of shoots and leaves. In the latter case the plant is growing, and the roots are increasing in proportion to the leaves. But in the former case the plant is engaged in reproduction, which is to some extent weakening and exhausting. So all lovers of flowers should bear in mind that as the removal of leaves, to any considerable extent, weakens a plant, so the cutting off of flowers or buds strengthens it. We should never be afraid to cut Rose-blooms : we sometimes hear "Oh! I thought it was a pity to cut that splendid Rose on that little plant," when as a matter of fact it was still more a pity to leave it.

A large head of clustered Rose-buds is a great strain on the root and the plant, and the sooner this strain is 
relieved the better by far will be the bud that is left and the earlier and finer will be the autumnal bloom.

In growing for exhibition this operation of disbudding is most important (see Chap. XI.) and must be strictly practised on the Teas as well. But for general purposes many of the Teas are greatly improved in beauty if a bud or two be left with the Rose, only those immediately surrounding the central bud being removed. 


\section{CHAPTER VII}

\section{STOCKS}

RosEs are not generally grown on their own roots, but "worked," that is, budded or grafted, upon other more free-growing sorts. This is done, firstly, to save time: a plant in its full strength, capable of giving the finest flowers, can be obtained much quicker by budding the Rose on the wild stock, as it thereby gets at once the full benefit of the strong roots of the briar, and often yields the best blooms the first year after budding. In the propagation of new Roses, where it is required to raise as large a number of plants as possible for the following season, nurserymen are often able, by commencing in the winter under glass, to raise three generations in one year.

And, secondly, Roses are not grown on their own roots, simply because the very large majority of them do not either grow or flower so well when thus treated, as when worked on suitable stocks. I have four plants of Maréchal Niel in a row against a wooden fence, where they have been about six years. Two of these I raised from cuttings, and they are therefore on their own roots, and two I budded on briar-cutting stocks. Either of the budded plants is bigger than the two on their own roots put together, and affords three times as many flowers. 
The principal stock used is the common Dog-Rose or briar (Rosa canina) of our fields and lanes, and probably three-fourths of the Roses cultivated in this country are now grown upon this stock. It is used in three forms: first, as a standard, which is the actual wild plant dug up from the hedges, with the Rose budded on the lateral branches proceeding from the stem. Secondly, the briar cutting, which is a shoot of the briar struck as a cutting, and budded, after it is well rooted, as low down on the stem as possible. Thirdly, the briar seedling, which is the growth from the seed of the wild Rose, and has the bud inserted on the actual main root or underground stem.

Next in popularity comes the manetti stock. This is a form of wild Rose, introduced from Italy, some sixty years ago, by the late Mr. Rivers of Sawbridgeworth : it is only used in the form of plants struck from cuttings to make dwarf Roses. Other sorts of Roses which root strongly as cuttings have been used as stocks, such as the De la Grifferae, used by some for the Gloire de Dijon race and strong climbing forms of Teas and Noisettes, and the Polyantha, which may still be said to be under trial; but at present the stocks that "hold the field" are the three different forms of the briar and the manetti cutting.

A large proportion of amateur Rose-growers will, from various causes, be unable or unwilling to propagate their own plants, and so will have to rely upon those they purchase from nurserymen. Even in this case it is desirable that they should know something about the different forms of stocks, so that they may order those most suitable for the several varieties and the purposes for which they are designed. Except that we cannot now, fortunately, purchase Teas upon the manetti stock, 
as the union is universally acknowledged to be a failure, the principal varieties of Roses may now be obtained of those nurserymen who make them a specialty upon the four recognized stocks-standards, briar cuttings, briar seedlings, and manetti. Which shall we choose?

The advantages and disadvantages of the standard stock may be summed up as follows. It does very well for the old-fashioned summer Roses of the Hybrid China and Bourbon races, where a fine head and a grand mass of bloom just in the season is desired, but is not suitable for the Mosses, Austrians, and the majority of the other kinds that bloom but once. It is also a good stock for most of the H.P.s, forming large heads with the strong-growing sorts, and perhaps producing more refined flowers from those which are inclined to be coarse. For a time, the weaker-growing varieties also do well on this form of stock, perhaps even better than as dwarfs, but only the very hardiest and most vigorous are as lasting on the standard as are properly planted specimens on the cutting and seedling briar.

A majority of all sorts of Teas, Hybrid Teas and Noisettes give better and finer flowers on standard than on dwarf stocks. The natural idea would be to have the stronger forms of Teas, such as Marie van Houtte and Anna Olivier, as standards, and those of weaker growth, such as Comtesse de Nadaillac and Cleopatra, as dwarfs. As regards the outward appearance of the plants, when first put in, this would be correct: but experience shows that some of the more vigorous Teas do as well on dwarfs as on standard stocks, and that the weaker ones, though they do not seem suited for the position, and look very poor upon standard stems, yet give the best flowers when grown in that form. It has been observed, indeed, that the weak growers, both among H.P.s and Teas, are 
a little stronger as plants when grown as standards, though it is hardly apparent without actual comparison with dwarf forms of the same varieties. In deciding as to standards the purchaser should therefore consider whether he cares more for quality in the blooms themselves, or the general appearance and uniformity of his beds.

He should also take notice that there are severa] disadvantages belonging to the standard stock. One of the greatest of these is that every plant must be staked, and with a large number this becomes a serious item, as a gale of wind is sure to break some of the ties and the stakes themselves if they be wooden ones. Standards are also more expensive, and there is often far less choice of really good plants. A great deal of care in graduating the height of the stems is also necessary to make the Rose-bed "look nice," while a good general appearance is much more easily arranged with a bed of dwarfs.

I advise then that the standard form be not chosen for the H.P.s, for as a general rule quite as good blooms and a better general appearance, with less cost and trouble, can be obtained from dwarfs. La France, Lady Mary Fitzwilliam and most of the H.T.s must be taken as exceptions. Let the Tea Roses also be grown as dwarfs, if a bed of beautiful Roses be desired rather than extra fine blooms, or if the locality be liable to severe frost; but for exhibition purposes, or where the quality of the flowers is the principal object, they should be grown as standards, if it be found practicable to keep them alive during the winter.

The next question, and it has long been a keenly debated one among Rosarians, is, which of the three dwarf stocks, briar cutting, briar seedling, or manetti 



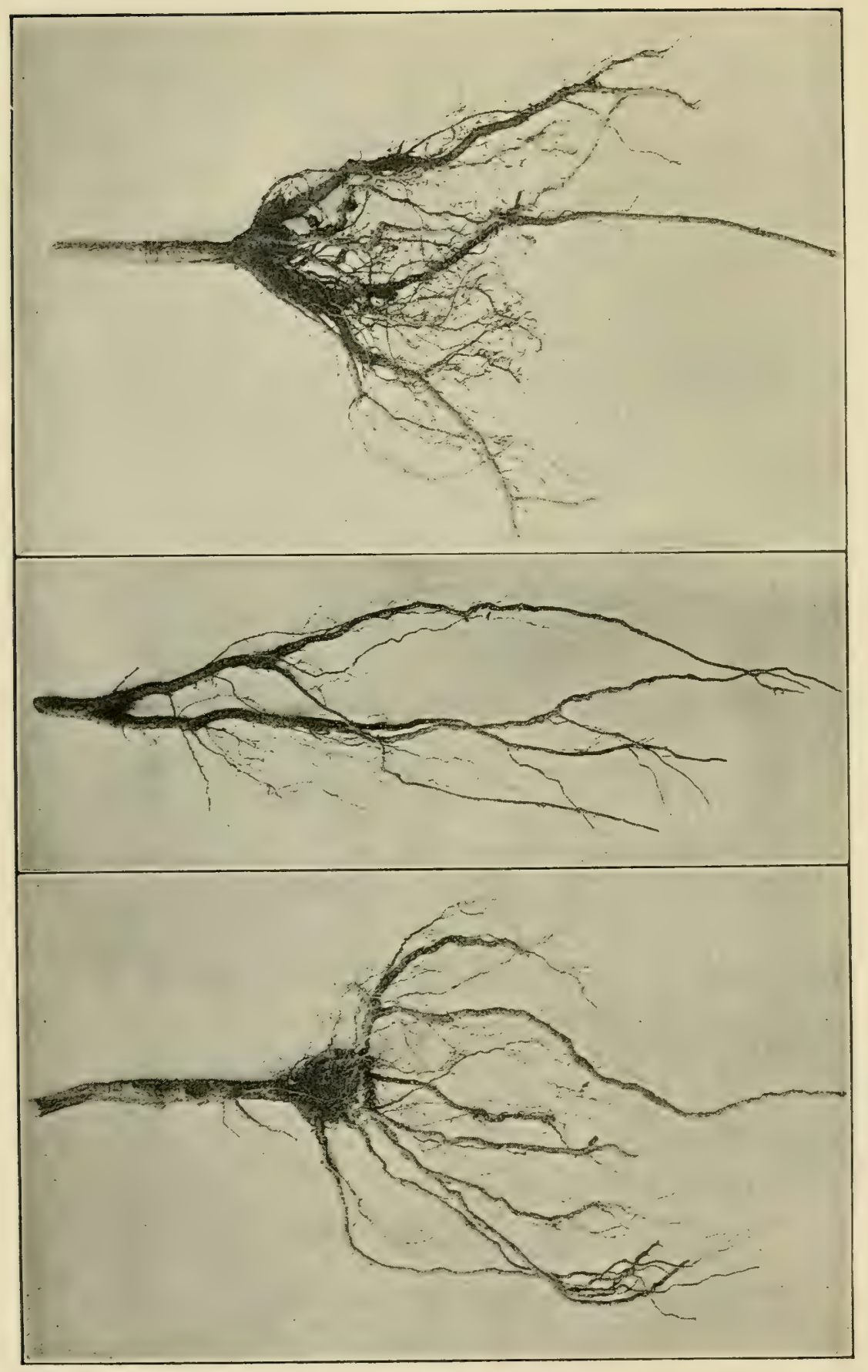

ن⿺辶万户

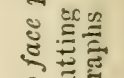

응

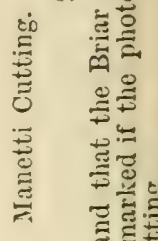

ह

Soํํ

을.

可产

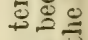

단

폴

핑

.

vi

$\therefore$.

吸引导

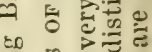

는

芯芯芯芯

대융

롤을

ติ

co

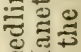

पू

$\cong \cong$

๘ 즁

F士

苍要

20

芯

छ

总

ㅁ. 댕

앙

$\exists ㅇ$ ㅇ

宁

$\pm$

馬 
cutting, is the best for purchased plants. The voice of the majority in the Rose world, with which I thoroughly agree, places the value of these stocks for permanent plants in the order named above. The advantages of the briar cutting are that it makes the finest permanent plants, that, taken all round, it gives the best blooms, and that its tendency to comparatively shallow roots makes it the most amenable to good cultivation. Its only disadvantages are that it is not quite so early in blooming as plants on the manetti stock, and that its want of deep roots prevents its being able to stand neglect so well as those on the briar seedling. This is however a poor advantage to claim for the briar seedling, as the growth from the deep roots will not be satisfactory or free-flowering. Even if the tap-roots are taken off, the plants are generally somewhat inferior to those on the cutting, and are the latest in blooming of all. Mr. Prince's magnificent culture of Tea Roses on this stock caused it to be very generally tried and used for this purpose, but I have not found any advantage from its adoption.

The manetti stock is not suitable for purchased plants. Its disadvantages are that unless the union of stock and scion is planted at least an inch below the surface of the soil, the Rose will simply die:- that as a general rule it dwindles and gets weaker every year, though there are exceptions to be found where the Rose itself has thrown out roots to aid the stocks:-and that the suckers, which it is sure to throw up as the plant gets weaker, are so like the growth of the Rose, that it requires a trained eye to detect the difference. The manetti has its uses, in the propagation of new Roses and in the growth of "maiden" plants of most of the H.P.s for exhibition blooms, but it should not be employed 
for permanent plants. Some years ago it was difficult to get dwarf plants upon any other stock but this, which was said to be generally more suitable to the lighter soils; but, with the increased use of the cultivated briar for dwarf stocks, this idea has died out, and dwarf H.P.s upon either of the three stocks can generally now be obtained of the leading professional Rose-growers.

There are still I believe a few amateurs who grow Roses in quantity, and show them well, yet never bud or propagate them themselves. I cannot understand this, for I find a large part of the delight of the pursuit in the raising of my own Roses, and I have but a few among all my plants which were not budded with my own hands. There is much fascination in the whole operation of budding:-you have before you rows of strong wild plants, rough and untidy as the worst of hedges, and in one short year you transform these into splendid Rose-plants of all varieties with noble foliage and glorious flowers of many shades, certainly as good and probably better than any that can be got from bought plants. A due mingling of hopes and fears is essential to true enjoyment, and there is plenty of both in Rose-budding, from the planting of the stock to the cutting of the maiden bloom. But when all dangers are passed and over, is not that glorious flower more truly and verily your own? You may see your Rose marked for the Silver Medal at the Crystal Palace, as the best in its section. Yes ! it is your Rose, even if it was your gardener who ordered, planted, pruned, fed and cultivated the plant, and cut and showed the bloom. But if it was you alone who had found, chosen, and grubbed out the stock from the hedge, or cut, prepared, planted, and transplanted the briar or manetti cutting -if no hand but yours had budded it, cared for it in all 
stages, and finally cut and shown the Rose, then, when perchance it is declared on all hands to be the finest specimen of the variety ever shown, it must be an additional pleasure to know that it is your Rose indeed, for that, as far as all human aid is concerned, you made it yourself !

Or again, you go to see a brother enthusiast, and to admire and take stock of his collection. You see one or more, perhaps several, Roses which are new to you and you would much like to possess. If you are not a "Buddhist," you can only take down the names, and order a plant or two of each from your nurseryman to be sent you in November. It may be that you do not mind the cost, but plant as carefully as you may, with all possible good fortune, you will be lucky if you get any first-class blooms the next year from these newly-moved plants. But if you have plenty of good healthy stocks at home ready to be budded, how much more speedy and effectual and less costly the whole matter is. Your friend immediately cuts you off a shoot or two of the required sorts with good buds on each, or promises to send you them by post if there are none now ready. If the leaves are at once snipped off, all but the last inch of the footstalk of each, they may be safely carried home, or they will travel by one day's post, even without any wet moss as protection, though of course they should not be left in the sun for any length of time. Do not be afraid your friend will refuse you, unless his plant is very small, weakly and precious; not only from the universal good fellowship of the craft, but also because he naturally expects that you will do the same for him, and that the benefit will thus be mutual. You put in these buds which have cost you nothing but an exchange which you can very well spare, and the very next summer you 
have the shoots and flowers in their fullest vigour, with the additional charm of watching a variety which is new to you spring into leaf and bud and bloom from the tiny bud which you brought home in your pocket.

What a pleasure, too, to help a beginner, or one who has lost his plants, by sending a large parcel of buds in early August when they are plentiful and you can spare a good quantity of them. But still, the choosing and cutting, preparation and packing of them takes some time, and I should advise the making of a rule that whoever asks for buds by post should send labels with the names required, as this will save some trouble at least. From budding Roses, the amateur will very likely be led on to budding his own Apples on Paradise, and his own Plums and other fruit-trees, and his interest in all these features of the garden will be much increased when his own hands have thus propagated his fruits and his flowers.

I would strongly advise the enthusiastic amateur, if he lives quite in the country and has plenty of room, to get and raise his own stocks. Not only because it will greatly add to the interest of the matter and save expense, but also because the stocks themselves, especially standards, will be stronger and better. A sufficient number can be raised every year by one man to keep up a collection of Roses large enough to enable him to show in the highest amateur classes. As standards undoubtedly produce as a rule the finest 'Tea Roses, and there are probably few amateurs who personally get their own from the hedges, I will endeavour to describe my mode of procedure.

First, as to outfit:- I never had any special suit, but an old one each year is condemned to the work, and verily it is never likely to be used for anything 
else afterwards. In a short time it is more fitted for a scarecrow than a parson, but my craze is known, and I keep to the fields. An old hat capable of protecting the ears is necessary, for you must get your head into the very thick of it; and strong boots and gaiters will of course be required. One other article of dress is wanted: even if not used for pruning, strong thick gloves are necessary for stock-getting, for there are no thorns in England like the curved scimitars of Rose canina. Summer thorns may be disregarded, for whilst they are green they are fairly pliable and soft: in winter they are as hard and sharp as steel, and as brittle as glass. Get the white stiff hedger's gloves at the village shop, made I believe of horse-skin: they are very hard and uncomfortable at first, but become more supple by use.

For instruments, first and most useful is the "Grecian" pruning draw-saw, which might perhaps be kept in a sheath attached to a waist-belt, though I have always simply carried it. Next in importance is a small stock axe: I have quite a miniature one which was made on purpose for me and can be used with one hand: all digging can be done with this, and there is no use for a spade. A pruning-knife and strong sécateurs or pruning-shears in the pocket complete the equipment. It is here, I suspect, in his instruments, that the amateur has such an advantage over the professional stock-getter. It is impossible to do justice to this, the very first step in successful Rose cultivation, with a spade, a bill-hook, and a full-sized stock axe. It is very difficult to strike accurately with the lastnamed tool in a thick place, and many is the fine stock that is grievously injured by a hasty stroke turned aside by a twig, and I am sorry to say sometimes 
mended afterwards with putty. I use my tiny stock axe almost exclusively for digging round the roots, and all of any size are then severed neatly and cleanly in the ground with the Grecian saw. The sécateurs will clear the way a bit, and lop off the head, and the pruning-knife will cut off and shorten all bruised roots, and make the edges smooth where the saw has done its work. The result will be far better stocks than those gathered by professionals, for even Mr. William Paul recommends trimming the roots of standard stocks before planting with a bill !

The greatest number of stocks, and the finest to look at, will be found on heavy land, but, as a rule not without exceptions, those on lighter land will have more numerous and fibrous roots. The stocks will be either rooted suckers from the main stool, or the actual plant itself with the stout principal root of the seedling briar. In either case, as little as possible should be reserved of the underground stem or main root, consistent with the preservation of some fibres; for it is these latter, with many others which form in the spring, that will support the new growth of the plant: the thick main roots and underground stems will only throw up suckers if they live, and if they die are likely to harbour fungus which is hurtful to the living fibres.

In many localities the hedgebanks are the only available places, where the stocks are difficult to get at, and naturally have roots only on one side, and often fantastically curled about. Briars growing in the open undergrowth of a wood, or in any rough half-uncultivated level space, are much easier to get at, and probably have a more even spread of roots. When going along hedgerows, I lay the stocks out as I get them on the erlge of the ditch with the roots covered 
with wet leaves and grass, and collect them as I come back. I then cut an elm sucker as a withe and make a little faggot, which, regardless of the sufferings of my poor coat, I carry home rejoicing. Those stocks which are taken from an old stool may probably require trimming at home with a more powerful saw, and sometimes it may be better to reserve till then the work of the pruning-knife, in shortening bruised roots, smoothing saw cuts, shaving off suckers, and carefully cutting out all semblances of buds below the ground surface.

In selecting standard stems, if there is plenty of choice, take only two-year-old shoots; next three-yearold, avoiding one-year-old shoots unless they be extra well ripened, and old stems unless you are very hard up. I have seen a great many stocks in nurserymen's quarters that I should never take unless I was very short-old, spotted, and cankered. For it is instructive to notice that canker may certainly be found on the wild Rose, in its natural state, even where there seems to have been no outward injury to the stem. It is true that some of the grey hidebound old stocks will make very good growth when cut back and transplanted, but some will not, and you never can tell where they will break. A sharp frost, after they are moved, will be fatal to a large number of the one-yearold stems, which are too soft and pithy to stand the ordeal of transplanting. A stock without any fibrous roots at all on the main root will often grow, and if it does, do well, but it cannot be depended on and should only be used if quantity is required.

There are a great many varieties of the Dog-Rose, and a great difference will soon be noticed in the general appearance of the stems. It used to be said that the red-barked, very thorny, variety is the best, and perhaps 
this is true, but I have formed fine plants on smooth stems. I should not generally choose the water briar with its deep green bark, and running slender growth almost like the Ayrshire, but I have grown good Teas upon it. The sweet briar does not form a good stock, though, as I have found it growing wild only in light soil, I fancied at one time it ought to do well with Teas on gravel.

It is not always the thickest stems that are the best; those not stouter than the fore finger, if healthy and with good roots, will often do as well if not better for the Teas of moderate growth. Still, an extra stout stock is a prize for strong growers that should not be neglected; vitality can always be diminished in many ways, it is the increasing it that takes almost all our care and trouble. I cut all my standard stems to the height of two feet, making them thus what are termed halfstandards, for there does not appear to be any advantage in having them higher, except for the formation of weeping roses; even for the middle row of a bed, more expensive stakes must be used, the wind exercises more leverage upon the roots, and suckers are more likely to be formed. It is said, however, that in very close sheltered places tall standards are better, as exposing the Rose to less stagnant air.

It should be understood that no laterals or branches, however small, should be left on the stems, and it is better that there never should have been any side-growth from the portion of two feet which is left. They should be planted in rows, the stocks a foot and the rows a yard apart, but they may be a little closer if for Teas, and room be precious. I plant in double rows, every other row being only one foot apart. Do not plant too deep : the "collar," that is, the place from which the stem springs 
(generally at an angle) from the root, should not be more than an inch below the surface. No stakes will be needed during the year of wild growth and budding. but it is a good plan to put a thick smear of paint over the pith exposed at the top of the stem. For an insect pest in the spring will be on the watch for any such exposed pith, even on large shoots pruned back on the Rose itself, and the grubs which proceed from its eggs bore down the pith, leaving a hole which holds the rain water and leads to decay.

Mr. W. D. Prior, in his useful little book upon Rosegrowing, suggests the cultivation of standard stocks by layering. To do this, any old useless stock or briar plant should be cut quite down to the ground and encouraged to form side suckers running through the soil for a little distance. A nick beneath the underground stem of these suckers will cause them to root independently, especially if a little cocoa fibre be added, and rooted standard stocks will be produced. But the time and trouble required for all this will not be appreciated, where wild standard stocks are available. I have collected 1800 of these in one winter, but they were not selected ones or all of first-class quality.

I feel, however, that very few amateur Rosarians will appreciate with me the charms of getting standard stocks from the hedges-most could not from various circumstances, if they would. The stock-man, who would probably say that I have been trying to take the bread out of his mouth, must therefore be relied on, but if possible let the barbarity of his tools, the big stock-axe and the bill-hook, be pointed out, and the charms of the Grecian saw explained to him. If a novice, it will be well also to ascertain that he knows a Dog-Rose when he sees it. 
When I was ill one winter, I was pleased to hear that a parishioner had brought me a nice lot of stocks at a reasonable price. One of the first acts of my convalescence was to inspect their quality. And alas! not only were the majority practically useless from chops and other injuries, but a third of the whole were not Rose stocks but blackberries !

This reminds me of another amusing incident, which I will relate exactly as it occurred. It refers to the spelling of the word briar, but throws no light upon the debated point whether an ' $e$ ' should take the place of the 'a.' The occasion was the examination of a night school for the Government grant, and the teachers were allowed to conduct it subject to the rules sent to them. A young East Anglian labourer was going through the reading ordeal, and his teacher's, of whom I was one, were anxiously watching his struggles. He had sunk twice-I mean he had made two mistakes in his allotted piece-and three would mean failure. He came to the word in question, stopped dead, and spelt it slowly. We encouraged him, and patted him on the back, for he had all the appearance of having a word in him but of being afraid to part with it. At last, after much exhortation to play the man and "out with it," he spelt it again very carefully, "b-r-i-a-r," and then the word burst forth quite suddenly like an explosion, "brumble-bush !" "Well well! yes, oh yes!" said my dear old colleague (long since deceased): "eh? pass that-oh yes! he knows what it means." I said nothing, and I am afraid the Education Department was slightly defrauded; but my Rosarian conscience was against it, for I knew that to the Suffolk rustic both briars and blackberries were "brumblebushes."

An amateur will want even more briar cutting's than 
standard stocks. These are cheap to buy, ready rooted for next year's budding, and it is not always easy to raise a good crop of them at home. There is a good deal of trouble connected with it, and it may perhaps be said that all this extra labour to raise one's own stocks is like the enthusiasm of the man who blacked himself all over to play Othello. Still too much enthusiasm is better than too little, and as I can raise better briar cuttings than I can buy, the way to do it shall be described.

It is rather a monotonous business, with much less interest in it than the getting of standard stocks. About the middle of October is the time for commencing operations, which should be got over before the planting of Roses and rooted stocks is undertaken. The ripest possible wood of the year's growth should be chosen and cut up into lengths of ten inches. Material for this choice will be found in the wild growth of the briar stocks budded that year, and only pieces without any lateral growth should be selected. The cuttings should now be trimmed with a sharp knife, every bud except the two nearest the top being clean cut out with the knife, not rubbed off with the fingers, and all the thorns removed. All this is important, as every other bud or part of a bud left will be sure to produce a sucker, and the thorns will prove a hindrance in many ways if suffered to remain. The bottom of the shoot should be a clean cut, not too sloping, and no "heel," or portion of older wood, should be retained. A "heel" is recommended where cuttings of the Roses themselves are taken, as it makes root growth more easy; but, as a sure and fruitful source of suckers, it must not be allowed for briar cuttings, which will generally root fairly if they be formed of ripe wood and are properly planted and cared for: 
We have now the cuttings ready for planting, smooth shoots of wood ten inches long, with two buds left at the top. These should be at once set in a piece of fairly light and very clean soil, deep enough to almost cover the lower bud. Double rows may again be used, ten inches and four inches alternately separating the rows, and the cuttings three inches apart from each other. It is advisable to set twice as many as you expect to want: for, though the trimming of the cuttings takes a considerable time, the crop is uncertain, and there is much virtue in the comfortable old adage to "make a job of a thing while you are about it." The soil should be made as firm as possible about the cuttings, but nevertheless if you come after a sharp frost and just touch the top of one with your finger you will find that it has been raised up, sometimes an inch or more, in its hole. They should all be gently pushed down again till they rest firmly.

They grow but slowly in the spring, but increase in rapidity of growth when they have once become rooted and some will probably make quite strong shoots in the autumn. These might in some instances be budded at once, but it is best to leave them all to the next year for that operation. With the summer will be realised the advantage of the advice to choose a piece of clean soil free from weeds. The shoots are close to the earth, and the first ones grow horizontally almost on the ground. Not only therefore is it almost impossible to hoe them, but a full growth of weeds can almost entirely smother the briar shoots. The weeds must therefore be hand-picked, a troublesome and unpleasint job.

In the planting season they must all be dug up, remembering how deep they are planted and that all 
the roots which are to be utilised are at the bottom, and the plants trimmed. All roots must be cut cleanly off, except those proceeding from the very base of the plants, and those retained shortened to one uniform length. The growth at the tops may also be shortened to two or three buds, and the plants then transferred to their. budding quarters. Here they should be planted about two inches deep, care being taken if possible to spread the roots out in every direction, as few fresh ones will come from the base of the cutting, and if there is a side on which there is no roots the plant will never be firm against the wind from that quarter. If the plants are permanently to remain where they are budded, the distances between each will depend upon the varieties of Roses worked on them, as explained on p. 47. But if it is intended to move them after the maiden growth of the Rose, nine inches apart between the plants, more or less, accordingly as they are intended for Teas or strong H.P.s, will do for distance.

It is plain that by thus raising our own briar cuttings we lose a year compared with the plan of buying them ready rooted. This difficulty should be overcome by buying rooted cuttings the first year, as well as setting a supply at home. An amateur commencing business had better buy a double supply of cuttings the first year, half rooted for budding the next year, and half unrooted for the year after.

Manetti cuttings, which are useful to an exhibitor for the production of early maiden blooms of the H.P.s, may be raised and treated in exactly the same way. They strike much easier than the briar cuttings, and there should be very few which fail to root.

I have never gone the length of trying to raise briar seedlings, as they are cheap to purchase in quantity, and 
I have not much faith in the stock for highly cultivated Roses. The seeds should be rubbed out of the ripe heps, and sown an inch deep in drills about a foot apart. All will not germinate, and a great amount of difference will be found in the plants by the end of the year. Many will still be quite tiny things, and a person unacquainted with their power of growth would think the finest far too weak for budding the following August. But the second year's growth is astonishing: puny plants, with roots hardly bigger than knitting needles, and weak shoots in proportion, will sometimes in that short time have become veritable bushes with strong fleshy upright shoots, and a main root to bud on as thick as a man's finger. Those that are evidently too small for budding the following summer should be reserved for another year, or transferred to pots for budding or grafting there.

The seedling briar has naturally a tap-root; in fact, as with all seedlings, there is only a tap-root at first. When purchased, the length and straightness of the roots are remarkable: and it seems probable that this want of balance between the head and the roots accounts for the remarkable growth of the second season. The tap-roots should be boldly shortened, as it is our object to encourage comparatively shallow roots as much as possible. There will still be a tendency to root deep, and, when Rose plants on the seedling briar are moved, roots with a downward inclination should be suppressed and any horizontal ones encouraged. In planting out briar seedlings for budding, the "collar," or place where root ends and stem begins, should be upon the surface of the ground not beneath it, for the rose is budded in this case upon the main root below the collar. 


\title{
CHAPTER VIII
}

\author{
PROPAGATION
}

Budding is so much the most important mode of propagating Roses, that it naturally occupies the first place. We will suppose that a goodly supply of stocksbriar standards, cuttings, and seedlings, and manetti cuttings - have been planted during the winter as described in the last chapter, and commence their growth in the spring. Do they need any special care till the time for budding arrives? If they do, they very seldom get it, but the Rosarian who intends, and is able, to do everything thoroughly, to promote all that is useful to his Roses, and war against all that is hurtful, may find some useful work here. During the grub and caterpillar season in April and May he will give occasional turns of examination and handpicking to the wild growth on his stocks, besides the systematic and close search which he will make on his Rose plants. It is true the wild growth will battle through the insect attacks, and there is no bloom to be injured; but some check at least will be experienced from these causes by the stocks, and if the insects are allowed to fulfil their course they will breed and increase, and we shall have to deal with their progeny on the Roses. We can hardly exterminate these pests, but we ought not to allow them to breed on 
our premises, on the ground that they are not doing much harm just where they are.

The next point of importance is the treatment of the standard stocks. In almost all the books on the subject that I have read it is advised that, sooner or later before budding, all shoots from the standard stems be removed except the two or three near the top which are reserved to be operated upon. I would say: Do nothing of the sort-do not remove unnecessarily a single leaf, save of suckers from beneath the surface of the soil, and let these be gently but firmly pulled out as will hereafter be described. Remove no lateral branch or part of one during the whole season of growth: and as this seems opposed to general recommendation, I will endeavour to give the reason for the advice.

A plant in its natural state has always a complete balance of strength between the parts above ground and underground - the branches and the roots. If, in summer or during the period of growth, the roots be injured, cut off, or lessened, the foliage, which is the most prominent outward sign of vigour, will suffer in proportion, but if not killed will restore the balance of root power as soon as possible. If, on the other hand, shoots or leaves are cut off or injured during the summer, the roots will cease to increase till they have restored the balance of power to the foliage. Thus, in summer, cutting back the roots hinders the growth of the plant, and taking away shoots with leaves on them checks the growth of the roots.

But if roots or shoots are cut off during the sleep of winter, no immediate check is given by either to the other, and the first thing the plant does when it wakes up in the spring is to try to restore the balance. If it finds itself with a large growth above ground and roots 
that have been lessened, the plant will comparatively stand still just alive till the roots have grown up to the balance again. If, however, it finds itself with strong powerful roots, and only two or three buds left on the plant into which the sap can pass, it makes up the balance as quickly as it can by unusually strong growth and large fleshy leaves.

This is what we aim at in trying to make a maiden Rose plant by budding on the wild stock. We want it to grow as strongly and as quickly as possible, for among H.P.s the very finest blooms are thus produced and some very choice varieties give their best flowers only during this first year of extra strong growth. We therefore bud on wild briars which have as many branches as possible-knowing that each branch represents so much root power below-that if one of these be removed the . roots will cease to increase till the balance has been restored-and that if we can next spring divert the root power of many wild branches to the one or two buds we have inserted, the growth is sure to be extra strong and fine.

This principle is well known in the difference resulting from the summer and winter pruning of fruit-trees. If we cut back the strong woody shoots in summer, next year's growth is partially checked because the roots suffer awhile in proportion: the lower wood buds therefore ripen and consolidate to form fruit buds. But if we cut back these strong shoots in winter, when there are no leaves and all is at rest, the roots when they wake in the spring try to make up the balance of foliage by strong woody growth equal to that which has been cut off.

So is it with our standard briars. If we cut off any shoots in summer we hinder the roots from attaining 
their full development. But if we cut them off in winter, when the roots have attained to their maximum and are resting, their full strength can be devoted to the buds in the spring.

But some of the advocates for the removal of those branches which are not to be budded have given their reasons for the advice. They say the object is to divert the entire strength of the plant into the selected shoots before they are budded. This is not quite correct: the full strength of the plant will be lost, for the check to the roots will be considerable. Yet it is true that the selected shoots will grow more vigorously, for the plant will try to make up the balance in both ways, in lessened root power and also increased growth in such branches as remain. But, in the first place, we do not want such extra stout branches to bud on; if big enough, the union will be better than on a very large shoot, because a small one will have to swell and increase with the strong growth rising from it. And, in the second place, what we do want especially is as much extension and strength in the roots as we can get for the support of the maiden growth of the Rose.

It is naturally much easier to bud upon standard stocks where some of the shoots have been remover than it is upon such a rampant hedge of thorny growth as will be formed by a row of unrestricted stocks if they have grown well. But the knowledge that all this prickly luxuriance represents the power we are going to put into the growth of our buds next season should be an encouragement for a bold attack, and a comforter against thorny assaults. The branches should be carefully shifted and turner aside to expose the places for operation, and the thorns can be compelled to make themselves useful, as the branches 
will catch and hold to one another wherever laid without tying.

The principal time for budding is the latter part of July and the whole month of August. I have successfully budded Roses out of doors in each of the six months commencing with May and ending with October, and there would not be much difficulty in finding stocks in the proper condition in June and September, but to get buds in the right state would then be more difficult. Manetti stocks may be well budded with hardy H.P.s in September; and a commencement should be made with the Teas first of all if possible. This is not only because the inserted Tea bud will thereby become better ripened and more able to withstand the winter, but also because these buds, in many of the varieties, are difficult to procure, and it is good policy to begin early, and use them whenever they can be got.

I have used no illustrations to aid the description of the process, because they have always seemed to me unsatisfactory; for all manual operations example is far better than precept, and I would strongly recommend the seeing it done by an old hand, even if only once, in preference to relying upon descriptions or figures alone. It is best for an amateur to learn of an amateur, provided of course the teacher be experienced and trustworthy; for, without throwing any discredit upon the wonderfully clever and rapid performances of professional budders, it is plain that an amateur works upon rather different lines. He has not such a wealth of "stuff" to fall back on, either of buds or stocks, and having more time can afford to be more careful and particular about every stage of the operation.

No tonls are required beyond a budding knife. It is 
hardly necessary to say that this should be as sharp as possible, but a hone is not so often required as in pruning, since no hard substances will require to be cut. The curve at the end of the bone handle for turning up the bark of the stock is made of different shapes, and a young operator will soon find which is most convenient for him. A bundle of ties of Raffia grass, split where too thick, and shortened to ten inches or a foot each (better too long than too short), should be fastened to the waist so that one tie can be slipped out easily as required.

The buds chosen should be half ripe, and plump but not grown out. Experience will soon teach the proper condition: but, as a general rule, at the end of July and beginning of August, buds in the proper condition will be found on the shoot from which a bloom is then cut; before that time the shoot must mature more or less after the flower is cut before the buds are ready: after it the buds will be ready on the shoot before it has bloomed, and in September only the latest shoots which are still growing will be of use. Those who grow for exhibition will generally have a difficulty in finding early buds; the shoots are so forced by high culture and feeding that the buds begin to grow out all up the stems before the flowers open, and a more natural state of things later on must be waited for. A fully developed plump bud is desirable, but this is of less importance than the condition of the shoot, which should not be more than half-ripe, with the sap still flowing freely so that the wood parts easily from the bark. Professionals will often use a shoot for budding, where some amateurs would say that there were no buds, as none are visible. There is always a bud under every leaf-stalk, and it is far better to use those in this undereloped condition 
when the wood will come out satisfactorily than older and more attractive looking buds which cannot be properly prepared.

As a rule, buds should always be taken from a shoot which has, or has had, a good bloom on it. Some sorts, like François Michelon, often have long strong flowerless shoots, with plenty of good wood buds on them. If these buds be used there is a strong probability of no flowers being produced the first year. In Tea Roses, the next bud to the bloom is often flattish and pointed instead of round and plump. These should not be used, as they will often produce, if they take, just a poor little bloom upon an inch or two of stalk, perhaps with no leaves at all, and soon die.

The chosen shoots should be cut off with scissors, and all the leaves immediately snipped off, leaving about an inch of footstalk to each. This is not only for convenience, since it must be done before the buds are used, but also because evaporation takes place through the leaves, and the whole shoot will soon wither if they are left on. A quantity of buds may be carried about for some time without taking any harm if the leaves are thus removed at once: but if a great quantity is taken at a time, or the buds have been received by post, it is better to carry them about in water.

Standard stocks are budded upon the laterals, the growth of the year, as close to the upright stem as possible. The general practice is to bud two branches, though only one is necessary. Should both of these fail, a use will be found for the other laterals, which have not been removed for the reasons given above, for it will be better to bud on these fresh shoots as the reserved ground than on one where a bud has already failed. 
Like the buds, the branches of the stock should be "half-ripe." If worked on too soon, while still soft, or when the wood appears green instead of white when the bark is turned back, the chances of success are much diminished, and the shoot is very likely to break off at the cross cut. If attempted too late, a stock which has not got a strong root hold often ceases to grow for a while in a dry August, and the flow of sap being lessened, the bark does not rise freely and readily. It is absolutely useless to attempt budding in such a case, where there is any difficulty in raising the bark. An experienced eye can generally tell by the appearance of growth or the want of it in the tips of the shoots, whether the bark will rise and budding may be done.

Do not necessarily choose the strongest laterals, but medium-sized shoots half ripe but growing freely. Rub the thorns off the two inches of the branch to be operated on which are nearest to the main stem. Next make a cross cut half an inch long and about an inch from the stem; and be sure it goes clean down to the wood, then make a clean straight longitudinal cut at right angles to the first one as far as the stem. Insert the bone handle of the budding knife into this cut, and pass it evenly down under the bark on both sides from cross cut to stem, raising it a little, so that the two cuts form a T. It is best so to choose the position that the longitudinal cut does not pass through or near a wild natural bud, as this will leave a little projection which will hinder the smooth passage of the bud. It is not worth while to try and get the new bud just where a wild one was before.

The stock is now ready and we turn to take a bud from our Rose shoot. This should be sliced off so that we have the leaf stalk with the bud under it in the 
centre of about an inch of bark, the other side being flat and smooth and containing a portion of the wood of the Rose.

Now comes the most critical point. The wood has to be cleanly removed from the inside of the shield of bark without taking with it the immature soft growth or cambium, which forms the inside of the bud. If the bud is in the right condition the wood generally breaks away from the bud leaving the appearance of a hole which is filled up. But if the inside of the bud appears hollow, a fresh one should be taken, as a large percentage of failures arises entirely from this cause. Occasionally some may grow, but a good union is unlikely and most will fail utterly.

The point of the budding knife carefully inserted at one end is usually the means by which the wood is got out, though I knew an old gardener who said he "kept a thoomb-nail o' purpose," a gruesome object which he exhibited with pride. The beginner had better try several ways till he finds what suits him best, remembering that the one object is to get the wood out clean, and yet leave the inside of the bud. Which end of the wood should be raised first will naturally depend upon whether it is to be lifted, pulled, or pushed out.

If the wood comes out all right leaving the bud, there will probably be no trouble with any buds on that shoot. And vice rersa, for it is the condition of the shoot which is at fault, if you find that you have pulled the interior of a bud out, take extra pains with the other buds on that shoot if a better one is not to be found; in obstinate cases, the knife itself may be passed down under the bark, and help the desired object. But care must be taken that the inner surface of the bark of the 
bud be not bruised or cut and that no grit or foreign substance whatever gets in.

If the wood will not come out clean but adheres in places, the bud is over-ripe and should not be used. If it be very small or not ripe enough, some advise that it be inserted without removing the wood. In such a case the bud will sometimes grow, but this is grafting not budding, and the union will not be so good or lasting.

The bud thus prepared must without any delay be slipped under the cross cut and down the longitudinal one, so that it just touches and fits to the cross cut. This is not essential but is more likely to ensure success. Many make the shield of bark containing the bud considerably longer than the longitudinal slit which is to enclose it, and cut it across when it is in so that it exactly fits the cross cut. This is the mode generally adopted by professionals, and requires a steady hand, good sight, and a very keen knife. Amateurs probably more often make the bud the right length to start with, cutting the upper end square. The leaf-stalk will form a useful handle for pushing the bud down into position.

The bud should now be tied in, making the bands of raffia touch one another and cover the whole of the slit wood except the bud itself. The tic should be made firm and fairly tight, and should not be removed for four weeks, unless it is seen to be cutting into the bark. The bud will generally have taken or failed by the end of three weeks, but sometimes this is a little too soon to remove the ties entirely. No shading is necessary in the hottest weather, if the stock continues in good growing order.

There should be no shortening of the budded shoots, before, at the time, or after budding. Shortening 
checks the flow of sap to the bud instead of increasing it. When the ties are removed, standard stocks that have failed may be re-budded on fresh shoots. The date of budding each stock or row should be entered on the label or in a book, that the proper time for removing the ties may be known.

Some recommend budding with only the longitudinal cut and no transverse one. This may be a more satisfactory operation when it is done, but it requires an expert hand to get the bud in under these circumstances, and the cross-cut system answers very well.

Budding on cutting or seedling stocks to make "dwarf" plants is practised in just the same way, except that in this case the bud is not put into the branches, but into the old wood of the main stem beneath, if possible, the surface of the ground. As before, no growths should be cut away or stopped, but the shoots may be bent back to allow access to the stem. A trowel or the blunt stump of an old knife may be used for removing the earth round the stock to the depth of an inch or more. The stem should then be rubbed with the hand or a piece of old flannel or cloth to make it clean and free from grit, no harm being done by the removal of the epidermis or outer skin of bark.

The operation now proceeds as in standards, only one bud being put into each stock, and great care being taken that no particles of earth or extraneous matter get in between the bud and the stock. With extra strong manettis, or in any case where a small bud has to be put into a strong rough thick-barked stock, thin slices may be taken from the lips of the bark to prevent its completely meeting over the bud, and "drowning" it in growth. Formerly the material 
CHAP.

used for the tying in of buds was bast or Russian matting, and then soft thick white cotton, called "bonnet cotton," was much used by amateurs. But the introduction of Raffia grass supplied a material of just the right consistence, softness and pliability, which has also the happy knack for the purpose, when close to the damp earth, of gradually rotting, so that at the end of a month or more the ties on dwarf plants become loose of themselves.

It is not therefore necessary to unfasten them: but amateurs will generally like to inspect the result of their operations, and where there has been a failure the stock can generally be rebudded on the other side, or lower down. The bud will be the better for being exposed to the air, but, after it has taken, accidental re-covering of earth will seldom do any harm.

Seedling briars are to be budded on the main root immediately below the "collar," which is full of dormant buds. This root is often crooked, with fibres proceeding from it, and the best available spot for budding should be chosen even if it is some little way down. It is the most difficult stock to work, and, in case of failure, room can seldom be found for a second attempt.

Occasionally the buds will "grow out" as it is termed, that is, start into growth and even give good blooms the same season that they are budded. There is no harm in this provided it has not been forced by the shortening of the wild growth. On the contrary, with hardy sorts it makes the establishment of the Rose plant a matter of certainty. The shoot should be secured to a stake and not shortened, but pruned back very close in the following spring.

No further care will be required for the budded 
stocks, beyond removing the ties at the expiration of four weeks or a little less, till October or November. In the middle of the former month, where the buds look weak or doubtful, all the wild growth may be cut away-in standards, reserving one or two wild buds only on the worked shoots above the inserted bud, and cleanly removing all others which have been unsuccessful or unbudded-on dwarfs cutting away the actual stem with all the wild growth upon it to within three or four inches of the bud-and on seedlings cutting away above the bud and below the collar. Where the buds look strong and healthy all this work should be left till November, or they might commence growth which would be very undesirable; but a week or two of genial weather, before the roots are quite dormant, may sometimes strengthen and plump up a doubtful bud, and encourage it to live through the winter.

The buds of Teas will, in many places, require protection during the winter, as described in Chapter IV. Some of the earliest buds may begin to grow even in March, and all, whether dormant or growing, will need constant examination during April to protect them from insect enemies, especially weevils and the black grub.

Some recommend the pinching closely back of those buds which start with only one shoot, to cause them to break again in two or more shoots. I used to find it necessary to "harden my heart" very much to perform this operation: and, since a sharp frost supervened one year and killed nearly the whole of these mutilated buds, I have given it up completely, believing one shoot "in the hand (or at all events securely tied up) to be worth two in the bush." It is regularly done, however, in many large nurseries, even with the tenderest Teas. 
It is absolutely necessary that the growing shoot be tied to some support as soon as possible, and that care should be taken throughout the first season to see that it is really secure. Great caution should be used in making the first tie with a strong stiff shootthe union is very insecure, and even a crack from bending too much, or a sudden jar, may ruin all in a moment. Never mind spoiling the shape or look of the plant: we may think of that next year. The union is not perfect, at least for some time, during the first season, and the shoot is generally top-heavy. The finer the growth and the better the head formed, the more certain it is to be blown out if not securely tied. Nothing is more aggravating than to come out some morning in spring or summer and find the whole thing blown clean out of the stock. The plant is absolutely destroyed, and all the time and labour from the first getting of the stock is simply thrown away.

It is best not to try to be economical in such a case, or when buds have failed, by budding on the same stock again. Fresh stocks are better in every way, and briar cuttings whose buds have failed will not form good dwarf standard stocks for the next year, though I have often tried them.

Bamboos are now the best stakes and supports, at all events of a temporary nature. Budded stocks of manetti, briar cuttings and seedlings should have fairly strong bamboos, of length according to the growth expected of the Rose, driven firmly in beside them, and securely tied to the small portion of stem left of the cuttings, and to the root if possible of the seedlings. Without this tie, if the bamboo receives a blow or a push, the Rose shoot fastened to it may be pulled out. The stake should not be behind the stock, that is, on 
the opposite side to the bud, but beside it, for if the shoot is stiff and grows out at an angle there may be a difficulty in fastening it securely till it has grown some length.

Extra stout bamboos should be employed for standards, a foot or more, according to the variety budded, higher than the topmost bud. The same stake will thus support the stock and the growing shoot of the Rose. As soon as the bud has fairly started in the standard stocks, the small portion of the wild shoot remaining may be cut away with a clean sloping cut close to the bud. The reason for leaving it is that it may sometimes be found useful in coaxing a bud to start, by letting a wild bud push for an inch or two thus drawing a flow of sap, and if that does not answer stopping it back again.

These dormant buds that will not begin to grow are a great trial to the standard stock as well as to the patience of the cultivator. The strong roots, equal in balance to all the growth that was removed in November, keep sending up full supplies of sap, and the plant will endeavour to get rid of it by making growth in every possible direction, above ground and and below, except sometimes through the one tiny channel where it is desired. Such buds will occasionally start after all, in June or July, or even the following year; but there is something amiss with them, and they are not likely to form good plants.

The principal thing to remember of the maiden growth of newly-budded plants is that no search for insects, remedies for mildew or admiration of the glorious blooms should hinder the one care of tie-tietie, or all may be lost in a moment.

Grafting.-This mode of working the Rose upon another stock is so inferior to budding in many ways that it only survives because, with the aid of heated 
houses, it can be practised in the winter. A nurseryman, or any one who has the proper appliances, can thus increase his stock of any particular variety many fold in the middle of winter, and thus multiply the number of buds he will be able to use when the outdoor stocks are ready.

It is in this way that new Roses are so quickly propagated, but of course any other variety which has become scarce can be increased in the same manner. Healthy young stocks not too large should be established in pots the year before for the purpose. They may be manetti or briar cuttings, but the manetti is best, from its ready rooting power, and its susceptibility and readiness to grow when exposed to heat. If the supply of stocks be short, suitable pieces of briarroot, taken from stocks where budding has failed, have often been found to answer the purpose well. It is not intended to form plants for flowering or permanence, but only to provide a larger amount of buds for outdoor propagation.

The operation is generally performed in January when both stocks and scions are in a dormant condition. All available shoots of the Rose should be cut off and stuck into the ground somewhere where they will not be injured by frost or excited by heat, but kept in the winter sleep. The stocks, however, should be just a little forwarder, by having been brought into the house a short time before, not actually started but ready to grow at once on the application of heat.

The method of grafting usually employed is the easiest and simplest-whip-grafting, which is an ordinary plain splice such as a fisherman would make to his broken rod. The stock is cut straight across with scissors an inch or two above the soil in the pot, and is 
then sliced up on one side only with a sharp knife to form the stock half of the splice.

For the scion, if the sort be new and rare, only one bud is used. The shoot is snipped into little bits, by cutting across as close as possible above each bud. This will leave, below each, an inch or more of wood, which should then be sliced up to form the other part of the splice. Stock and scion should be as nearly as possible of the same diameter, but it will not matter if the stock is somewhat the bigger of the two.

The essentials of grafting are; - that on one side at least the inner bark of stock and scion should exactly meet, that flow of sap in the stock should take place at once, and that air should be excluded till the scion has made some growth.

To meet the first of these necessary points is very important. Of course the two parts to be brought together will not fit exactly once in a hundred times, and the only care therefore should be that the scion should fit on one side of the stock and not be placed in the middle.

To prevent its slipping during the tying is rather a difficult task till one has seen "how it's done." Two or three turns of a thin bit of Raffia are first taken round the lower part of the sloping cut on the stock leaving the ends underneath. A third hand comes in very usefully here, and the operator generally utilises his mouth for the purpose. The end of the scion is thus held ready for putting into position under the tie which is then tightened and finished by the hands.

It is not necessary to make the circles of the tie touch each other, nor are wax or clay used for keeping out the air. The pot is immediately placed in bottom 
heat in a frame which excludes the air, and it is most interesting to watch the callus or cambium growth forming between the two barks. The bud will probably start in about three weeks, and then air will be gradually given, and a high but even temperature maintained till the plant has grown sufficiently to be hardened by degrees and to stand exposure to an ordinary mild atmosphere.

The young growths will be very liable to "damp off," and the usual precautions against this catastrophe, of admitting air above, even in frosty weather when the heat must be increased, must be strictly attended to. Roses propagated in this manner are of very little use for planting out, and the amateur, in ordering new varieties, should see that he does not get them.

Where there are no appliances of close frames with bottom heat, the operation must be deferred to a little later in the year, the stocks must be in a more forward condition, and grafting wax must be used to cover the whole of the operated parts closely, as is the case with fruit-trees grafted in the open air. French grafting wax which can be used cold is preferable to home-made material, but winter grafting can hardly be considered worth the trouble for amateurs, unless it be carried out on a large scale, and close frames with bottom heat in properly constructed houses can be provided.

Roses on their oun Roots.-It is constantly being put forward as a new discovery that Roses, especially some varieties, may themselves be struck as cuttings, and will in time form fair plants and give decent blooms. "Why then," it is said, "take all this trouble about stocks and budding? You plant your cuttings in the autumn, in any quantity, as it is all wood that you will cut away at the spring pruning, and you thus get real 
genuine Rose bushes-Roses on their own roots, which cannot be killed by frost unless root and all perish together and whose suckers are welcome as they are only increase to the Roses."

The simple answer to this is, that not only does it take longer thus to form plants which will give fair flowers, but that it is a fact that Roses on their own roots do not grow so well or flower so well as those which are budded on stronger rooting stocks. Nevertheless some varieties, especially of the free and hardy garden sorts, will answer in this way, and the best modes of striking the cuttings shall therefore be described.

The usual time for taking them is November. They should be prepared of as ripe wood as can be found of the current year's growth, about ten inches in length. The thorns had better be trimmed off, but none of the buds as all these will help if they grow. If a small portion of "heel" or older wood be left at the bottom, the likelihood of striking will be increased. If taken so early that the leaves yet remain, all should be removed save the two top ones, and in this case a good soaking with water should be given after the cuttings are set out.

They should be set deep, only two buds showing above the soil, in double rows as recommended for briar and manetti cuttings. It will be a great help to the emission of roots if the shoots rest firmly at the bottom upon some sharp sand or sifted cocoa-fibre dust. Attention must be paid to them, as to briar cuttings, after sharp frosts which lift the shoots in their holes. In the winter they may be gently pressed down again, but if thus raised by frost later when possibly roots may have formed, it will be better to tread the soil firmly round 
them. In the following autumn those that have made good growth may be moved, and planted shallower in their permanent quarters, and it will then be seen how poor are the roots in comparison to those of the stocks on which Roses are budded.

If this method of propagation is carried out during the summer, a close frame or at least a hand-glass is necessary. The cuttings need not be more than four inches long, and should consist of short-jointed wood with a heel to each. They should be syringed and kept close for a while, and much care will be requisite to prevent damping off. Bottom heat is a great help towards getting them on quickly, but all this is generally great waste of time and energy, as only a few of the hardiest, strongest and commonest sorts will do well on their own roots, and these will root fairly as November cuttings.

Suckers and Layering.-The Scotch and Austrian Roses and some other sorts, when grown on their own roots, form suckers at some little way from the plant, and these when rooted may be cut off and transplanted to form plants elsewhere. A cut on the under side of the sucker beneath the ground will encourage the formation of roots.

Dwarf plants of any free-growing variety may be "layered." To perform this operation the shoot must be bent down so that it will touch the ground some little way from the tip. A small hole should be prepared here and filled with rooting material, such as leafmould, sand, and cocoa-fibre dust: the shoot should be cut halfway through and then longitudinally so as to form a tongue, and then pegged into and planted in this hole, when in due time roots will be produced and a new plant formed. 
It is possible also to raise Roses from mere buds or eyes as vines, but letting the leaf remain. There are other methods of inducing the wood and buds of Rose shoots to put forth roots, but for the propagation of established sorts there is nothing to equal budding, with winter grafting for the rapid multiplication of rare varieties.

Roses from Sced.-A chapter on propagation would be very incomplete without at least some reference to the raising of Roses from seed, the principal means by which new varieties are gained, and to the hybridising or crossing of special sorts which has been so successful of late years with some raisers. Unfortunately I can give no minute practical details, not having attempted it myself, and successful hybridisers being naturally unwilling to part with the secrets of their craft. But something may be said on the matter, which may give an outline of the proceedings, and lead perhaps some amateurs to make experiments in such a fascinating pursuit.

It is hardly worth while to undertake it except on a somewhat large scale: only a very small proportion of the seedlings raised will be found worth anything at all, a good many coming single, and of those that are pretty good, few will be found to be any advance upon existing kinds. A great deal of patience will be required: it is sometimes as much as six years before a representative bloom can be got, and two or three years more at least, perhaps twice the time, may elapse before a good stock of the sort can be worked up.

Hybridising consists in preventing the pistil of a Rose being fertilised by its own stamens, and conveying to it the pollen from the stamens of another Rose. This 
is sometimes, perhaps often, done in the open by bees and other insects, and some means must be taken, by muslin bags or by working only under glass, to prevent their access to the blooms. When the stamens of the Rose to be crossed have been taken away, and the pistil is ready, the pollen is conveyed to it repeatedly for a day or two from the stamens of the other Rose by a small camel's-hair pencil, and this pollen may be stored if necessary in a box in a dry place before the operation, which should be performed with great care on a dry and sunny day.

Both plants should, of course, always be kept in a thoroughly healthy condition, and as the ripening of the hep or seed pod will take about three months even in favourable weather, it is plain that the crossing should take place early in the season.

The seeds should be sown at once, when the pod is ripe, a point that may be judged from the bright red colour and general appearance of the Rose-fruit. They should be sown in pots, in a compost of equal parts of loam, burnt earth, and sand, well-drained but pressed firm. About half an inch of sand should cover the seeds which may be put about an inch apart. The pots should now be thoroughly watered and kept in a temperature of from $45^{\circ}$ to $55^{\circ}$; but, however managed, the seeds come up most irregularly, few germinating before the lapse of six weeks, and some taking as many months or even a year or two before they grow.

Even when they have come up, a good many will soon die though the utmost care be given them; and with anything like neglect of the strictest requirements of young plant life, wholesale destruction may be expected. The first opportunity should be seized, after they are pricked out and have commenced to grow, for budding or 
grafting them on manetti or briar stocks, for it is very difficult, especially for a novice, to estimate the value of the first bloom on the seedling plant itself.

If unwilling to experiment in hybridising, an amateur may still leave a few of his earliest Rose pods on the chance of their ripening, as many did in the hot season of 1893. If these be carefully sown, as described above, a rich prize may possibly be attained (though the number of blanks is astounding), for a large number of our best Roses were raised in past years by French nurserymen in this haphazard fashion. 


\section{CHAPTER IX.}

\section{PESTS.}

INSECTS.-A large number of insects of different sorts are injurious to Roses and Rose plants, and I do not propose to treat of these entomologically but only from the Rosarian's point of view-what they are, what harm they do, and how to destroy them. As to what they are, which in ordinary scientific description would mean giving the generic and specific Latin names of each, my very slight investigations into the matter tend to show that this is no simple task, the specific and even generic names depending a good deal upon the authority studied and followed. However, a remembrance of the many Rose synonyms for the same flowers convinces me that it is not politic for Rosarians to find much fault in this direction; and in most cases what we want to know is how to keep the enemies off, and how to find them when present, and there will not I think be much trouble about their identification.

The keeping the plants in vigorous health is the first preventive measure, for it seems undoubted that aphides, the scale insect and red spider show a partiality in their attacks for plants which are in a weak and sickly condition. Against all caterpillar and grub depredations, 
late pruning, after the plants have burst into leaf, is the only prevention that I know of; when this measure has been found necessary through the earliness of the season, a considerable diminution is found in caterpillar numbers; and it is plain that in such cases the parent insects have laid their eggs on the bursting buds at the top of the shoots, and that all have been happily swept away at the pruning.

I was surprised on first looking into the matter to find that most of the common caterpillars or grubs which haunt and injure the Rose are the larvæ of moths. We sometimes see a good many flies of different sorts and sizes about our Rose shoots on sunny days in April and May, but rarely moths, though there may be, later on, two or three moth grubs on every plant. The reason of this would probably be that the parent moths visit the plants only at night or at all events in the dusk, and that they are mostly small, insignificant, fluttering insects of the most harmless appearance, and likely in general to be unnoticed.

Among the flies we may perhaps notice some active creatures, less than half an inch long, looking something like slender-bodied long-legged ants, with iridescent wings; these will be saw-flies, the parents of very hurtful grubs, and each one caught will probably save some trouble and loss. On the other hand some of the flies may be ichneumons, which lay their eggs in the bodies of caterpillars and therefore do good, but it is a safe rule to suspect all insect life; foes are numerous and friends are few, and the more free the Roses are from insects of any sort, the better they will be. Bear in mind, however, that, next to the aphis or green fly, certain small moths are the commonest enemies of Rose plants, and if any such innocent-looking flutterers 
be seen among them they should be hunted and destroyed.

Earliest in appearance among the moth larvæ is what is generally known as the black grub. This is "the worm i' the bud," the Rose grub par excellence, being the larva of a pretty and delicate-looking moth (Tortrix). It may be found in April or even earlier, the first strong pushing shoots of maiden plants being often infested. It is more like a fat brown maggot than a caterpillar, but has the power of spinning a thread with which it fastens the leaves together to form its concealment; and it can let itself down to the ground when disturbed by a line which serves for a ladder on its return. A little experience of the proper appearance of healthy Rose foliage and of the twisted and folded leaves which betray the presence of this pest will suffice for its discovery on a developed shoot, but it is not always so easy to detect it on the precious first pushing bud of a maiden plant. If any such bud should make a little start and then stop, showing no signs of growth since the last visit, it should be carefully examined and probed; in most cases the stoppage will be found to be the work of the black grub, which should be promptly destroyed.

Next in point of time, and continuing much later, is another moth larva, of the same group (Tortricina), and with the same sort of manners and customs. This is a dark green grub with a black head, and not so plump in body. It folds the leaves togeth $x$ in the same way, and generally acts in the same obnoxious manner; but it is more active; and has the power of running backwards as quickly as forwards, so that it will often escape and fall to the ground, where it lies quite still and is not easily found. 



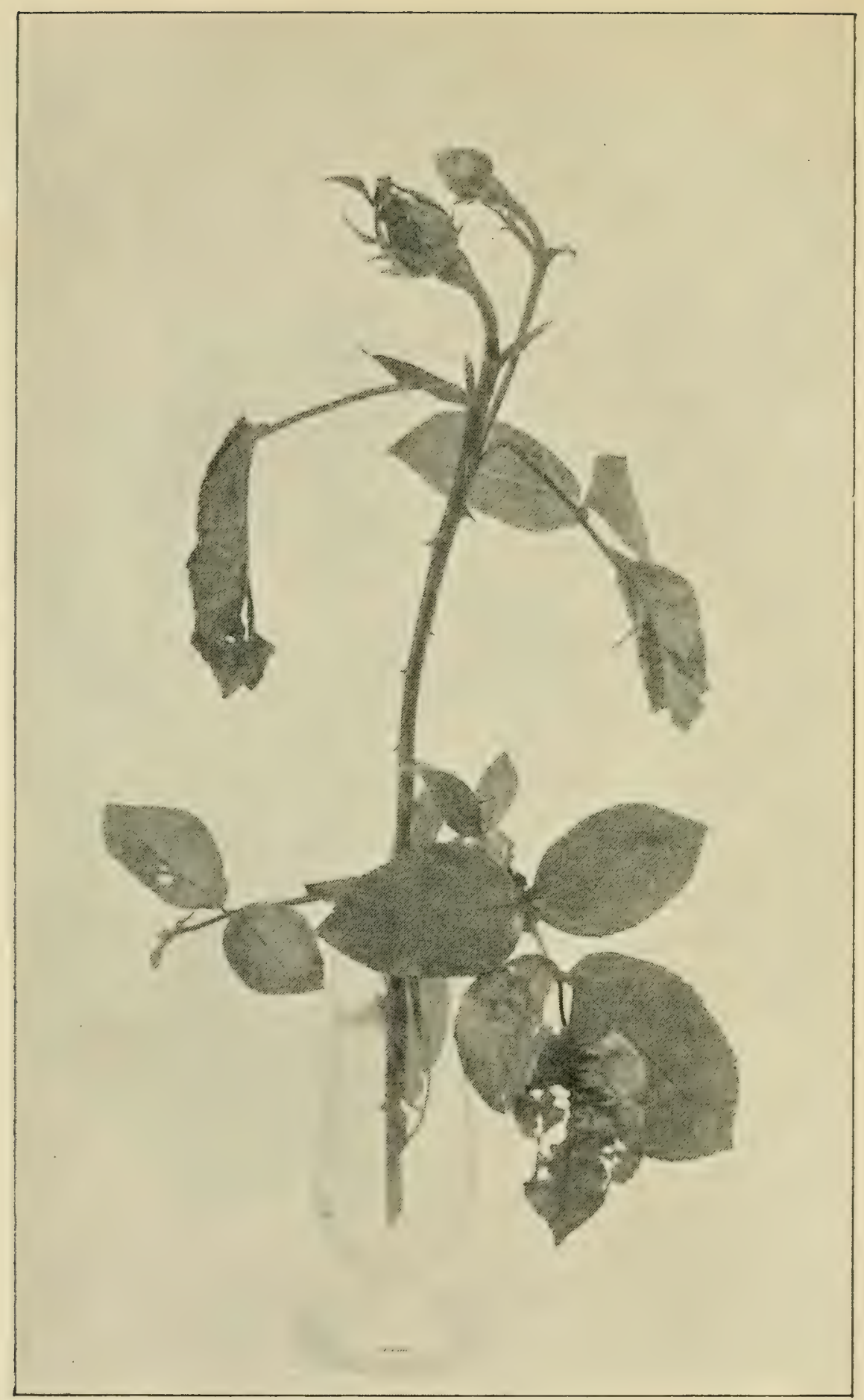

Caterpillar on Rose Shoot.

To face p. 145.

The lower leaves have been unrolled in vain, the creature having passed to an upper one, nearer the bud. 
We shall now begin to find those larvæ of moths which are more generally called caterpillars. Most of these belong to the group of loopers, or geometers, i.e. earth measurers, so called because the middle of the body, where there are no legs, is constantly being raised in a loop as the creature progresses.

Many of the geometers do not fasten the leaves together, trusting to other means for concealment, but the commonest of all, at least in my garden, does do this. There are a great many species, but the habits and general appearance are much alike. They fasten the leaves together and hide between them; and feed on the leaves but always work towards the top of the shoot and will attack the bud as soon as it is formed. It will be noticed that the caterpillar, if hatched as usual on the point of the growing shoot, keeps hold by a silken thread of each leaf as it unfolds, and thus is able at any time to leave its hiding place for a new one in a leaf spray higher up, and thus gradually to mount towards the bud.

By this means it also sometimes escapes; the distortion of the leaf spray it has just left is very conspicuous, but its new abode is most cleverly concealed, looking quite natural except that two leaves happen to touch back to back. A novice on unrolling the curled leaves would often come to the conclusion that the insect had escaped or been taken by a bird, but the experienced eye will always look upwards to the next leaf spray, and the experienced finger will always go there first, and not waste time on the decoy beneath. These caterpillars are often very abundant from the end of April to the beginning of June, and as they grow very fast they cannot be looked for too frequently.

Other geometer larve do not hide themselves or 
spin the leares together, but trust to their colours and attitudes for concealment. A dark brown one (Phygatia) simulates the appearance of a dead stick, and another, of a lighter brown with a yellow stripe, imitates a dead leaf stalk. Their attitudes are stiff and motionless, and it is astonishing how easily the searching eye passes them over though they are comparatively large caterpillars. When one is found the appearance should be carefully noted that the eye may be trained to detect another and not be again deceived, for though not so common as the leaf-rollers one of these pests will soon destroy a bud.

The larvæ of a good many other moths occasionally feed on the Rose plants, and in certain districts some may become locally special pests. The caterpillar of the gold-tailed moth (Aurifua) sometimes called the palmer worm, I have found occasionally devouring Rose leaves. This is a beautiful and highly coloured caterpillar, with bright tufts of hair; it feeds on the leaves of many sorts of trees, but I have most commonly found it on the hawthorn.

The saw-flies (Tenthredinidce) are so called from the shape and nature of their ovipositors, the instruments with which the females pierce the leaves or bark for the insertion of their eggs. There are several genera and species which feed on Rose plants, but I have found it impossible, with these as with the moths, to name them all. I am told by the Rev. J. H. Hocking, who has most kindly assisted me in the identification of insects, that there would be no room for Roses in my book if I were to attempt it. In my grounds there are two special saw-flies (Selendria), very distinct in habit, and perhaps including more than two species, which are particularly troublesonie. 
The presence of the first may be known by the singular appearance of the lower and older leaves of the plant, which seem to be semi-transparent in patches as if the colouring matter had been eaten away but the leaf not actually pierced. In such a case the upper and under sides of the leaves should be carefully examined, and good eyes will soon detect the culprits. These are small slug-like larvæ, tapering in width towards the tail, and exactly the colour of the leaves so that they are very readily overlooked. They are easily destroyed when found as they make no attempt to escape, but as they do not appear till Midsummer, when eyes are naturally more occupied with the blooms, they often escape notice. As far as I have seen they always work gradually up from the lowest leaves, and I have never known them do any harm to the buds.

The other saw-fly is also late in its visitations, and fortunately not very common, as it is I think without exception the most destructive insect among Roses that I know. The female deposits her egg in the top of the strongest shoot she can find that has not yet formed a bud, and thereby absolutely prevents it from doing so, without any remedy that I can see. The grub when hatched bores straight down into the pith of the shoot for an inch or two; the leaves do not flag till all the harm has taken place, and only a tiny black spot in the top of the shoot, which seems to have stopped growing, reveals the mischief that has been done. Cut off about an inch of the top of the stem and you will find it hollow; at the bottom of the excavation a fat maggot of a transparent white colour may be seen, and pray do not omit to execute summary justice, for it will be readily understood that this is a most dangerous 
insect whose presence cannot be detected till the shoot is ruined. Preventive measures consist in having all the shoots in bud fairly early-in this point and in many others the early man has an advantage over his competitors. I only find this grub on the latest and strongest shoots, and fancy that when once the bud is formed it is safe from this pest's attacks. It has been unusually abundant with me this year (1894), but fortunately has confined its visitations principally to the shoots of briar and manetti stocks.

Another boring grub, probably the larva of a beetle, does only incidental damage, as it confines its operations to old wood, where a large shoot has been cut off at the pruning, exposing the pith. It is most injurious to standard stocks as it hollows out the pith at the top of the main stem sometimes right down to, or even below, the shoot wherein the bud is inserted, thereby leading to the settlement of water and consequent decay. It is best, to prevent this, to smear the cut off ends of the standard stocks when planted with paint or some similar substance which will protect the pith. If, at the first pruning of the maiden standard, it is required to cut off the top part of the stock down to the newly formed Rose-head, this smearing should be renewed, as any freshly exposed pith is liable to attack.

Perhaps the best known of all insect pests of the Rose is the aphis or green fly (Aphis rosac). These creatures are formidable by their astonishing powers of increase, and it is only in multitudes that they do any harm. In their anxiety to obey the command to increase and multiply, the presence of males is postponed as a useless luxury till the season is nearly over. In the meantime each individual, as soon as full grown, which will be in favourable circumstances when about a week old, 
begins to produce young ones ready to commence juice sucking at once, at the rate of a dozen or so a day for months. In this manner it is said as many as seventeen generations may be produced before the males appear, and it is calculated that the descendants of a single aphis in one season might thus be reckoned by millions.

Strength, vigour, and cleanliness in the plants seem to be the best preventive measures. It may appear strange that vigour and health should keep off an insect foe, which we should fancy would be naturally congregated where there was the greatest abundance of sap for food, but though they are to be found on healthy plants, it will, I think, be generally allowed that the weaker ones are the most attacked.

Destructive and remedial measures are many and various. Almost every insecticide known is advertised as destroying them; and no wonder, for they are delicate creatures with no power of escape, and are easily killed. The golden rule for all pests-attack the first symptoms with immediate vigour-is especially applicable in this case. A constant look out, and crushing every one as soon as seen, never leaving it till to-morrow, is the remedy for aphides.

Of all instruments and apparatus for the destroying of pests there is nothing like the industrious finger and thumb, used in the early stages. When a zealous amateur discovers a few aphides and sends off at once to get and boil his quassia chips, according to the approved recipe, for elaborate operations on the morrow, while finger and thumb might have destroyed them all in a short time, I am always reminded of the story of the man who was vending some nostrum for the destruction of certain nameless parasites. When the "directions 
for use " of his specific were disclosed, it appeared that each creature had to be caught and a little of the powder inserted into its mouth, death following infallibly. The obvious objection to this invention was that when once finger and thumb held the victim no more aid was required.

The aphis brush, deftly used, may take the place of actual fingers where the pest has attained some dimensions: and when, through neglect, or such a sudden and wholesale attack as sometimes occurs, wholesale means must bo applied, a syringe and the quassia and soft soap mixture will probably prove the best resort.

Mr. B. R. Cant's directions for the use of this remedy are: "Take $4 \mathrm{oz}$ of quassia chips and boil them ten minutes in a gallon of soft water; then strain it, and while cooling dissolve in it $4 \mathrm{oz}$. of soft soap: to this may be added another gallon or two of water." The plants should be syringed with this in the morning or evening, or badly infested shoots may be dipped in it. Pure water should follow the next day to cleanse the leaves and shoots. For pot plants under glass smoking with tobacco is the usual remedy, but the too much despised finger and thumb should check the pest at its first appearance.

Occasionally there is a visitation of winged swarms late in the season in such abundance as to be formidable from sheer multitude. Such an invasion occurred in Suffolk one autumn some years ago; it was like a miniature plague of locusts, for they literally covered the whole of the plants on which they alighted till it seemed as if there was not room for one more. With me they lighted principally on green peas, but at Colchester a good many Roses were injured and even killed outright. Syringing on a large scale with a 
powerful garden engine is the remedy in such a case.

It is pretty well known that ants frequent the shoots which are attacked by aphides for the purpose of feeding on the sweet juice which they secrete, called honey-dew. Entomologists tell us that the ants treat the aphides as their milch cows, and even convey them about to fresh shoots; and I once found a singular instance of this. Some poor briar cuttings had been planted in an odd corner of my garden, on the chance of their doing well enough to be worth budding. They did not turn out well enough and in consequence were neglected, but I noticed in the summer a few aphides on the shoots and that there were ants in the ground. The stocks were dug up to be thrown away in mid-winter, and I then found the aphides quite underground feeding on the roots, and attended by ants. It seems a fair inference that, on the approach of winter, the ants had carried the aphides underground for safety.

Ants in themselves are a pest and should be looked on as such. I am doubtful whether they ever attack a Rose-bud unless it has been first pierced or scratched by another insect or some mischance. But they are readily attracted by the exuding sap from the smallest wound, and flock to the place in myriads, disbudding sometimes offering them such a spot in an undesirable position. When once they have thus attacked a bud nothing short of finding and destroying the nest with boiling water will prevent their devouring the whole of it-even finger and thumb fail here because of the immense reserve force behind - and, as the bud is certainly spoiled, and it will take them some time to demolish it, I generally leave it for them to keep them out of other mischief. It is better thongh to watch all ants on the 
Rose beds, especially the black variety, to their nests, and destroy them there. I have tried a preparation called Formacicide, advertised as useful for their extermination, without much success.

Frog-hoppers, commonly known as "Cuckoo-spit," are very troublesome in May in some places. The larva, looking something like an aphis, is to be found in the little patch of froth which is generally situated in the axil of a leaf. He must be dislodged and crushed, for it is plain that all that froth is made somehow from stolen sap from the shoot. Be sure you have him, for he will dodge about and hide in the hollow of the leafstalk most cleverly, and will be quite satisfied if you wipe away the froth and leave him behind.

Earuigs only do serious harm in certain seasons. In 1888 their great numbers, even early in the year, were a serious nuisance in many ways to dwellers in the country, and but for the cold wet weather they would probably have developed into an actual plague. Somebody who came to see me was incredulous as to the number to be found in the Roses, so I picked two large old withering blooms, and counted the occupants. I myself was astonished at the result: there were, oddly enough, twenty-nine earwigs in each Rose!

Bean stalks, or hollow lengths of last year's cowparsley stems laid on the ground or among the plants are good traps for earwigs; they may be blown out the next morning into boiling water, but chickens will soon learn to pick them up very quickly and be the better for them; I always blow the contents of my stalks into my garden pool, and my pet trout take care that none escape.

It is difficult to realise that earwigs can fly, but in ejection from the stalks the wings, which are wonder- 
fully folded, being nine times the size of the wing covers or cases, are sometimes blown out and can then be seen. A white earwig may be found occasionally, having just changed his skin. The female is said to sit upon her eggs; not of course that she helps to hatch them-she only remains with them to protect them from enemies, and will collect and shelter them and the young ones when scattered; I have found her coiled over her eggs in a little hollow part under the ground, once or twice. Unless in very large numbers, these creatures do but little harm to the Roses.

Certain Weevils (Otiorhynchus) are often in small collections a very destructive pest to newly budded Roses, especially standards. Anxiously each day in April the amateur watches the dormant buds of some new and precious sort to see if they are starting. At last he sees that something has been biting at the buds, but no trace of any insect is to be found. Day by day the damage increases till at last the buds, cven every bit of inserted bark, are eaten clean out of the stock, and still no vestige of the enemy itself is to be seen. This is the work of that most malevolent pest, the weevil. There may be plenty of strong Rose plants close by, but he will touch none of them if there is a dormant inserted bud anywhere where there is a chance of destroying a whole future plant. It is just the same with fruittrees, as far as I have seen: I have never observed any injury to an established tree (possibly because it would not be noticeable), but a bud or graft is sure to be attacked if there are any weevils of this sort about.

The reason they are not visible is because they only come out at night. Go with a lamp after dark to the infested places and you will soon find them, little 
brown beetles with long noses. I used to find the employment of a pretty strong pair of tweezers comforting to my feelings after many buds had been destroyed, but they will drop to the ground at a slight alarm and be most difficult to find. A white cloth spread under the Rose tree to catch them when they fall is a safe precaution.

Other weevils (Phyllobius), of the most brilliant green colour, may be found on the Rose shoots in the day time. The injury they inflict is but slight, but they should be destroyed, as they form a nuisance when present in large numbers.

Thrips, well known as a pest on many plants under glass, are often very destructive in hot seasons on dry soil. These active, tiny, black insects cannot eat much it is true, but as what they do eat is the petals of the Roses themselves they often just suffice to spoil an otherwise perfect bloom. In many places they seem to be hardly known as an out-door pest; and I could scarcely get some friends to believe how much all my light-coloured Roses suffered in this way in rusty and disfigured petals till the year 1893, when owing to the drought the nuisance was more widely felt.

I am seriously inclined to think that for Teas, at all events in my garden, thrips are the worst of all pests. From two good rows of standard Teas in fine health and growth I gathered in 1893 but one decent bloom, the petals being terribly discoloured and even distorted in every other case, and each flower swarming with the enemy.

The remedy for thrips as for red spider is moisture; but unfortunately for Tea Roses the remedy is as bad as the disease. It is probably a good plan to syringe the plants, and the buds before they actually begin to 
open, with some good insecticide. Syringing, even with plain water, will undoubtedly keep off the thrips, and if continued as long as it is safe without injuring the petals from damp, the pest will not in most seasons be found in much strength. Constant damping of the soil under the blooms would probably be useful.

A species of upholsterer bee (Megachile) lines its nests with pieces cut out of the leaves of Rose-trees. These pieces are taken so evenly, neatly, and cleanly away from the sides of the leaf, generally in a semicircular form, that the work of this insect is readily distinguished from the depredations of caterpillars. It is not very common or occurring in large numbers, and usually attacks Roses of free and strong growth. Still, it has the habit of continually coming back to the same plant for its supply of upholstery, and may be found a pest in certain places. The bee may be easily caught in a butterfly net, or when laden can be traced to its nest which can then be destroyed.

"Scale" insects (Aspictiotus) may often be found on the shoots of neglected wall-Roses. Finger and thumb or a solution of soft soap will soon remove them. Red spider (Acams) is not likely to be found anywhere but under glass, and the remedy for this is a moister atmosphere. There are other insects which occasionally do damage to Roses, especially chance visitations of caterpillars which naturally prey upon other plants, but these cannot fairly be included among the pests of the Rose.

Protective Insects.-There are a few flies and grubs which actually do good by preying upon well-known pests, and thus acting as allies and friends of the Rose grower. It is important that these should be known, for it is well that we should be able to recognise 
and spare our assistants, though the enemy is in such overwhelming majority that the advice to suspect and destroy all insect life is common and even safest in cases where the friendly forms are unknown.

Ichneumon flies form one of the strange provisions of Nature for keeping in check the undue increase of insects. These flies lay their eggs in the eggs of moths and butterflies, or in, or on, the bodies of caterpillars and grubs, and thus destroy them. They are of all sizes, some very small, and of so many species that almost every insect has a parasite of this class specially belonging to it. On shoots where aphides have been some time there may often be seen small brown motionless creatures, like aphides solidified and changed in colour. These are aphides which have been pierced by tiny ichneumon flies, whose eggs have hatched in their interior: a magnifying glass will often show a hole in the body from which the new-born fly has emerged. These brown transmogrified aphides are therefore foes transformed into friends-an effort of Nature to assist the negligent Rosarian in dealing with the aphis host. There is no need to allude further to the ichneumon flies, for only the perfect insects are generally seen, and these are not likely to be destroyed, nor, as far as I know, capable of being increased.

The well-known lady-bird (Coccinellee) in its larva state feeds upon aphides, but I am bound to say that it is not common enough to do much good. You must have a lot of green fly before the prudent larlybird will lay her eggs on the shoot among them, and the careful Rosarian will hope to see nothing of one or the other. Still the shape of the larva, quite unlike that of a Rose-eating grub, and suggesting the perfect insect by its spots, should be noted, that this small 
family of friends may be saved from the general massacre.

A bee-like looking insect (Symplurus) also subsists in the grub state upon aphides. This creature is very apt to be summarily squashed as an enemy instead of being protected as a friend. It may be known by its shape, which is something like that of a leech, being widest at the tail and tapering gradually to almost a point at the head. It is blind, and resting on its hind parts sways about the head and neck groping for aphides and when it finds one holds it up in the air and devours it leaving the skin behind. I have often seen and pointed out this larva to friends, that it may be recognised by its shape and escape destruction, for in size and colourgreen with a light central stripe-it is much like one of the common caterpillars; but I would not advise that too much reliance be placed on the efforts of our blind ally, for aphides can only be kept completely under by sharp eyes and fingers industriously and constantly used.

A very beautiful lace-wing fly (Chrysopa, i.e. goldeneyed) also lays its eggs on a strange bunch of stalks among aphides, and the larvæ when hatched despatch them very quickly.

It will be seen, however, that all these insects naturally require the aphides to be present before the female will lay the eggs which are to produce the larva to destroy them. We want to exterminate the aphis, and this is necessarily not the object of the aphis-eaters for in that case their food and occupation would be gone.

It is said that the Government of China pays a handsome salary to the court physician while the emperor is well, stops his pay when he is ill, and chops 
off his head when he rlies. This extremely sensible system might, with the omission of the last clause, be applied with great advantage by farmers and other residents in the country to ratcatchers and other professional destroyers of vermin. Unfortunately we cannot make use of it in connection with the aphiseaters, as they must perish if deprived of their usual food. So that, after all, the wholesale destruction of all insect life, though slightly irrational in that it destroys a few friends among innumerable foes, will do more good than harm to the Roses; and I am afraid it is better that a few friends should perish than that any enemies should be allowed to remain.

To take another analogy from vermin of the farm, there is one rat, most difficult to catch of all, for whose tail the farmer will willingly pay an extra price, and that is the last one. Naturally perhaps, he is often left, and before long the nuisance is as bad as ever. As aphides are, during the summer, practically sexless in the matter of breeding, it is even more important in their case to get the last one on each shoot, and if finger and thumb or any such means are employed for their destruction the search should be thorough, and the same shoot should again be examined the next day.

Fungoid PEsts.-Garden roses are subject to an unusual number of parasitical fungi, between thirty and forty having been enumerated. Happily two only are sufficiently prevalent among healthily grown plants to be worthy of description and warning, and these are mildew and orange fungus.

Mildew.-This is a pest indeed. Sometimes it appears in force all of a sudden in several places at once and spreads like a fire: the hoary leprous growth covers 
the leaves, checks the transpiration or breathing, and lowers more and more, as it increases, the vitality of the plants and the consequent spread of the roots. I gather from Mr. Cranston's book on Rose culture, the first edition of which was published in 1855, that it was not so prevalent at that time as it has since become. The greatly increased culture, and the introduction of varieties of weak constitution with soft spongy leaves, have probably been responsible for this.

It is an error to suppose that stout thick leaves are proof against mildew : if soft and succulent these are often the earliest attacked. It is the hard shiny wellglazed leaves upon which the mildew spores can find no footing; and Teas, whose leaves are rather more of this character, do not generally suffer much from mildew, except under glass, till late in the season.

Few indeed are the collections of Roses which now pass through a season without at least traces of this pest, though close and confined situations always suffer more than those which are open and exposed to free currents of the air. The amount of harm done will greatly depend upon the time when the mildew first makes its appearance. It is a bad look out to see the first plague spots in June, for if war is to be waged it must be unceasing, as the enemy will constantly reappear when it has once shown itself. When well into July the buds will probably be sufficiently advanced to escape serious damage in themselves.

The life-history of the fungus, called Oüdium leucoconium in its summer and Spharothece pannosa in its winter condition, has been thoroughly investigated, a full and interesting paper on the subject having been published in the Rosarian's Year Boot for 1886, by Mr. Worthington G. Smith. 
The spores or seed are set free from their winter resting places by the heat of early summer, and float in the air, some at least commencing to germinate and throw out roots even before they alight. Like other parasitical fungi-spores, a certain condition of the atmosphere and also of the leaves on which they fall is necessary for the actual development of the fungus growth; when these are present the first visible sign is a spot or curl on a young leaf, which is raised or depressed according as the mildew has attacked the upper or under surface.

It should be noticed, as an important thing to remember, that the mildew is always worst on the under side of the leaf, and is often found there alone. For this at once puts aside as useless the merely dredging the affected parts with sulphur, as this cannot touch the worst places; and it is evident that it must be puffed from below as well as from above, and that in all syringing with liquid the under surfaces of the leaves must have even more attention than the upper.

The first thing the mildew spore does when it begins to grow on the Rose-leaf, is to form the myceliumthe tiny white threads which are common to all fungus growth from mildew to the mushroom of the fields. This, when woven closely together in masses, forms the spawn, and then the white efflorescence is seen on the leaf.

The leaf breathes through pores on the under surface: these are choked by the woven mass of mildew spawn, which also pierces the membranes and lives upon the juices. The leaf may thus be said to be suffocated and bled to death at the same time.

At such a time-the first appearance-the time for 


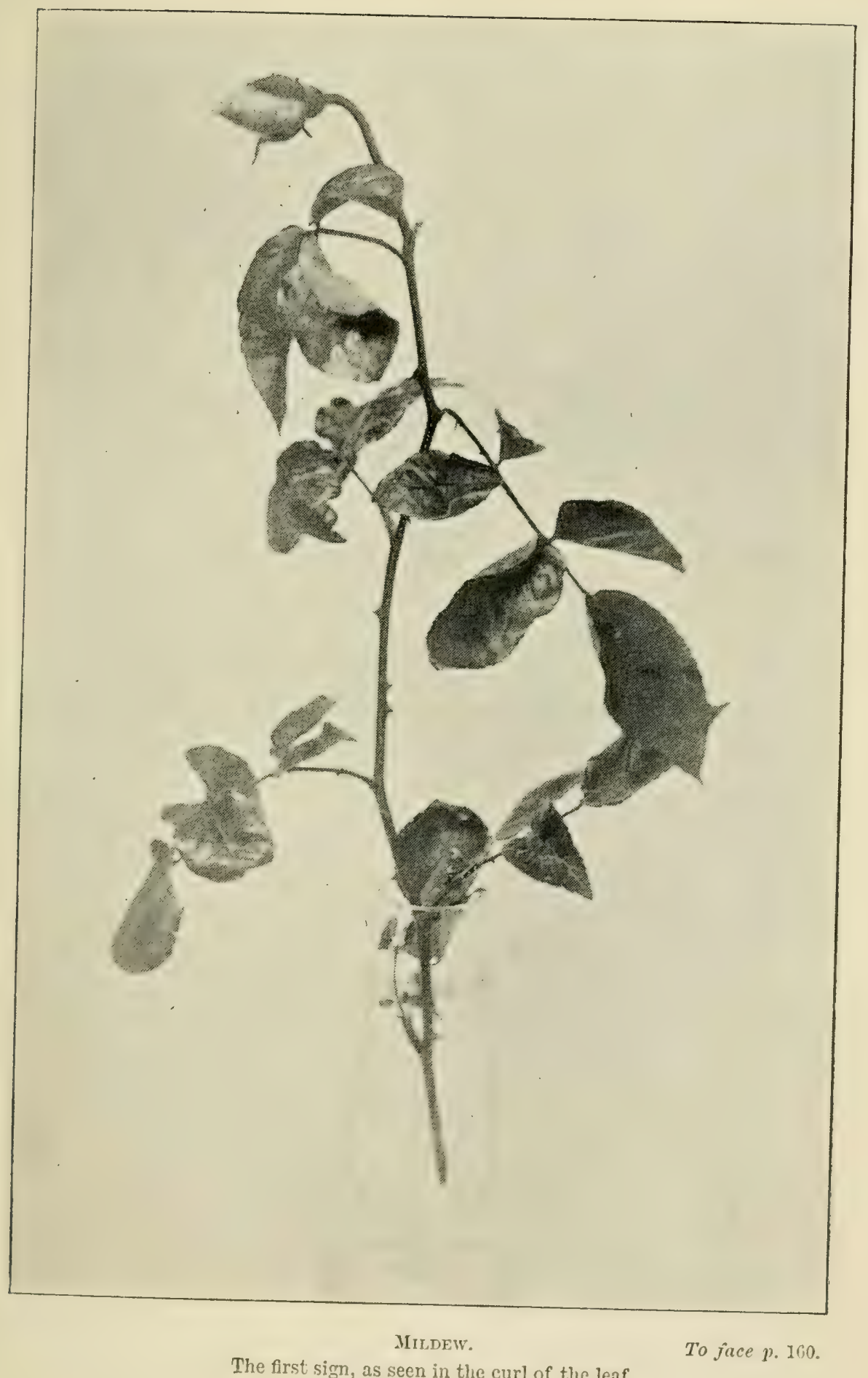

The first sign, as seen in the curl of the leaf. 

checking a pest-I quite believe that, as in the case of aphides, there is nothing to beat the human finger and thumb. If dipped in sulphur every now and then, the manipulation will be more efficacious: but even without it, both sides of the leaf can be treated at the same time and the mycelium can be destroyed before it has had time to reproduce itself, without injuring the leaf.

When the pest is advanced and whole plants covered with readily disturbed fresh spores have to be dealt with, other agents, destructive to the mildew and applied by mechanical means, must be employed. For the plant, so to speak, of the mildew very soon springs from the spawn, and fresh spores are ready in a wonderfully short time to be borne by the wind to other leaves.

On touching a shoot infected with mildew on the roof of a greenhouse or anywhere where there is plenty of light underneath, quite a little shower of dust or mildew seed may be seen to fall. Nothing need be feared from those that fall to the ground: they are very shortlived, and cannot stand much of heat or cold, dryness or' moisture. Their strength is in their appalling numbers, and their chances of falling on another Rose leaf depend entirely upon currents of air.

With the first touch of cold weather in Autumn mildew, as we know it in its summer form, disappears and is seen no more that season, only dark unhealthylooking marks on the shoots showing where the pest had spread from the leaves to the stems. In such places, and especially on the leaves which are now fallen, the mildew seeds have retired to rest for the winter, and no frost or cold, drought or moisture can harm them.

These winter places of retreat are tiny black spots, 
only visible on the dying leaves by the aid of a magnifying glass, though a higher power of the microscope reveals them as round black receptacles or boxes, each containing eight spores. In these minute black spots on the leaves Rose mildew passes its winter sleep, unhurt by all that may befall save fire or being buried deeply in the ground. The sun of the following summer will burst the walls of the cases, and set free the spores once more.

Collecting and destroying by fire the fallen leaves is thus plainly the only mode of prevention, which in most cases will probably be found impracticable, but even a partial carrying out of this plan should have some effect. It is impossible to say how far the spores may be carried by a strong wind, but probably many miles. An actual stamping out of the pest is therefore I fear beyond our reach.

Preventive measures consist first in the choice of an open situation: in a confined place the seeds floating in the wind are more apt to drop, or to be carried round and round till they do attach themselves to leaves: where there is free passage for the air, the same wind that brings them will take most of them farther on, and only a few will find resting places.

Draughts should be avoided: places where the wind comes round a corner or even through an open door are often the first to be attacked. And another point is just what we should recommend to a human body exposed to disease-germs: keep up the constitution and general health and hardiness as much as possible. Avoid drought by hoeing rather than watering if practicable: see to the food supply, and avoid unhealthy conditions.

Certain Roses are peculiarly susceptible to mildew, 
Her Majesty for instance. It is a good plan to grow these among the Teas, or, better still, by themselves, where they will not, in the carly part of the season, do so much harm by infection.

For remedial measures, keep the sharpest look out when mid-June arrives, or even before, for the first spots. Search them out, and attack them all above and below with finger and thumb, powder distributor, or syringe. Sulphur alone is good enough, if it reaches every part, the under as well as the upper side of the leaves.

The objection to the nse of a solution of sulphide of potassium seems to me to be that being merely a liquid without any greasy nature it runs off the leaves at once. A mixture of soft soap and sulphur in water is best for the syringe, which must be used if there is any wind: but I still believe that puffing sulphur from below as well as above, when the air is still and the leaves are damp, is as good a remedy as is to be found. Sulphur is the destroying agent, whatever mixture or specific is used.

For Roses under glass preventive measures will consist of great care in the ventilation. One year, by way of experiment, I never opened the ventilators at all for my Maréchal Niel, and it bloomed extremely well. Better no air at all than a cold draught when the sun is hot, I am sure. Sulphur upon the hotwater pipes is the well-known remedy, and for pot Roses I should use finger and thumb with sulphur or sulphur solution.

Orange Fungus or Recl Rust. - This fungus-pest is not so well known or so harmful as mildew; but it is more difficult to combat, either by preventive or remedial ineasures, for its growth is inside the leaves and stems of the Rose, and it is only when the spores are ready for dissemination and seatter with a touch that it 
bursts the membranes of the Rose plant and appears outside.

The life-history of this fungus, known as Colcosporium pingue and several other names according to its different stages, is much the same as that of Rose-mildew. Orange fungus has, too, the resting stage of winter in small but visible black spots on the fallen leaves, the woven mass of mycelium of spring in the leaves or leafstalks attacked, and the summer spores which proceed from it.

It can be recognised at once by its colour, which in the spring is a purple spot with a concave yellow centre on the upper part of the leaf and a convex bright orange spot underneath, sometimes red at midsummer, changing to simple black spots on the leaves which fall quite early in August. In my own garden I see very little of the yellow or orange stages, but plenty of the last one.

A considerable point in favour of this pest is that it very rarely makes its presence disagreeably and harmfully felt till the first bloom, the "season" of exhibitors, is over. August is the month of its power, and at that time whole rows of Roses of certain sorts may be sometimes seen standing leafless except for just a tuft of the youngest foliage at the top. All the other leaves, covered with the black spots, have withered and fallen, as if it was winter.

The Victor Verdier race are the most liable to suffer in this way, and in fact are generally badly off for leaves by the end of August, but a great many other H.P.s are often victims, especially the very dark ones and all that are budded on manetti. Teas are entirely exempt from it, and it is rare under glass.

Partly from the fact that the first and principal bloom 
is not affected by it and that it does not seem to do much harm to the next year's growth, and partly because there appears to be no remedy short of cutting off the attacked shoots and burning them, this pest is very little heeded by nurserymen or even by amateurs, and I confess I take no notice of it and have never found it do my summer blooms any practical injury.

It is plain, however, that the loss of the leaves, in what is but little past the middle of summer, must be a considerable check to the plants, and it seems probable that we hardly know how good and strong the Victor Verdier race (which is always more or less affected with me) would be, if it were not for this pest.

As the growth of the fungus is within the membranes of the rose plant there seems to be actually no remedy short of cutting off the orange-spotted leaves and shoots in early summer and burning them; brt I think gentle rubbing with finger and thumb with a pinch of sulphur is likely to do good in the early stages.

On light soils, especially those rich in humus or vegetable matter like an old garden, the attacks are less frequent. They are worst in a dry hot August on heavy lands which have not had much farmyard manure. It would be almost impossible to stamp out the fungus, as it is much more frequent than mildew on the wild briar. The Dog-Rose in fact seems to be its natural host, though it is sometimes found on other plants. Manetti stocks themselves are rarely troubled with it, though it often comes first on the Roses budded on it, but seedling briars often suffer much and are seriously crippled by its attacks.

I can suggest no other remedies than finger and thumb or cutting off and burning in the carly stages, and diligent hoeing, with watering if necessary, in early 
August. Exhibiturs, whose season is over by mid-July, are rather apt to neglect the hoeing and general culture when the important operation of budding is in full swing. As no real remedy is known for the red rust, and little if any practical damage is done by it to the blooms, it is not to. be wondered at that it is often unheeded as a minor and necessary evil.

Suckers may be looked upon as a pest among the growing Roses, which must at all times be looked for and eradicated. They are most common from standards, especially tall ones which are insecurely staked. These latter, when pressed by the wind, naturally throw out suckers to support themselves-a shoot goes out from the underground stem for a foot or so, then grows up and in due course sends a little root down, which forms an anchor for the original stem-two or three more on the opposite sides and the plant is held firm and cannot be rocked by the wind.

The wild stock will, however, often form suckers on well-staked standards and on dwarfs, particularly if the Rose be weakly, and underground buds on the stock were not originally extirpated. A keen look-out should be given to all plants on manetti, as only an eye well accustomed to the appearance of the growth of this stock will distinguish it from the Rose, and many a gardener has hopefully pruned great bushes of manetti for years, wondering at the absence of bloom, and ignorant that the Rose itself has been starved and killed outright.

The usual way of removing suckers is by the aid of a spud, cutting them off as close to the main underground stem as possible. This course must be pursued with any that had started the year before or that 
do not prove anenable to other treatment. But there is some risk in doing this of cutting or injuring useful roots, and even a small bit of sucker left will often start afresh.

The best plan, as with all pests, is to take the suckers in time as soon as ever they are seen, and then, not to cut them, but to pull them out. This can be done with practice in most cases, and when done it is thoroughly effectual : the sucker comes clean away right out of the socket, and grows no more. It requires humouring, and testing, and trying first this way then that, now up and now down.

When the great red shoot pushes up through the soil, plump and gross and brittle like a head of asparagus, lift it and handle it gently_. "treat him as though you loved him," as Isaac Walton said of the worm to be threaded on the hook-try to find out the angle at which it grows from the stem, and then, grasping it as low down as possible, pull so that the strain comes on the very socket, and it will generally yield. If it breaks, the spud must complete the operation.

As I write, the Rose world is lamenting one of the worst of pests - a sharp May frost. These are often very harmful, and do more injury by distortion of the just-formed buds than is ever imagined at the time. Happily, such a visitation as that of May 21st, 1894, coming as it did after an unusually early and forward spring, is not common, at all events in the Midland and Home Counties, and it is to be hoped that it will be long before we have such another.

Preventive means are possible, at all events in small collections. A little weather knowledge, with a careful study of the themmoneter, will generally give warning of the approaching calanity before sumset, and if the 
danger is great all hands should be roused and encouraged to noble efforts, even though the work must be continued by lamp-light well into the night.

The first thing to remember is that the greatest danger is to those buds that are just formed, hardly visible; forwarder buds that have got hard will stand some frost without injury, and shoots where the bud is not yet formed, even though apparently crippled at the time, will often eventually grow through it and completely recover.

Protecting material must evidently be very light, as there will be little time to spare for driving stakes into the ground to support it above the highest shoots. Anything in the shape of light muslin or similar material should be hunted out and spread as gently as possible over the plants; bent shoots can easily be straightened again, but of course care must be taken that they are not cracked or broken. The frost is not likely to be dangerous at that time of year if there is wind, as that will probably bring cloud, the best and safest of all coverings; so even old newspapers or any large sheets of thin paper may be made useful in such cases.

For remedial measures, when serious May frost has come and caught us unprotected, I would recommend, first and foremost, patience. Touch nothing at first: no one can tell for some little time, till the sun has shone warmly on the plants, how much or how little damage has been done. Then it may be plain perhaps that some shoots, utterly blackened and shrivelled at the tips, are done for ; but still I would advise the removal of nothing till such time as fresh growth has commenced.

The soil should be well stirred, and a little nitrate or some other stimulant applied; this will hasten the 
renewal of growth, and we shall then see which of the shoots that had not formed buds have been actually "stopped." Those that grow straight away again as before from the tip of the shoot are all right. Never mind some leaves having been destroyed; the shoots are young and they will "grow out" of the injury, just as a child will from a severe wound or accident. Those that are stopped, and commence growth again from the side buds, are not likely to produce exhibition blooms that year; but it is better to let the top bud grow and pinch out all the others, if most of the shoots on the plant are in the same condition, than to cut them all away or severely back, as that must involve a severe check to the roots and the strength of the plant.

I am sure it is a mistake to cut away the shoots in a hurry before fresh growth has shown how far the injury has extended. It is better to put up with browned and maimed foliage for a while than to risk destroying a shoot that may yet recover. It is always sad to suffer from not having "let well alone." A friend of mine had a fine Wellingtonia, of which he was justly proud, growing near his house. One year, to his disgust, he found that it had developed two leaders; he naturally wished to cut one of them away, but the tree was very tall, and too pliable and slender at the top to bear the weight of a ladder. He was (and is) a capital shot with rifle or gun; and having an air-gun that threw a bullet accurately, he determined to try and cut off the offending shoot with it. He rested his weapon on the sill of an upper window, took a very careful aim, and with the first shot succeeded in doing what he wanted - the false leader was cut off. Much pleased, he now noticed there was another shoot that had somewhat of an upward tendency, and would be better removed- 
he fired at that, with perhaps less care than before, and by a cruel mischance actually cut off the sole remaining leader !

To find out for certain what buds have been injured by the frost will take more time and patience. By no means remove them in a hurry; some will soon be seen to becone a paler green with white unhealthy-looking blotches on them. One or two of the worst of these might be cut open, and if the rudimentary petals are brown, the bud is rotten and would soon drop off of its own accord. Others may be tested by pinching, when the points of some will be found soft and hollow; these are of no use. Gradually thin and disbud them; take off no side buds till you have settled whether the crown bud is worth leaving or which of the others is the best; or, remove only the worst at each time of inspection till there are only two between which to choose. The lower side buds of Teas, if the parts above them are removed, will often make a good bit of growth, and practically become the main stem. Above all, remember, after a severe May frost, that the power of recuperation in the main shoots of a Rose, while they are yet soft, young, and growing, is very great indeed; but nevertheless it must be confessed that no embryo bud which is in existence during a frost that injures the leaves is likely to come to any good.

Almost as bad a pest in country districts, especially where a piece of grass field has been taken in to grow Roses to perfection, is that wretched Mr. Nobody who leaves the gate unfastened between the Roses and the field, and thus lets cows or other live stock in. In this case-experto crede-there is no real remedy, especially where there are children, short of a padlock on the gate, and a stile beside it. 


\section{CHAPTER X}

\section{ROSES UNDER GLASS}

THIs is a large subject, capable of being treated at considerable length, for if there is so much to be said upon the growing of Roses out of doors under natural conditions, even more care, skill, and experience are required for their cultivation under artificial circumstances, and at unnatural seasons. There would, however, I think be no need for such a treatise in this book, even if I were capable of compiling it. Professional Rosarians and skilled gardeners have nothing to learn from me in this matter. I write for the genuine amateur Rose grower and Rose lover who takes a warm personal interest in his favourite flowers. If he be wealthy enough to grow and force them on a large scale he will no doubt employ a man who has learned the art under more able guidance than mine; but for others I hope to give some general principles and outlines of routine which should help those who wish to make "a bit of glass" useful in the cultivation of the Rose.

The glass-house for Roses, whether it be merely a "pit" or "lean-to," or a more ambitious structure, should run lengthways north and south, so as to catch the sun in the morning and afternoon, and not suffer from excess of heat in the middle of the day. I do not propose to 
enter into any details of structure: but in a cool house, especially if the Roses are planted in the soil and not grown in pots, it is advantageous that the whole of the roof should be removable during the summer, when canvas may be substituted for the glass for a short time if necessary till the plants are hardened to exposure; and in all cases the ventilation should be principally at the top, and means should be provided in tanks and troughs on the hot-water pipes for the evaporation of moisture within the house. For early forcing a pit is best, because the plants can be placed nearer the glass and the light, and the pots may be so arranged that they can be lowered to keep them the proper distance from the glass as they grow higher. Something in the nature of an outside blind, which can be pulled up under a ridge on the roof, is a very desirable adjunct to a house where Roses are grown after the sun has attained its summer strength.

The simplest form of Rose culture under glass will consist of standards or dwarfs planted in beds in a cool house where the roof, and indeed as much as possible of the structure, can be entirely removed by the middle of June. The plants will then be subject to natural conditions and treated in the usual manner till about the middle of October, when the roof may be entirely replaced, but plenty of air may still be given on fine days. Many late buds thus sheltered from the damp which would have destroyed them in the open may be preserved in this way, and some of the thin and free-flowering Teas may continue to produce a valuable bloom or two up to nearly Christmas. The formation of these late buds may be promoted by removing all flower buds in the summer till the end of August. 
In a cool house like this nothing but protection is aimed at, but that is quite sufficient to make the plants bloom much earlier than they would in the open air. They should not be pruned before January, if there are no means of keeping the frost out in severe weather, and in the meanwhile the soil should be cultivated and cared for in the usual manner. As soon as the plants commence growing, however, they will require a good deal of attention, and some at least of the many troubles of growing Roses under glass will be experienced.

Every outdoor pest has also to be contended against under glass, and mildew, red spider, aphides, and thrips are even more troublesome than in the open. One of the greatest difficulties is the maintaining just the right amount of moisture in the air. If there be too much, mildew will probably show itself, and may soon make terrible havoc, the tender leaves being much less able to resist it than the hard foliage of outdoor Roses at Midsummer. Incautious ventilation, to dry the air, will probably increase the evil, unless the weather outside be very mild. If, on the other hand, there be a lack of due moisture, red spider and thrips are sure to appear, and may do as much damage as the mildew. To hold the scales evenly in this matter of moisture is one of the most important points of successful culture under glass, and it seems difficult to frame any special rules on the subject save those that are founded on experience with a knowledge of the dangers on either hand. The uninitiated would probably err in keeping the plants in pots too dry; syringing them three times a day seems a strong measure and likely to lead to the danger of mildew, but it is practised by some of the best growers during April and May; we are apt to forget, 
perhaps, that out of doors, in the spring months at least, the air, earth, and foliage are almost always very damp at night from dew, which much refreshes the foliage.

Insect pests of all kinds, and especially aphides, will come whether the house be damp or dry. Prevention is better than cure, and sharp eyes constantly looking for the first aphis, assisted by ready fingers to catch and destroy it at once, form the best protection. I remember, on going through a large range of glass houses, where different flowers, not Roses, were grown, hearing a boy who was evidently employed there addressed as "Mealy." On enquiring whether that was really his name or only a sobriquet, I was informed that it was his sole business to go over all the houses from end to end and look for "mealy bug." There had been a great visitation of this pest, which is very difficult to exterminate, and constantly reappears; but the boy's eye became by training and sole use so sharp at its detection, that the houses were quite clear of it before long, and "Mealy" got a change of occupation, and I hope of name.

A determination that no aphis shall be seen is a saving of trouble in the end, but there are now safe and effectual insecticides which may be used in spraying and syringing without the disagreeable and dangerous fumigation with tobacco. But in such cases it should be remembered that one or two of the enemy are sure to have escaped: a close examination the next day is necessary, and often a second application may be desirable.

When the blooms are just ready to open we may take a hint from Nature, and, remembering that Roses in the open, especially H.P.s, are far better when a dull cooler day follows after some hot weather, endeavour to shade the plants from the full sun, and keep them, if possible, 
a little cooler. If a light blind be used, or the glass roof be syringed on the outside with a mixture of whiting and milk or some similar clouding material, the flowers will be brighter, more lasting, and altogether of better quality.

Ventilation is a most important matter in all forms of Rose cultivation under glass : the foliage is very tender, and a cold draught is almost sure to bring on mildew. It is far better to give no air at all than to open the ventilators to an icy wind. Still, Roses must have air, and there will be few days when it cannot be admitted on the lee side for an hour or even less. Where the plants are grown in beds in a cool house, air should be given as often as possible, and in increased quantities as the season progresses: the final removing of the roof or top lights, after the plants have bloomed once, should be arrived at by gradual and easy stages, so that as little check as possible may be felt when all covering is taken away.

As an early second crop of flowers may be expected, and a third from some of the freest sorts, especially of Teas, it is necessary that the feeding and cultivation of the soil should not be forgotten, or the plants neglected because the outdoor Roses claim so much attention. Some of the weaker shoots may be thinned out after the first blooming, but there should be no pruning except in the winter or early spring, for one of the most prominent objects in view is to have strong dormant buds on well-ripened shoots, to prune back to in the winter and to rely upon for the production of good vigorous growth for the next season.

If the plants grown in the cool house be in pots, they should either be planted out in the open ground about the second weck in June, or plunged in coal ashes and 
mulched with good decomposed manure in an open airy place sheltered from strong winds, where the shoots, slightly thinned, may ripen and mature. In either case, they should be re-potted about October, the crocks being removed, and also as much of the surface soil as possible without disturbing the bulk of the roots. The compost generally used is two-thirds of fibrous but strong loam with one-third of thoroughly decomposed old cow manure. For the Teas, a little sharp grit and leaf mould may be added.

Roses, if well taken care of, get used to a pot life, whether forced or more naturally treaterl. 'They will get accustomed to an early spring growth, and will rest and ripen in the autumn as if it was really their winter. They should however be kept rather dry at that time, to help the ripening and check undesirable growth. After re-potting, they will of course require watering and attention that the roots may spread in the fresh material provided. By November the pots may be taken into the cool house, for pruning in January, and to be ready for a warmer house to be forced.

In forcing Roses, it should be remembered, as $\mathrm{Mr}$. William Paul so well explains in The Rose Garden, that we change all the seasons for the plants under our care. We make winter spring, spring summer, and summer autumn, and we must make autumn like winter, in that it shall be a season of rest. In making artificial seasons we must see that they come gradually as they do in Nature, and when we commence to start the plants about the New Year, we must remember that spring: nights are cold, and spring days are not very warm, so that a temperature of from $45^{\circ}$ to $50^{\circ}$, or $55^{\circ}$ from sunheat, by day, and $38^{\circ}$ to $40^{\circ}$ or a very little more by night, will be quite high enough for a beginning. 


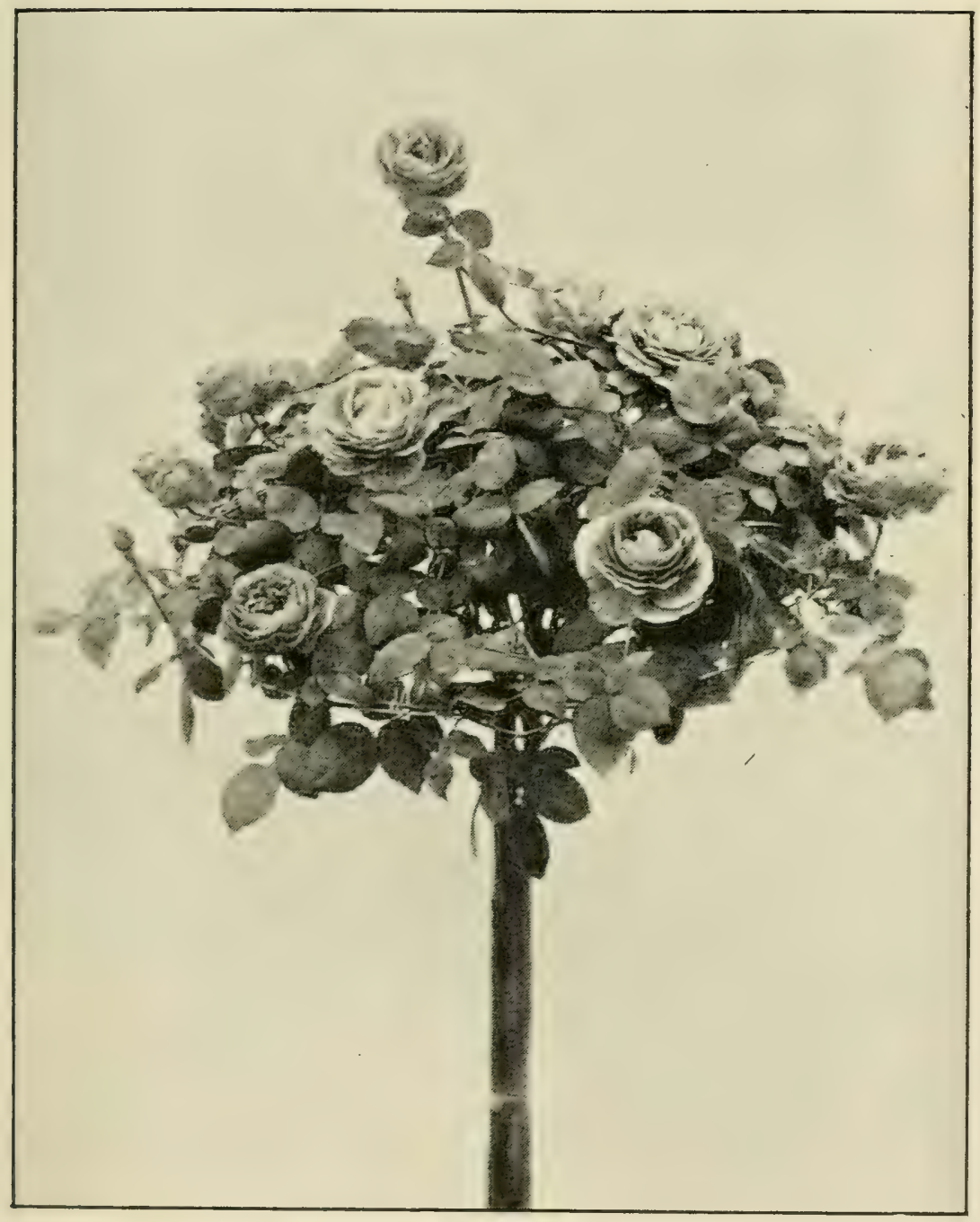

Sipecinen Standard Pot Rosfe, Ulrich Brunner H.P. To face p. 176 . E.hibiterl by Psi't is Sos, of Cheshunt. 

A commencement should be made with plants purchased in pots and specially prepared for forcing, for without the education of an autumnal rest they will not break and grow strongly in mid-winter. Several firms make a specialty of this branch of the business. The plants used generally to be grown on their own roots, but H.P.s on the manetti and Teas on the briar is now the usual practice. If the pots have holes at the bottom of the sides it will facilitate giving liquid manure when necessary by plunging, but the embedding them in the house pretty deeply in cocoa fibre or some similar material is not now generally recommended.

The plants should be pruned rather closely to well-ripened outlooking buds, and the first year, while they are young, only a few shoots well apart from each other should be allowed to grow. It is most important that there should not be too much heat at first, and that it should very gradually rise with the increase of light. Even when the buds are well formed and soon about to open, the artificial temperature should not exceed $75^{\circ}$ by day and $50^{\circ}$ at night. A further slight rise from sun heat will do no harm, nor a small decrease when the weather outside is very dull and cold.

Next to temperature, the most important point is moisture. The aim should be to keep the plants and atmosphere sufficiently damp by syringing and wetting of exposed surfaces in bright weather to avoid red spider and thrips, and yet not so damp as to bring on mildew; two syringings a day may be taken as a general rule, three in dry hot sunshine as the season advances, and in very dull damp weather only one. Some fresh air is most desirable; if the weather be at all mild, the top ventilators may be opened a little, but not on the windward side and only for a short time-mind they 
are not forgotten; and do not open the house at all to let in a wind which is really cold, or in frost or fog. Watch for all insects, especially aphis-try how soon you can get the first one, and perhaps it will also be the last.

Clear liquid manure may occasionally be used for the feeding; as the plants increase in vigour, do not nake the food stronger, but give it gradually a little oftener, with always pure rain water, which should never be below the temperature of the house, between each dose. Very strong ammoniacal liquid manure is kept by some growers in troughs on the hotwater pipes, and it is generally believed that the plants benefit through their leaves from the gases thus diffused in the air.

For a succession, the simplest plan is to bring in fresh plants during the first few weeks, if there is only one house. As the Tea Roses, and those that are sensitive to wet, begin to show the petals, some care should be taken to aroid syringing the blooms, but the house must by no means be allowed to become dry: the paths and walls should be damped three times a day in sumny weather at 8 A.Mr., noon, and 5.30 P.M. : and there should be at least an hour or two every day, at the time the buds show colour, when air can be given. If there is also a cool house, those plants, especially the H.P.s, which are nearly opening their blooms, will show better and more lasting flowers if they can be removed to it, or at all events shaded from bright sum. A slight fall of temperature and a little less light are always beneticial for the actual blooming, but of course the decrease of heat should not be great.

There is considerable danger in over-watering forced Roses in pots when the growth is young: and the flower buds are forming, for " lamping oft" is even a worse misfortune tham milclew. Talpping the pots with a knob- 
stick or something similar, to judge by the sound whether it be wet or dry, is a well-known device, similar to that of the wheel-testers on railways. A clear sharp sound indicates dryness and soundness, and a duller one damp or fracture.

After blooming, summer-Howering Roses, if any such have been forced, may be removed at once to a cool pit or some other shelter and hardened off ; the others may be shifted to a cool house, and will give another useful crop of flowers in April and May. If there be no other house, and warmth is still desired to be kept up in the forcing house, some means must be resorted to for gradually hardening the plants off till they can be finally removed out of doors. Then, instead of all trouble being orer with the pot plants for the year, comes as important a time as any, for next year's growth and Howers will depend rery much upon the strengthening, maturing, and ripening without breaking, of the dormant buds at the base of the shoots which have flowered.

The pots should be plunged out of doors in cocoa fibre or some similar material with a bottom of coal ashes, and a top) (lressing in each pot of good decomposed manure, in a sheltered position but where they will get some sun: and here they should be kept thoroughly clean and be by no means neglected, but encouraged as much as posisible gradually to get into a condition of rest, not growing much, but ripening and hardening the wood. They must be frequently examined for aphides, and should have only sufficient water to keep them in health, not so much as to encourage them to grow. If they have already bloomed twice, or in any case if it does not excite the dormant buds lower down, flower buds should be picked off.

About the end of September or the beginning of N 2 
October they should be re-potted : they must be turned out of the old pots, the crocks or charcoal drainage removed, and also as much of the surface soil as can be got away without disturbing the main ball of roots. Thoroughly clean pots should be provicled, a size larger than before if necessary, and the loam in the new compost should be as fresh as possible, that from an old pasture being the best. The new drainage, whether crocks or charcoal, and everything else should be fresh, clean and sweet, the plants potted very firmly, and then plunged afresh in a similar position out of doors. They will require a little more water after the potting but if the operation has been delayed till the season mentioned, though many fresh rout will form in the, new soil, no growth will be made except at the tips of the shoots, where it will do no harm. The pots may be removed to some cool shelter when there is danger of frost or snow, and about Christmas the earliest plants may be pruned and brought into the forcing house for another season.

To have Roses in bloom in Norember and December the plants in pots should be so managed and arranged as to form a crop of flower-buds out of doors in October. Thin-petalled, readily opening sorts should be chosen, especially the free-flowering thin Teas, such as Safrano; but some of the freest, semi-double H.P.s will also answer the purpose. These should be lightly pruned about August, and supplied with more water: when the buds have formed in October the plants should be left outside as long as possible, and when brought into the house ought to be kept quite cool, giving plenty of air whenever it is mild enough. Keep the house rather dry, and the buds will open at any time by the application of a little gentle heat, or even without it. 



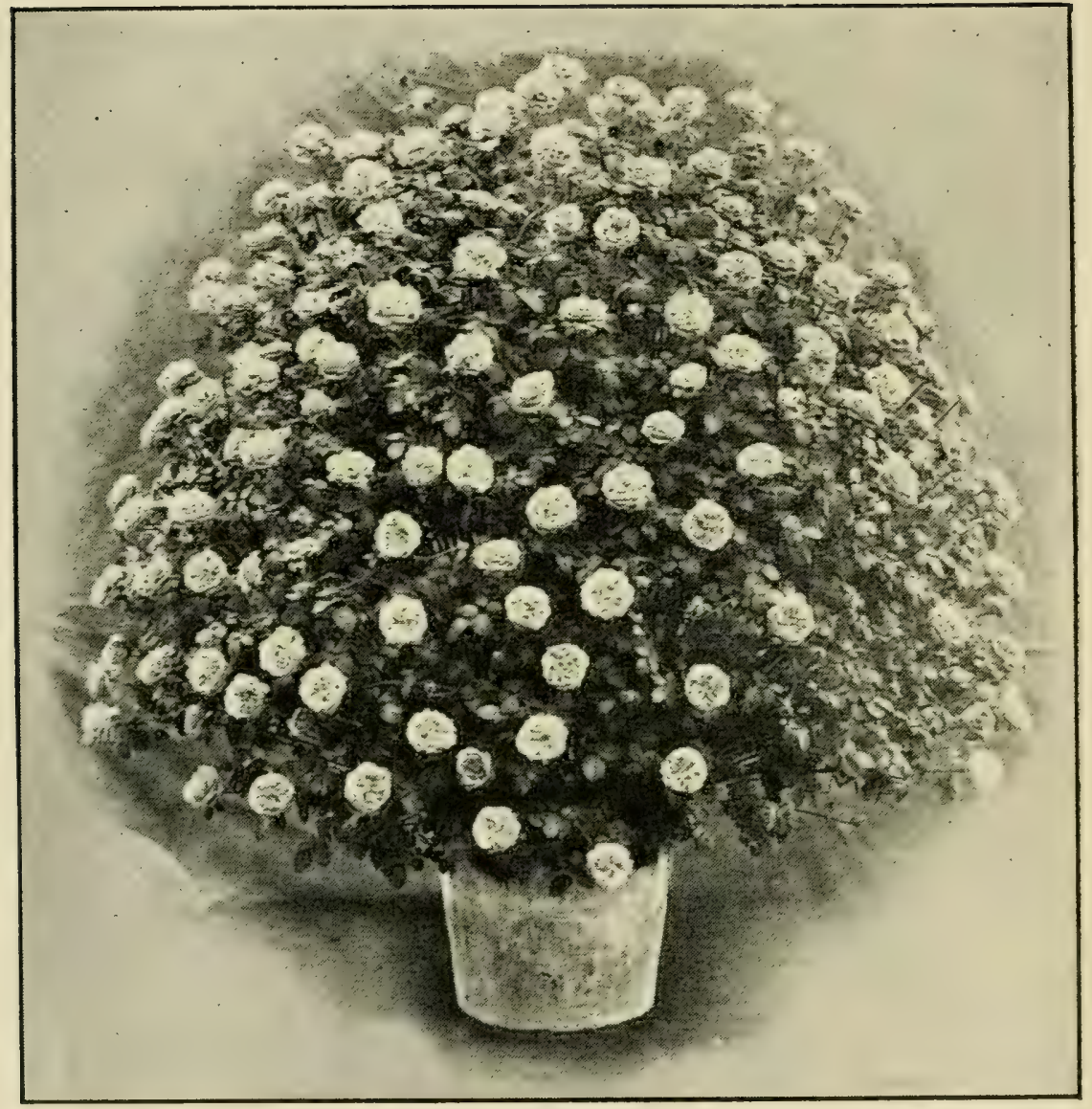

Specimen "Dwarf" Pot Rose, Paul Perras, H.B. To face $p .181$. Exhilited by Mr. C. TURNER, of Slough 
Few amateurs will care for the trouble that must be incurred to produce the wonderful specimen pot plants which are exhibited in May by some of the professional growers. These are generally summer Roses, Charles Lawson H.C. being a favourite variety for the purpose, as this group has the habit of bringing the majority of its flowers to perfection at the same time. Such a pot plant, eight feet high, seven feet through, and with between 300 and 400 expanded full-sized blooms upon it at the same time, is a grand sight, but an immense amount of labour, care, and time will have been expended to bring about such an astonishing result. There is no real difficulty in the matter, as the summer Roses grow freely after the bloom is over, and patience and care for several years in disbudding and tying out the required shoots at the proper distances from each other is all that is required. I have been told it will often take a man three days to tie out and wire one of these big plants. The lower shoots are given sufficient lateral direction by long ties fastened to wire surrounding the pot: and these are pruned first to give them a start over the central upright shoots, which would otherwise get more than their share of the sap. A pyramid or cone is the usual shape aimed at, but sorts of short stiff growth are sometimes trained in globular form. Onesided plants, having the back flat without growth or bloom, look well where the pots have to stand against a wall.

For the pruning and training of Maréchal Niel and other similar climbing Roses under glass, see Chap. VI. (p. 95). In this case, if the roots run in the outside border, little or no syringing will be required, and as a consequence there will be less necessity for fresh air in cold weather. 


\section{CHAPTER XI}

\section{EXHIBITING}

The instructions hitherto given have been meant to show how to grow Roses in the best possible manner, so as to produce the finest blooms. There are probably few who will go thus thoroughly into the matter without desiring sooner or later to put their care and labour to the test by showing, in friendly rivalry, against their brother Rosarians. The true Rose lover may perhaps enjoy and appreciate all the winter and spring work simply from his personal devotion to the Queen of Flowers. But if he visits Rose shows he will soon be anxious, I think, to get an important judgment upon his own blooms, and see what rank his much-cared-for plants can take in the world of Roses.

We may perhaps hear a man say, "Oh! I don't exhibit, but I can assure you I cut some very good Roses from plants under such and such a treatment" (perhaps from plants on their own roots, from cuttings). In such a case, without throwing the smallest doubt upon his veracity or bonc fides, we are apt to wonder what he considers "very good" Roses, and unless his blooms have been seen by a competent and impartial judge, or, better still, actually tested at a show, the 
assertion loses weight, as his stindard of excellence may be a low one.

It is odd to notice how generally those Rose lovers who do not exhibit are set against Rose shows, and have hardly a good word to say for them. According to these critics, the least lovely of Roses are most shown and encouraged, the manner of exhibition is faulty, the grace and beauty of the flower's are lost, and the public taste is generally led astray. Even the accusation of ignorance is sometimes laid at the doors of men who have made the Rose the study of their lives, though such a charge naturally defeats itself.

It is not unlikely that some good has been done to the Rose and to Rose showing by such critics. Any cause is purified and strengthened by a little healthy opposition: there may be a grain of truth here and there in the sweeping charges made, and there is no doubt that a mania for exhibition does sometimes tend to the destruction of good useful types, and to the setting up of unnatural and undesirable ideals.

It is, perhaps, owing to a reaction against show Roses of approved form that there has been of late a good deal of interest taken in what are called "garden" Roses. Many of these varieties of "the common or garden" Rose are merely old sorts which have been superseded as florists' flowers, but are still cherished by some from sentiment and love of the old-fashioned, or memories of childhood.

An immense number of new Roses are put forth every year, and those few only survive which stand the test and prove superior in comparison with existing varieties. A very small proportion indeed of those thus failing in the struggle for existence are retained as garden Roses, only those which in colour, habit, growth, or 
freedom of bloom are superior or very different to those already known. Yet most of the modern failures are probably much better than the old-fashioned garden Roses which still have their worshippers, thus proving that sentiment and affection rather than merit cause them to be still recognised.

This is very likely as it should be: it is well to see those old Roses of forty years ago, if only to realise and be thankful for what we have gained: the grand H.P.s and Teas of the present day have certainly no cause to be jealous of the old favourites, or to dread comparison with them; and the most inveterate exhibitor will rejoice that the Roses which so charmed our fathers are still loved and admired by some.

It will be found that more or less serious objections may be urged against all exhibitions, where a "fancy" or fashion decrees arbitrary points in the things exhibited apart from their useful qualities. Thus it has been said of dog shows that breeds notorious for their service for sporting or other purposes are not judged or awarded prizes for their useful qualities, but for fashionable points of colour and shape. And it is also alleged that certain varieties of poultry have deteriorated because they have been judged by their feathers and other useless points to the detriment of their capabilities of furnishing plenty of good eggs and chickens.

On the other hand, fewer complaints are made against shows of fat or dairy cattle, because there is no "fancy" here, and the animals are usually judged according to their market value for use. And if it be said that there is a "fancy" in Roses, and that the very term "showRose" proves it, we must see what are the desirable and useful properties in Roses, and whether the system of exhibitions favours or hinders them. 
Beauty and fragrance are the charms of the Rose. It may be said beauty is a matter of taste, but, as tastes differ, for the purposes of competition ideals must be agreed upon and rules laid down. In this matter I think the show system of the National Rose Society has laid down correct canons of beauty. Unhappily, fragrance cannot be accounted for in competition at Rose shows. It is plain that among such a number it could not be tested, and that rules for estimating the amount and quality of fragrance in each bloom could not be satisfactorily framed. Individual taste will also differ much in the appreciation of it, the scent of Maréchal Niel, for instance, so highly estimated by some, being not a pleasant one to my senses.

In fact, the judging of fragrance would have to be a matter for experts, properly trained, as tea-tasters are, for the part. Such persons, who have made the matter a special study, tell us that there is no scent of tea among what we call Tea Roses, but that some of them, like Maréchal Niel and Madame Bravy, have a fruity odour resembling the raspberry, that Safrano has the odour of pinks, the Macartney Rose of apricots, and the Dog-Rose of mignonette. They even say that some Roses have a disgusting scent, the flowers of certain varieties of the Sweet Briar (of all Roses !) developing a mixed odour of coriander and a certain horrid parasite which shall be nameless: I gather these and a few other items as to Rose scent from a pamphlet callerl Phodologia, just issued by Mr. J. Ch. Sawer, F.L.S., of Brighton, which will be found useful to those interested in the scent of Roses, especially from a commercial point of view.

So it is a charge against shows that scentless Roses are encouraged, and fragrance, a chief part of the dowry 
of the Rose, is ignored. But there are really not many scentless Roses, and I think fragrance is sometimes over-estimated. Would Baroness Rothschild have attained no fame without exhibitions? or is it fragrance which lifts the Rose so high above the mignonette and the violet?

Another common complaint against exhibitions is that prizes are given for mere size, and not for beauty. This is not correct: size has its influence, all other things being equal, as it rightly should, a Rose which is good in all points and large being naturally better than one which is equally good but smaller. "But," it may be said, "we hear of so-and-so getting the first prize because his blooms were 'heavier.' Are Roses judged by weight like dead geese?" The answer to this is that "heavier" means greater thickness and solidity of petal; and it will not take long for a young Rosarian's eye to become sufficiently educated to prefer the thick fleshy petalled and consequently lasting Rose to one that is formed of more flimsy material.

Another complaint will probably be that show-Roses are all so formal and regular, and that négligée forms, often so truly artistic, are not appreciated. The answer to this will be, that Rose shows are held to test cultivation, as to who can grow the best Roses, rather than decorative powers, as to who can show them the best. A large advantage is held, as it is, by those who are gifted in the power of display, especially in Tea Roses, but if all the merit were in the showing there would be small encouragement for the cultivator in his yearly round of work.

And also that as the judging must be accurate and by strict rule, so only those formal styles of beauty which can be judged by rule can be held admissible. 
It is very unsatisfactory to enter into any competition where you do not know precisely by what rules you will be judged. Classes for artistic display in bouquets, baskets, and so forth have been attempted by the National Rose Society, but for the reasons mentioned have not been found generally successful.

Thus the charges against Rose shows are that they encourage size and formal beauty, and care nothing for fragrance or artistic elegance. Even if these accusations were unanswerable, which I do not think they are, it must be considered whether exhibitions have not done very much for raising the popularity of the Rose, for the increase of varieties not only of show sorts but of every description, and for making England the true home and centre of the national flower?

The large and rapid growth of the trade since Rose shows were established would be sufficient answer to these questions. Where ten Roses were at that time raised by nurserymen and grown by amateurs, a thousand would now be a more likely figure: and whereas such a thing as making a living out of raising Roses alone had not then been heard of in England, and the number of Rose nurserymen of note might be counted on the fingers, there are now three large and flourishing establishments for the growing of Roses in one English town, two of which devote themselves solely to this object.

It cannot be doubted that the popularity of the Rose, and its greatly increased cultivation, have been much fostered by Rose shows and by the National Rose Society which encourages them. With a possible exception in the matter of fragrance, I do not think that exhibitions have fostered any undesirable qualities in the flowers: it is true that some modern show 
varieties are weak and difficult to grow, but they are often so lovely that it would have been a great loss if they had not been known: and even the few scentless forms would, I believe, have found a footing on their merits.

A young exhibitor should begin by making sure that he knows a good Rose when he sees it-that he is well acquainted with the types and ideals which authority, as represented by the National Rose Society, requires. And the first thing to be learnt is that "form," the shape of the Rose, is the most important point of all.

In Latin, "forma," shape, is "beauty," and "formosus," shapely, is "beautiful." Form comes before colour as drawing before painting. A tumble-down cottage or a lopsided spray may be picturesque, but it is only formal beauty that is amenable to the strict rules necessary in competition. The "tumble-down" style of beauty may be admired in the garden, but cannot be admitted to judgment at Rose shows. A Rosarian soon becomes accustomed to look upon form as the primal beauty of the Rose, and to regard colour, though necessary, as a secondary consideration.

The N.R.S. Catalogue contains figures of four types of form in exhibition Roses-the imbricated, globular, globular with high centre, and the cupped. Originally there was another, the flat shape, the type given of which was Souvenir de Malmaison. This was rightly dropped, as every one must admit that the flat plate-like form was inferior. Of existing show-Roses Marguerite de St. Amand most nearly perhaps approaches this shape, which somewhat detracts from the merits of a fine Rose of beautiful colour.

The cup-shape will probably soon be expunged also, as it is difficult to find a true type of it or make a 
definition of its requirements, and in all other types a hollow centre is regarded as a disfigurement. The type given in the N.R.S. Catalogue is Baroness Rothschild, but this cannot be called a cupped form, and if it was it would be considered defective. The cupped form is unknown among modern Roses because the very opposite, a high centre, much more beautiful as well as more easy to attain, is now looked for. I can only remember seeing one perfectly cupped bloom, and that was a specimen of Anna de Diesbach H.P., a superseded variety. Løelia H.P. and Coupe d'Hébé H.C. were also cupped forms, but very rarely perfect.

I find, however, that some look on the cup-shape as the outward form only, i.e. the profile as viewed from the side without reference to the interior. In this case, the shape of a chalice would probably be meant, of which Marie Verdier H.P. might be taken as a type. In favour of this view, some good fellows would maintain that a cup is in its best form - " the most perfect phase of its possible beauty" - when it is not hollow but " full " to the brim: some festive souls might even add that a high centre, if possible, would be their ideal. But this meaning of the word "cupped" would be different from the general one in scientific and botanic nomenclature, where it always I think represents a hollow and concave form. Baroness Rothschild does not secm to me to represent either of these views.

Little difference can be found between the types called "globular" and "glubular high centre" in the N.R.S. Catalogue, and a great many phases of the usual forms of Roses are meant to be included under these definitions. Madame Bravy, the nearest approach to the "incurved" form of chrysanthemums, and in a less degree Violette Bowyer H.P., would be 
types of the true globular form, gradually merging through several varieties to the "pointed" shape, so much admired, as in Catherine Mermet and Comtesse: de Nadaillac, Teas, and in General Jacqueminot and Fisher Holmes, H.P.s.

The "imbricated" form, which is of equal estimation with the "pointed," implies that the petals are regularly and thoroughly reflexed upon each other, with a "pip" in the centre, like the flowers of a camellia. A. K. Williams and Le Havre H.P.s are good examples of this shape. There are several gradations also in this form, some being half-imbricated, and some with the outer petals only reflexed. Madame Cusin is a form which would be imbricated, but that the petals, instead of lying close, stand apart from each other.

Variations of the above standard forms may be found in Madame de Watteville, which might be called the "winged" or "butterfly" rose, an addition to the pointed shape being found in the long outer petals which project as wings: and in Innocente Pirola, where the petals radiate away from the centre point in the perfect form of the whorl of a shell. But a regular shape, with fiul somewhat high centre, smooth circular outline, and perfect arrangement of petals is necessary to every form of a good Rose.

The yearly round of care for Rose plants intencled for Exhibition purposes will begin with a strict attention to the rules of planting, winter protection, and manuring. Pruning for exhibition has already been noticed (p. 93), and it must be really severe to ensure strong growth. In the subsequent thinning of the buds and shoots he who would win cups and first prizes must "harden his heart," and see that he does not leave too many, 
however strong and healthy they look. Before rubbing off the others the selected young shoots should be carefully examined to see that they have not been injured by frost or grub, as the hopes of the plant will now depend on them.

Even among dwarf cutbacks, stakes should be supplied to support all Roses with flexible stems such as Earl of Dufferin and Marie Bammann among H.P.s and most of the Teas. A sufficient number of bamboos or other stakes of various heights should be stored in handy corners ready for this purpose.

As a general rule, all buds but the centre or crown bud should be removed as soon as possible, and when the wood buds push, further down the stem, these also should be rubbed out. A quill toothpick or knife point is sometimes used for the removal of the tiny buds as soon as they can be distinguished, but finger and thumb will soon get expert at the work and do it mechanically.

Be careful about delegating this operation to inexperienced hands. I remember a trade exhibitor telling me that he once thought he would employ some women at it. "I want you," said he to them, suiting the action to the word by taking the cluster at the end of a shoot and rapidly removing all but the centre bud, " to take off all these buds like this." They set to work with a will, and when he came back some time atterwards to see how they were getting on, not a single bud of any description remained on the rows which they had devastated.

The rule has its exceptions: there are certain Rosen which are apt to come coarse, or too full, so as to be too long in opening if they are over firecly supplied with sap. The treatment in these cases must be modified, the small buds being gradually destroyed, or one or more 
left on till the end. Only experience, a good knowledge of the habit of the variety, and a regard to the strength and number of shoots on each plant and the character of the weather can guide the grower in this most needful regulation of sap supply. If the season be hot and dry more buds may be taken away, as the Roses will open easier and the natural supply of sap will be less and more quickly assimilated.

The same caution must be exercised with maiden plants: some of the weakly grower's will give the best blooms if only a single stem with one bud on it be left. But many would come coarse or deformed under such treatment: and in these cases if there be only one maiden shoot, one or two, according to the weather, of the lower wood buds should be allowed to grow out, and they may form perhaps almost as good blooms as the older one.

The central bud should be curefully examined before it is entrusted alone with the sole responsibility of the shoot. Any insect perforation however small, or any unusual appearance or sign of deformity, should cause the dethronement of the crown bud at once, and the election of the most perfect of its two or three companions in its place. Even with the utmost vigilance many a fine bud will be tended and cared for and only found to be malformed at the very last when it should be in perfection and ready for show.

Where there is still a choice of buds later on when the first signs of colour are visible, signs of malformation may often be detected in an uneven appearance of the green calyx enclosing the petals. If this is irregularly disposed so that more colour shows on one side of the bud than the other there is a strong probability of there being a deformed arrangement of the petals, 
leading to the bloom being "divided" or "quartererl," a very serious detriment to the shape of many of the finest blooms. There is no remedy: another bud, if possible, should be chosen in its place. An exception must be made in the case of Madame de Watteville, whose buds are curiously wrinkled to enclose the great wing petals.

Before the buds begin to open measures must be taken to shelter the delicate blooms from rain and sometimes from sun. Almost all the Teas and certain of the H.P.s are liable to a good deal of injury from rain and sometimes even from heavy dews. Of the many kinds of protectors which have been tried, from old umbrellas to strawberry punnets and tin or glass shades, there are probably none better than the cones made of Willesden waterproof paper which are now manufactured and sold in large quantities.

My stepfather, the Rev. C. Ward, of Maulden Rectory, Beds, an excellent florist who died in 1879, was I believe the first to use this material for the purpose in the shape of cones. I introduced the subject to the trade, but I have still one made by Mr. Ward, of as good material and shape as those now turned out, though considerable improvements have been invented in the mode of suspension and fastening. In placing the protector over a bud great pains should be taken to see that both are firm and not likely to be moved by the wind. Severe gusts often accompany thunderstorms, the protectors offer a good deal of resisting surface, and the bud if chafed while it be wet is sure to be spoiled.

The protectors should be raised or removed when the rain is over, particularly if the bud is close to the ground, as they check the evaporation from the wet 
soil and keep the bud in a damp state. Pendulous Teas on dwarfs are apt to be splashed with mud in heavy showers, and this forms an additional recommendation for standards for such varieties; no protection short of a universal mulch is much good, but when all Roses are wet, simply dipping a splashed Tea face downwards a time or two in a pail of clear water has often marle it look at least as well as its fellows.

I believe there are very few Roses which are benefited by being shaded from the sun, except to preserve the colour. Exposure to the sun undoubtedly takes the depth of tint from almost all Teas, making them paler: but still they rejoice in the sun, and it is only in a very hot and dry season that we can afford to keep it from them. There secms to be little effect in shading to prevent the 'burning' or browning of the petals of dark H.P.s.

Papering the buds, that is, wrapping them while yet undeveloped in cones of white paper, has sometimes a very good effect with the pointed forms of Teas, making the bud grow longer and preserving the richness of colour. It only answers in quite dry weather; if rain comes, the paper must all be removed at once or the Roses will commence to rot.

Boxes of the approved shape and size, with Foster's tubes and wire supports, can now be readily purchased, saving much trouble with the village carpenter. Strength must not be sacrificed to lightness, as heary men will not scruple to stand on them in railway or horse vans. The corners should be bound with iron, and there should be some readily distinguishable mark on the lid of each, a white bar or star or something of that sort, so that each man can count his own boxes in transit, or find his own lids easily at the end of the show. 
They should all be made exactly alike, so that lids and trays are interchangeable. Spare trays pierced for trebles should be provided, and a large deep box for spare blooms is very useful but unwieldy. The boxes all ought to be of the same size, that is, there ought to be a regulation size for $12 \mathrm{~s}$ and another for $24 \mathrm{~s}$ and so on, but as long as there is not, and others take advantage of the fact, smaller boxes with the tubes set closer together should be provided for Teas and oceasions when the blooms are small. Setting the Roses clower together somewhat conceals their want of size.

The providing a sufficient quantity of good moss for placing on the trays between the tubes is sometimes a difficulty when there are many boxes to be prepared. The ordinary moss of hedge-row banks is generally used, but it is sometimes difficult to find in a gravelly district. The north side of a clayey railway embankment is generally a good place. It should be taken up cautiously so that it may be placed root downwards and not half of it upside down, in the boxes, and will require the weeds and grass to be picked from it.

A much more effective moss is that which grows on old thatch or even roof-tiles, but it is apt to lose colour. If a water-mill or lock gates be in the neighbourhood, there is often delightfully fresh moss to be found on the old walls near the water. These sorts have a far more velvety appearance than the first kind mentioned, which sometimes looks little better than badly made hay.

The trays when trimmed with moss should be watered occasionally and kept in the shade. But a good overhauling is desirable before a night journey. In one very dry season my mosser boxes had been kept, in the shade and duly watered, with the result that, 
two huge slugs each as big as my thumb came attracted by the damp, and concealed themselves either in the moss or underneath the trays. It was either in the night journey or during the very early hours of rest at the Crystal Palace that one of these brutes crawled out and ate away just the top of my very best H.P., a large specimen of Her Majesty.

Boxes and all are ready-to-morrow is the day of the show-when shall we cut the blooms? The distance and the convenience of trains will almost answer the question, for a start at three or four o'clock in the afternoon is by no means unusual for those who live at a distance from main lines, and want to show on the other side of the country.

It used to be always laid down that the morning of the show is the time to cut, and that those who are near enough at hand to do this are at an advantage. Modern instances, and especially I think the superior staying power of modern Roses, have considerably modified this view. If the show is within driving distance one would naturally cut in the morning, but very small advantage, if any, must be expected over those who have come from a distance and had to cut over-night.

I used often to get up to cut very early in the morning, an hour or more before the mowers made their appearance in the neighbouring hayfield, but have long ago come to the conclusion that unless one can cut after six o'clock in the morning it is even better to do it the evening before.

I soon noticed that about six o'clock a change came over the Roses, every one taking, so to speak, his day's step forward, and that many fine lasting blooms altered and aged as much in half-an-hour about that time, 
whether cut or not, as they would in the whole of the long summer day to follow. So, if it is possible to cut after that hour and yet be in time, we may be glad to do so, and can choose blooms a stage in advance of those we should have cut over-night. But I believe it to be just as well and perhaps better as getting them in safety before a chance shower, to cut at from four to seven o'clock the evening before, rather than at four or five o'clock in the morning.

Begin in good time: it is better to start at two or three o'clock in the afternoon, having cold water in the tubes and the boxes in deep shade, than to be hurried at the last. There are several H.P.s too, Horace Vernet and Le Havre for instance, which shut up their petals towards night, and though they will open all right next day it is difficult to choose the best specimens when they are closed.

Roses should always be cut with strong sharp scissors; if at any time a stranger is allowed to cut blooms from your plants, forbid the use of a knife or damage by the breaking of a shoot is sure to be done.

Perhaps it is best to commence with the Teas, as these are most lasting, and require longer time for selection. A large number of them hang their heads down, and a great many must be lifted and examined, while among the H.P.s few are so pendulous as Marie Baumann and Earl of Dufferin. Be sure that the examination and selection is thorough: I have gone off once or twice at least without a good Tea Rose, overlooked because it was hidden under some protection.

Cut the stems long enough : they must be set up high when they are shown, and it is very annoying to find that a good bloom must be set lower than the others to keep it in the water. It is a shock for a precious little 
plant of Comtesse de Nadaillac to cut away so much wood, but this is the hour of the Rose's trial and wouldbe triumph, and now if ever it must be prepared to make a sacrifice.

Some expert cxhibitor's do little arranging, choosing, or setting up at the time of cutting, but, putting a sufficient quantity of their best blooms into the tubes, leave all that for the place of exhibition. A beginner, however, had better wire and set up his best Roses at once as he cuts them, taking others for spares and arranging them all afresh at the show.

Wiring with Foster's supports, like all mechanical operations, should be learnt by watching an old hand; it is a very different business now to what it used to be when we had to tie the stems in two or three places to a small stick or simple straight wire. Plenty of spare supports should be taken to save time in undoing discarded blooms at the show.

A beginner should label each bloom as he brings it in, and it will always save time even with those who know the Roses well. The printed labels look nice-at first-and are convenient if you can always keep them arranged so as to find at once the one you want. But they very soon get dirty, especially if not removed before the home journeys, and many find the writing each name in pencil on blank labels as required the shortest and most handy in the end. But please write plainly.

In cutting the day before a show, the state of the weather must be considered. If a very long journey and a hot night are in store, allowance must be made for rather more than one day's age in the Rose; but for a short journey and a cool night, some of the fullest Roses and those with the thickest petals may be cut almost as it is hoped to show them. Nothing but experience 
can aid the judgment in this case. If there is plenty of choice take another bloom of the same variety not so far advanced, and three times out of four the younger bloom will be found the best when the time comes.

Most Roses are at their best when about three-quarter's open, but some will stand the full exposure of their charms, and thin-petalled sorts should be shown when not more than half open. It is a good plan. to tie up the petals of such sorts to prevent their opening too quickly, and most of the pointed varieties are safer if thus tied.

Soft German wool should be used, and the outer row of petals being left free, the point or spike of the bloom should be firmly tied round sufficiently low to prevent its slipping. The form of knot should be the first half of an ordinary knot, only with two turns instead of one: an inch or two of ends should be left, and then the advantages are, that though the knot will not slip it can always be tightened by pulling the ends, and is very readily removed. At the place of show it will often be advisable, if the bloom upon examination seems hardly trustworthy, to tie it up again and only remove it at the last moment.

Teas are much more lasting when cut than H.P.s especially if they be really good blooms of first-class sorts. On one occasion I showed a specimen of Comtesse de Nadaillac at three separate shows; on the first occasion it won the distinction as best Tea, on the second the medal as best Rose, and the stand in which it was exhibited won first prize at the third show. On another occasion I showed twelve Teas unsuccessfully at one show: the same blooms with the exception of two or three were shown two days later at another place where the competition was quite as severe, and 
won first prize. Much rain had fallen in the two days, and freshly cut Teas were spoiled.

In the hot season of 1893 , I cut a bloom of Marie van Houtte on the Monday and showed it well in my winning stand at the Crystal Palace on the Saturday. It was kept for three days in a dark and nearly airtight cellar, and for two days more in another cellar with a little light. A few drops of spirit of camphor were added to the water in which it stood, but I am doubtful if this has much good effect. I think the equable temperature of a dry cellar has a good effect in preserving the blooms, but they will probably lose colour.

If rain is feared, and efficient protection is not to be had, the Teas should be cut in good time, even though the buds be hardly opened enough. It may be noticed that Maréchal Niel improves in colour after being cut and a really fine bloom may often be better the second or even the third day, if it be dry when gathered.

If the boxes remain at home during the night, it is best, especially if the Roses are not dry, to give some air by propping up the lids a little way, so as to exclucle chance trespassers in the way of cats and the like. Still this admits of the entry of slugs or earwigs, and as we should think little of keeping the boxes entirely closed through a night's journey, it is not necessary. The lids should be securely fastened when they are shut down for travelling, care having been taken that the Roses are sufficiently low in the tubes to prevent the roofs of the lids touching them, but only those perfect persons, who never even in a hurry leave their keys at home, should use locks.

Railway porters are now becoming used to the sight of Rose-boxes, and recognise that "something belongs 
to" the careful handling of them, to use a Suffolk expression. But personal supervision at all times when they are moved is still very desirable, and the legend "Flowers in water, this side up, with care" is not much heeded if there is no one prominently visible from whom a tip may be expected.

On one occasion Mr. Burrell of Cambridge and I were travelling together by night to the Northern Provincial Show of the National Rose Society. At a certain station we had to change, and after keeping guard over our pile of boxes for a while, we thought, as all seemed quiet, we might leave them for a little. We were not absent more than five minutes, but on our return all the boxes had absolutely disappeared. It was not till just as our train was starting that we were assured, and satisfied ourselves by the dim light of a lamp, that our boxes were all in the van. We thought it was all right, but my pet twenty-four, on which I had spent a great deal of trouble, travelled the whole of the rest of its journey actually upside down. My companion, who had arranged to take care of the boxes on our arrival during the small portion of night that remained, discovered the mishap soon after I had left him: and with a kindness I shall not readily forget did his best to restore order, and comfort, and cleanliness to the poor Roses with such success that they gained a third prize.

At another of the N.R.S. Northern shows I was going to show "six new Roses." A six box is, or at least mine was, nearly square, but that does not seem a legitimate reason why a porter should have rolled that poor box out of the van just as if it was a cheese. Though my remonstrance was meant to be severe, the man hoped I should "remember him," and I have done so. 
'Truly much depends upon the setting up and final arrangement of the Roses at the place of exhibition, and, in Teas especially, a man who shows his Roses well will often beat a worse performer even though the latter have better raw material. An old friend and rival, who by his splendid showing had often beaten me when I felt my blooms were naturally the finer, once most good naturedly set up my Teas as well as his own at the Crystal Palace, though we were showing in the same class. Poetical justice was for once triumphant, for we came out equal first.

Though perhaps a pity, it is inevitable that the art of display should have this advantage; it would never do for the judges to pull the blooms about and see what they are capable of. So the beginner must learn how to show his Roses to the best effect in the first place by watching other's; and he will find that, next to experience, plenty of patience with a good allowance of time is the principal requisite.

Little care will be needed with those blooms that are just right and likely to remain right when they meet the eyes of the judges. But some, though still perfect, may give cause for anxiety lest they should open too far and show an eye, and weak blooms of thin varieties will sometimes do this very soon in a hot tent. If the shape will admit of it they had better be tied up for the present as before recommended, and tested again at the last. But the judges may be delayed and a younger though smaller bloom is generally the safest. An old hand by keeping the points of his Roses tied up till the last minute will sometimes present for judgment fineshaped perfect blooms which two or three hours later have opened and lost their form and beauty. It may be matter of regret that this can be done, but some 
risk is run, and ingenuity and boldness, provided that all is fair, should have their chance of reward.

Some blooms will be found hardly more than buds, and these will require a little assistance to make them open further. The National Rose Society was quite right in framing rules against "dressing" when this took the form of forcibly bending down the outer petals by creasing them. This gives quite a different appearance and shape to the Rose. Yet a little assistance, by removing short malformed or discoloured outer petals, and by gently pressing back at the base the next row is a legitimate accessory of the art of exhibiting.

The handle of a budding knife was the instrument formerly used for opening a bloom, and I have seen a pencil do wonders in experienced hands; still a camel's hair pencil of fair size is the best thing to use, for it is soft and does no injury to the petals and may be utilised for the removal of specks of dirt, aphides or thrips. Work patiently away at the outer row of petals only, without creasing them down: it is no use meddling much with the inner rows, except by a sharp puff or two from the lips which will sometimes improve matters somewhat.

Some sorts cannot be opened at a show, Reynolds Hole for instance; however much the petals be pressed back, nothing short of creasing or mechanical obstruction will prevent them from closing up again. I remember a case where a fine-looking bloom of this variety was being examined by the judges as the most likely candidate for the silver medal for best H.P. The owner of the Rose at the door of the tent was anxiously watching the movements of the arbiters, and was horrified to see one of them pull the bloom downwards through his lightly enclosing hand. Click! the petals, released from the 
laborious mechanical opening, sprang back to their places, and Rose and owner were "shut up" simultaneously!

Other Roses, of the "thin" type, like Thomas Mills, are pretty sure to open well enough, and due regard will have been paid to this at the time of cutting, as such sorts should be taken to the show in an earlier stage of their development than the very stout and lasting ones like Reynolds Hole or Horace Vernet. Great attention should also be paid to the weather and the place: a hot tent forces on Roses wonderfully, but it is generally fairly cool in the Crystal Palace.

It seems hardly necessary to say that the setting up and arrangement at the show should be in a cool and shady place, but even this rule may have an exception. On one occasion I cut my blooms for a celebrated southern show in a very undeveloped condition, expecting that my assistant who was to go with them, as I was unable to do so, would have a hot time for his night's journey. The weather unexpectedly changed, the night proving very cool, and when he arrived at the place of exhibition, he found to his dismay that my Roses were not nearly open enough, and that they made no show at all by the side of the developed blooms against which he had to contend. Being a plucky man of resource, he resolved on an unusual experiment; he uncovered the boxes, and set them to stand for a considerable time in the full glare of the sun. Whether the others took him for a lunatic or an ignorant novice I do not know; but I do know that he brought me back the first prize.

In several of the handbooks of instruction on how to show Roses the exhibitor is warned to be careful how he arranges them as to colour for general effect. Of course this is worth doing, if it means arranging all the best 
blooms thus, but under no circumstances should a light or dark bloom be introduced for the sake of colour if it is not worthy in itself. I am bound to say that it is very rarely that judges pay any heed to the arrangement: they look at the merits of the blooms themselves and a preponderance of dark over light flowers or vice vers $\hat{\imath}$ would have usually no effect with them. Successful arrangement is only taken into consideration where rival stands are very nearly equal in the merits of the individual blooms.

There will seldom be any need to look over the stand at the last to see if there are any duplicates, i.e., two of the same sort, if care has been exercised in this respect from the beginning, and no Rose is introduced without being sure about it. But a bloom may sometimes be accidentally changed without altering the label, so these should be run over to see that they are right. The National Rose Society authorities are lenient in this matter, provided there be no duplicates, but country judges are sometimes more strict.

There is room for a good deal of legitimate manœuvring and generalship in the last hour or so before the judges enter. If a man, who has entered in several classes and is only moderately strong, divides his best specimens among his several stands, he will probably get no first prize and runs considerable risk of being out of it altogether. He should concentrate his strength on one or at most two classes, take a critical survey of his rivals' blooms, and show pluck or discretion as the case may be in selecting the best class in which to put all his finest flowers.

On one occasion, late in the season when it was not likely that there would be more than one or two serious rivals, I sent my assistant (being unable to go myself) 
to a large show, with stands of thirty-six and twentyfour. He found one rival only of any note, but he was Mr. X. and to beat him just then requirerl the best anateur Roses in the kingdom. My man returned with two seconds, saying triumphantly, "I ran Mr. X. close: for he came and looked at me five times." I could not help replying, "If you had followed his tactics and gone and looked at him, you might rery likely have got first for the twenty-four." By rlivirling his forces my man was beaten in both classes: the expert hand came and looked so often to satisfy himself there was no concentration of strength requiring a similar move on his part.

No personal fancies, or likes and dislikes of certain Roses, should be entertained by the man who wishes to be successful. Some have an antipathy to the appearance of the striped Pride of Reigate: and I have heard "Oh, I don't like that rose" of such sorts as Marguerite de St. Amand and Souvenir d'un Ami. It is all very well for such as can afford it, but few can: and it is to be remembered that the judges will not let their own personal predilections have any weight in deciding on the merits of each Rose.

JUDGING.-Nothing is more surprising to exhibitors of dogs, poultry, \&c., than to hear that at all National Rose Shows the judges are appointed from those who are actually exhibiting at that very show. Of course, no one judges in the class in which his own stands are, and as a matter of fact probably no exhibitor would have it otherwise than it is. Nany judges are required at a large show, and even with much subdivision they have often as much or more than they can do to get through their task in the hour: and besides this, eyes thoroughly accustomed to the appearance of Roses as shown are 
required to recognise the different varieties, and note subtle distinctions of merit. A year or two's absence from Roses and Rose shows would probably seriously impair a man's efficiency as a judge.

Judging is performed by the rules of the National Rose Society according to the form, size, and brightness of each bloom which should be at the time " in its most perfect phase of possible beauty." A general survey of the class should first be taken, for it may be that the case is clear and beyond a doubt. Where the stands are of large numbers-thirty-six and upwards-there should be another survey a little way off to judge better. by comparison, and to give at all events an idea of which stands are "out of it," and which seem to be more nearly equal.

Those stands about which there is any doubt should now be "pointed," i.e., judged by pcints. Minus one, nought, one, two, three, or in rare cases four points should be awarded to each bloom according to merit, one of the judges suggesting the number of points to each, the others assenting or dissenting, and one noting the number of points totalled.

The first thing to be done is to choose and agree upon a certain rose worth three points to serve as a standard. This is important: being useful not only for reference in cases of disagreement, but also in the large classes of forty-eight or seventy-two to prevent the standard becoming insensibly depreciated. Pointing generally begins with the back row and from left to right: boxes are often set up in the same order, and the exhibitor would naturally put his worst blooms in last, which would therefore be at the right hand of the lower row. At any rate considerably smaller and weaker blooms will generally be found in the front row, and the 
judges must take care that their standard remains unaltered; the fall in the scale is often very gradual, but a frequent reference to the chosen standard, which one of the judges might carry in its tube, will prevent any lowering or raising of the ideal.

In cases of equality, or when in a large class only a point or two of difference is found between two stands, it is well to "point" them over again, beginning at the other end of each. If still there is little difference, taking the boxes down and holding them with their long sides touching, in closer juxtaposition, will sometimes throw additional light on the matter. Viewing them at a little distance may sometimes give another point of comparison; and if the verdict should still be doubtful, arrangement, neatness, foliage and even moss may help to turn the scale. In such extreme cases, however, it is better to judge them as equal where the prizes are money and can be divided: if a cup be in question, of course one must be declared the winner.

I went once some little distance to a show solely as judge, there being no class suited to me. The prize was a cup for forty-eight, and there was no second or other prize whatever. I was the only judge, and the exhibitors were two noted rival nurserymen of the very first calibre. I was shut up quite alone in the tent, and proceeded to my task with cheerfulness, not knowing what was in store for me. I "pointed" each bloom with great pains, and took care not to add up the total of the first stand till I had done the other, lest I should be insensibly influenced. To my horror they came out exactly equal. I went through them again from the other end and this time I did get about one and a half points' difference, but still felt that the second judgment was not quite so trustworthy, as I might be unconsciously 


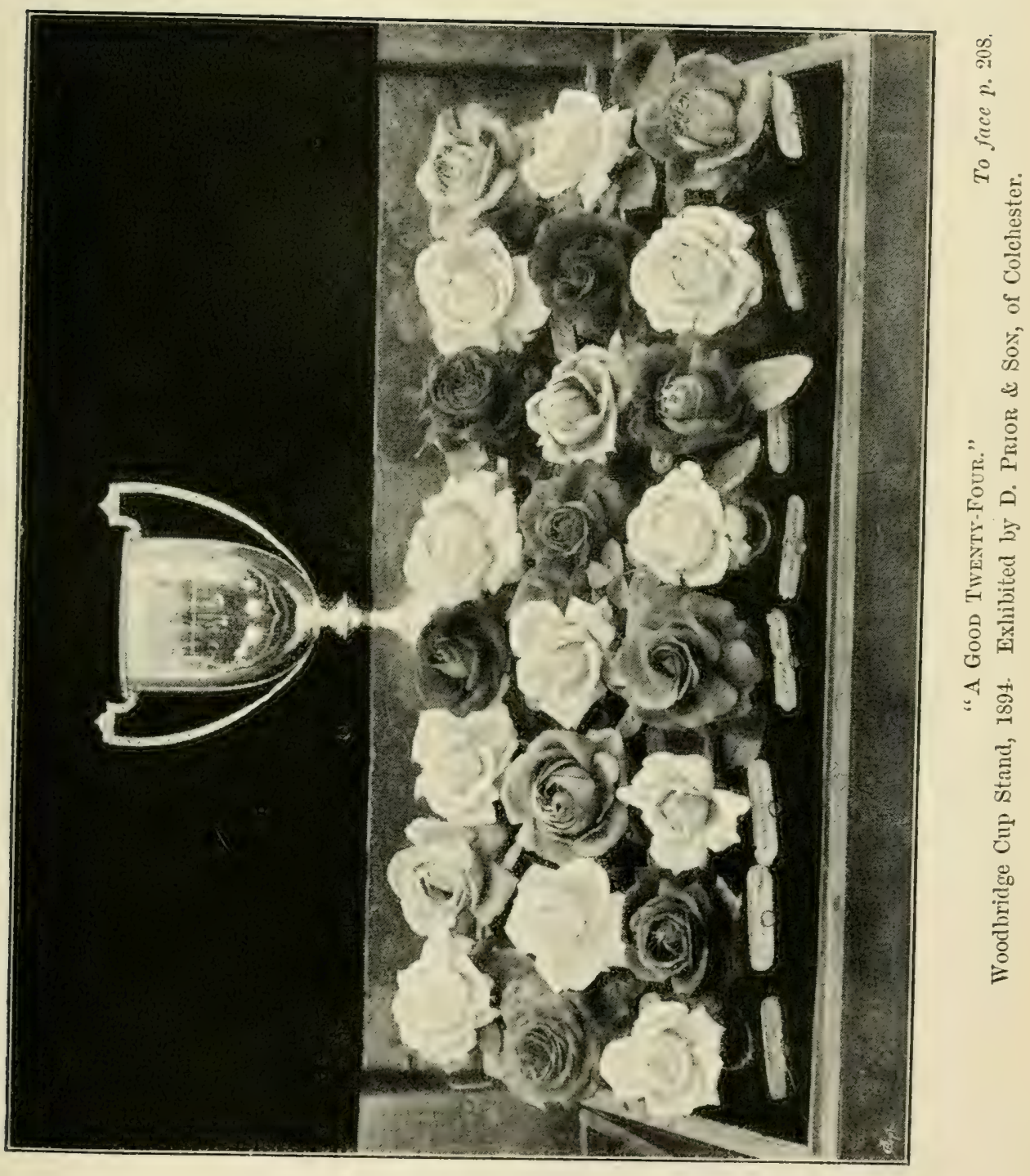



anxious to find a difference. I compared them in every way I knew, but still could make hardly more than a point between them, if so much. No difference was to be found in arrangement. I knew who the exhibitors were as I had seen them, but I did not the least know which stand belonged to each. Their style was the same as they had been brought up in the same school, and they were well known as at that time of very nearly equal strength. Yet one must have the cup and the other get no prize at all. In my perplexity I mounted on the central table in the tent, and took a careful bird's-eye view, holding on by the pole. This confirmed me in my previous idea that there was the slight shade of difference that I had noticed at my second attempt: I gave my judgment accordingly, and was most sincerely pleased when I found the loser was quite satisfied.

Another very equal case was in a class for seventy-two at a Northern show. I had the proper number of two coadjutors this time, one being a very experienced and able Rosarian, and the other a local man who was generally discreetly silent. We pointed through both the best stands without any disagreement except in the case of one bloom where I was for three points and my experienced friend for one only. The third judge opened his mouth for the first and only time, and gave his voice against me. That decided the principal prize of the show, for we found only one point of difference between the two stands of seventy-two each, and if my view of that one bloom had been acted on, the other seventy-two would have won by one point.

The silent judge played his part and did what was required of him. He did not act, I hope, or give his judgment from the same motive that influenced one at 
a village cottager's' show. 'There were three judges for' the fruit and vegetables \&c.-Mr. A, the head gardener from the big house-and Messrs. B and C, gardeners in humbler establishments. Mr. A, by right of his position, took the matter in hand and distributed the awards, the others humbly assenting in silence. Presently C, perhaps thinking it was better, if only as a matter of form, to assert himself a little, suggested a small point of disagreement. The matter was promptly referred to $\mathrm{B}$, and he decided the question by saying, "Oh, I always goes with Mr. A!" It was all right, for Mr. A was a good juclge, but it was plain that, unless for ornament, $\mathrm{B}$ and $\mathrm{C}$ might as well have been at home. 


\section{CHAP'TER XII}

\section{MANNERS AND CUSTOMS}

ON looking over a good collection of Roses a kcen observer, even if he be unlearned in their culture, cannot fail to be struck with the difference observable in what is called the "habit" of each sort, for there is almost endless variety in wood, leaves, thorns, strength, and manner of growth, apart from the blooms themselves. He would also probably notice a good many of what he would call "red" Roses, very much alike to his untrained eyes in general appearance, and he might wonder how they could all be distinguished apart. But as a good shepherd can tell every member of a large flock of sheep by a diligent study of their faces, and an English apple, or even apple-tree without its leaves, can be correctly named by some clever pomologists, so a fairly representative bloom of any Rose can be distinguished by a thoroughly expert Rosarian.

Descriptions of the different varieties are to be found in the catalogues issued by nurserymen, and many of these are now fairly full and accurate. The colour, naturally enough, occupies the principal part of the descriptions: but the different shades, especially of Teas, are very difficult to express to ordinary readers in langlinge that they will clearly understand, for some are 
extremely variable in their tints, and others come much fuller in colour when grown strongly.

It is not every one who is, without studying the matter, well conversant with the different tints expressed in the terms frequently used. Among these may be found-ivory, cream, lemon, chrome, straw, canary, sulphur, salmon, nankeen, saffron, apricot, fawn, buff, copper, bronze, blush, flesh, peach, rose, cerise, carmine, coral, cherry, currant, madder, vermilion, scarlet, lake, lilac, plum, violet, magenta, claret, maroon, and amaranth. It requires not only a good eye for colour, but also a certain amount of training, for an ordinary man to distinguish accurately between these shades. I confess that some of them beat me, and that even the first two on the list, ivory and cream, as seen in Roses, would present very slight distinctions to my eyes.

A good many of the Tea Roses, especially the light yellows, come practically, if not pure, white, when exposed to strong and continued sun; and as these are generally credited as to colour with the first descriptions of the raisers as seen under glass, there is sometimes a little disappointment with the tints as seen out of duors. Thus Devoniensis, Edith Gifford, and Innocente Pirola used to be described without any mention of the word 'white,' which must seem very strange to those who know the Roses.

Such good old colour-words as white, yellow, pink, red, scarlet, and crimson are my strongholds, and in the following catalogue I shall mostly leave the descriptions of colour to be found in the trade-lists, the best of which are carefully compiled from a long and widespread knowledge of the various sorts, and a study and comparison of the different shades. My endeavour will be to supplement these descriptions with other 
matters that the purchaser and chooser would like to know, as an addition to and commentary upon published catalogues.

For instance, the novice student of these seductive pamphlets will only require a little knowledge of human nature to enable him to take a fair discount off the description given by the raiser himself of any one sort: and he will find it advantageous to be acquainted with some slight vagaries in catalogue-English which custom has sanctioned. In this language "mediumsized" means "small," and "pretty" generally implies the same. In growth, "moderate" means "weakly," "free" describes a plant which is rather weakly but branching, and "vigorous" stands for ordinary growth. "A good pot Rose" might very likely mean that it would not stand any bad weather out of doors, a "nearly full" one shows an eye, and we should probably be doing no injustice in supposing that a Rose which is "good when caught right" is bad as a rule.

It has become a matter pretty generally known how unwise it is for a begimner to select his sorts from those blooms which take his fancy at an exhibition: and there are drawbacks to the cultivation of a good many of the show varieties, which we cannot expect to find noted in catalogues for sale. These demerits and bad habits of certain Roses I want to point out as well as their good qualities, as they are of the utmost importance to those who wish to choose their sorts, and have only trade catalogues and the flower's to be seen at shows to go by. For, among Roses, there are a great many "little ways" belonging to the different tribes, families, and individual varieties, and many an otherwise excellent sort has a nasty habit of doing this or that or the other which just prevents its being as good as it might be. 
A variety may be faulty as a plant, having an - unhealthy constitution, weakness of growth, deficiency of foliage, a special tendency to mildew or orange fungus, or a lack of freedom of bloom, or of good qualities in the autumn. And if the plant is all that can be desired, there may be serious demerits in the flower's as a rule, however good an occasional specimen may be. Among such faults may be-a liability to be stained, gummed or rotted by rain, or to "burn," that is, turn brown, in hot weather, or to come badly shaped, malformed, quartered or divided, or to have some deficiency in stoutness and smoothness of petal, fulness of centre, accuracy of form, or brightness of colour.

The Teas have a special fault in that some of them will not bring blooms to full perfection when grown as dwarf plants, and they are also peculiarly liable to be injured by rain; but, on the other hand, they are somewhat less injured by mildew and completely free from orange fungus. Besides these general faults, many Roses have private habits, either good or bad (generally bad!) of their own. It is most desirable that these should be known, but it should be added that situation, climate, soil, and culture have much effect upon the manners and customs, sometimes to a very striking extent.

It is quite common to hear one amateur say of a certain variety that it is useless with him-that it will not grow, or the blooms come to no good-while another answers that he finds it all he could wish in growth and flower. After a fair trial, it is far better to give up a Rose that does not answer: there are plenty of different sorts and many new ones each year, and I should strongly advise a vigorous weeding out every autumn of all those which have been thoroughly tried and found wanting.

Usually it takes two or three years' trial at least of a 


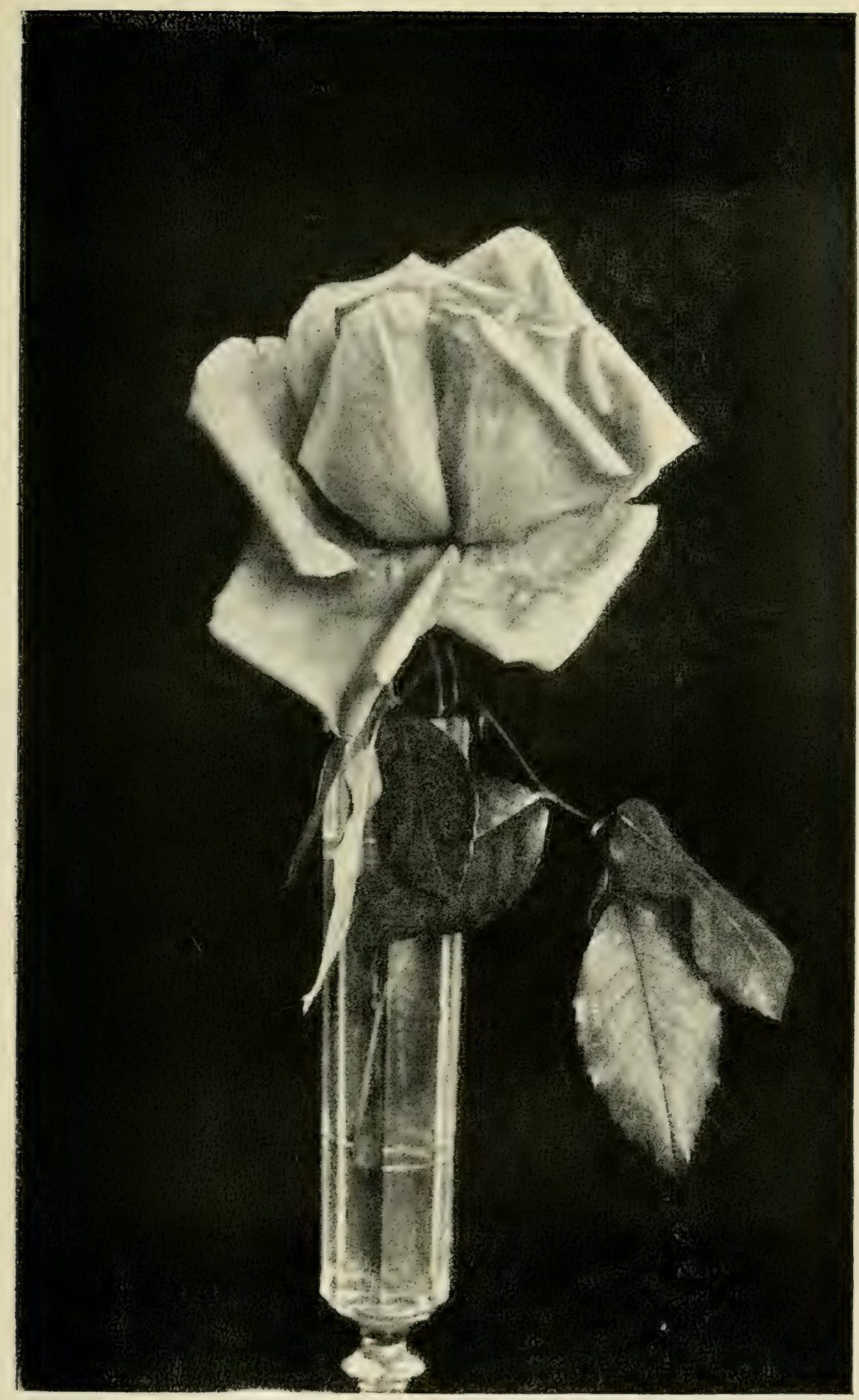

Rose Faults. $\Lambda$ "Divided" Rose.

To face p. 214. 

new sort to find ont its own particular manners; so that, unfortunately, I cannot give a reliable account of the newer Roses, of which Rosarians of standing who are exhibitors will most wish to hear. Not only that, but all lists and catalognes get out of date before very long, the least valuable sorts being superseded as others, more perfect in their especial line, come into commerce.

In preparing the following list, I have confined myself mainly to the N.R.S. Catalogue, with some additions and omissions : and, however Heeting and ephemeral lists and selections may be, a great many are here mentioned which are not likely to go out of date for some time, and whose manners and customs are now thoroughly established. I have included Hybrid Teas and Bourbon Perpetuals in the large well-known class of H.P.s.

\section{HYBRID PERPETUALS}

Abel Carriere (Verdier, 1875).-OOf uncertain growth. Often makes strong secondary shoots, yet refuses to grow strongly in the spring. Foliage second-rate, and rather liable to mildew and orange fungus. The blooms often "come" bad: not " divided," but malformed and "anyhow": as a rule a small percentage only arrive at perfection. Not particularly goorl in petal: but the true shape, partly imbricater, is good when you get it. Beautiful colour, one of the really dark ones: a fair bloom to last, but not of the largest size. Like many of the dark Roses it requires hot, clull, dry weather, and in some seasons the petals will burn, i.e.turn brown, but I am doubtful if this is actually caused by the sun. Rain is more or less hurtfiul to all Rose-blooms, but the 
dark H.P.s, and this among them, will stand it as well as any. It cannot be called a free-bloomer, a good autumnal, or an early Rose. Perhaps best as a standard.

Abct Girand (Damaizin, 1865).-A useful early garden Rose of very strong stiff hardy growth, with fine foliage, and stout and numerous thorns. This is a good type of the "garden" Rose, as, though its flowers are not good enough for show, the plant is vigorous and hardy, doing fairly well in poor soil, strong of constitution, not liable to fungoid pests, and flowering freely in summer and in autumn. The pink blooms are of large size, open and flat and rather weak in the centre, not very lasting, and with thin petals. It has sported once or twice to a lighter shade, one of these variations having been fixed and named "Bessie Johnson," and a climbing sport of this has also been issued.

Alfred Colomb (Lacharme, 1865).-Of fine growth and foliage in good soil but not on poor or light land. Not very liable to mildew and can stand some rain. The blooms generally come good, but occasionally divided, of fine typical shape, what the N.R.S. Catalogue calls "globular, high centre," which is a good description of this Rose in its perfection: very good in petal, centre, size, lasting qualities, and colour. This is a first-class late show Rose, good as a standard, fragrant, free in bloom, and fine as an autumnal, with clean, smoothskinned, handsome wood, striking well as a cutting. The flowers are often extremely like those of Marie Baumann, though the wood and habits of the plant are very different. In my opinion, if either of these two well-known Roses was now brought out as a novelty, having been hitherto unknown, it would be considered synonymous with the other. Marshal P. Wilder is held to be too much alike and therefore considered a synonym. 
Alfred Colomb has not, to my knowledge, had any seedlings of note, save Comtesse de Casteja (Margottin, 1882), which is valueless.

Alfred K. Williams (Schwartz, 1877)._Makes long shoots as a maiden, or at times on good soil as a cutback, but the constitution is weak. Thorny, with good foliage, and will stand some rain. This is a Rose of great reputation, because the blooms nearly always come perfect, forming first-class examples of the popular " imbricated" shape, i.e. something after the form of a camellia. Not a good bloom to last, or of the largest size, but prominent as a show Rose from its shape and bright colour. It is not a very free bloomer but comes again pretty fairly in the autumn. It is quite a late Rose with me, as the shoots, though not very stout, run up to some height; but it comes early with some growers. The plants are not hardy or longlived, and fresh ones should be budded every year, preferably on the briar, as, though some do well as cutbacks, maidens are more to be depended on : some find it answers best as a standard. Grand Mogul is said to be a seedling from this beautiful Rose.

Alphonse Soupert (Lacharme, 1883).-Very thorny growth, but not strong with me. 'This Rose is included in the exhibition sorts in the N.R.S. Catalogue, but the blooms are rather loose and by no means first-class. They are large and may be valued where the first Roses are esteemed, as they are quite among the earliest. The petals are rather thin, and the shape is somewhat uncertain : still it is said to be a "showy" Rose, which in catalogue-English generally means "showy at a distance," i.e. that it will not bear a close inspection. Said by some to be a good pot Rose.

Anna de Diesbach (Lacharme, 1858).-Of very strong hardy growth, but has the same fault of general loose- 
ness and unevenness in the blooms. They are of the largest size and more or less of the true cupped shape; but a perfect one is a rarity.

Annie Larton (Laxton, 1869).-A garden Rose, with good growth, unusually fine foliage, and strong constitution. Not liable to mildew or much injured by rain. One of the earliest, sometimes good enough for exhibition, a free bloomer and good autumnal. The flowers are of fair size and bright colour, somewhat flat and often irregular in shape, with rather thin petals.

Annie Wood (E. Verdier, 1866).--Here we have a Rose with manners and customs (fortunately) peculiar to itself. It is a fine strong grower, with fair foliage, liable to mildew and orange fungus, but not much injured by rain. A great quantity of buds form on each stem: the top bud of all, which one would naturally reserve, is nearly always cracked, hollow, and distorted before it is much bigger than a thimble, and sometimes has a great green pip in the centre. You may search for the best-shaped bud, and do away with all the others for its sake. Even then, nine out of ten buds will show a great eye before they are more than half expanded, and the tenth will do it soon after being cut. You make up your mind to discard the sort altogether: but, just at the close of the season, a beautiful bloom makes its appearance on a shoot you had not noticed, with brilliant colour, full size, delightful fragrance, and good imbricated shape-a lovely Rose: and the plants are spared to serve you just the same trick another season. The title of this chapter being what it is, it seems impossible to avoid sooner or later bringing in the timehonoured anecdote of the traveller who, describing the "manners and customs" of some native tribes he had been visiting, was constrained to dismiss one of 
them with the terse remark, "manners none-customs disgusting." If it be possible to say anything so bad of a Rose, I am doubtful whether a better example than Annie Wood can be found for such a description in the N.R.S. Catalogie. The good blooms come generally on old plants-it is of no use as a maiden. It should not be pruned too severely-a rule that generally applies to all those which are not good as maidens.

Auguste Rigotard (Schwartz, 1871).-Of fair growth, with smooth wood, and fine foliage. Not particularly liable to mildew or orange fungus. A late light red Rose, sometimes very fine, good in autumn, but having no private peculiarities.

Augustine Guinoisseau (Guinoisseau, 1889). - This is a very nearly white sport from La France, with all the habits of that popular variety, best as a standard and on not too heavy soil. It has not hitherto been found good enough for exhibition, but may possibly improve in that respect.

Avocat Duvirier (Leveque and Sons, 1875), see Maréchal Vaillant.

Baron de Bonstetten (Liabaud, 1871), see Monsiemr Boncenne.

Buroness Rothschild (Pernet, 1867).-This is one of those very distinct Roses, like Gloire de Dijon among the Teas, which stand by themselves in their respective classes, and become, sooner or later, the heads of characteristic families. The growth, which is termed "robust," is typical : comparatively short, thick, stumpy, stiff, upright wood, with grand foliage right up to the blooms, which are generally produced singly. Hardy, doing equally well on manetti, standard or dwarf briar, airly free from fungoid pests, of a strong constitution, and not much injured by rain. The blooms, which are late 
generally come well, of globular shape, and a beautiful pink colour. They are very large, and come again well in the autumn, but are quite scentless. A party of villagers came to see my Roses one day, and one good dame who was behind all the others stooped to catch the perfume of a fine specimen of the Baroness which had attracted much notice. She was disappointed, but saw the reason at once. "Oh, they've sniffed all the scent out of this 'ere one"! It is rather wanting in fulness of centre, apt to open quickly in hot weather, and must be cut small for exhibition. Although thoroughly hardy in constitution, this fine Rose has either deteriorated in the last few years, or has simply had to take a lower place through the introduction of so many new fine sorts. At all events, "Rose elections" show plainly that it is not nearly so highly esteemed now as it was ten or fifteen years ago.

It is much inclined to sport to white. Mabel Morrison and White Baroness were comparative failures, but Merveille de Lyon has achieved a great success. Mabel Morrison has however atoned for personal failure by its wonderful progeny, Her Majesty. "The Baroness," as we used to call it, as if there could be no rival, may fall still further in popularity, but will live in its descendants, among which we may probably reckon Spenser, which seems to be simply a fuller Baroness Rothschild.

Beauty of Waltham (W. Paul and Son, 1862).-Fair in growth and foliage, and not much liable to injury from fungoid pests or rain. The blooms come true and well, being seldom divided or malformed. The shape varies according to situation and cultivation. The N.R.S. Catalogue calls it "imbricated," and the raiser "cupped": my specimens do not come in either of these 
forms, but the petals are very closely curved inwards in the centre in a manner that proclaims the variety at once. Nevertheless it should be noted that on better soil than mine it does come regularly of semi-imbricated form, and is then a fine flower. Like some others somewhat of this shape, and those of the pointed form, this Rose has the good custom of closing in and guarding its centre more tightly in hot weather when it is most needed than at other times. A free bloomer, rather late, good in lasting qualities and as an autumnal, but not very large. It has produced a seedling, Lady Arthur Hill (Dickson, 1889), of a novel shade of colour, but not large enough.

Benoit Comte (Schwartz, 1883).-Very distinct in foliage and habit, and much liable to mildew. The growth is long and strong, but the flowers, which are among the very latest to open, have been very poor with me.

Black Prince (W. Paul and Son, 1886).-Of fair growth and fine foliage, and occasionally gives quite a good dark bloom, but so rarely that I am forced to look upon it more as a pretender than a prince.

Boule de Neige (Lacharme, 1867). - A cross with the Noisette class, of good growth and foliage, hardy and strong, doing well on the manetti or as a standard. The blooms come in clusters, after the Noisette fashion, and are sometimes distorted. They should not be thinned, or the probability of malformation will be increased. The N.R.S. Catalogue gives the shape as "open cupped," but with me the blooms are imbricated, perfect Rosettes in every sense. A pure white charmingly shaped Rose, but it is an abuse of even catalogueEnglish to call it medium-sized, as it is impossible to deny that it is very small. If it were of full size, we 
should have nothing to equal it for show as a white H.P. Stout in petal and lasting in bloom, very freeflowering and good as an autumnal.

Camille Bernarclin (Gautreau, 1865).-Of fine long growth and good foliage, but the wood is not very stiff, and the flowers are sometimes pendent. Not much injured by rain, but decidedly liable to mildew. The majority of the blooms come well, and are good in petal, fulness and shape, but not very large. Not imbricated with me, but of the pointed form. Lasting and fragrant, rather late, a free bloomer and a good autumnal. A Rose of good constitution, useful and reliable for garden or show purposes.

Captein Christy (Lacharme, 1873).-OOf the robust habit of growth, but the wood is unique and something like that of the Victor Verdier race. Lately declared to be a Hybrid Tea, an assertion which seems at present wanting in proof. It has splendid foliage, of a lovely colour when young in the spring, coming well up under the flower. Not much liable to orange fungus or mildew, and though not liking rain can put up with it better than many of the light-coloured Roses. The summer blooms are apt to come divided and badly shaped particularly on strong shoots, but the good ones are fine in petal and fulness, fair in lasting qualities, and of the largest size, but rather open in shape. The shoots should be left rather long in pruning and not much thinned, for it is very full, and apt to come coarse and rough if grown too strongly. A free bloomer for one of the robust habit, and as an autumnal quite one of the best H.P.s we have, for flowers in September or even October are sometimes better than those of the summer crop. A grand Rose if "well done by," grown on the briar (preferably as a standard) 
on good soil; but rather dainty, nearly scentless, and does not like the manetti stock or being starved. A climbing sport of this Rose was issued by Ducher in 1881.

Caroline Testout (Pernet and Ducher, 1890).-A Hybrid Tea of too recent introduction to have its manners and customs spoken to with any certainty. The flowers are very large, quite distinct, and of very good form. It is a free bloomer, and a high reputation has already been attained.

Charles Darvin (Laxton, 1879).-Good growth and foliage, the blooms having a colour described universally as brownish-crimson. I have been unable to detect the brown shade, but must, as I have said, leave these delicate distinctions of tints to experts. Rather late, and a good autumnal. The shape is open, and the variety does not prove very satisfactory with me, though often well shown by others.

Charles Lefebre (Lacharme, 1861).-Synonyms, Marguerite Brassac and Paul Jamain. Of strong growth with stout stiff smooth wood and fine foliage, requiring strong soil. The secondary shoots are much stronger than the early ones, and on cutbacks the latest blooms of the first crops are generally the best. More liable to orange fungus than to mildew, and can stand rain pretty well. 'The flower's generally come good, fine in petal, centre and size, lovely in colour, and bcautifully round and smooth in appearance. The shape is open and semi-imbricated, which is very effective, but not a good form to last. Free in bloom and a good autumnal. This is the G.O.M. of the dark crimson Roses. Longfellow's "Hiawatha" metre always scems to me to suggest

Charles Lefebrre, the King of Roses. 
Chestunt Hybrid (Paul and Son, 1873).-This was the earliest Rose to be recognised as a Hybrid Tea. It is of very vigorous growth, sufficient for a pillar or a paling, hardy and strong with fine foliage, decidedly liable to mildew. A free and early bloomer, but the shape is open and the colour is wanting in brightness, and a dull Rose is surely a poor thing however many good qualities it may have.

Comte de Paris (Leveque, 1886).-A large full red Rose, of ordinary growth and habits, with flowers of "reflexed" shape.

Comte de Raimband (Roland, 1867).-Of good average growth and foliage, and clean handsome wood. Not particularly subject to fungoid pests or to injury from rain. A fairly reliable semi-imbricated crimson Rose, which appears to be growing in favour, and seems to be considerably more appreciated now than it was ten years ago. This is unusual, but there is evidence that some Roses do improve as they grow older while others deteriorate.

Countess of Orford (Guillot, 1869).-One of a large family of smooth-wooded Roses, all I believe descended from Victor Verdier (1859). Some of them, such as the one under notice, Eugénie Verdier or Marie Finger, S. M. Rodocanachi, and Pride of Waltham, are quite first-class. All the different member's of the family have the same or similar manners and customs. They have characteristic smooth wood and good foliage which is most lovely in the early spring, and does not suffer much from mildew but is especially liable to the attacks of orange fungus or red rust, the early shoots being often quite bare of leaves by the end of August. They do not like light soil or the manetti stock, but the flowers will stand rain fairly. Countess of Oxford is of 
the largest size, sometimes even inclined to be coarse, good in petal and centre. The shape, which is rather open, is fairly lasting, but the colour soon gets dull, and is much lighter on weaker plants: a free bloomer but not so good an autumnal as some of the family. The variety is especially liable to sport, Pride of Reigate, Pride of Waltham and others having already appeared. A white sport of this variety, of which Pride of Reigate gave some hope, would be an acquisition.

Comtesse de Serenye (Lacharme, 1874). - Of fair growth and foliage, rather liable to mildew, and easily spoiled by rain. A very free bloomer and good autumnal. This is a Rose with awkward manners, for it has great possibilities and can be very fine when it chooses, but it is one of the "coarse" varieties, too full in petal, in regard to which the stronger you grow them the worse they are. On a maiden growth, especially if the buds be thinned, the survivor will often be a most unsightly object, and indeed it is very seldom that a large bloorn will come without distorted shape; but on the side-shoots of a cut-back in a dry autumn flowers of a beautiful "globular imbricated" shape may be got, of good lasting qualities.

Countess of Rosebcry (Postans, 1879).--Of long strong growth, with distinct smooth wood and fair foliage. A little liable to mildew but not much injured by rain. The blooms do not come very well, only a small percentage being quite regular in the shape, which is somewhat open. The petals are good and very smooth, and a capital specimen may be had occasionally, though not of the largest size. Only fair in freedom of bloom, and not first-class as an autumnal. Duchess of Fife is a light coloured sport of this variety.

Crown Prince (W. Paul \& Son, 1880).-—Of good 
growth and foliage. The blooms are large and full, with a decided purple tinge. Very free-flowering and a good autumnal. Useful as a garden Rose, or for forcing, and often good enough to show.

Danmark (Zeiner, Lassen, \& Dithmer, 1890).--A sport from La France, with the same manners and customs, save that it is darker in colour, a little stiffer in growth, and seems thoroughly wedded to the one bad habit of the type-coming in a round ball instead of opening properly with a point in the centre.

Dr. Andry (E. Verdier, 1864).-Of capital growth and foliage, hardy and of strong constitution on all forms of stocks, early in flowering, not much subject to mildew or orange fungus, and standing rain fairly. The blooms generally come with a pretty good point, but are apt to be divided, and sometimes irregular in the circular outline. Good in size, petal and centre and very bright at first in colour, but as often happens this does not last so well as the shape. It is very free flowering, a row of it making a grand show for a few days, but is not very good in autumn. A useful and thoroughly reliable Rose, which will do fairly well in weak soil.

Dr. Sewell (Turner, 1879).--Rather weak both in growth and foliage, and best as a maiden. Liable to mildew and orange fungus, and to being "burnt" in the petals, but can stand some rain. The blooms cannot be depended upon to come good, but when they do the sort is seen as a fine distinct dark Rose of good pointed shape and moderate size, but not of high quality as a free bloomer or an autumnal.

Duchess of Albany (W. Paul \& Son, 1888).-Another member of the La France family, entirely similar in habit, the flowers being of a deeper colour than Danmark, not so large, but better shaped. 
Duchess of Bedford (Postans, 1879).--Of rather weakly growth and best as a maiden. A lovely and striking flower, beautiful in its semi-imbricated form, and bright with glorious colour, a mixture of scarlet and crimson. Not strong in constitution, free-flowering, or good as an autumnal, but the growth and habit have much improved with me of late years.

Duchesse de Cuylus (E. Verdier, 1864).-Syn. Penelope Mayo (Davis, 1878). Only fair in growth with rather weak foliage, the wood and habit being very distinct in appearance. Not liable to mildew or any injury from rain. The blooms come wonderfully well, every one being alike, and the sort is on this account useful to exhibitors for showing in triplets. Sweet-scented, perfect in form, good in centre and bright in colour, but decidedly below par in size. Not free-flowering or a good autumnal, and has dropped out of the N.R.S. Catalogue.

Duchess of Fife (Cocker, 1892).-A lighter and beautifully coloured sport from Countess of Rosebery, similar in all other respects.

Duchesse de Morny (E. Verdier, 1863).-Of fair growth and foliage in strong rich soil, the wood and leaves being very distinct and characteristic. Decidedly liable to mildew, and cannot stand much rain. The blooms come well shaped with very smooth stout petals, beautifully full, of distinct and lovely colour, large size and fair lasting qualities. This Rose is one of the very smoothest and most regular in globular imbricated shape that we have; a free bloomer, but not so good in autumn, and rather dainty as to soil and treatment. The buds should be well thinned, for this is one of the true aristocracy where no fear of coarseness need be entertained. The shoots often come wholly or partially 
fasciated, i.e. two or more laterally joined togethera bad habit, and such growth at pruning time should be clean cut out.

Duchesse de Vullambrose (Schwartz, 1875).-Requires good soil and generous treatment; with these it will grow strongly with distinct habit and foliage, but it will not thrive everywhere. It is not very liable to mildew, but the blooms cannot stand rain at all, and being of a light colour are subject to injury from thrips in a dry season. They have a decided tendency to come badly shaped, often with me having a gap or chasm in the outline as though a piece had been cut out. The shape is rather too open and flat at the best, but it is of large size, free-flowering, fair in lasting qualities, and pretty good in a dry autumn.

Duke of Connaught (Paul \& Son, 1876).-A very bright velvety crimson Rose, of globular shape, not quite good enough as a grower for a garden Rose, and seldom large enough for exhibition.

Duke of Edinburgh (Paul \& Son, 1868).-Of strong good growth and foliage, with characteristic wood; the secondary shoots are very long and rather spindly and pliable, so that the blooms are sometimes pendent. Not very liable to mildew, or much injured by rain, but in some places a victim to orange fungus. It generally comes true to its shape, which is good so long as it holds its point; but the petals are not very stout or the centre very full, and it is not a good laster. Of full size and most brilliant colour, vermilion crimson. In strong specimens the crimson predominates when the bud shape is passed, but the self vermilion, which is generally found only on the weaker blooms, is perhaps the most effective. Not lasting in colour or shape, but of large size, a free bloomer and fair autumnal, good on all stocks. This 



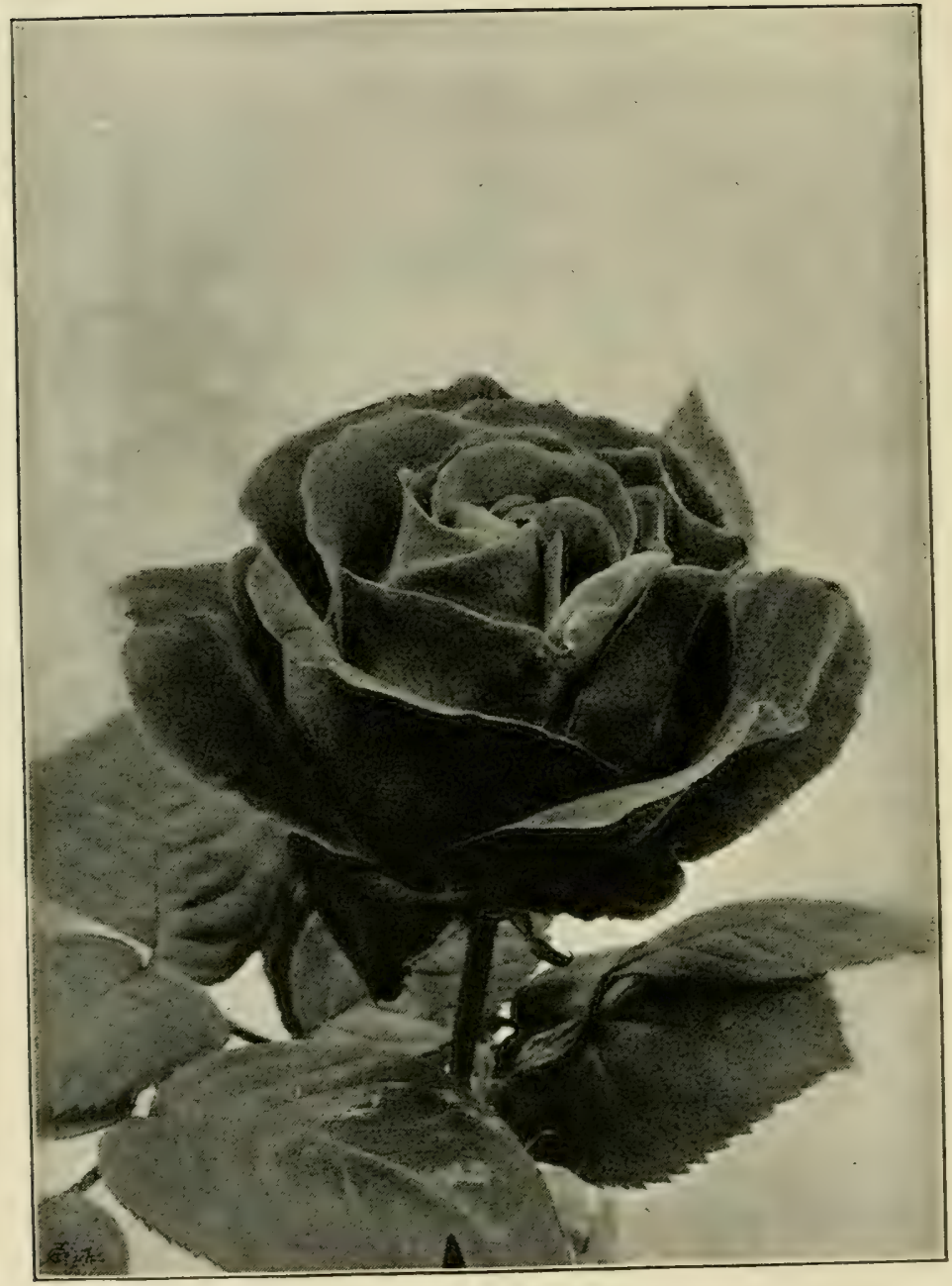

H. P. Rose, Duke of Welington. To face $p .229$ 
was for years the brightest of all red Roses, but has been surpassed in this respect by later introductions. It was "The Duke" par crecllence, as Baroness Rothschild was "The Baroness," though Duke of Wellington, not so bright, was of earlier introduction. A lady friend used always to pounce upon any red Rose in my garden that showed extra brilliance, saying she knew what that Rose was-it was the Duke of Edinburgh. Of good constitution, but rather apt to run to wood instead of to bloom, especially in autumn, and on the manetti.

Dule of Tect: (Paul \& Son, 1880).-Very like the last named in most particulars. Others of the same habit and apparently of the same family, all coming from Cheshunt, are Reynolds Hole and Sultan of Zanzibar, but these last two are very delicate in constitution while the Dukes of Edinburgh and Teck are strong and hardy. Duke of Teck is not so dark in crimson and not so brilliant in vermilion as the earlier type. The shape is also more globular and less pointed, and it is not a favourite Rose with amateurs, very seldom coming really good with me, but is of good repute under glass.

Duke of Fife (Cocker, 1892).-A rich crimson sport from Etienne Levet, with probably identical manners and customs. Noteworthy, because a sport generally comes of a lighter colour than the type. Too new to say much of, but likely to be a fine addition to show Roses.

Dule of Wellinglon (Granger, 1864).-Syn. Rosieriste Jacobs. This is marked in the N.R.S. and some other catalogues as moderate, i.e. weakly in growth, but it is quite fair in vigour and foliage with me, and does well as a standard in many places. Of strong constitution, my oldest dwarf plants on briar cutting being still my best and stoutest. Not very liable to 
mildew or much injured by rain, a free bloomer and quite a good autumnal. The blooms come well in what I call the pointed form, and are capital in petal and fulness, and grand in dark crimson colour and lasting qualities. Medium, i.e. small in size, according to the N.R.S. Catalogue, which I can quite believe to be the case where the growth is moderate, but well up to the average with me. Will not do in hungry soil or where not well treated, but high feeding and close pruning will generally produce splendid blooms. Older than the Duke of Edinburgh, and, in spite of general repute, much the better show Rose of the two with me. 'This is one of those varieties which close their petals in the evening, thus seriously disconcerting at times exhibitors who have to choose their blooms at late hours.

Dupuy Jamain (Jamain, 1868)._-Of very strong, stiff stout growth and foliage, good on all stocks, with vigorous clean smooth shoots, such as a Rose should have. Not liable to mildew, and but little injured by rain. I ought to say that all H.P.s, except perhaps Paul Neyron, Ulrich Brunner, and some others inclined to coarseness, are sometimes attacked by mildew, and are the better if rain does not fall on the open flowers, so "not liable" must be generally taken as not especially liable. The round fat smooth shoots of Dupuy Jamain produce round fat smooth blooms, which generally come well shaped, but the petals are not so stout as they look, and the centre is weak in hot weather. For exhibition it should be cut young and the point tied up for travelling, as it opens only too well. Of large size but a bad one to last; very free in bloom and perhaps the best autumnal of its colour. If I wanted a red Rose at the end of October I should come here first, and if any H.P. will bloom at Christmas 



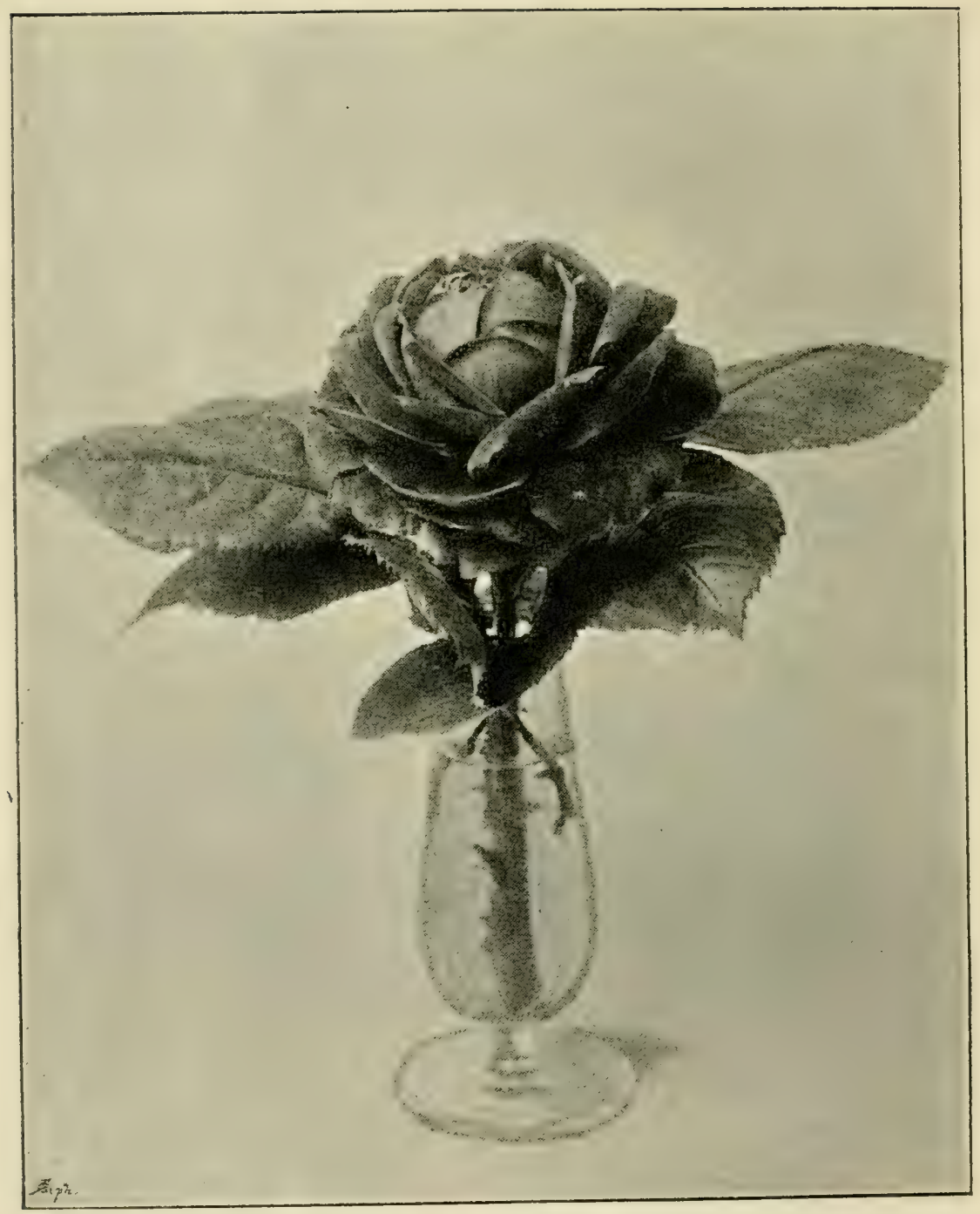

H. P. Rose, Eclair.

To face p. 231. 
this will. A good and reliable cool season Rose, of strong hardy constitution, which will grow almost anywhere and well repay good treatment.

Earl of Dufferin (A. Dickson \& Sons, 1887).-Of long but pliable growth, which, in the case of dwarfs, must be staked, or the heavy bloom will bend the shoot right down to the ground. The foliage is rather weak, and the buds even when they begin to open do not look promising or attractive. Nerertheless they slowly grow into large highly coloured blooms of thoroughly globular shape, sweet-scented, lasting, and sometimes very fine. It is quite a late Rose, not very free-flowering, nor of much use as an autumnal. Its principal fault is roughness of outline, as the true globular shape is most exacting in this respect, and this sort does not often come well with me. A Rose for exhibitors, but not for garden culture.

Enrl of Pembrolic (Bennett, 1882).-Of fair thorny growth, late, and a distinct shade of colour; a free bloomer, rather thin in petal, and only worth classing for its value in autumn, when it is often at its best.

Eclair (Lacharme, 1883).-Worthy of notice, as being a good specimen of the true globular form which is rather unusual. The growth is good, the colour very bright, the form lasting, and it is also very good in the autumn. It is difficult to get perfectly-shaped blooms of this form, and they are best avoided by the beginner.

Ella Gordon (W. Paul \& Son, 1884).-A brighter form of Madame Victor Verdier, with the same manner's and customs.

Emilie Huusturg (Leveque, 1868) - A rather weakly grower, with characteristic very green wood and foliage, not much liable to mildew. The blooms come very late, 
and not unfrequently are thoroughly bad with a green pip in the centre. The variety has accordingly dropped out of some catalogues, but I generally get some beautiful blooms, large and smooth, of first-class globular imbricated shape, with good petals but inclined to be weak in the centre; of good size, lasting in shape but not in colour, and of no use as a free bloomer or autumnal. Thus this finely shaped and very distinct Rose is in a fair way to be discarded, being generally too late for exhibition, and too shy in blooming and weak in growth to be useful for other purposes.

Eticnne Levet (Levet, 1871)._-Of robust and smooth but very uncertain growth; long, strong, and stout in rich soil where it has a good hold, but otherwise quite short and stumpy. The foliage is very fine, and the blooms come early and well with large very smooth shelllike petals: there is, or should be, a good point, but the general shape is open, the centre weak, and the form not lasting. Must be cut young for exhibition and tied up at once, for it is not reliable in hot weather. Not much injured by mildew or rain, but not good as a free bloomer or autumnal. It is of large size, and its grand petals and smooth even outline make it an effective show Rose in a cool season; but, though it does well on the manetti, for general cultivation or on weak soils it is not one of the best.

Eugene Fürst (Soupert et Notting, 1875).-A very strong grower with good foliage, liable to orange fungus, and to mildew which appears even on the petals, but not much injured by rain. This is a Rose whose manner it is to waste all its strength upon the wood, and have none to spare to swell the bud. We have some Roses which promise more than they perform, and others which perform more than they promise. Thus, 
in H.P.s this rose has small blooms on very strong shoots, while François Michelon has very large flowers on thin small shoots. In Teas, the class of those who promise more than they perform finds an exponent (with me at least) in Etoile de Lyon, while the good part of François Michelon is ably played by Comtesse de Nadaillac. Eugene Fuirst comes generally well, of a good dark velvety colour, and nice shape, lasting fairly.

Eugénie Verdier (J. B. Guillot, 1869).-Syn. Marie Finger (Raimbaud, 1873).-_This Rose used to be called Mademoiselle Eugénie Verdier, but the title word seems lately to have been dropped by common consent, a matter of more importance than appears at first sight, for there are two other Roses named Madame Eugene Verdier, one H.P. and the other Tea. Moreover in the case of this Rose the synonym Marie Finger is most commonly used to save this confusion, but we must have a rule with regard to these troublesome synonyms and stick to it, and it seems fair that the oldest name should be the one to abide by, though an exception seems almost needed in this case. The Rose is of Victor Verdier race, with all the manners and customs of the family, and is certainly one of the best of them. The growth is often marked moderate, but it is fair with me when well treated. A beautiful colour, often nearer what I call "salmon" than any other Rose. Lady visitors will generally be drawn away from the brightest crimsons by a row of this variety in good bloom. Of large size, but not of very good lasting qualities, the centre being rather weak, and the form soon lost. Very free blooming, and an excellent autumnal. Should be cut small and tied up for exhibition.

Exposition de Brie (Granger, 1865), see Maurice Bernardin. 
E. Y. Ters (E. Verdier, 1874).-Only moderate in growth and foliage. Not much liable to mildew, and stands rain fairly. The blooms come well, very full, of compact regular smooth globular shape, very bright colour, and good lasting qualities, but below the arerage in size. Fairly free in bloom, but of little use as an autumnal.

Ferdinand de Lesseps (Verdier, 1869), sec Maurice Bernardin.

Fisher Holmes (Verdier, 1865).--Of good growth and fair foliage. Particularly liable to mildew, but not much hurt by a little rain. The blooms come well, of the good pointed shape of the Duke of Wellington. The N.R.S. Catalogue speaks of it as "rather thin," but I have not found it so: on the contrary, with me the shape is lasting, though the brightness soon fades. Below the average size in ordinary soil, but free blooming and a capital autumnal. This is a most useful sort, which accommodates itself well to circumstances-shuts up its petals at night, tightens its point in hot weather, and forms a beautiful button-hole in autumn or when not thinned for show purposes.

Francris Michclon (Levet, 1871).-Of peculiar and very characteristic growth, with green slender yet fairly stiff stems, and thin poor foliage. This is the Rose above all others whose performance is better than its promise. It seems incredible that such a little bud on its spindly stem should open into what is one of the largest and finest show Roses we have: but it does. The petals look thin and the growth seems so weak that an exhibitor who did not know the Rose would be slow to believe it would stand or hold its shape in a hot tent: but it does this too. Little affected by mildew, but soon injured by heavy rain, the blooms 
come fairly well, but the centre though almost always well covered has seldom a defined point and is sometimes irregular. The outline is often rough and the colour is not lasting. It cannot be called a free bloomer, and is one of the worst autumnals in our list of H.P.s, a large proportion of the plants having no second crop. In propagating this Rose and others which are shy bloomers and bad autumnals, care should be taken to bud from a flowering stem, for the young plant will probably not bloom the first year if the bud has come fiom a non-flowering autumnal shoot; and a "runaway maiden" is a source of disappointment, even among Roses. Requires the briar stock and generous treatment. This Rose is apparently the progenitor of Mrs. John Laing, one of the most worthy of the gold medallists.

Général Jacqueminat (Rousselet, 1853).-Good but rather slender growth and fine but thin foliage; liable to mildew, but not much injured by rain: very freeflowering, fragrant and a good autumnal, but decidedly thin. It must be grown very strong and cut young to be fit for exhibition, but it is often well shown, principally by nurserymen and large amateurs, and is best as il stanclard maiden. As bright as Duke of Edinburgh when grown to perfection, but not lasting or of the largest size : still "le brav' Général" knows its weakness, "pulls itself together" in hot weather, and tightens its point as hard as it can. Few Roses have had such a lasting reputation: for this grand old veteran is the great grandfather of almost all our red H.P.s, and is still grown very largely on all stocks for market and florists' purposes, "Generals" being almost as well and affectionately known in the trade as "Niels."

Germaine Caillot (Pernet, 1887).-Apparently a 
Hybrid Tea, of quite dwarf habit, but of stont, stiff, robust growth. This is a fine early show Rose, large, very full, bright and glistening and of perfect shape, white tinted with salmon rose. Its short growth makes it quite unsuited for anything but show purposes, but the constitution seems fairly good, and I am surprised that it is not grown more largely by exhibitors.

Gloire de Margottin (Margottin, 1887).-This is a good deal like an improved form of Gloire de Rosomenes (Vibert), which is, I believe, the progenitor of General Jacqueminot. The growth is long and rambling, and it does well for a pillar, or especially for being pegged down as a bedding Rose. It is exceedingly bright in colour, but thin in petal, and not very full: nevertheless the shape is good and pointed while it remains, and it is perhaps the brightest of all the true red Roses. . It seems likely to be very effectual if forced for market purposes, but has not I fancy as yet superseded "the General."

Gloire Lyonnaise (Guillot, 1884).-A Hybrid Tea, said when sent out to be a yellow H.P. : but it is practically white, the yellow shade being very faint. Of very strong growth, even in poor soil, not liking clay land. It will not do on manetti and, like most Hybrid Teas, is best as a standard. The buds are beautiful, but the petals are very thin, and it will not stand in hot weather. Not free-flowering if pruned hard, but capital in autumn, when fine well-shaped blooms may sometimes be gathered.

Grace Darling (Bennett, 1884).-This was sent out as a Tea Rose but pronounced to be a Hybrid Tea by the National Rose Society, the foliage being more like that of the H.P.s : of good growth, not much liable to mildew, but requiring dry weather. It is rather wanting in stout- 


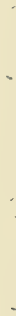




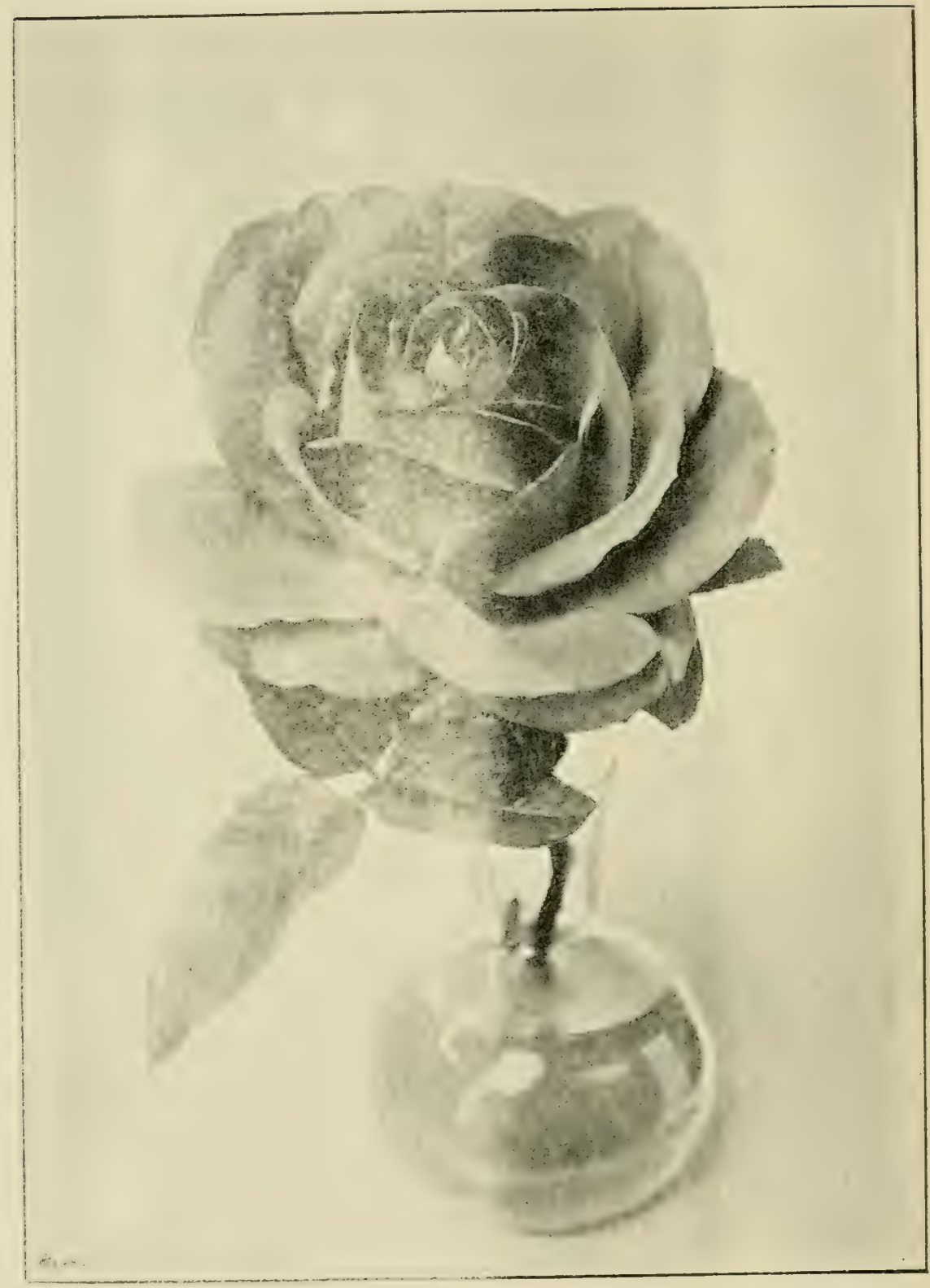

útistave Piganeau.

To face $p .23 \%$. 
ness of petal and fulness of centre, but comes well and opens readily. Distinct in appearance and colour, of good shape and medium size, not often large enough to be shown among H.P.s, and hardly lasting enough to be shown at all. Hardy, very free-flowering, and a good autumnal. Best as a standard, and requires goorl soil and generous treatment.

Grand Mogul (W. Paul \& Son, 1887), see Jean Soupert.

Gustave Piganean (Pernet \& Ducher, 1889).-Very short in growth, which is nearly the only fault of this very fine Rose. The foliage is good, and the plump fat buds above it open into very large, brilliant, grandly shaped blooms, with broad stout petals, and beautiful centre. Very little liable to mildew, and not much injured by rain. It was a great disappointment when this splendid Rose proved to be a poor grower. Moreover the plant is not lasting in vigour, but often gets weaker, and it is best as a maiden, either on briar or manetti. It is very free-flowering, which seems to be a cause of its weakness of growth: it will not make wood, but is constantly forming buds. A good autumnal, capital for forcing, and a large lasting reliable exhibition Rose of the first rank.

Gustave Regis (Pernet \& Ducher, 1890).-A yellow Hybrid Tea, of fair growth and foliage, with long pointed buds. It falls abroad when expanded, and should be cut in the bud stage, when it is fine for button-holes.

Harison Weir (Turner, 1879).-A weak grower, suitable only for show purposes. Only one stem should be allowed to a plant, as it cannot be made too strong and if cultivated in this fashion, good growth and foliage may be obtained as a maiden. Not very liable to 
milclew or to be spoilt by rain: a fine bloom, coming pretty true, stout in petal, globular in shape, a trifle weak in centre, but of beautiful velvety colour and fragrant scent. Of full size and good lasting qualities when grown strong on the briar, but a Rose of weak constitution, of no use as a free bloomer or autumnal.

Heinvich Schultheis (Bennett, 1882). - This was a most useful introduction. A hardy strong Rose, of capital growth and fine foliage, an early and free bloomer, and a good autumnal. Not liable to mildew or injury from rain. The flower has large handsome petals, and is of beautiful shape and colour when young, but soon loses both, the centre being generally disappointing. It must be cut small and tied up for exhibition. An excellent hardy Rose, of beautiful fresh colour, and large size, of which the following sports have been issued, Paul's Early Blush and Mrs. Harkness, lighter than the type and too much alike, and Merrie England, a striped Rose.

Her Majesty (Bennett, 1885).-A well-named Rose. We all know the fable of the lioness, the queen of beasts, who, on being taunted with having only one young one at a birth (which is not the least true, by the bye), said it was so, but that one was a lion. We acknowledge the imperial claims of Her Majesty, and that when a bloom does come it is often a queen, but on diwarf plants I have, till lately, rarely succeeded in getting a bloom to each. It is a little better as a standard, and is no use on the manetti. Manners and customs are notoriously strict and exacting in royal circles, and in this remarkable Rose we certainly have some striking peculiarities. Of long, strong and yet robust growth if well fed, but by no means free: it makes extraordinary growth under favourable conditions, but a 
poor show if not treated regally and favoured with queen's weather. Prune high or low you will get but few shoots to a plant, and if the single growth of a maiden shoot be stopped, instead of breaking in several places like the vulgar herd, Her Majesty generally shoots only from the top bud left, and continues one stem upwards as before. We may place the plants close together, for the stems of each are few in number and upright and stiff. It has fine foliage and large stems with tremendous thorns, the whole being extremely and notoriously subject to mildew, so that it is best planted by itself or among the Teas, where the infection will be less dlangerous in the summer season. If grown well, a large proportion of the blooms come good, and they can stand a little rain. They have fine stout petals, and are wonderfully full in the centre, so much so that the Rose has quite two shapes, and the best one was not known for the first year or two: for it has in the first stage a grand regular semi-globular shape, and when expanded and overblown it is yet so perfectly full, even when as flat as a pancake, as to show no eye, and to be still presentable and wonderful though not so beautiful as a Rose. The colour is best and purest in the first of these stages: in the second it is more mixed, something like a gigantic Marie Cointet. When presented for the Gold Medal, which was granted by acclamation, it was shown by $\mathrm{Mr}$. Bennett in great quantity, several large boxes of it being staged. Every bloom was fully expanded, and its true beauty remained unknown. It was then sold to America and we had to wait a year for it. When it was at last obtainable, there was a large demand for the half-guinea plants, with the result I believe that there was hardly a bloom seen in the country that year, the plants having no 
doubt been budded from non-flowering shoots. The following year the true form was seen, and it is not now quite so shy a bloomer as it was. In size and lasting qualities it is quite at the top of the tree: as a free bloomer and autumnal, absolutely at the bottom. A secondary or true autumnal bloom is rare: it does bloom as a maiden, otherwise its title to the term Perpetual might yet be in abeyance. In this and other respects it is already better and may still further improve: every year it seems to act a little more like other Roses than it used to do. Another remarkable point about this Rose is its reputed parentage; for it is said, though it is generally supposed there must have been some mistake or accident, to be a seedling from the old Tea Canary, a yellow flimsy thing according to modern notions, and Mabel Morrison, a white sport from Baroness Rothschild which is particularly open and deficient in the centre. Mr. Bennett was one of the first to practise hybridising in this country, and sent out his new issues as Pedigree Roses: but one would think that on beholding the illustrious progeny of this apparently ill assorted pair he must have been inclined to consider chance still as likely to be successful as the careful choosing of seed-parents.

Henri Ledechanx (Ledechaux, 1868) and Hippolyte Jamain (Lacharme, 1874) are both members of the Countess of Oxford or rather Victor Verdier family, with the same general manners and customs, which it will not be necessary to repeat. Fairly good growth, with smooth characteristic wood, the first shoots losing their foliage early, being very liable to orange fungus or red rust; objecting strongly to light soil or the manetti stock; free producers in summer and autumn of blooms of good globular pointed shapes, but not very 
lasting. Of the two here mentioned, the former is very thin and not suitable for exhibition, but has a charming bright bud for button-holes; and the other is early, large, with fine foliage, and sometimes a good autumnal and a fine show Rose, but requires rich soil.

Horace Vernet (Guillot 1866).-A typical show Rose; grand in the extreme in every way on the exhibition table, equalled by few, and surpassed by none; but to be sedulously avoided by those who grow Roses for ordinary garden purposes. The plant is of a thoroughly weak constitution; and in a general way cannot be kept in health and strength beyond a year or two. Indeed it is in many places useless as a cut-back; no other Rose is more worthy of the annual system of culture-budding anew on fresh strong stocks every year and cutting away the old plants to get the strongest buds-and for none is it more necessary. When thus treated, the growth and foliage are good enough, one would think, to keep the stock roots in health; but the plant is almost sure to dwindle if preserved, lasting best, I am told, on the seedling briar. Not very liable to mildew or to be injured by rain. The blooms generally come good; and good they are, with the stoutest of petals which shut up at night, capital centre, perfect shape (pointed, passing to imbricated), good dark colour, and lasting qualities of the first order: Not a fiee bloomer or a good autumnal : thesc are "lions," to be made much of, and we must not expect many of them. Cut away the plant, as soon as it has bloomed, with a ruthless hand, to get the best and biggest buds for propagating. Waste none on weak stucks or on manetti, and bud a good many, not delaying tor long, for some may fail and require rebudding; amd, whether you keep the old plants or not, you will not cut from them so long as you have young plants to 
CHAP.

go to. Hundreds of gardener's and Rosarians, who would otherwise never have heard of the great French artist, have had his name "familiar in their mouths as household words" by the help of this most noble Rose his namesake.

James Brownlow (A. Dickson and Sons, 1889).-A scedling from Paul Neyron and Marquise de Castellane, and inclined, as was likely from such parentage, to be cuarse from being too full. The growth is uncertain, but the colour is distinct and brilliant. Tery late in blooming and generally much wanting in smoothmess and regularity, but on rare occasions a fine lasting bloom may be obtained. The family of Paul Neyron is practically free from mildew.

Jean Liabaud (Liabaud 1875). - Of fair growth and foliage, not liable to mildew or injury from rain. A free bloomer, but a poor autumnal, and a Rose of shocking manners. Occasionally one gets a lovely bloom, of open imbricated shape, not strong in the centre, but shaded in the most beautiful way with all sorts of tints from vermilion to the deepest crimson or maroon. But if you get one such in the course of a year from a dozen plants you will be pretty lucky, for most of the flowers come distorted in all sorts of ways. Worth mentioning for the mere beauty of colour shading, but an amateur; with not much room to spare, will probably soon have had enough of this Rose.

Jean Soupert (Lacharme, 1875).-Syn. Giand Mogul (W. Paul and Son, 1887). It is strange that these two Roses should be so very like, not only in flower, but in wood, habit, manners and customs, when the latter is said to be a seedling from A. K. Williams, which is two years younger than Jean Soupert. At any rate, the National Rose Society was no doubt right in pronouncing them too 


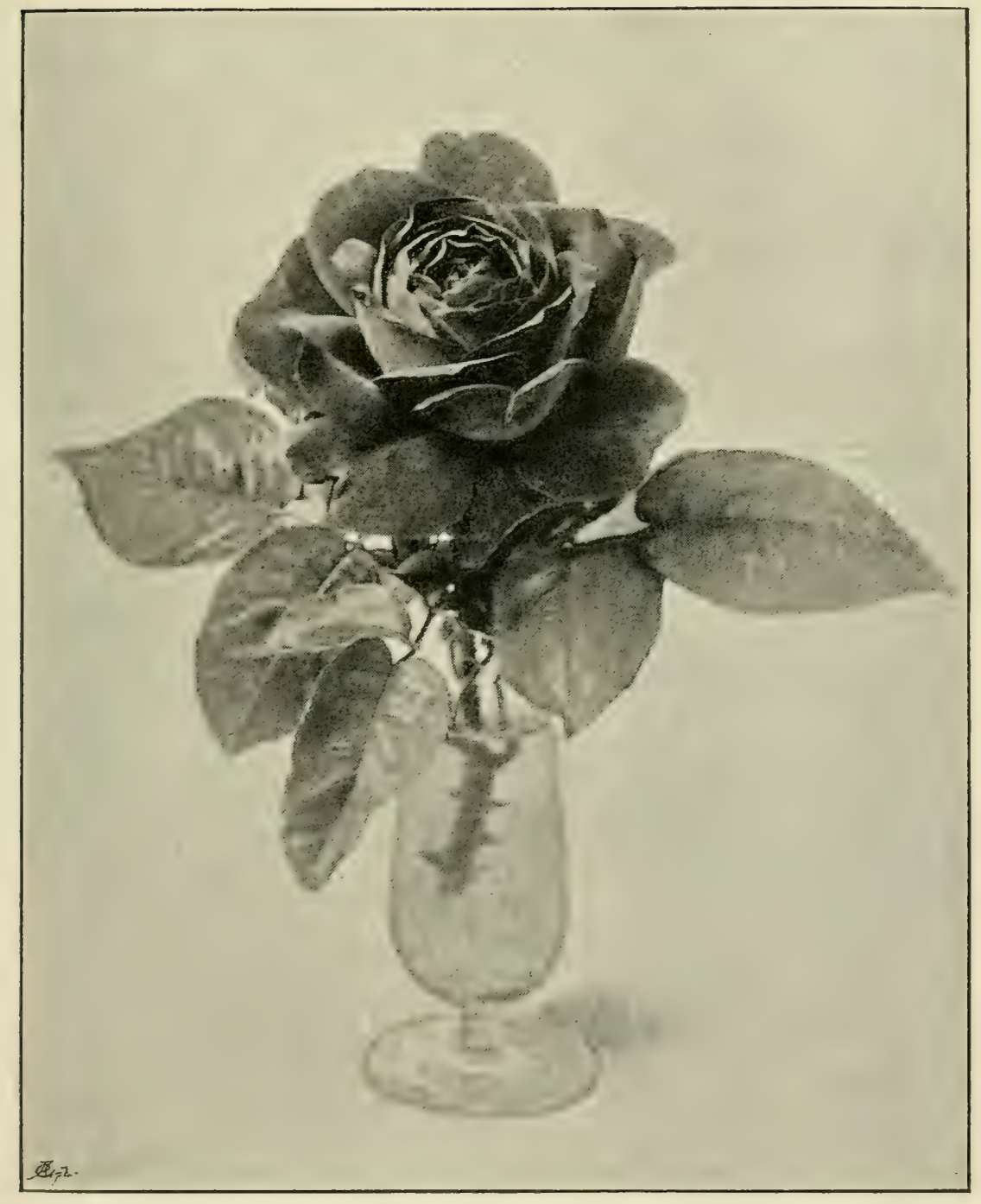

H. P. Rose, Jeav Soupert.

T'o face p. 212. 

much alike, and therefore synonymous. The foliage is fair and the growth good but characteristic and peculiar. One or two shoots run away considerably above the others and give promise of good blooms, and when the bud forms, it is of very good typical shape and seldom comes cracked or divided; but now, when you expect the plant to put all its strength into the bud, it does not do so; the stem thickens at the base, and tempting buds for budding form all up the stem, but the flower buds swell very little, although they open slowly. The bloom, though sometimes of fair average size, is smaller and weaker than one would expect from the size of the shoot, but the shape is quite first-class, with a round smooth button in the centre, the petals perfectly imbricated, and the outline regular. It is quite one of the three or four best examples of the imbricated form among H.P.s. The bloom is not very lasting, the colour though striking in its very deep shade is sometimes rather dull, and it cannot be called a free bloomer or reckoned as a good autumnal. Decidedly liable to mildew, which sometimes affects the petals. A late bloomer, which is well worth growing if only for its thoroughly distinct appearance in many particulars.

Jeannie Dickson (A. Dickson and Sons, 1890).Apparently hybridised, though perhaps remotely, with the Teas, the shape of the foliage suggesting some such strain. A good grower; but requires generous treatment, not liable to mildew or much injured by rain, freeflowering and pretty good in the autumn. The blooms have capital long large smooth petals, with centres high and finely pointed. Not very lasting, and difficult to keep clean in trying weather, but a fine show flower if grown strong, cut young, and tied up if necessary.

John Hopper (Ward 1862). $-\Lambda$ well-known and 
formerly very popular English Rose, raised near Ipswich. A very strong grower, very hardy, with good constitution and foliage, liable to mildew, but not minding a little rain. The blooms come early in the season, and are fairly regular, but the shape is open and not of the first class. The colour is beautifully fresh at first, of a different shade on the under side of the petals, but is even more fleeting than the form. Of fair size, a free bloomer and a good autumnal. A capital garden Rose, doing well on all stocks, or even on its own roots as a cutting, and on poorish soil.

John Stucert Mill (Turner, 1875).-Of strong long growth, not liable to injury from mildew or rain. A late bloomer, uncertain as to quality and usefulness. In some seasons all the flowers come as mere red lumps, but in others the majority come of fine imbricated shape and colour, and it is then a good show Rose, of average size and fair lasting qualities, but it is not a free bloomer or a good autumnal. In my experience it comes best in a cool season, but some other growers find it more generally reliable.

Jules Margottin (Margottin, 1853).-Of very strong, thorny, hardy growth, with good foliage and strong constitution. A very free bloomer and good autumnal, but a poorly shaped rough bloom from a florist's point of view. Early, sweet-scented, and not particular as to stock, soil or treatment. A useful old-fashioned garden Rose, hardy, capable of being grown on its own roots, and suitable for cottage gardens or odd corners. The seed parent of Edouard Morren, another very strong grower, with huge globular flowers, generally rough and unsymmetrical.

Kaiserin Auguste Victoric (Lambert and Reiter, 1891).-A new Hybrid 'Tea of fine form and very 
promising; but not yet sufficiently tried to have its full value and possible demerits described.

La Frầcheur (Pernet and Ducher, 1891).-Also a new Hybrid Tea, of high promise. The growth is moderate, the buds long and pointed, and the blooms large but not lasting, with fine high centres and broad smooth outer petals. It should be remembered that as a rule all the Hybrid Teas, as well as the true Teas, give better flowers when grown as standards.

La France (Guillot, 1867).-Very well known and popular, a Rose by itself, of great merit and of a thoroughly distinct type, pronounced somewhat suddenly by the National Rose Society to be a Hybrid Tea. There does not appear to be sufficient evidence or authority for this distinction, and opinions on the matter are divided; but some signs of affinity to the China race are to be seen in the habit and freedom of bloom. It seemed likely to be the founder of a new race, but Augustine Guinnoisseau,Duchess of Albany,Duchess of Leeds, and Danmark have only appeared of late years, and not one of them is an improvement upon the original. The growth and foliage are good and very characteristic, not much liable to mildew, but the blooms are rather sensitive to rain. In strong rich soil, or if too closely pruned and thinned, the blooms often come spherical and ball-like without defined shape, but on lighter land and when grown as a standard the form is very fine. The petals are good but the centre is sometimes weak or divided. The colour is beautiful, and should be of a silvery brilliance, but it is rather difficult to keep the flowers "clean." In freedom of bloom and as an autumnal it is of the very highest class : of the largest size, but not a good laster, and should be cut young in: hot weather as it opens quickly. The scent is most 
distinct and exquisite: in that respect I should place it at the head of all the Roses of this section. It would occupy the same position in the estimation of a good many as a general all round Rose for everybody, exhibitors, gardeners, cottagers and all, for it is hardy and of strong constitution on all stocks, showing pretty buds well into October, and will do well or even better on lightish soil, but should always be grown as a standard.

La. France de '89 (Moreau, 1889). - Is a bright large showy red Rose, sometimes pretty good, and has no connection with the above.

Lady Arthur Hill (A. Dickson and Sons, 1889).-A seedling from Beauty of Waltham, distinct in colour but small.

Lady Helen Stewart (A. Dickson and Sons, 1887).The same fault, want of size, is noticeable in this Rose, which is however very bright and free blooming and a good grower.

Lady Mary Fitzuilliam (Bennett, 1882).-A Hybrid Tea, of very dwarf growth, said to be a cross between Devoniensis T. and Victor Verdier H.P. It is not weak in constitution, as the growth though very short is hardy and robust, and is very free-flowering, so that perhaps, as noted in the case of Gustave Piganeau, the growth is simply checked by the habit of constantly forming very large and exhausting flowers. It is surprising what a number of good and fine blooms will be produced from a very small plant. Not liable to mildew, but the blooms are apt to be spoilt by rain or even heavy dew. The shape is excellent, and the petals are long and fine. It seems absurd to perch such a dwarf sort "on a stick," but it does better and even grows better" as a standard, and can be successfully cultivated on manetti as a maiden, though the union is often bad. 
It is a good autumnal of high merit in many ways, and should be of a light pink colour, but is apt to come quite white, Lady Alice, White Lady, and Maid of the Mist having been sent out as sports of this variety.

Lady Sheffeld (Postans, 1881).-A late show Rose of only fair growth, brilliant and distinct in colour, with good shape and fine petals, but not large, a free blommer, or a good autumnal.

Le Havre (Eude, 1871).--Of fair average growth, with good foliage: not specially liable to mildew, but rain will impair its quality. A beautiful show Rose, one of the best examples of the imbricated form, but the blooms will not come of good shape or colour in bad weather. Almost like A. K. Williams at its best, but not often large. Like Fisher Holmes and some others, this Rose shuts up at night, the petals crinkling inwards: best as a maiden, not free in bloom or a good autumnal, but with a high reputation for its lasting qualities on the plant as well as when cut.

Lord Mucculcey (W. Paul \& Son, 1863).-Hardy and strong, with fair growth and foliage. Good bright colour and very full shape, medium in size. Freeflowering and very reliable, for a majority of the blooms come good though not first-class. Might be useful as a garden Rose, but it is not a good autumnal.

Lonis vun Houtte (Lacharme, 1869).-Of weak growth and small foliage: not much injured by mildew, but suffers from orange fungus and rain and "burns" in hot weather. The blooms will only come fine if strong shoots are produced: and this is a difficult task with purchased plants, as the constitution is weak and does not bear removal well. It is best to bud it annually: but plants which have not been noved will sometimes do well as cutbacks for a few seasons. It requires high 
culture on the briar and is not free-flowering or good as an autumnal, but it is a fine well-built bloom when you get it good, with stout petals, high centre, fine globular outline, full size and dark, sometimes rather dull, colour. The flower's being heary and the wood weak, flowering shoots of dwarfs should be staked when the bud is formed. The lasting powers of the blooms are particularly good, and it is worthy of notice, as an example of the odd manners and customs of Roses, that some of the weakest growers have the most lasting flowers, and rice versî. For instance, Marquise de Mortemart and Madame Ducher, two H.P.s that have practically dropped out of cultivation from their extreme poorness of growth, are especially noted for the lasting character of their blooms, while such strong growers as Heinrich Schultheis and Thomas Mills show the opposite side of the picture. Louis van Houtte will not do with me: a respectable bloom even on strong shoots is a rarity: but many others grow it well and esteem it highly. For anything but exhibition purposes, howerer, it should be generally avoided.

Mabel Morrison (Broughton, 1878).-A pure white sport from Baroness Rothschild, but smaller and very weak in the centre: only worthy of notice as a seed parent of Her Majesty.

Madame Charles Wood (E. Verdier, 1861).-Formerly of considerable reputation as a show Rose, but a bad grower, of weak constitution. The blooms often come divided and rain will spoil them. Sometimes a strong fine Rose, with large petals, rather flat in shape, and tightly incurved in the centre. A good lasting flower, of full size, but a "bad doer" and not to be recommended.

Madame Clemence Joigneaun (Liabaud, 1861). - A very 
strong grower with fine coarse foliage almost proot against mildew. The blooms are apt to be rough and badly shaped, and it seldom has sufficient form or smoothness for exhibition. Of large size and very sweet but rather a dull colour. A free bloomer, but not very good as an autumnal. A hardy garden Rose, useful, early, of strong constitution, which will do pretty well in light soil. Margaret Haywood and William Warden are sports of lighter colour from this Rose.

Madame Charles Crapelet (Fontaine, 1859).-An old Rose, but still very good at its best, as a smooth refined show Rose of the popular imbricated shape. Rather a weak grower, and liable to mildew, but not soon spoiled by rain, and a sort which well repays high cultivation. This variety, like a good many other's, has its good and bad rear's, and is probably best in a cool season. Of capital form, very smooth, regular, and full, of good listing quality and fair size. Not a free bloomer or a good autumnal, but though never of strong or hardy constitution, and now excluded from the N.R.S. Catalogue, it cannot, I think, like some others of its age, be suspected of having deteriorated.

Madame Eugene Verdier (Verdier, 1878).-Grows well as a maiden, but the first growths of cutbacks are sometimes very short: still the blooms come just as well, and the foliage is fine. The constitution is delicate in some localities and the plants often gradually die; severe pruning seems to produce canker. It is not very liable to mildew, but a slight shower will stain the colour, and much rain will cause the petals to "gum," i.e. stick together, and rot. The blooms are likely to be coarse and are not often of refined shape or appearance; but they are very large with wonderfully fine petals and well-filled centres. Fairly free in bloom and a pretty 
good autumnal: the shape is globular but delicacy and regularity of outline are often wanting, and really it is sometimes almost like a prize cabbage for it is quite one of the largest Roses. It should be noticed that there is a Tea Rose of the "Dijon" race, of exactly the same name, besides Eugénie Verdier whose synonym is Maric Finger.

Mudeme Gutiel Lui:ct (Liaband, 1877).-A Rose of distinct habit, with strong vigorous growth, after the manner of a summer Rose. The foliage is very fine, but much liable to mildew : it is however maintained through the autumn more completely than that of any other H.P. The blooms are occasionally divided, but generally good. On cutbacks they come early and all at once, also after the fashion of summer Roses, and as they are easily injured by wet, two or three hours of rain at a critical time will destroy three-quarters of the crop. A rery popular Rose and general favourite, for exhibition or bedding and massing purposes. It is not particularly good in lasting qualities but of full size, very smooth with good petals and a capital pointed centre, and is noted for its delightful fragrance, and for its colour, which is the most attractive shade of pink among H.P.s. A very free bloomer in the season, but a shocking autumnal, hardly averaging more than one or two poor things as secondary blooms to each large plant. Hardy and of strong constitution, good on all stocks, making a great deal of thorny growth in the autumn, and forming quite a big bush or fine standard in good soil. It should be left long in pruning and only the outer shoots retained.

Madame Henri Pereire (Vilin, 1886).-A crimson rose of pretty good growth that is generally well spoken of, but it is very liable to mildew and proves of little value with me. 
Madame Hippolyte Jamain (Jamain, 1871).-Of good smooth growth and foliage, not very liable to mildew, but rain will injure the blooms. A coarse Rose, generally rough and irregular if grown strong, but occasionally of even globular shape in hot dry weather, and then valuable for exhibition as it is very large, full, and lasting. A free bloomer in the season, but not much of an autumnal. It should be noticed that there is a good Tea Rose of exactly the same name as this, besides Hippolyte Jamain H.P.

Madame Isace Pereire (Margottin, 1880).-Apparently a perpetual Hybrid Bourbon and the founder of a new race. Of extra strong stout growth with fine foliage, not liable to mildew. The blooms are very large and sweet, sometimes of good form but weak in the centre. It makes a fine show as a garden Rose, being very free-flowering, and capital in autumn. Thoroughly hardy and makes a fine standard, but does equally well as a bush. A seed parent of Mrs. Paul, and of Madame Pierre Liabaud which is identical with the type except in colour, and also, I hope, of others to come which will perpetuate the good qualities of the Bourbon family, in autumnal flowering and sweetness. Madrine Lachume (Lacharme, 1872).-Of fair growth and foliage, with characteristic habit. The shoots themselves require to be severely thinned, and then they must be looked over from top to bottom several times during the growing season, as it is such a free bloomer that every woor bud will break and try to form a flower bud before the top one has begun to swell. Very liable to mildew, and absolutely spoilt by any rain even at quite an early stage. Even a heavy dew will sometimes soil the blooms. These are of a pure white, and for years this was the best H.P. of its 
colour, a row of it in full bloom looking most charming just as the dusk of a July evening comes on. Water appears to wash the colour off the petals and leave them transparent, for they are of the most delicate texture and will show the ravages of thrips very readily; and as these are sure to come in some places in hot dry weather, and wet is even more fatal, Madame Lacharme has often a bad time of it. The shape is good and lasting, globular with the centre well filled, but the size is not up to the average. It will come again well in the autumn, if it should be particularly dry and fine, but as the best white H.P. it has been completely eclipsed by Merveille de Lyon, and must put up with the qualification " best under glass."

Madame Noman (Guillot, 1867).-Another pure white H.P., but a weak bad grower with small foliage. 'The blooms also are quite small but of exquisite form and the purest colour. This Rose and Boule de Neige are much better shaped than Madame Lacharme or Merveille de Lyon, but are so very small in comparison as to be completely out of it.

Madame Prosper Laugier (Verdier, 1875).-Of good strong stiff growth with characteristic appearance and habit. Distinct also in colour, but unreliable and not to be recommended for ordinary purposes.

Madame Victor Verdier (Verdier, 1863).-A very strong grower with fine foliage beautifully coloured in the early spring. Not especially liable to injury from mildew or rain. A well known crimson Rose, forming large clusters of buds which should be carefully thinned. The later blooms on the longest and strongest shoots are the best, and occasionally these are very fine, full, lasting and bright. Fairly free-flowering and good as an autumnal, but though it is a hardy good grower 
with strong constitution, high cultivation is necessary for the production of really good blooms.

Magna Charta (W. Paul \& Son, 1876).-Exceedingly strong growth, with large foliage: not liable to injury from mildew or rain. A very large flower, inclined to be rough and irregular, very full and showy. Like most Roses which are too full, and therefore apt to be uneven and "coarse," it is worst on maidens and best on cutbacks. Fairly free blooming considering its size, but a very bad autumnal. A hardy, showy Rose for massing, doing well on all stocks.

Marchioness of Downshire (A. Dickson \& Sons, 1894). A fine new Rose, of good substance, colour and form, which gained the Gold Medal in 1894, and will, I hope, pxove worthy of the distinction, but at present it is untried in growth and habit.

Marchioness of Dufferin (A. Dickson \& Sons, 1891).A Gold Medal Rose of large size, fine colour and good form: not, apparently, a very good grower, and the blooms seem easily injured and stained by rain, but they are excellent in fine weather, lasting, and quite distinct.

Marchioness of Londonderry (A. Dickson \& Sons, 1893).-Another winner of the Gold Medal for the Irish firm. The flowers are extremely large with grand petals, but the grayish white colour is not very pleasing, and I fear they will fail to open properly in damp weather: however it is too soon to speak of it with any certainty.

Maréchal Vaillant (Jamain, 1861).-Syn. Avocat Duvivier. Of good growth and foliage, well thought of in its day, but now superseded by better sorts. A useful garden Rose, good on all stocks.

Margaret Dickson (A. Dickson \& Sons, 1891).-A Gold Medal Rose, said to be a cross between Lady Mary Fitzwilliam and Merveille de Lyon. When first shown 
by the raisers, it was heartily welcomed as the finest white H.P. yet known, for it supplied just what was wanting in Nerveille de Lyon, long petals forming a good point in the centre: and a pointed white H.P. of good size was unknown. It is a good illustration of the impossibility of describing the manners and customs, merits and failings, of any variety till it has stood the test of some year's' experience, that up to the time of writing English grower's have generally failed to get blooms of this variety approaching in excellence those which are still so well shown by Messis. Dickson. A considerable improvement in this respect has taken place in 1894; over-propagation has been known to act prejudicially on a Rose; and it will be a great gain if we can all grow such specimens of Margaret Dickson as those which won the Gold Medal. It is very strong and vigorous in growth, with fine foliage sadly liable to mildew, fair in freedom of bloom but rather a poor autumnal.

Marguerite Boudet (Guillot, 1888).-Of small weak growth, and only suited for exhibitors. The blooms are most delicate and easily injured by damp, but sometimes a very fine and first-class flower is produced.

Marguerite de St. Amand (Jamain, 1864).-Of fair thorny growth, with good foliage, very green in the spring. Not liable to mildew nor much injured by a little rain. The blooms almost alway's come well, of a delightfully fresh pink colour, and regular but open and rather flat shape, well filled in the centre. One of the best of its colour, early, free blooming and a good autumnal, of large size and good lasting quality. It is an unfortunate custom of this Rose to be particularly palatable to rabbits, who will search out and attack it first among a large collection. 


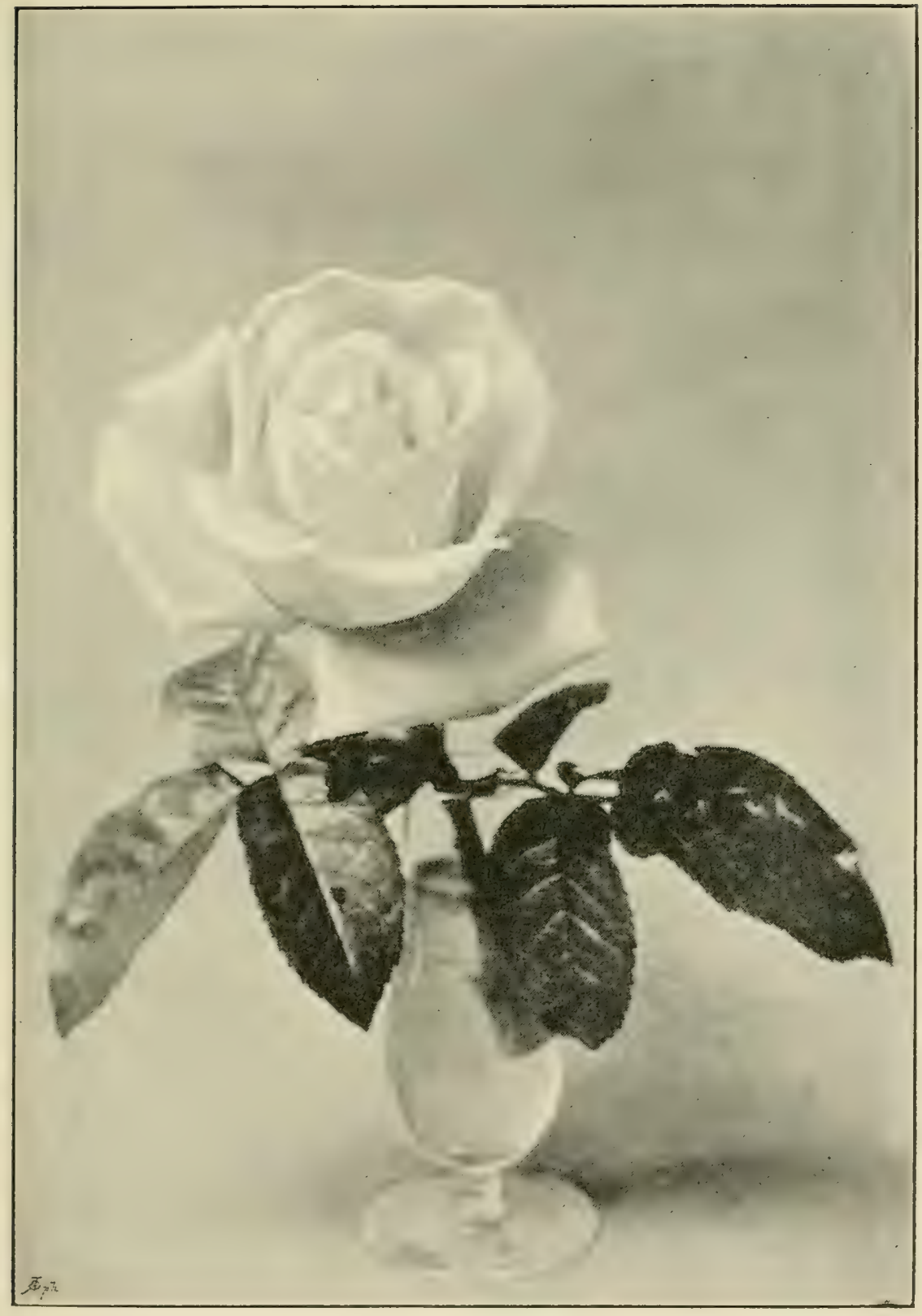

H. P. Rose marguerite Boudet.

To face p. 254. 

Marie Banmann (Baumann, 1863).-Syn. Madame Alphonse Lavallée. A Rose of great reputation. The growth as a cutback cannot be called more than fair, and the foliage is not large. The wood is weak and pliable, and the flowering shoots of dwarfs must be staked, as the stem is not stiff enough to support a heavy bloom. This habit much detracts from the appearance of the flowers while on the plant, as they generally fall over with their faces to the ground. Fragrant, not much injured by rain, but decidedly liable to mildew. It is especially noted as one of the most reliable of Roses, for the blooms nearly always come good and well shaped. Free blooming and a good autumnal, fair in petal, good in centre, of large size and fair lasting qualities, and particularly excellent in smoothness and regularity. More often good than Alfred Colomb, which is sometimes very like it in shape and colour, though the habits of the plants are widely different. Does fairly as a standard but not so well on the manetti, must be highly cultivated, and requires rich soil. Not a hardy sort of strong constitution, but it has been for many years, and appears likely to continue to be, one of the most popular of exhibition Roses.

Marie Cointet (Guillot, 1872).--One of the "weak robust" sort, lilse Madame Charles Wood in growth, stoutish but short. Not liable to mildew, but a colour that suffers in rain. The blooms do not often come well, but the petals are thick and good, the shape sometimes but rarely fine, and the centre well filled. A delicate dwarf plant, and the blooms though very lasting are decidedly deficient in size.

Marie Finger (Raimbaud, 1873), see Eugénie Verdier. 
Maric Racly (Fontaine, 1865).-Syn. Comtesse de Choiseul. Capital strong growth and foliage, not very liable to mildew, but the flowers are utterly destroyed by any rain, even when quite in the bud state. Requires dry hot weather and then frequently brilliant and superb; a striking contrast to the ugly brown rotting balls which are seen in a showery time. The blooms are large and particularly heavy, and any poet who speaks of being "pelted with Roses" as an æesthetical luxury may, I think, be convinced of error if he will allow me access to my Marie Radys in a damp season. A free bloomer but does not shine as an autumnal. The buds are very hard and do not open readily, but a fair proportion come well if the weather be right, with stout petals, very full centre, globular shape sometimes rather rough, brilliant red colour, and capital lasting qualities. It does not do well as a maiden, as is common with those Roses which are extra full, and to my mind has deteriorated somewhat in the last few years. Still it is a good healthy, hardy, late sort, likely to be in demand after a dry season, and to be neglected after a wet one.

Marie Verdier (Verdier, 1877).-O Of short growth but fairly strong, with good foliage, very green in the spring. Not very liable to mildew, but loses colour in rain. The blooms come generally well, the shape being lovely, externally of the form of a chalice, with the centre most regular and symmetrical. Its strong points are the size, thickness, and smoothness of its petals; in the last two particulars it is hard to be surpassed. Fairly free blooming, but not good as an antumnal. A most refined and high class Rose, not very hardy in constitution, but particularly noticeable for its regularity and smoothness. 


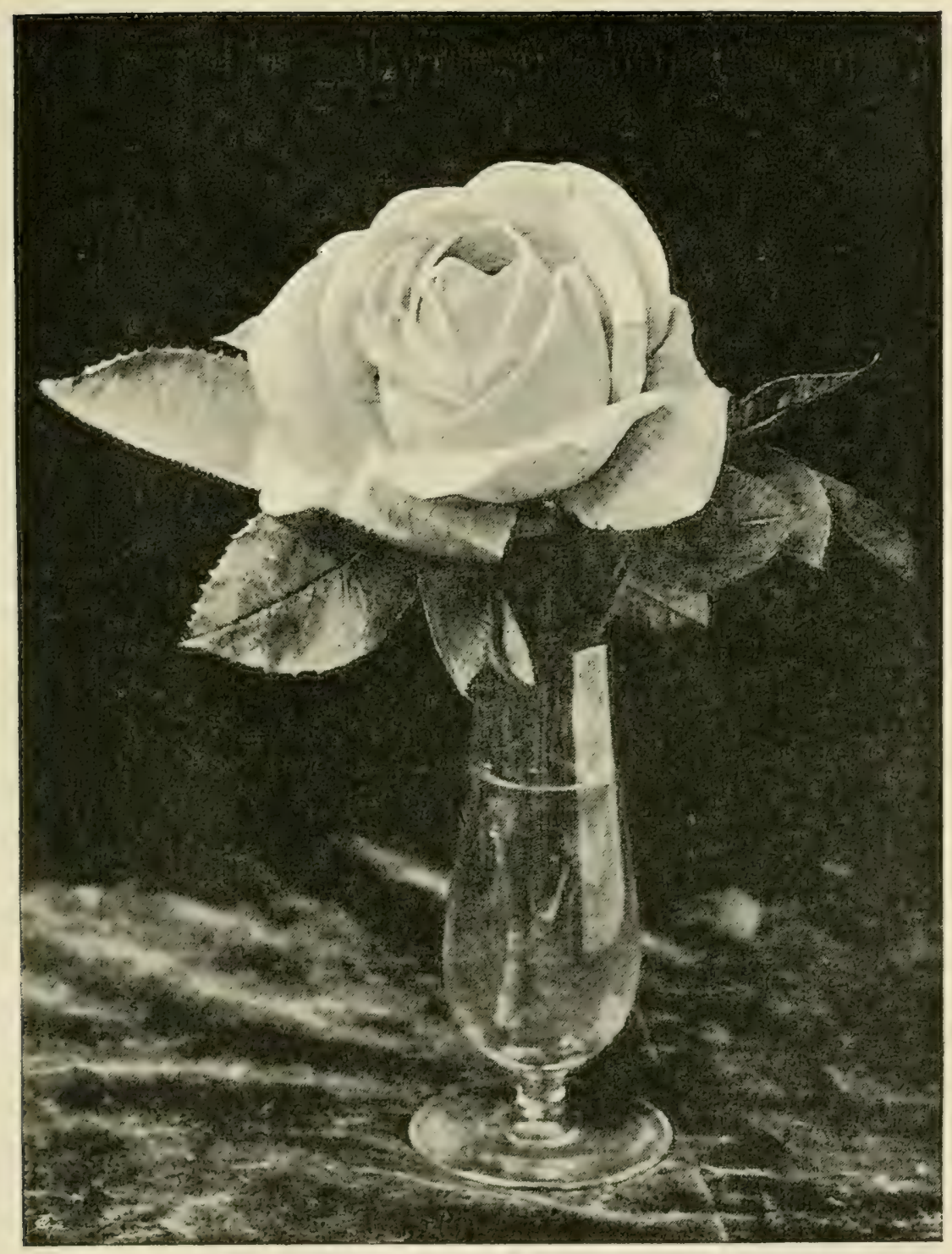

II. I'. Rose, Mapile Verdifr.

To face $p .256$. 

Marquise de Castellane (Pernet, 1869)._Of robust habit; sometimes a very strong grower with thick long thorny shoots and fine foliage, but capricious in this matter, and rather difficult to please. Not only does it do well in some places and badly in others, but my own plants, treated all alike, are most uneven, some being very weak and some very strong. Sometimes it will grow well in light soil, but at any rate it will be of little use if it does not make strong growth. The blooms are frequently of uneven shape, occasionally rough and coarse, but they are large, and effective when they come good with a pointed centre. Not liable to mildew or much injured by rain, early, and free-flowering if it grows well. Not very good in lasting qualities, but quite noted as an autumnal, fine large blooms being frequently produced even till quite late in the season.

Maurice Bernardin (Granger, 1861)._-Syn. Exposition de Brie, Ferdinand de Lesseps, and Sir Garnet Wolseley. Of good growth and foliage, rather liable to mildew but not much injured by rain. The blooms come pretty well, of good semi-globular shape and fair general qualities. This variety, as shown by the number of synor vms, represents a fair average crimson Rose not particular as to the stock it grows on, and free from unusual peculiarities or special manners and customs.

Merveille de Lyon (Pernet, 1882)._-Of Baroness Rothschild race, in all habits resembling it in every particular. While Margaret Dickson seems still unestablished, this sort remains the finest white H.P. It is generally of a lovely pure white colour, but comes sometimes rather pink in the autumn, and occasionally a shoot will revert back to Baroness Rothschild. A grand Rose of the largest size, wanting only the point in the centre, which Margaret Dickson has under its raiser's 
CHAP.

cultivation, to make it perfect. It opens quickly, is weak in the centre, and must be cut quite small for exhibition. This race has a splendid hardy robust constitution: no blanks occur in my rows of cutbacks of this Rose and the Baroness. The plants are alike and even: none die, or are ever "sick or sorry." They do well on any stock or even on their own roots, and are splendid autumnals but scentless.

Miss Hassard (Turner, 1875).-Of strong thorny growth, hardy, free blooming and a pretty pink colour, but weak and loose in shape. A garden Rose, worthy of note as being one of the earliest to bloom.

Monsieur Boncenne (Liabaud, 1864).-Syn. Baron de Bonstetten. A strong grower with fair foliage, but liable to mildew and orange fungus, and not liking rain. Very early: one of the first to show flower buds. A poorly shaped flat bloom at the best, only a small proportion of them coming good, but a beautiful dark colour, particularly "velvety." Requires a hot season, and yet is liable to be "burnt." Fairly free blooming and of average size, but not lasting or a good autumnal and of no use as an exhibition Rose.

Monsienr Noman (Guillot, 1866).-A capricious grower, often very weak, and better in growth on light soil though the blooms are then poor. The characteristic wood is very enticing to prune to, if you do not know "its tricks and its manners"; for the base of every shoot swarms with great strong red wood buds, looking as if the plant was going to grow with great vigour: but the experienced pruner will leave very few indeed of these buds, and allow only two or three shoots to remain. It is best as a maiden, budded annually on small fast-growing stocks. Not liable to mildew, but absolutely spoiled by rain, which in the 



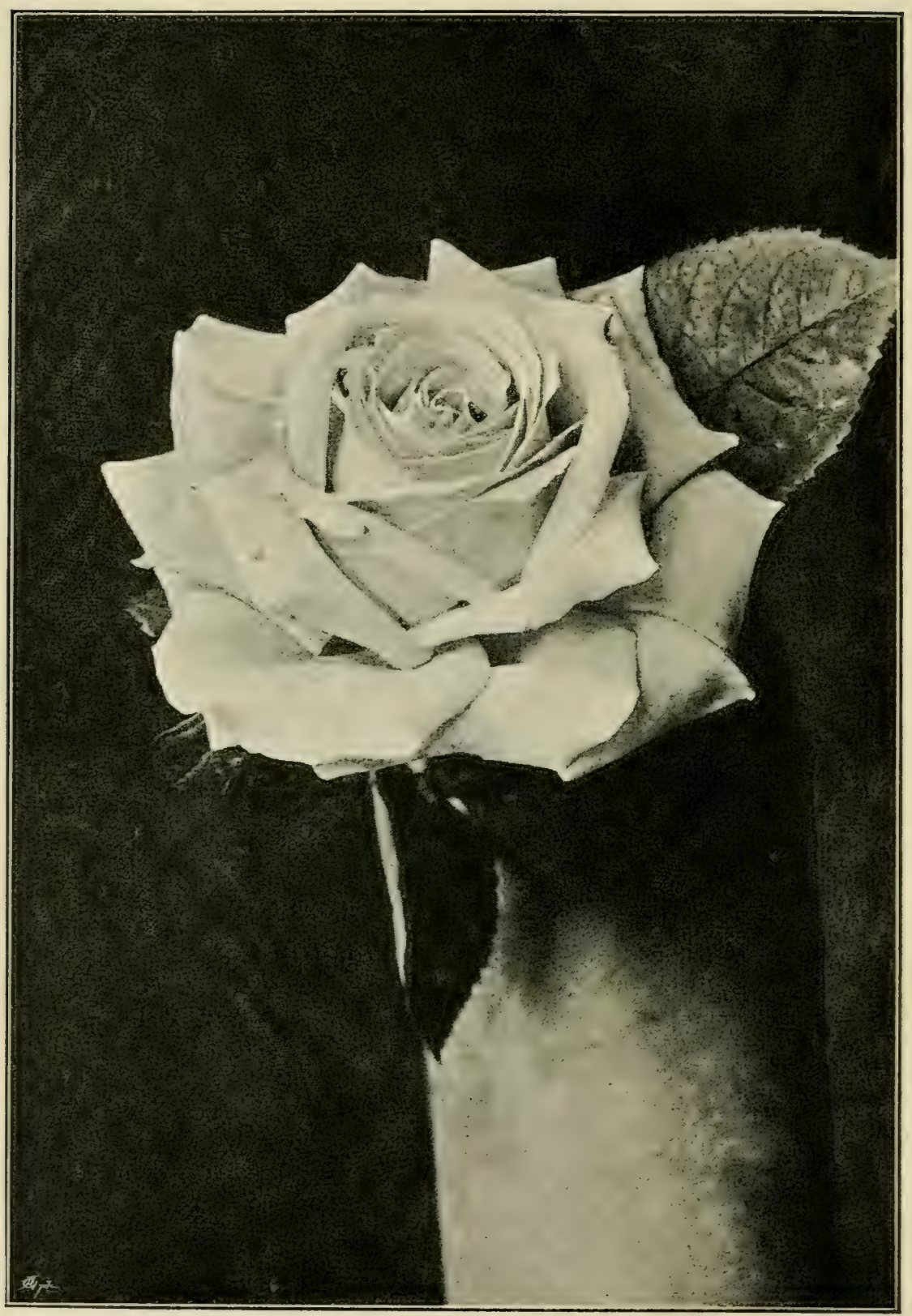

H. P. Rose, Mrs. Johy Laing.

To face $p .259$. 
earlier stages will cause the young blooms to gum and rot without opening, and will sadly stain the flowers when they are opened. It pays well for protection in showery weather, for it is fine in petal and shape, clear in colour, and large in size. One of the earliest, a very free bloomer, but from its weakness of growth of no use as an autumnal.

Mrs. Batier (Laxton, 1876).-Of Victor Verdier race, with the usual habits of the family. The brightest of them all in colour, with a beautiful pointed shape, one of the earliest of H.P.s, of large size, but not very lasting in colour or form.

Mrs. Harry Turner (Turner, 1880)._-Of strong characteristic growth with good foliage, but the plants are apt to canker and die back gradually if pruned hard, and the manetti stock should not be used for them. This is perhaps the brightest of all the deep crimson Roses, and would have a great reputation if it had but lasting qualities. Unfortunately the centre is weak, and the whole bloom very short-lived, so that it is hardly possible to show it. A free bloomer and fair autumnal. A grand garden Rose, sure to attract attention by the splendid glow of its colour.

Mrs. John Laing (Bennett, 1887).-One of the best half-dozen, apparently, from a similarity in the wood, a scedling from François Michelon, but stouter and stiffer in stem with much better foliage. Coming so soon after Her Majesty, this Rose, though not so showy at first sight, was a still greater triumph for Mr. Bennett and English-raised Roses, and was even more worthy of the Gold Medal. In the matter of "coming good," it may strongly dispute the palm with Marie Baumann, for it rarely suffers from any malformation even in the autumn, and whether the season be cold wet and late, 
or hot dry and early, the variety may still be seen at its best. Not liable to mildew or injured by rain, and retaining its foliage well in the autumn. First-rate in petal, fulness, globular pointed shape, lasting qualities, size, and freedom of bloom in summer and autumn, the only thing that can be said against it is that the pink colour is not very decided or bright. Hardy, doing fairly well in lightish soil, and excellent as a standard or a dwarf, it is everybody's Rose, with perhaps fewer imperfections than any other.

Mrs. Paul (Paul \& Son, 1891).-Hybrid Bourbon, a seedling from Madame Isaac Pereire, but it is at present a poor autumnal, and seemed likely at first to be only a summer Rose, like the old H.B.s. This is, however, a winner of the Gold Medal and often a really fine show Rose, which none of the old H.B.s were, a most distinct and noteworthy flower when seen at its best. The growth is very strong, and the foliage of a lovely tint in the early spring and not liable to mildew. Only some of the blooms come good, a certain proportion being loose and very deficient in centre, and they are often rather too flat; but the good ones are large with a fine well developed centre showing grandly against broad smooth stout petals regularly imbricated. The colour is rather blotchy and not very artistically shaded, and the shape is not lasting, the centres requiring to be tied for exhibition. The manners and customs can hardly be said to be thoroughly established, and, as some improvement has already taken place, it is to be hoped that this fine Rose, when a little older, may prove more free-flowering, and gain at least a better reputation as an autumnal.

Mrs. R. G. Sharman Crawford (A. Dickson and Sons, 1894).-This Rose gained the Gold Nedal in 1893, and 
appears to be a valuable introduction, free-flowering, and of fine form and colour; but it is much too soon to give it a reliable character.

Paul Neyron (Levet, 1869).-Alphabetical order is strictly impartial, and we have here, following three Gold Medallists, one of the "best abused" of Roses. Of unusually strong growth and foliage, almost entirely untouched by mildew and little injured by rain, with giant blooms, stout in petal and very full, Paul Neyron is yet justly considered to be too coarse, and wanting in delicacy and symmetry, for a florist's flower. It is, however, highly esteemed in France and America, and many thousands are yearly exported to the latter country, where they are principally grown under glass. The outside world have often (most unjustly) taunted Rose exhibitors with going in for mere size, it being their idea, I believe, that Edouard Morren and Paul Neyron are the special darlings of our hearts. I remember on one occasion a worthy gentleman sending six Paul Neyrons with considerable confidence to a show in his neighbourhood and instructing his gardener to pick out the "biggest." They formed a most ludicrous sight against other well shown Roses; so utterly overblown, shapeless, and discoloured that a cow would have turned up her nose at them. It is occasionally shown in fair form, and would perhaps be oftener thus exhibited, medium-sized flowers not too much thinned being chosen, but Rosarians have felt the weight of the unjust stigma alluded to, and poor Paul Neyron, the biggest of Roses, has become a by-word and a reproach. Fairly free-flowering and pretty good in autumn, with strong growth and constitution, doing well on all stocks, it is a good garden Rose for those who admire a mass of petals and colour of the pxony type. But, taking also into considera- 
tion its remarkable immunity from mildew, its evident use is as a seed-parent to instil vigour and size into refined but weakly sorts. Mons. Levet has already made use of it in this way, as we know, and Paul Neyron lives again, with vastly increased reputation, in Ulrich Brunner.

Pierre Notting (Portemer, 1863).-Of vigorous strong growth, good on all stocks, with extra large fine foliage rather liable to mildew. A fine-weather Rose that will rot without opening in a wet season. It comes badly as a rule, slow in opening, and often showing a great hollow in the centre down to the eye before it expands. The plants are passed by as hopeless again and again : then, with some mysterious climatic change, for fine weather alone will not do it, toward the end of the season the blooms sometimes begin to open properly when all the strongest are over, and we see what a grand flower it can be when it chooses. Though still inclined to be weak in centre and endurance, it is then excellent in shape, colour, size, fragrance, and substance, and " bad manners" alone keep Pierre Notting from a high position. It is aggravating to see such fine shoots produce nothing but ill-formed hollow things which can ha "y be called Roses, while the plant has such good possibilities within its reach. It is free-flowering but late, and not a good autumnal, as the second crop is rarely of any value. The violet shade on the outer petals is one of the nearest approaches to blue that we have: and appearances seem to show that the first blue Rose (when will it come?) will be a dark one.

Pride of Peigate (Paul and Son, 1885).-A sport from Countess of Oxford, with all the manners and customs of the Victor Verdier race. This Rose has at 



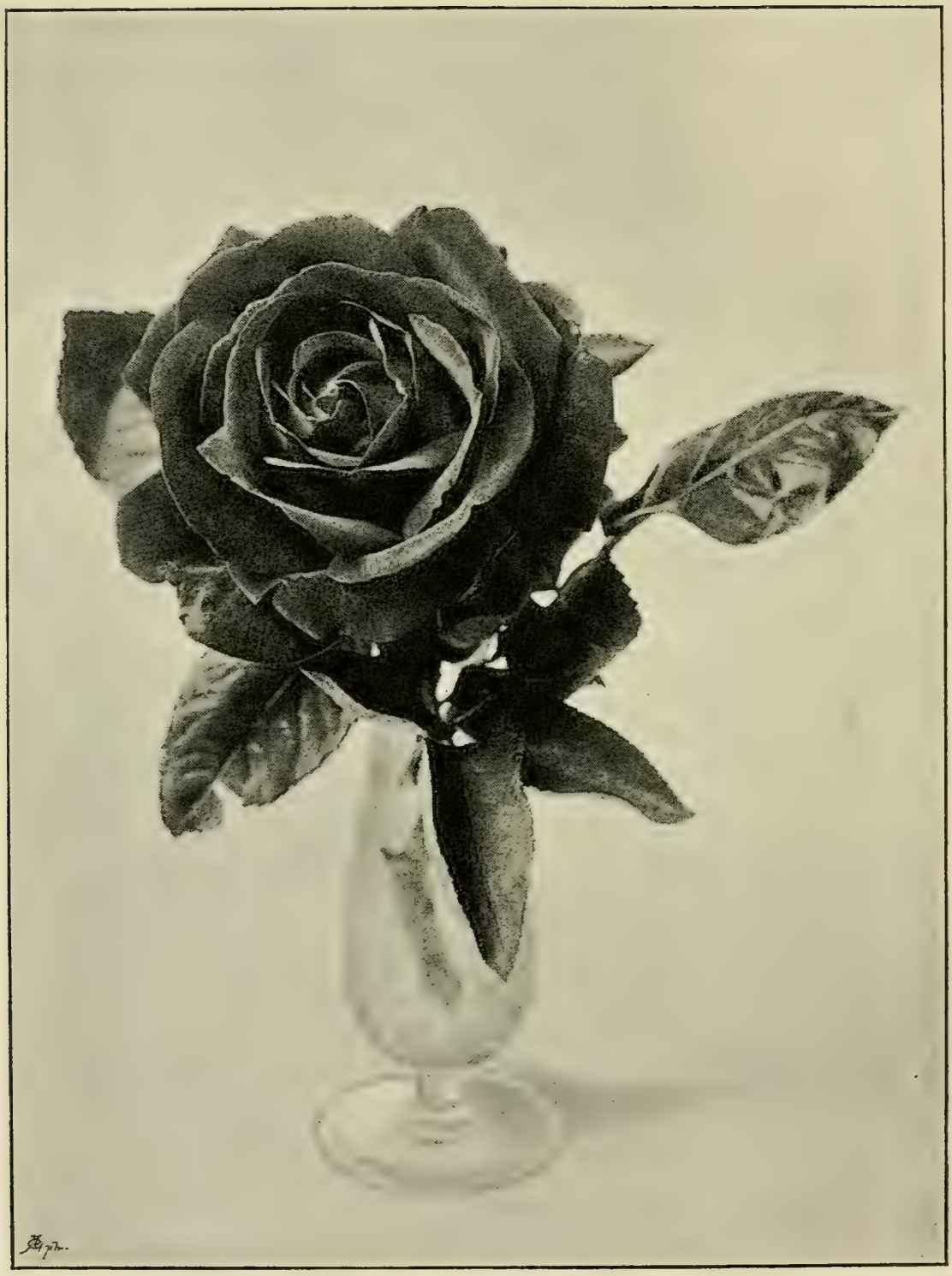

H. P. Rose, Prince Arthur.

To face p. 263. 
least the merit of being the most distinct in colour of all H.P.s, so that the merest tyro could pick it out anywhere, for it has the dark ground shade of the original striped and splashed with white. 'The appearance does not seem very satisfactory, but that may be a matter of taste. A white ground, striped with some fairly bright colour, as in the old damask Rose "York and Lancaster," seems a more attractive combination, but it does not appear likely that a striped Rose will ever find great favour.

Pride of Waltham (W. Paul and Son, 1881).Another of the same family, being also a sport from Countess of Oxford, and a very valuable one. As a show Rose this is one of the best of this important race, for it is as good a grower as any of them, and the blooms are very large, opening well to a grand shape, with stout petals and fine colour. Even Waltham may well call this Rose its Pride.

Prince Arthur (B. R. Cant, 1875)._-Of good vigorous growth, but the wood is not quite stiff enough to support the blooms, and the shoots of dwarfs should be staked: liable to mildew and orange fungus, but not much injured by rain. The blooms come generally well, in a capital characteristic form, and though the petals are thin and the flowers look fragile, they last well. I gather from $\mathrm{Mr}$. B. R. Cant that the origin of this fine Rose is rather obscure, but the general appearance points to Général Jacqueminot as an ancestor. It is however inuch darker in colour, larger, and does better with me in every way. Very free blooming and fairly good in autumn, but requires good treatment to be seen in perfection, though it is hardy and healthy in most soils.

Prince Camille de Rohan (E. Verdier, 1861).-Syn. La Rosiére. Of good growth and foliage, very liable to 
mildew and orange fungus. The blooms are apt to "burn" but are not much injured by rain, thin and apt to show the eye, below the average size, but remarkable for colour. It is still the darkest of all Roses when grown strong, and velvety in the highest degree. Being much the oldest of all the dark Roses of merit, it was a very well known name in past years; now however it has not only been passed in the race by larger and more enduring sorts, but has also apparently deteriorated in itself. Though very free blooming and a good autumnal, hardy, a good doer, and easily propagated, it requires to be highly cultivated and grown strong to show its true colour, for it will come of quite a different hue-more of a scarlet crimson-on weaker shoots. It requires a cool season, and came to light again wonderfully in the shows of 1888 , being hard to beat at any time as a very dark bud for a button-hole.

Princess Louise Victoria (Knight, 1872).-Of extra strong growth, a useful pink garden Rose, sufficiently strong to do for a pillar, and yet flowering freely as a strong standard.

Queen of Queens (W. Paul and Son, 1884).-Of Victor Verdier race with the usual habit, but not quite so strong in growth as most of them. Hardly full-sized, but of nice globular form.

Reine Marie Henriette (Levet, 1878).-A Hybrid Tea Rose, of very strong climbing growth, with good foliage, not much liable to mildew or to injury from rain: very free-flowering and a capital autumnal. Being brighter than Cheshunt Hybrid, this Rose has been for a long time considered the best of the red climbers, and is sometimes, most incorrectly, called a red Gloire de Dijon. The Waltham Climbers (W. Paul and Son, 1885), of which No, 1 is the brightest and No, 3 the best 
shaped are its strongest rivals, but they may possibly all have to yield except in size of flowers to Turner's Crimson Rambler, the climbing Polyantha which gained the Gold Medal in 1893.

Reynolds Hole (Paul and Son, 1872).-A seedling from Duke of Edinburgh, of long strong growth when in health with smooth characteristic wood, but of bad constitution, for the plants are sadly apt to become weak and die and are best as maidens. It is liable to mildew and orange fungus, to injury from rain, and to "burning": a good average of the blooms come well shaped, but the weather must be hot and dry or neither colour nor form will be perfect. The flower is fully filled in the centre, lasts extremely well and hardly ever shows an eye; but it opens slowly and must not be cut for exhibition before it is fairly expanded, for nothing in the shape of long journeys or hot weather, pencils or budding knives, force or violence will make it open except on the plant. It will not put up with light soils or the manetti stock, but sometimes does better as a standard, is late and not very free-flowering, and, being so dainty, cannot be expected to become a good autumnal. But a good bloom of it is truly superb, in petal, shape, size, and especially in colour, worthy of the name it bears of the President of the National Rose Society who has done so much to render Rose growing popular.

Scelamander (W. Paul and Son, 1891).-A Gold Medal Rose which has hardly had sufficient trial for its manners and customs to become well established. The growth and foliage seem to be good, and I have had no mildew on it. The blooms are bright and almost always try to come of good pointed shape, and in a cool season on a good soil they may possibly be excellent, but it seems to be 
rather a small and thin Rose and hardly likely to be a good laster in a general way. It is fiee blooming and a fair autumnal.

Senateur Vaisse (Guillot, 1859).-Of good growth and constitution, and not very liable to injury from mildew or rain. The blooms come pretty well with fair petals and size, good centre and very bright colour. An old Rose that stills holds its own, a free bloomer and good autumnal: hardy, fragrant, and not over particular as to soil, but must be grown strongly to show its brilliant colour at the best.

Silver Queen (W. Paul and Son, 1888).-Of Victor Verdier race, of the same class as Queen of Queens, from which it appears to be a lighter coloured sport. Very free-flowering, a good autumnal, fragrant, of fine form, and attractive colour.

Sir Gamet Wolseley (Cranston, 1875), see Maurice Bernardin.

Sir Rowland Hill (Mack, 1888).-A sport from Charles Lefebvre, which gained the Gold Medal for its unusual and most distinct colour. "Deep velvety plum" is the general description and, when seen at its best, it certainly has a very deep, almost dark blue, shade. But it must be grown very strong to show its colour to perfection, and more often comes of a dark claret or maroon, or even simply crimson; it is inclined to revert to the original and I have cut a good Charles Lefebvre from a plant of it. It seems decidedly less hardy and strong, and not so good a grower as the type from which it sprung: in other respects it has the same habit. A Rose of unique colour, but tender, liable to orange fungus and requiring high cultivation.

Souvenir de Monsieur Boll (Boyau, 1866).-A strong hardy grower, with very large full red blooms, very 
sweet, and occasionally good enough to show, making a useful garden Rose.

Sorvenir de la Malmaison (Beluze, 1843).-A wellknown old favourite, of the true Bourbon race, and aptly named as a remembrance of the garden of the Empress Josephine where modern Rose culture maty be said to have taken its rise. Of excellent growth in a good climate and soil, always stout and stiff, and free from mildew, but the half opened blossoms are injured by rain. The shape is flat when expanded, and it cannot now be looked upon as a show Rose, but it is very free blooming and is noteworthy for the two good qualities of the Bourbons, abundant fragrance and excellence in the autumn. Indeed it comes often better in September, as the flowers of the first crop are frequently divided and malformed. An excellent garden Rose, or in good soil for bedding or massing purposes. A climbing sport of it has been introduced from Australia.

Spenser (W. Paul and Son, 1892).-Of too recent introduction to have earned a reliable character, but apparently a stouter and fuller Baroness Rothschild, with similar growth and habit. Likely to be very valuable, if this estimate should be maintained: but, as seen up to the present, its additional fulness makes it a bad opener in wet weather.

Star of Waltham (W. Paul and Son, 1875).-Of strong growth with magnificent foliage, not very liable to mildew but requiring fine weather. This Rose cannot be depended upon to come good, but it is a splendid bloom when seen at its best, in petal, shape, colour, smoothness, size, and lasting qualities. Not one of the best as a fiee bloomer or autumnal, and will not answer on poor land; it requires the best of weather to show its qualities to perfection, and should be left 
long in pruning and the buds not thinned too much, as it is extra full and often fails to open properly.

Sultan of Zansibar (Paul and Son, 1876).-Similar in wood and habit to Duke of Edinburgh and Reynolds Hole, but a weaker grower with a very bad constitution. This is one of the very few Roses I cannot keep alive at all, and I do not think I have once succeeded in getting even a decent bloom. A magnificent dark colour, and a splendid flower as sometimes shown, but a Rose to be avoided as more than likely to give absolutely no return.

Suranne Marie Rodocanachi (Leveque, 1883).-Of Victor Verdier race, and requiring therefore no description here of manners and customs. A noble Rose, certainly one of the best, if not actually the best, of this important family. The colour is not only bright, glowing, and most attractive, but also lasting, a most desirable attribute for a show Rose. The growth is good, it does well as a standard, is free-flowering and a good autumnal, and the blooms are very large and well formed, but nearly scentless. A Rose held in high and increasing estimation by exhibitors, and worthy of a name more suitable to British tongues and pencils.

Thomas Mills (E. Verdier, 1873).-Of very strong growth and good foliage, growing well on all stocks, not much liable to mildew or to injury from rain. The blooms come well in fine weather, but they are thin and most deficient in lasting qualities. The colour is very bright scarlet crimson, the shape beautifully pointed and imbricated, and the size large: but it is a veritable snare for the inexperienced exhibitor, who finds it impossible to believe that those glorious halfopened flowers are usually not worth taking. It does better in cool weather, but the colour and shape are 



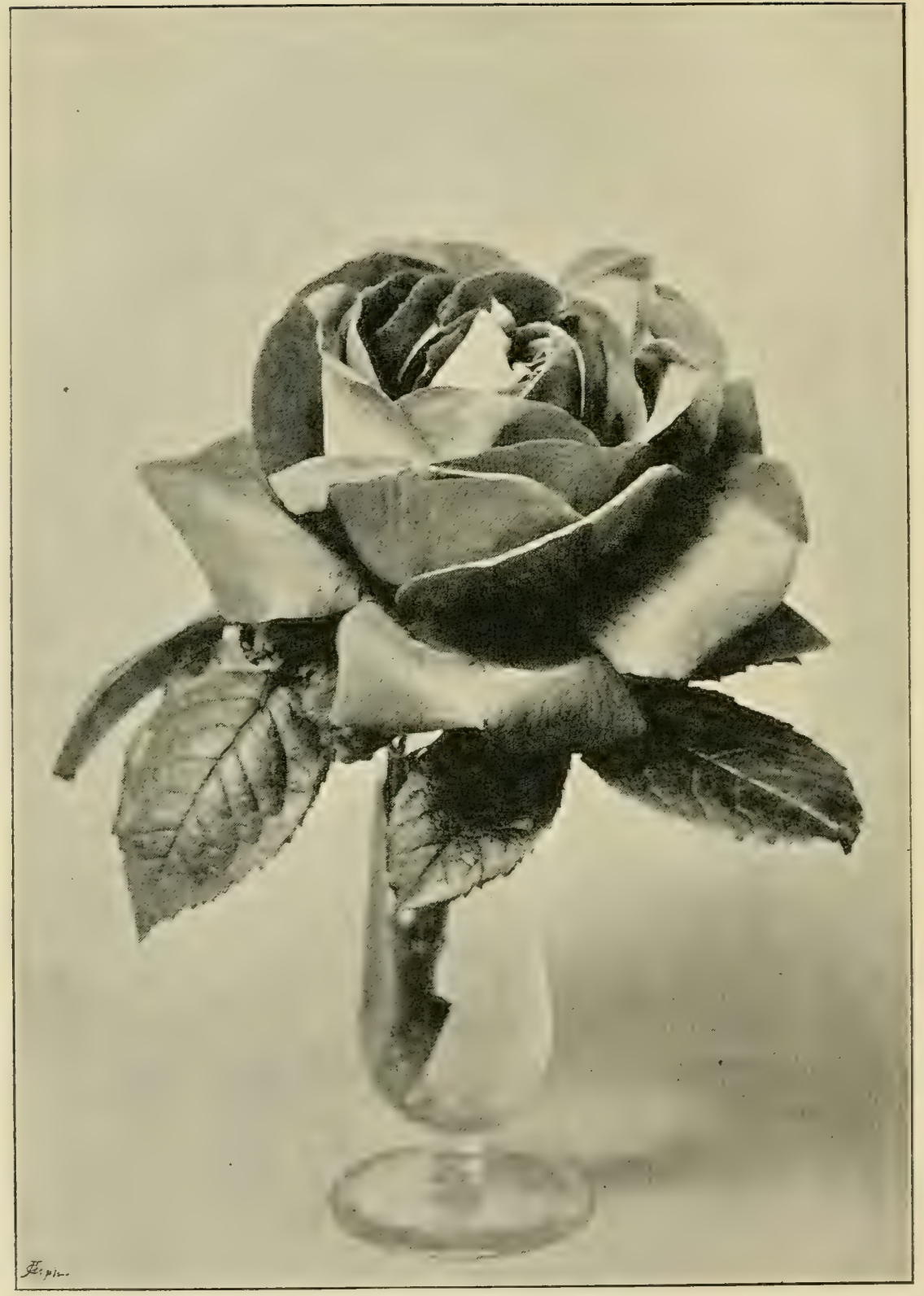

H. P. Rose, Ulrich Bruxyer.

To face p. 269 
then often deficient. Splendid at times in the garden in the early morning, and said to do well in the northern counties. A fairly free bloomer, but not a good autumnal, many of the secondary shoots running to wood only.

Ulrich Brunner (Levet, 1881).-A seedling from Paul Neyron, of very stout stiff growth and foliage, untouched by mildew. The blooms come well, of extra large size, with stout petals generally tightly incurved in the centre, fine regular smooth shape as a rule, and capital lasting qualities, not much injured by rain, though the colour soon fades. A great Rose in many ways: free blooming and capital in the autumn, hardy and of strong constitution and does well almost anywhere and on all stocks. When asked to recommend three good H.P. standards for cottage gardens, I suggested La France, Mrs. John Laing, and Ulrich Brunner, as likely to give satisfaction.

Victor Hugo (Schwartz, 1884).-O Of good growth in rich soil with distinct foliage, liable to mildew, and requiring high cultivation. When "well done by," the blooms are very handsome, of fine shape, fair petal and centre, glorious colour, and good size. This is a very taking sort from the glow of its crimson: the constitution seems pretty good on strong soil, and it is fairly free blooming in summer and in autumn, but the petals are rather thin, and the blooms not very lasting. A really fine bloom of this Rose, seen at its best, will attract great attention.

Victor Verdier (Lacharme, 1859).- -This Rose has probably some admixture in its parentage of a strain from the China or Tea groups; at all events the entire habit is most distinct, and it has become, as we have seen, the parent of a large and valuable race of smoothwooded Roses, all of which show the fimily traits in 
almost every particular. (For a description of these manners and customs see Countess of Oxford.) The majority of those which have been noted are superior in some respects to this their common ancestor.

Viscountess Follicstone (Bennett, 1886).-A Hybrid Tea, of fair growth and foliage, doing decidedly better in growth and bloom as a standard. A most distinct early Rose, of quiet but taking colour : the blooms open very quickly, and soon become loose and shapeless, but are even then beautiful and highly decorative. When the weather is cool, it may sometimes be shown well, if cut young and tied up at just the right stage : it becomes then a large and fine show Rose with grand petals as long as it holds its shape. Very free-flowering, fragrant, and a capital autumnal, with the usual immunity of Hybrid Teas from mildew and orange fungus.

W. F. Bennett (Bennett, 1885).-A Hybrid Tea, of good growth, and crimson colour, thin in petal but very free-flowering and sweet-scented. This is a Rose which has proved most useful for forcing and cutting in the bud state.

Xavier Olibo (Lacharme, 1864).-Evidently a seedling from Général Jacqueminot, as the wood is very similar. A weak grower with poor constitution, not liking manetti, and rather liable to mildew, answering best if budded annually on the briar either standard or cutting, but occasionally doing fairly as a cut-back if not moved. This Rose used always to be described as "velvety black, shaded with amaranth," a taking description especially to those who had hazy ideas of what colour "amaranth" is. The word means "fadeless" or "everlasting," and seems to have been applied to the cockscomb family of flowers because of their lasting 
qualities. In describing a new Rose of purplish crimson, the French raisers therefore called it "amaranthe," i.c. " cockscomb colour," a fair description of the shade of Xavier Olibo. The blooms come divided sometimes, but it is often a tine Rose, with centre sometimes incurved and sometimes with a fine point: a good lasting bloom, of full size. It will not answer on poor soil, must be well and highly fed, and from its weak growth is necessarily not good as a free bloomer or autumnal.

Climbing. Sports. Of late years a good many H.P.s, as well as some Teas, have made climbing sports, of much longer, though not necessarily of stronger, growths than the originals. They are not of much value, as Roses of other groups, Dijon Teas, Noisettes, \&c., are usually more suitable for pillars and walls, and the blooms are not so good, as close pruning and concentration is impracticable. Bessie Johnson, Captain Christy, Charles Lefebvre, Edouard Morren, Jules Margottin, Eugénie Verdier, Monsieur Boncenne, Pride of Waltham, Queen of Queens, Souvenir de la Malmaison and Victor Verdier with some other less known Roses, have had such sports put into commerce, but they are not to be recommended for the open ground.

\section{Teas and NoIsetTes.}

The National Rose Society has probably acted wisely in cataloguing these two groups under one heading, for they have always been united in exhibition schedules, and there is already considerable difficulty, which will probably increase, of drawing a strict line of demarcation between them.

The Noisettes are hardy, very strong growing 
nearly evergreen Roses, blooming in clusters. The flowers are naturally quite small, but almost all of them have been further crossed with the Tea race, which has had the effect of much increasing the size and beauty of the blooms, but at the same time rendering the plants less hardy and more liable to injury from frost. The true Noisette is itself said to be a hybrid between the Musk and Tea or China Roses, so that it seems difficult to decide what is a pure Noisette. Of those mentioned in the N.R.S. Catalogue, Aimée Vibert and Ophirie show less of the Tea cross than the others.

The true and Hybrid Noisettes have a characteristic custom, which is shared by the Gloire de Dijon race, of blooming from nearly all the buds of the long secondary shoots of the previous year, which should be left with only the tips shortened. Many of these will hardly bloom at all if closely pruned.

The Teas, that is, Roses of the true Tea-scented China group, are especially liable to the following bad manners: impatience of frost, of rain, and of being grown as dwarfs. But these are more than counterbalanced by their good qualities, viz. being generally freer in the summer from mildew than the H.P.s and entirely exempt from orange fungus, nearly all free bloomers and the best of autumnals, lasting better than H.P.s, and thriving better than they do on light soil. All the Teas and Noisettes require dryness and warmth in the soil as well as the air: thorough drainage is a first essential, and strong heavy land, such as is most loved by the majority of H.P.s, is not so much appreciated as that which is at the same time highly enriched and thoroughly porous.

Adam (Adam, 1833).--Syn. President (Paul \& Son, 1860). Of poor growth and small reputation. The 
blooms are large, globular and very sweet, but loose and untrustworthy, and the sort is of little value as a free-flowerer or autumnal.

Aimée Vibert (Vibert, 1828).-A true Noisette, showing it by its hardiness and clusters of small flowers. Very strong growing, rambling, and practically evergreen, though a severe winter may destroy the foliage. The climbing form should be chosen when it is used for pillars or walls, as the original strain was of less vigorous growth. The blooms are quite small, full and rosette-like, but it is not so effective as a white cluster climbing Rose as some of the Ayrshires and Evergreens.

Alba Rosea (Lartey, 1862), see Madame Bravy.

Amazone (Ducher, 1872).-Of rather poor slender growth, with long pointed buds of a good deep yellow, a colour which is still much wanted in this class. Some of the Teas are only valued in the bud state, for cutting and market purposes, and those that have long slender buds are much more suitable and graceful for decoration and wreaths than the globular sorts. They are useful for this purpose, even if the shape be poor when fully opened. Amazone has however, much helped by its colour, been occasionally shown successfully; but it is very loose and wanting in centre, of no value as a free bloomer or autumnal, and can by no means be reckoned among the best.

Anna Olivier (Ducher, 1872).-A good grower with bright foliage, but the secondary shoots from the base are inuch stouter and longer than the spring growth. It does better as a dwarf than perhaps any other of this class: quite as well, many think, as on a standard. All the Teas are liable to be spoiled by rain, the petals sticking together and then decaying. Those which are fullest and stoutest in petal are the worst in this 
respect, and this Rose, being inclined to be thin and not so full as some, does not suffer perhaps so much. The blooms usually come well, it being the case with Teas, as with H.P.s, that the largest and strongest blooms are the most likely to come divided or otherwise malformed. A lovely Rose of the charming pointed globular shape, and capable of reaching a full size: it requires to be grown very strong to be fit for exhibition, but is then very effective. The colour varies very much, a terra-cotta tint, generally present at the base of the petals, sometimes attaining to a more lively shade and covering nearly the whole bloom. The presence of iron in the soil is said by the Revd. F. R. Burnside, a high authority on Tea Roses and an excellent exhibitor, to account for the extra prevalence of this shade of colour. Not in general a Rose of lasting qualities for a Tea, though its extreme freedom of bloom throughout the season, vigour of growth, and fair amount of hardiness should combine to give it a place in almost every list.

Belle Lyonnaise (Levet, 1869).-A Rose of the Gloire de Dijon race, whose manners and customs will be described under the name of the head of the family. All are inferior to the type in freedom of bloom, and some in hardiness; otherwise they differ only in the shades of colour. This is one of the earliest descendants of the ever popular Gloire de Dijon; the colour is pale yellow, and the growth fairly hardy.

Bouquet d'Or (Ducher, 1872).--Another of the same family, and one of the best, being quite distinct in colour, hardy, and superior in form to the type, sometimes good enough to show, a fine yellow with coppery centre. This Rose was sent out, perhaps by accident, as a Noisette. 
Bridesmail (F. L. Moor, 18.93).-A higher coloured sport from America of Catherine Mermet, of which no reliable character can be given at present. It is already extremely promising, and seems likely to take a high position, for any good sport from this much-esteemed type can hardly fail to be valuable.

Curoline Kuster (Pernet, 1872).-This is a Hybrid Noisette, but for all practical purposes it may be classed among the Teas, to which it shows a strong affinity, as it is not of climbing growth and will flower as freely as any Tea if closely pruned, which other Noisettes will not do. Of strong good growth for a pure Tea, with sinall foliage: the blooms sometimes come divided, especially the strongest ones, and they are weak in colour, but good in petal, shape, fulness, lasting qualities, and size. 'This is an accommodating' Rose; a strong established plant in good soil may be cultivated, either by slight pruning and not thinning the buds, as a most useful bush to "cut and come again" at for serviceable pale yellow buds throughout the season; or, by severe pruning and vigorous dis budding, to produce a few show blooms of fair quality and size, useful for exhibition in any stand. It is very free blooming and a good autumnal, doing well as a dwarf, and for a Tea Rose decidedly hardy.

Catherine Mermet (Guillot, 1869).-Of moderate growth, with not strong foliage, a little liable to mildew, and easily injured by rain. The blooms as a rule come well, and the amateur who can get some really strong shoots and keep the buds dry will generally be richly rewarded, for this is one of the finest of Tea Roses when grown to perfection. It must be strongly ferl, and all the power reserved for two or three blooms: then in petal, fulness, size, lasting qualities and lovely 
shape it is truly a glorious flower, but the colour is more fleeting than the shape. The variety should always be grown as a standard, as it rarely does really well as a dwarf. It is very odd why certain of the Teas, if budded on the briar close to or under the ground, do not flower so well as when budded on the same stock a little higher - even eighteen inches will make a great differencebut so it certainly is; and as even short standards are much more difficult to protect effectually in severe frost, this little piece of bad manners is especially annoying to growers in low districts. A Rose of great reputation, and by many considered the highest in merit among show Teas. The raisers of new varieties bear witness to its good name by the readiness they show to class their productions as "in the way of Catherine Mermet." But it cannot be called hardy or of strong constitution, particularly free in bloom, a good autumnal, or able to do anywhere. Three sports of this Rose have been issued, all from America, the Bride, Waban, and Bridesmaid. As the first of these has almost if not quite rivalled the type in popularity and reputation, it is to be hoped that the other two, which have not yet been sufficiently proved, may prove to be as great acquisitions. At present Bridesmaid seems much better than Waban. Some other sports are said to be in preparation for issue.

Celine Forestier (Trouillard, 1858).-Of good growth, but not sufficiently lengthy to make a high climber. The wood and foliage are very distinct, the latter being nearly evergreen, and particularly bright and shiningthe sort of glazed foliage which appears to be especially proof against mildew. It blooms in clusters, which should only be lightly thinned, for no treatment can make a show Rose of it owing to its flat open shape, and 



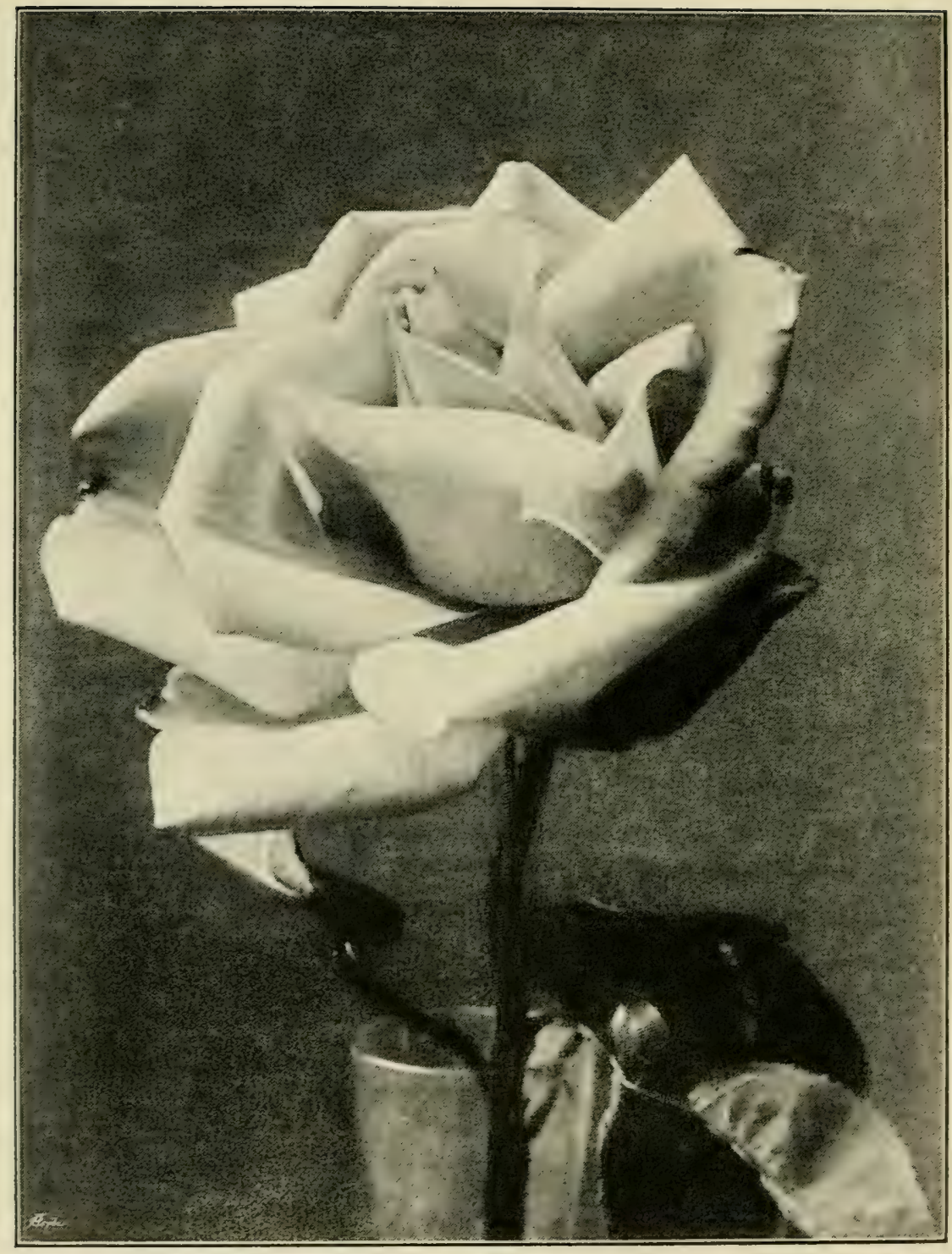

Tea-Rose, Cleopatra.

To face 1. 277. 
the prettily coloured buds add much to the beauty of the truss. A free bloomer and fair autumnal, best as a standard; will sometimes bloom as a maiden or if closely pruned, which many of the Noisettes will not do; tolerably hardy, but liable to injury in severe frost; of pretty good constitution, and doing fairly in poor soil.

Cleopatice (Bennett, 1889).-A poor grower, one of the worst in this section. The wood is fairly stiff but thin as well as short, and it is one of the most difficult to propagate as the buds are small and scarce, and to get two or three often involves sacrificing nearly the whole of the plant. The flower buds are particularly long and pointed, and if fair growth can be obtained they open into grand blooms, retaining the fine point in the centre, with splendid long broad smooth petals most symmetrically arranged. A truly magnificent Rose, but difficult to grow to perfection; best as a standard, but tender and requiring full protection ; hardly worth growing except where the situation and soil are very suitable, for though the buds are lovely, it is not free blooming enough to be cultivated for their sake, and it will only retain its point when expanded where it can be grown pretty strongly.

Cloth of Gold (Coquereau, 1843).-Syn. Chromatella. Of strong climbing growth on a south wall, liable to mildew, but can probably stand a shower. Here are manners, or rather the want of them, with a vengeance, for this Rose is unfavourably known as the shyest of all bloomers, and though acknowledged to be an excellent flower is not to be found in the N.R.S. Catalogue at all. A fine plant that I once had in the sheltered angle of a south wall only once in eight years flowered at all and that was after a very hot summer, when the wood must 
have been not only ripened but almost roasted. It is said, however, by those who used to grow it thirty years ago or more that it bloomed freely and well at that time, but received a check in a certain severe winter which affected the constitution of the whole variety. This may be possible, but perhaps jealousy was a hidden trait among its manners and customs, and that it shut up from envy at sight of the rising star of 1864, Maréchal Niel. It is said to do well still in Ceylon, Australia, and other warm places, but in this country it does not seem wise to waste time and space upon it. It has fine yellow flowers indeed, large and well shaped, but not so good as those of its great rival. Oddly enough, it may be seen blooming fairly as a maiden in the open in some nurserymen's quarters, but I have never seen a bloom of it exhibited, and it really is not worth growing in the British Isles.

Comtesse de Nadaillac (Guillot, 1871).-Of dwarf, thorny, and, unless thoroughly well treated, weakly growth and foliage; not liable to mildew, but spoiled by rain, though more tolerant of it than some. This is a Rose which, despite its small growth and generally feeble appearance, is commonly considered second to none as a show Rose, and it is seldom that a good stand is shown without it. The habit of this variety is peculiar, though that of Princess of Wales is somewhat similar: With almost all other Roses, the finest and strongest shoots give the finest blooms, but with this sort it is very difficult to tell which will do so. A bud at the end of a very small shoot may grow and swell for weeks before opening, and will then probably show a bloom that not only for beauty, but also for size, will utterly eclipse anything that can be produced from even such strong rampant growers as Gloire de Dijon or Climbing 
Devoniensis. If the bud remains hard and well-shaped -a perfect smooth cone-and swells slowly even in forcing weather, while the stem thickens and stiffens in proportion, it is a good sign. On the other hand a thick strong, tall, fleshy shoot may open its bud almost at once and produce a comparatively poor bloom. It does decidedly best in every way as a short standard, but will also yield fairly fine flower's as a dwarf. The blooms sometimes come divided, but when good they are firstlate indeed, in petal, fulness, and shape, and wonderful in size and lasting qualities. The colour is lovely, having many shades, and like many other Teas, is variable. Mr. Prince can show it as a yellow Rose, but this is generally when it is too much expanded and the point is gone, pink being much more predominant than yellow in my specimens. The plants are of pretty good constitution, by which I mean that they will live and not deteriorate for years if well cultivated, and they will stand close pruning, but are tender and must be well protected from frost. Though they are so dwarf they should not be put too cluse together, for the habit of growth is singularly lateral, and the principal shoots of old plants will often be nearly horizontal. It is a free-flowering sort for one of such dwarf habit, but is not of much use in the late autumn unless the weather be very fine and dry. Its freedom of bloom is a nuisance to the propagator, as it is often difficult to find a sufficiency of buds which have not started.

Comtcsse Punisse (Nabonnand, 1877).-OOf good growth, with stout stiff wood, and fine foliage beautifully coloured in the spring, doing well as a dwart. A very full Rose, which therefore will not stand rain and requires i hot bright sum. It comes quite large with fine stout petals where the growth is good, but the colour is very 
changeable. It is described by a good authority as "rosy buff shaded with carmine and violet," and it certainly does come in some situations and very favourable weather with a lovely combination of shades, but amateurs will find that a great many of these Tea Roses are practically white; and the reason of this is that they are first described as seen under glass properly shaded, but out of doors they only open properly in bright hot weather, and then the sun "takes the colour out." The second crop in autumn is often the best coloured with me. Not very free in bloom, but fairly hardy for a Tea Rose.

Comtesse Riza du Pure (Schwartz, 1876). - Of really strong growth, with good foliage. This Rose is very faulty in form, and a good shaped one is rare indeed. It is not large, a free bloomer or a good autumnal, and is only noticeable for its colour, which is a charming shade of pink, with an indefinable sensation of yellow pervading it, especially at the base of the petals. It is really not to be recommended, but a good Rose of its colour would be heartily welcomed.

Corinna (W. Paul \& Son, 1893).-Too lately introduced to be spoken of with any certainty. It seems very promising in growth, shape, and colour, and has been shown well.

Devonicnsis (Foster, 1838)-Of moderate but sturdy growth, nearly as thorny as Comtesse de Nadaillac, with rather small foliage; not much liable to mildew, nor (as becomes a native of Devon) as impatient of rain as some Teas. The strong blooms often come divided, but it is pretty good in petal, shape and centre, though deficient in size, very tender, and much liable to injury from frost. For a long time this was the best Englishraised Tea Rose and was highly rated, but now seem 
deteriorating and is seldom exhibited. It is said, however, still to grow and bloom well in some favoured localities, such as the Isle of Wight. Would probably do better as a standard, but is then not easily protected from injury in the winter.

Climbing Deroniensis (Pavitt, 1858).- This seems to have been the first of all climbing sports fixed and sent out, and till lately was the only such variation known among the Teas. It may have been noticed that several of the climbing variations among the H.P.s are sports of Roses which have quite a short growth naturally. This Tea Rose however " out-Herods Herod" in differing from the Devoniensis type, which is of quite moderate growth, for the climbing variation is the strongest, most untidy, and irregular grower we have. Growing is its strong point, and it gives so much attention to this as sometimes nearly to omit the Howering part of the business altogether. A strong long shoot of the Gloire de Dijon or Noisette races, if laid in well and uninjured by frost, will bloom freely all up the rod. Not so Climbing Devoniensis; away it goes again, if in good soil and on a warm wall, from the top bud of last year's shoot, and its sole endeavour seems to be to get to the top of the wall as quickly as possible, and as a plant to look as bare at the base, $u g l y$, and lopsided as it can. The great pithy, thorny, Howerless shoots are very susceptible to frost, and are not handsome at any time. The blooms when they do come are no improvement on the type, as they open too soon on a wall. I have seen it show better manners, growing moderately and blooming freely throughout the summer on a south wall where no attention was paid to it; and I believe this desirable state of affairs was attained by semi-starvation, but 
CHAP.

the buds were small and only passable as buttonholes.

Dr. Grill (Bonnaire, 1886).-Rather moderate in growth, a button-hole Rose only valuable in the bud, small, but free-flowering and distinct and attractive in colour.

Elise Fugier (Bonnaire, 1891).- Of moderate growth, highly spoken of at first, but at present not sustainmg its reputation. Of nice pointed form, but not likely to prove first-class.

Ennest Met: (Guillot, 1888).-Of good growth, stout and stiff, with fine foliage, best as a standard. The blooms do not come well, a large proportion of the finest being often divided and opening badly, and they must be sheltered from rain, but it is a very fine large Rose when there is no malformation, with strong stout petals, good centre, and fair lasting qualities. The stiff growth and large leaves show the flowers off well, and the plant is fairly hardy, but not very free in flowering. It should be left rather long in pruning, and not too severely thinned, as the strongest shoots seldom give perfect flowers.

Ethel Brownlow (A. Dickson \& Son, 1887).-Not a very strong grower, but in this and other respects it seems to have decidedly improved, for it was by no means a general success with amateurs for the first three or four years. Now it is fast rising in reputation, and it was plain, when first shown, that it was the best example of the imbricated form among Teas, if not among all Roses. The blooms come generally regular, and the well-formed point in the centre of good perfectly imbricated petals, which is the typical form but unfortunately seldom attained by the full-sized flowers, makes it a great favourite with those to whom shape is the first 
thing. It has very good lasting qualities in form, but the freshness of the first colour is very difficult to maintain and shading will destroy it. Rather late, and best as a standard, it requires fine hot weather, and needs protection against rain. Very free-flowering, the buds must be well thinned to get exhibition blooms, but are charming half-open in themselves. It is certainly one of the best of the roses raised in Ireland up to the present time, and would be likely to rise still further, I think, in general estimation, if the strong flowers would keep to the imbricated shape, and the colour prove less fleeting.

Etoile de Lyon (Guillot, 1881). - This does well as a dwarf, and has strong good growth and foliage, but is a very disappointing Rose out of doors, having been much over-praised. The blooms come generally badly, of confused and queer shapes, and require as a rule very dry warm weather; yet the sort did better, oddly enough, with ne in the cold wet summer of 1888 than many other Teas. A Rose whose performance is not up to its promise ; for when you do get a well-shaped and regular bloom from a strong and very stout shoot it is surprising how small and insignificant it looks when set up beside other Tea Roses cut from much slenderer and weaker stems. This is partially accounted for, no doubt, by the globular shape, and by the outer petals being short, and kept well up to the bloom. Those are always the most effective shapes, where the outer petals are the lomgest, and stand well away from the flower like great wings. As in the ancient sport of Falconry, the shortwinged Roses are of quite a lower order compared to the long-winged ones. It is something of the shape and colour of Monsieur Furtadlo, a very weak varicty now generally dropped, though larger, as indeed it 
ought to be considering the great difference in growth. Rather liable to mildew, of good lasting qualities when dry, it is best under glass and is not suitable for extended culture out of doors in our climate.

Francisce Krï̈ger (Nabonnand, 1879).-A Rose which does not seem to be so well thought of as its many excellent qualities deserve. It has good growth and foliage, not much liable to mildew, does well as a dwarf, and when once it has commenced to expand is not much hindered by rain. Though the habit looks delicate and is anything but robust, it is quite one of the hardiest against frost of all the true Teas, and it is very rarely that even the exposed portions of my plants are killed. It comes occasionally divided, malformed, or even with a green eye, but is often very perfect in form. A very free bloomer and a good autumnal; the small buds are lovely both in colour and shape, and a strong plant, well thinned and attended to, is capable of producing very fine exhibition blooms, large, very lasting, and of capital pointed form. A beautiful Rose, of variable and changeable colour, strong large specimens when fully out often showing an attractive shade of yellow through all the inner petals.

Gloire de Dijon (Jacotot, 1853).-Perhaps the best known of all Roses. There can be little doubt that this is not a pure Tea, but has a cross in it of some other race, for the plant is absolutely hardy, of very vigorous climbing growth, and the foliage is unlike that of the Tea-scented China, and more like that of the Hybrid Tea Grace Darling. Like the Noisettes, Roses of this race must not have the strong young shoots pruned back or wood instead of flowers will be produced: but when this is understood no Rose save the common China or "Monthly" blooms so profusely and constantly, early 
and late, as the one under notice. Dean Hole says, "Were I condemned to have but one Rose for the rest of my life, I should ask, before leaving the dock, to be presented with a strong plant of Gloire de Dijon." Exhibitors are often blamed for neglecting Roses of real sterling merit like this one for those of weaker growth, but though it has indeed many merits it is not a show flower. A plant of Gloire de Dijon may be a hundred times the size of one of Comtesse de Nadaillac, and may have more than a hundred times the number of blooms; but take the finest Gloire de Dijon that ever was seen and set it in a stand by a fair representative bloom of the other, and the great inferiority in every respect, even in size, would at once be manifest. The foliage is very fine indeed but not so evergreen as that of Maréchal Niel and some other of the Noisettes, nor does it clothe the bases of the branches so well as Rêve d'Or. It is not liable to mildew, cares little for rain, and its bushels of blooms come very true to shape which is weak to a florist's eye, and unusually uniform in colour. Last, but by no means least, among its good qualities, it will grow and flourish almost anywhere and anyhow, tolerably well even on a north wall. A Rose of such notoriety, which forms seed vessels freely, has naturally been a prolific parent of varieties of similar manners and customs, forming a race, almost a class, in themselves. All of them are decidedly inferior to the type in freedom of bloom, and many are not so hardy. Otherwise they differ only in colour, in different shades of yellow, salmon and white. Many have been raised on the Continent of late years, but few are of real value. Among the best are Belle Lyonnaise, Bouquet d'Or, Duchesse d'Auerstadt, Emilie Dupuy, Henriette de Beauveau, Kaiserin Friedrich, Madame Berard, 
Madame Chauvry and Marlame Eugene Verdier, but there are many others still in commerce.

Homere (Robert, 1859).--Of very strong growth, with fair foliage, but more suited for a pillar than a wall, and best as a big bush. I have never heard any doubts about this being a pure Tea, but it is of unique habit and manners, perfectly hardy, very vigorous and of strong constitution, and I wonder we have had no seedlings from it. It is not liable to mildew and but little injured by rain, does well as a dwarf, is a free bloomer and capital in the autumn, pretty in colour, but small in size. It is hard to prove a negative, and I will not say Homère never comes perfectly shaped, because I have heard of one or two though I have not seen them. Its bad manners in this respect are the more aggravating, because each bloom has the promise of a beautiful shape but marred by a malformation. As often happens, the strongest blooms are the most imperfect, and the buds should be cut small before their promise is spoiled. The exhibitor will have none of it, but for button-holes and bouquets he cannot deny it the despised epithet of "pretty." A capital cottage garden Rose, doing well anywhere.

Hon. Edith Gifford (Guillot, 1882).-Of good stout stiff but not long growth, with fine foliage, liable to mildew in the autumn, and requiring protection from rain. A very good Tea Rose indeed, an unusually large proportion of the blooms coming good, of fine shape, petal, centre and size. It is thoroughly reliable, an excellent show Rose, one of the earliest, very free blooming, a good autumnal and does excellently as a dwarf. A good Rose, and a "good doer," giving little trouble and ample returns.

Innocente Pirola (Ducher, 1878).-Only fair in growth 
and foliage; requires rich soil and in many places does not do well as a dwarf; rather liable to mildew, but for a white Tea Rose little injured by rain. The blooms come well, and the typical shape is unique, one of the most perfect we have, something like the whorl of a shell. Fairly free in bloom, and lasting, but not often very large till overblown. A first-class Rose, fine in petal and centre, it should be a great favourite with those purists (with whom I have much sympathy) who insist upon regularity and perfection of shape as the one thing desirable above all others.

Iscibella Sprunt (Verschaffelt, 1867).-Not a strong grower, a button-hole Rose, of light yellow colour; the buds are well pointed and effective for wear or decoration.

Jean Ducher (Ducher, 1874).-Of strong stout stiff growth, with good foliage; does well as a dwarf and is not liable to mildew, but perhaps the most sensitive of all Roses to wet or rain. It must have dry weather even when yet a hard bud as soon as it shows any colour, or it will not come to any good. The very strongest buds are apt to come rough or divided, but as a rule they do pretty well if the weather continues dry, and when a fine bloom does come at last it is grand in shape, petal, centre, size, colour, and lasting qualities. It is a free-bloomer, good in a dry autumn. and fairly hardy for a Tea Rose. The colour is variable: sometimes there is a good deal of salmon-pink about it, especially on the outside; rarely it is quite yellow except the actual outside petals, and then generally very fine: when overblown the blooms have a good deal of red in them, and are very decorative at a little distance. Ruby Gold, a Rose sent out from America, appears to be identical with Jean Ducher. 
Josephine Malton, see Madame Bravy.

Jules Finger (Ducher, 1879).-Of good growth with fair foliage; does well as a dwarf but better as a standard, not liable to mildew and can stand a shower. The blooms generally come well, but the shape is not a refined one, the centre petals being generally incurved, whereas we expect the more elegant pointed form in a Tea Rose. Pretty good as a free-bloomer and autumnal, not very large, and aggravating in colour. This is fairly good and pure when the flower first opens, but it will not hold it when cut, and if kept too long, for it has a lasting shape, it turns to a livid hue, which almost tempts one to use the word "ugly." Note that there is a Julius Finger among the H.P.s., a light-coloured flower of little merit.

La Boule d'Or (Margottin, 1860).-OOf short, almost dwarf, but stiff and stout growth, with good foliage: not liable to mildew, but being extra full it is a very slow opener and will not stand any wet. It does pretty well as a dwarf, but better as a short standard on a south wall, and the blooms come fairly well but occasionally divided. This is a Rose of very fine large petals, which give it great value for show purposes, but it has rather a bad name as one that will not open. Starvation, and even the cutting of the roots when the buds are well formed, have been recommended, but I would rather advise good treatment, the warmest possible situation, protection from rain, and patience. It is seldom of any use as an autumnal, but is freeblooming, capable of reaching a large size, and of extraordinary lasting qualities. I have seen a strong bloom on a south wall, exposed to a cloudless July sun, take nearly a week to open fully. The typical shape, as the name implies, has a round ball in the centre 
but fortunately it more often comes with a fine point, and it is then sometimes grand, the great petals standing out stiff and strong, and making it a splendid sample of a long-winged Rose. It is advisable to bud from shoots which have given pointed blooms. "Bright golden yellow" is the general description and the true colour, but this shade is unattainable out of door's, as it will not open without a good deal of sun, which makes the colour much paler. When a sunny time follows after cold wet weather, such of the buds as survive will open much more quickly than usual. Grand under glass, as the constitution and growth are good for a pot Rose, and it is easily propagated.

Lamarque (Maréchal, 1830).-A Noisette, which was highly prized forty years ago, when varieties were few. Of very strong climbing growth on a warm wall, with bright but small foliage not liable to mildew and not thoroughly evergreen. The blooms are large and effective, but open and flat, not fit for show, and liable to injury from rain. It flowers with great freedom once, but the second crop on a wall is small. Very sweet indeed, the fragrance being most distinct. It is not hardy, but is pretty safe on a south wall against anything but exceptional frost. Said to be the parent of Cloth of Gold.

l'Icéal (Nabonnand, 1887).-A Noisette of good growth, but not a vigorous climber. A button-hole Rose, of good shape in the bud, but very loose when expanded. Noted for its colour or colours, which are "extensive and peculiar," and very difficult to describe. Almost all shades of red and yellow seem at times to be mingled in its quaintly tinted buds.

Lacivle (Guillot, 1886).-A Tea Rose of rather poor growth, and again a button-hole Rose, with good long 
buls most chammingly tinted. A really beantiful burl, but a buttem-hole: Rose should be a strong grower and very free-flowering, or it is not likely to survive as one of the fittest.

Ma Capucine (Levet, 1871).-Another weakly growing button-hole Tea Rose, most charming in colour. The buds are quite small, and not particularly long or pointed, but sure to attract notice. These Roses should all be grown, as standards, by any one who makes a specialty or collection of Bud-Roses, but as there is a sufficiency of strong-growing free-flowering button-hole varieties, such weakly growers should generally be avoided.

Madame Angele Jacquier (Guillot, 1879). -Of firir average growth, doing pretty well as a dwarf but better. as a standard, and requiring rich soil and high culture for show uses. The blooms come pretty well, though sometimes divided, and a good exhibition flower may often be obtained, of fine petals, nice pointed shape, and full size. The colour is not striking, and however it may be described it is more white than anything else when grown out of doors. At one time this Rose was highly esteemed, but it has, probably from its feeble colour, gone out of favour and dropped out of the N.R.S. catalogue.

Madame Berard (Levet, 1870).-.-One of the numerous descendants of Gloire de Dijon, the majority of which do not seem worthy of separate notice. This one is placed in the N.R.S. catalogue as a show Rose, but it is very seldom seen well exhibited. It is a beautiful colour, and certainly better shaped than most of its family, but is not as free-flowering or as hardy as the type.

Mactame Bravy (Guillot, 1848), syns: Alba Rosea, 



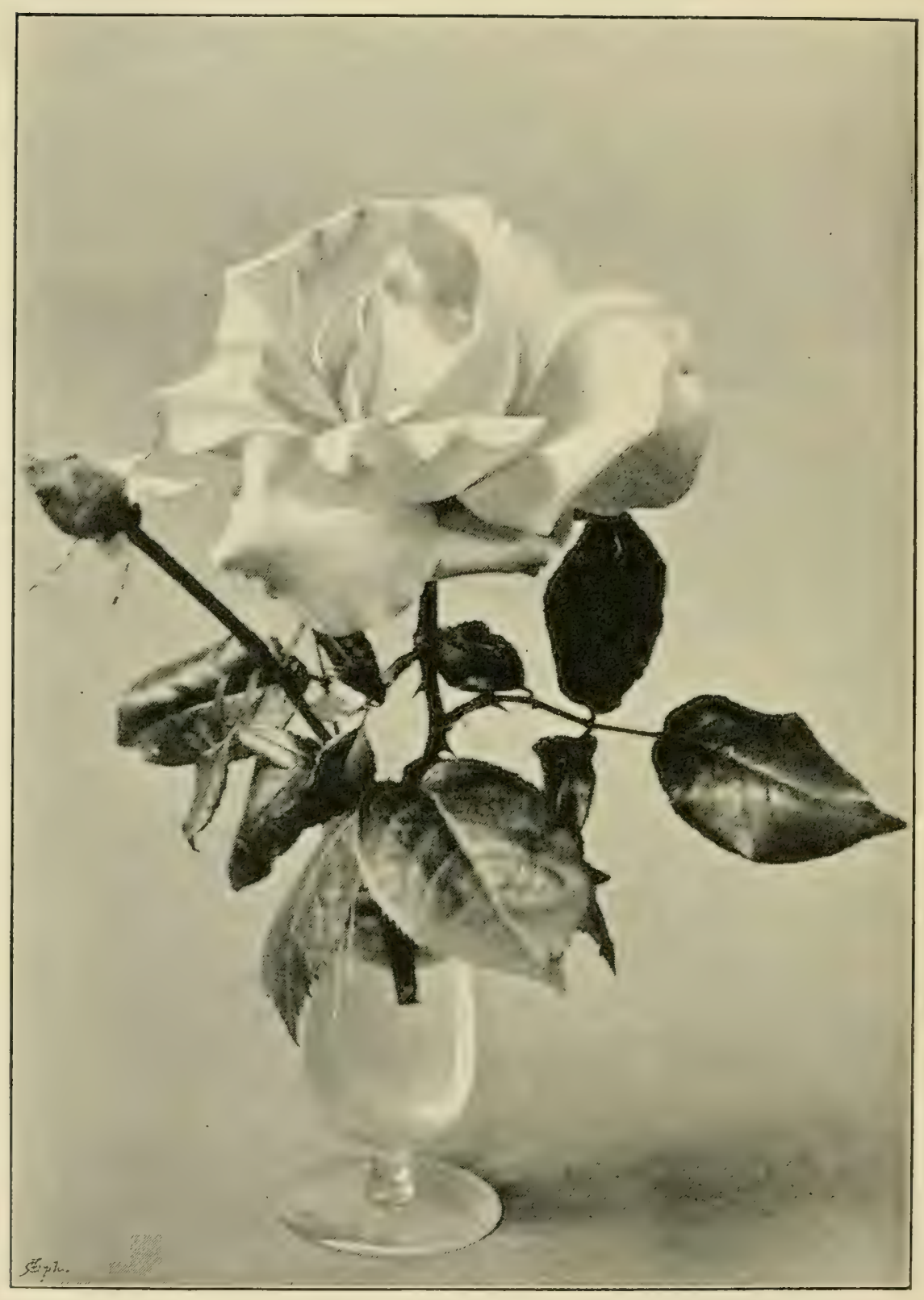

Tea-Rose, Madaje Cusin.

To face p. 291. 
Josephine Malton, and Madame de Sertot. Of average growth and fair foliage, very sweet, growing pretty well as a dwarf, but perhaps giving better flowers as a standard. The blooms come very well, but the shape is absolutely globular, almost like an incurved chrysanthemum, and such a form requires the utmost regularity, and shows at a glance the slightest imperfection. The wood is pliable, and the blooms are therefore pendent, and can only be seen in perfection when artificially supported in a vase or Rose-stand. A very freebloomer, requiring a good deal of thinning, but the autumnal buds rarely expand fully. It is of large size for the growth of the shoots, but owing to the globular shape and very short outer petals loses much in this r'espect when compared with other Roses, "long-winged" as I have called them, whose outer petals are large and stand well away. This Rose seems to have deteriorated somewhat of late years; it is certainly much less shown than it used to be, but perhaps this is simply from its becoming superseded for the reasons mentioned.

Madame Charles (Damaizin, 1864).-An improved strain of Safrano, which see.

Madane Chédane Guinoisscau (Leveque, 1880).-This is another of the button-hole Roses of moderate growth. The buds are pointed and well shaped, and the colour is bright yellow, a shade not sufficiently represented among exhibition Teas.

Mudame Cusin (Guillot, 1881).-Of short, thick, and often weak growth, with distinct wood and small foliage. It is rather liable to mildew and requires hot dry weather. Much better as a standard, from which a fine maiden bloom may sometimes be cut, but it is difficult to grow well and requires very good treatment. The blooms almost always come well, though they are 
often undersized, and the shape is unique and very good, with a fine point in the centre, and the petals arranged in imbricated form, but standing well apart from one another. This is the true form, but large flowers sometimes do not show it. No dressing for exhibition is required for this Rose, which naturally shows itself to the best possible effect. Very freeHowering: it must be well thinned for the production of exhibition blooms, but even the small flowers are lovely and of good lasting quality. A fine colour sometimes, but this is not often very lasting.

Mudume de Watterille. (Guillot, 188.3).--A notable and most distinct Rose, in habit and flower. The growth as a dwarf is frequently poor, and it is decidedly best as a standard. It is somewhat capricious, and some good growers have but little success with it; indeed, for the first few years of its existence it was, I think, only shown in its full beauty by one Rosarian, but several of the leading exhibitors are able to grow wonderful blooms of it now. They come well even though the buds be crinkled and apparently badly shaped, and it is quite a type of the "long-winged" Roses, the great petals standing out well, and giving it a most effective appearance. It is, in fact, perhaps more distinct in shape than any Rose. Liable to mildew, and very tender in hard frost; a free-bloomer of most charming buds, but these must be thinned with an unsparing hand to see the Rose in perfection. It is of large size if grown as it should be, well able to hold its own with H.P.s in a mixed class, and excellent in every good quality. Fair in a dry autumn, but having serious demerits in its uncertainty of growth and want of hardiness.

Madane Eugine. Fordier (Leret, 1883).-Apparently 


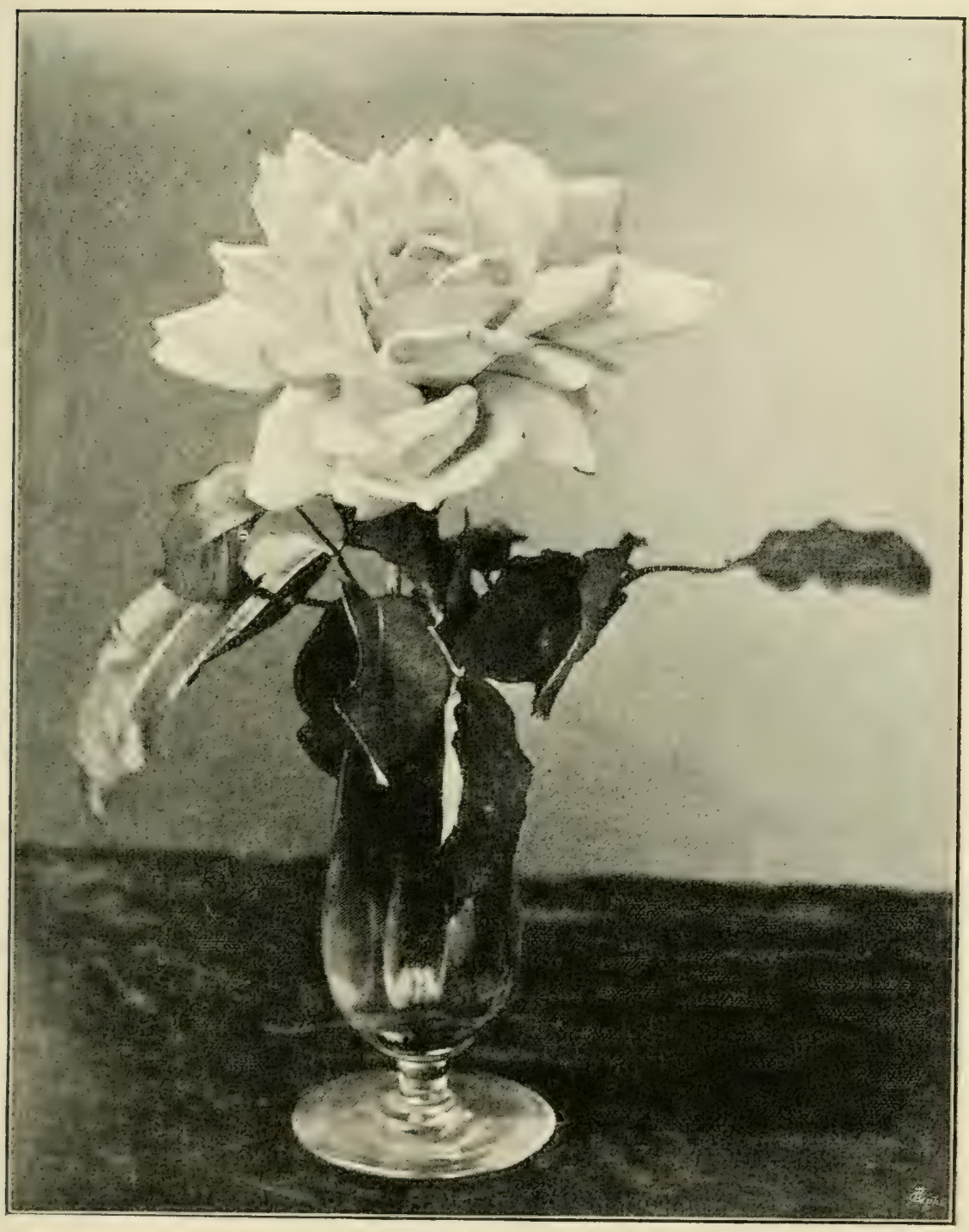

Tea-Rose, Madame de Watteyille. To facc p. 292. 

a "Dijon" rose, with the manners and customs of the family. The best coloured of them all, being really a good yellow. The blooms are not very large, though full and good, and it is not so free-flowering or anything like so hardy as its parent, as it is one of the tenderest of Roses. Late in flowering, and best in autumn. Note that there is a H.P. of exactly the same name.

Madame Fralcot (Guillot, 1858).-A button-hole Rose, of fair growth and foliage, useful in the bud state only. It is somewhat like Safrano, of deeper and brighter colour, and altogether better in bloom, but less hardy, of less vigorous growth, and not so free-flowering. A lovely bud, the exterior of the outer petals having often the most charming combinations of red and yellow, the inner petals being of a beautiful self-yellow. A good autumnal, but does not do well as a dwarf, and requires protection in the winter.

Madame Hippolyte Jamain (Guillot, 1869).-Of good growth strong enough for a low wall, which suits it well -not liable to mildew and can stand just a shower. The blooms come late and generally well, though occasionally divided, and the flower stalks are pliable, so that the blooms are completely pendent. The real beauty of the flowers is thus quite concealed on the plant, and few who have only seen it as growing would believe what a beautiful flower it is when properly shown at the right stage. At this period the outer petals fall well down when the bloom is held up, showing the purest glistening white on their inner sides, and a most charmingly tinted and shaped conical centre. Afterwards, in very hot weather or on a wall, it expands to quite a flat shape with a much yellower colour, and many would not recognise it as the same Rose; but it may be thoroughly depended on to last 
when cut in the right condition, for it requires fine hot weather to open at all, and was grand in the open beds in the summer of 1893. It does well as a dwarf in the matter of growth, but is best as a dwarf standard on a wall ficing east or west, and will then often be found not too carly for the exhibitions, for it is a late bloomer. It is only fairly floriferous, requires too much heat to be a good autumnal, and is not really of a large size; but the spread of the fine outer petals makes this and Roses of similar shape appear to the utmost advantage and larger than they really are. Note that there is a large light-coloured H.P. of exactly the same name as this Rose.

Madame Hoste (Guillot, 1887)._-Of good growth and fine foliage, doing pretty well as a dwarf but better as a standard. The flowers are rather thin, and though they stand a long time in the advanced bud stage, when once open they soon go, showing a weak centre. They are very large and well shaped in cool weather, making a showy appearance in rich soil, and are very effective in autumn, being often at that time larger and decper in colour. It is not a useful colour, as we have plenty of pale yellows, and want something more deep and decided in that shade. With stouter petals, fuller centre, and richer colour it would be a more notable Rose, but is much esteemed as it is.

Madame Lambard (Lacharme, 1877).-Of strong hardy growth with fair foliage, rather liable to mildew, but being a thin rose is less subject to injury from rain than many other Teas. The blooms come generally well, but the strongest are sometimes divided; they are thin in petal, not very large, and rather wanting in centre: must be grown strongly on rich soil to be well shown, and are not lasting flower's. A cool-season Rose 
very fire-flowering, but often of little account in July when other Teas which can stand the hot sum are to be had. In the late autumn Madame Lambard is a friend indeerl. If it be cold and wet the "thin" Tea Roses alone will open, and this one will be found among the freest and best. It does well as a dwarf, and is remarkable for its extreme variation in colour-some blooms of a bright light red, other's of salmon, and other's of rosy butf or lighter may occasionally all be found on the same plant at once.

Mertame Margottin (Guillot, 1866).-_Of time sturdy growth with good foliage. It does well as a dwarf, but the flowers are very easily spoiled by rain, as this is a Rose of the opposite extreme to the one last mentioned. It is very full with thick petals, refusing to open except in hot dry weather and consequently though free of bloom it is generally of no use as an autumnal. The blooms come very badly being often divided, and sometimes "quartered," i.t. with two rifts or divisions rightacross the flower. A perfect one is not often seen, but is very good, when found at last, in shape, colour, size, and especially in lasting qualities.

Madame Willemo: (Lacharme, 1845).-Of very sturrly strut growth with splendid foliage: an old Rose, formerly of considerable repute, but getting fast superseded by those of better manners. It is full of abundant promise in its exuberant foliage, but generally sarlly lacking in the production of handsomely shaped useful blooms when the critical time comes. The petals are very fine but the form is not good, those on the outside keeping up as tight to the bloom as possible, and a well-defined point in the centre being often absent. This is the worst shape for exhibition, as it makes the blom appear smaller than it really is, and 
a strong temptation arises to "dress" Madame Willemoz, or rather, say, to persuade her to unmask, by bending down the outside petals. The effect is very great, for not only does it make the bloom more of the shape of which Rosarians approve and the size appear considerably larger, but also the inside of the petals is naturally of a much purer and cleaner white than the outside; and thus, by this simple process, the Rose appears larger, better shaped, and of purer colour. It is however distinctly "altering the character" of the Rose, and the N.R.S. is probably right in setting its face against the presentation of any bloom in a shape which it never naturally assumes. On rare occasions it does open well in hot weather with a good point in the centre, and is then very fine. It does well as a dwarf, the stiff upright character of the wood being well suited to this form of culture. It cannot be called a free-bloomer or good autumnal, or be generally recommended.

Maréchal Niel (Pradel, 1864).-Of very strong climbing growth, with magnificent foliage, practically evergreen, but as liable to mildew as any in this class. The blooms come often divided and discoloured on standards in the open, much better on a wall though losing colour in hot sun, and nearly always perfect under glass. A most splendid Rose, the best of all the yellows, and with strong claims to be called the quecn of all Roses. It is grand in petal, centre, shape, colour, fragrance, lasting qualities, and size: a very free bloomer, and though on a wall the second blooms are not numerous, it flowers throughout the season on standards where these can be grown in the open. Very many of our best Roses lose their colour soon after being cut; but Maréchal Niel decidedly improves, and becomes of a deeper yellow after being kept for a day or two in water. It was sent out 



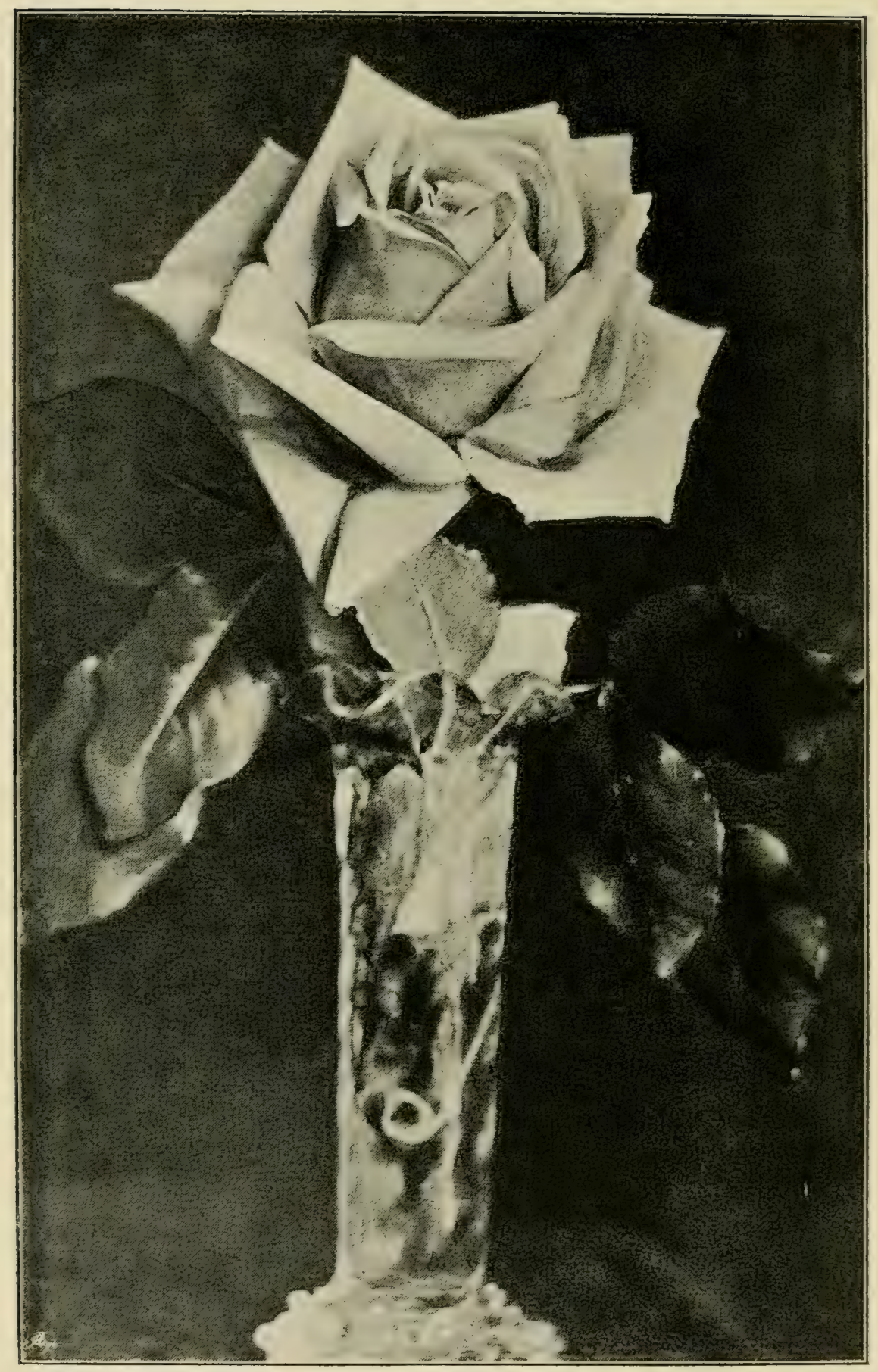

mybrid Noisetie Rose, Marechal Niel. To face p. $29 \%$. 
as a Noisette, and, like all the Roses of that class, the best blooms come on the long strong secondary shoots of the previous year, which should be left nearly of full length ; but it is evidently hybridised with the Tea race, as what is generally called the Tea scent is strongly present. To a large extent it stands by itself, as do several of the most celebrated Roses, Cloth of Gold probably resembling it most nearly. Though often grown on its own roots in pots, for it strikes freely as a cutting, it does much better if budded either high or low on the briar. It is decidedly tender, being liable in the open to be injured or killed outright by severe frosts; but on a wall, particularly if there be anything in the nature of a coping above, it will stand ordinary winters in most localities. It is easily forced, and much grown for the market, the best method of pruning and training under glass to get a fine crop of these splendid blooms in early spring having been described on page 95. Mildew in this mode of culture is the principal trouble, and the ventilators should be kept entirely shut when the wind is cold. The variety has another piece of bad manners, which is most troublesome under glass because there is more growth there, viz. a liability to canker, especially at the point of juncture between stock and scion. As this probably arises from the inability of the briar stem to swell sufficiently for the growth of the Rose, a useful preventive measure is to make one or two longitudinal cuts through the bark, passing through the point of union, and extending some distance above and below it. This will not cure established canker, but may help in a great measure to prevent and modify it. In a really barl case it is best not to attempt a cure. Good strong young plants are cheap and soon come into bearing; but. when putting in a new plant where a large Rose has 
stood, remember to take out a good deal of the old soil, and replace with rich fresh stuff in which Roses have not been grown. I know of no seedling or sports of Maréchal Niel, though weak blooms on a hot wall will sometimes show red on the outer petals.

Marie van Houtte (Ducher, 1871).-The strongest and best in growth of any of the pure Teas, with finc, nearly evergreen, foliage. A cooler time after hot weather, which is most favourable for all Roses, will show Marie van Houtte at its best, and it is but little injured by rain. In manners and customs and all round good qualities it must take first prize among the Teas: at all times a beautiful bloom, in perfection most lovely, excellent in petal, fulness, shape, lasting qualities and size, and delightful in colour, very free in bloom and a first-class autumnal. It does perfectly well as a dwarf, is not particular as to soil, and is undoubtedly the one Tea Rose no one should be without.

Medec (W. Paul and Son, 1891).-A new Rose, the cut blooms looking like full specimens of Madame Hoste: a good grower and free in flowering, but not likely to open well in wet weather.

IIrs. James Wilson (A. Dickson and Sons, 1889).... Of good growth when established, and fair foliage. The habit is peculiar, in that the centre or crown bud of a shoot is quite overwhelmed and starved out by the growth of the side flower buds unless these be thinned out at once; and even when this is done, the bud does not grow proportionately to the thickness of the shoot, and the blooms are rather undersized and disappointing. The petals are good and the shape nicely pointerl: it is late in blooming, and not many flower's come to perfection on one plant. A pretty colour, sometimes a little like that of Marie van Houtte. 
Monsicur Furtedo (Laffay, 1866).-This Rose still appears in the N.R.S. catalogue; but the growth is very weak, the flowers small and short-petalled, and though the colour is a good yellow it is certainly a Rose to be avoided.

Niphětos (Bougère, 1844).- This Rose is a good instance of what is termed "free" growth, i.e. neither long nor stout, but branching and generally growing somewhere. The foliage is good and not much liable to mildew, but the blooms will not stand rain. This old Rose has attained a very great reputation for its free-flowering qualities and its purity of colour. I do not know how many thousand feet run of glasshouses have been maintained for the purpose of growing the rose which Mons. Bougère, the raiser, appropriately named Niphĕtos ("snowy"), but I apprehend the figures would very much have astonished him could he have known them when he issued it, and he would perhaps have wished to attach his own name to it instead of to the much less valuable production (Bougère) of twelve years before. White flowers are always in special demand, not only because they are lovely in themselves, do not lose their colour, and go well with everything, but also because they are considered the most appropriate on the three great occasions of birth, marriage, and death. It so happens that Niphětos, the purest of all white Roses, has a long bud especially suitable for bouquets and wreaths, and is also free-flowering and bears forcing well. It is no wonder therefore that it is, and has been, cultivated for market purposes to an astonishing extent. It is also capable of being exhibited as a Rose of great merit, with very fine petals and of the largest size; but in this respect it seems to have deteriorater or been supersected, as it is certainly not so often shown now as 
formerly. The blooms come well, but occasionally they are divided, and the expanded shape is very loose. They must be cut young for show (when there is often a greenish lemon tinge in the strong young buds which is very becoming) as the shape is not lasting, and when the outside petals come down they fall completely, giving the idea of a total collapse. It is free blooming throughout the season, but the autumnal buds do not come large and require fine weather. It does not do as a dwarf, for the blooms come smaller, and the wood being neither stiff nor upright the petals get much injured by wind and rain unless the flowers are well held up above the ground. It is best for exhibition as a maiden standard, and does well, if fully fed, on a low wall.

A climbing sport (Keynes, Williams, and Co., 1889) gives promise of being very valuable for the production of cut flowers of this ever useful sort; but it does not seem yet to be thoroughly established, sometimes reverting to the old type and refusing to "run." Still, it has undoubtedly proved a success in many places, the long rods blooming from every bud after the fashion of Maréchal Niel, though it is as yet too early to say whether the new form will supersede the old one in the forcing of this popular Rose.

Ophiric (Goubault, 1841).-A true Noisette, one of the very few that can be so called. A strong, long, rapid grower of vigorous constitution and quite hardy, with abundant but not evergreen foliage, blooming in clusters of queerly coloured and still more queerly shaped flowers. They are very small and nearly always "quartered," which seems indeed the normal shape; and the variety is only noticeable for its quaint coppery red colour, which $\mathrm{I}$ have always imagined somehow or other to be the source of that shade wherever it appears in our Tea 
Roses. It should be pruned very little, merely cutting out any dead wood, and is then free-blooming and a good autumnal, but the plant is only worth growing as a curiosity or from old associations.

Perle des Jardins (Levet, 1874).-OOf good stout stiff growth, with reddish wood and fine foliage, doing well as a dwarf, but a Rose of shocking bad manners. We want much a well-shaped Tea of a good decided yellow to take the place of Maréchal Niel when it is off bloom; and Perle des Jardins is always promising to do this, and very, very seldom doing it. It comes divided, or quartered, or malformed in some way almost to a certainty during the summer, but manages to stave off execution of just judgment by the aid of better shaped and far more valuable blooms in the autumn. At that season it will often prove the only available sort which is really yellow, and even one bloom of this colour will make a wonderful improvement in a bouquet of autumn Roses. It comes better under glass and would probably do well in a hot climate, but is worth growing for its autumnal bloom alone.

A climbing sport of this Rose (Henderson, 1891) has been issued, but so lately that I can give no certain aceome of it. There is also a white sport called White Perle.

President (Paul and Son, 1860), see Adam.

Princess Bectrice (Bennett, 1887).-A poor grower, with a delicate constitution. It is one of the very earliest, and grows rapidly enough till the bloom has formed, and after that has passed often stands almost quite still, making neither growth nor bloom during the rest of the season. It must have very fine dry weather, and even then is not much good out of doors; but it is a well-shaped bloom, with lovely colour, though not large, 
when grown under glass. There is a II.P. rose (IV. Paul \& Son, 1872) of this name.

Princess of Trales (Bennett, 1882).-Of small dwarf growth and foliage, requiring fine weather. This Rose, though unlike in stem and wood, has something of the manners and customs of Comtesse de Nadaillac. A small stem will sometimes grow, stiffen, and swell for a long time without opening the bud, which when it does come will be a great and probably a good Rose, while a much stronger shoot of three times its length perhaps remains pliable, opens quickly, and produces a much inferior bloom. The shape of the smaller flowers is weak and undecided, but there is no doubt about its beanty in form and every other quality when it does come good, though it is seldom very large. It is variable in colour, and is somewhat capricious, doing well in some soils and badly in others, but generally best as a standard. There is certainly one H.P. of this name, if not two.

Rêre d'or (Ducher, 1869).-A very strong climbing Noisette, with stout and rapid growth and nearly evergreen foliage. This valuable Rose has one most desirable piece of good manners as a climber. Other Noisettes and Roses of the Gloire de Dijon race are apt, when grown on a wall, to become weak and bare in foliage towards the bottom, so that all the blooms are out of reach and the plants look unsightly from the naked appearance of the lower branches. This is not the case with Rêve d'Or, and it adds considerably to its merit as a climber that the lower parts of the plant are fairly clothed with blooms and foliage. It is not liable to mildew, and can stand a little rain as well as most. The blooms come in clusters, well shaped, of much the same colour as Safrano and Sunset, but not lasting or large 
enomgh for exhibition. It is wonderful as a free bloomer, the plant being smothered with flowers from top to bottom during the first crop, and a fair amount of blooms continue into the autumn. It is quite hardy, makes a good standard, and is to my mind one of the very best of climbing Roses. Not so large as Gloire de Dijon, nor quite so good as a continuous bloomer early and late, but superior to it in manner of growth for corering a wall.

Rubens (Robert, 18.99).-A good grower, producing strong clean shoots with very fine foliage, and quite capable as a short standard of covering the wall of a one-storied building. It is not liable to mildew, and the blowms, which are slightly pendent, can stand a little rain. They can be generally relied on to come of good hape, but the petals are thin and the form flecting. The fine half-open buds are well supported by grand foliage, but the flowers are difficult to exhibit well as they lowk weak and unsubstantial when shown with other Teas. It is pretty hardy, best as a standard and in cool weather: capital, early and late, against a dwarf wall: very free blooming and a good autumnal, thriving well on lightish soil.

Scuficun (Beauregard, 1839).-Of very strong growth with fair foliage, quite hardy, sweet scented, not liable to milklew, and hardly minding rain at all. This old Rose is very fiee blooming, but small and thin and quite weak and open in the centre. It is only useful for button-holes, and, likeall thin Teas, is especially valuable in the late autumn. When not another Rose is to be found anywhere from the cold and wet, a Safrano on a wall will come to the rescue. Of good constitution and ready to thrive anywhere, growing almost wild in the Riviera. It is of the sanne coloux as Rêve d'Or and Sunset, but the buds 
CHAP.

have sometimes the lovely red tinge of Madame Falcot. In fact, Madame Charles, Madame Faleot, and Safiano are very much alike in bloom, the first of these three giving the finest flowers.

Solfuterre (Boyau, 1843).-A Noisette of strong climbing growth with large open loose blooms of little merit. It is tender, not so good as Lamarque, a poor autumnal, and would probably never have been heard of if it had been raised at a later date.

Sonrenir d'Elise Fardon (Marest, 1854). - Not of free growth or of good constitution, but there ought to be at least one pretty strong shoot on each plant: not liable to mildew, but easily injured by rain. The blooms come generally well, though sometimes divided, and when it is fine on a strong shoot and taken at the right stage you have to my thinking the finest and best of all show Roses, either H.P. or Tea. It is getting quite an old Rose now, but, though new sorts are issued every year by scores, nothing has yet been raised to surpass or even equal it. If the medal for the best Tea Rose at an exhibition goes to another variety, it will be simply because Elise at its best is not there. It blooms early, as in fact do all the Teas, but they come again, while it takes a long time to work up fresh shoots to produce this grandest of Roses, and the second blooms never equal the first; but when the season is late enough for it to be shown in anything like perfection, no successful rival in any stand or competition has yet been found. It does rather better as a standard, but is tender against frost and quite capable of being grown to perfection as a dwarf. In freedom of bloom it is not good, for the blooms come singly, and the very weak shoots will not flower at all. The growth is shy and the constitution delicate. It is not a Rose suitable for 
garden purposes, but the sort for enthusiasts, with whom one perfect glorious bloom is worth a garden full of ordinary flowers. Every possible care should be bestowed in watching and protecting the bud, and diligently and highly feeding the plant until the medal bloom, the queen of the show, is cut.

Sourenir de Paul Neyron (Levet, 1871).-Of rather weak growth with small foliage, though occasionally a plant will grow pretty well. The first blooms often come badly, but with careful thinning of the buds some may be got of a good shape, with a glistening colour, and large size considering the smallness of the stems; but the plant is difficult to please and will not often do well as a dwarf, and being fairly hardy sueceeds better as a standard. It is a good autumnal where it will grow sufficiently, and very free-flowering in the season, every wood bud all over the plant trying to grow as soon as the flower buds are formed. This habit, which is more or less common to many of the free-flowering Teas of moderate growth, makes it very difficult to find buds for propagation without sacrificing some of the coming blooms. A good show Rose in a Tea box, when it can be got fine, but much less seen of late years.

Souvenir de Thérèse Leret (Levet, 1882).-Of pretty goud growth and foliage, especially as a standard, late in blouming and farrly hardy. This Rose is remarkable for its colour, which is a deep, dull, and sometimes blotchy crimson, forming a great contrast to the bright light colours common to the rest of this section. The blooms rlo not often come perfect, but are fine when they do, and very listing. If the colour was bright, pure, and velvety, it would be much better, but as it is it does not show well against the pure whites pinks 
and yellows of its sisters in a stand of Teas. Perhaps it ought to be more cultivated, but most fanciers of 'Tea Roses seem half ashamed of it, as if it had no business to be dark red, and it is not in general highly esteemed. Note, there is a 'Thérèse Levet, a pink H.P. of ordinary quality.

Sourenir d'un Ami (Defougère, 1846).-A grand old Tea Rose, of strong, healthy, vigorous growth with extra fine foliage. This is one of the hardiest of the show Teas, doing well on light soil, and fairly as a dwarf but much better as a standard: a free bloomer and a cipital autumnal, and the blooms generally come well, of fine shape, substance, and petal, the largest size and good lasting qualities. The principal fault is that the Hower soon loses colour and is apt to look dirty, but it is deservedly a general favourite for all purposes.

Souvenir de S. A. Prince (Prince, 1889), syn: The Queen.-This is a pure white sport from the last-named, and very valuable as giving us a really white Rose of good pointed form. In habit and general manners it is the same, but I cannot get the blooms to come as large as those of the type.

Sunst (Henderson, 1883).-A sport from Perle des Jardins, of the same colour as Rêve d'Or: a handsome, useful, strong-growing Rose, with foliage of a beitutiful red colour in the spring. It comes a little better shaped than its progenitor, and is a very good autumnal, but the blooms are always small compared with the size and stoutness of the shoots, and the plant is tender to frost.

Triomple de Rennes (Lansezeur, 1837).-This old Noisette is a fair grower but not strong enungh for anything but a low wall. The wood and habit are very charactoristic, and it is tender and eusily killed 


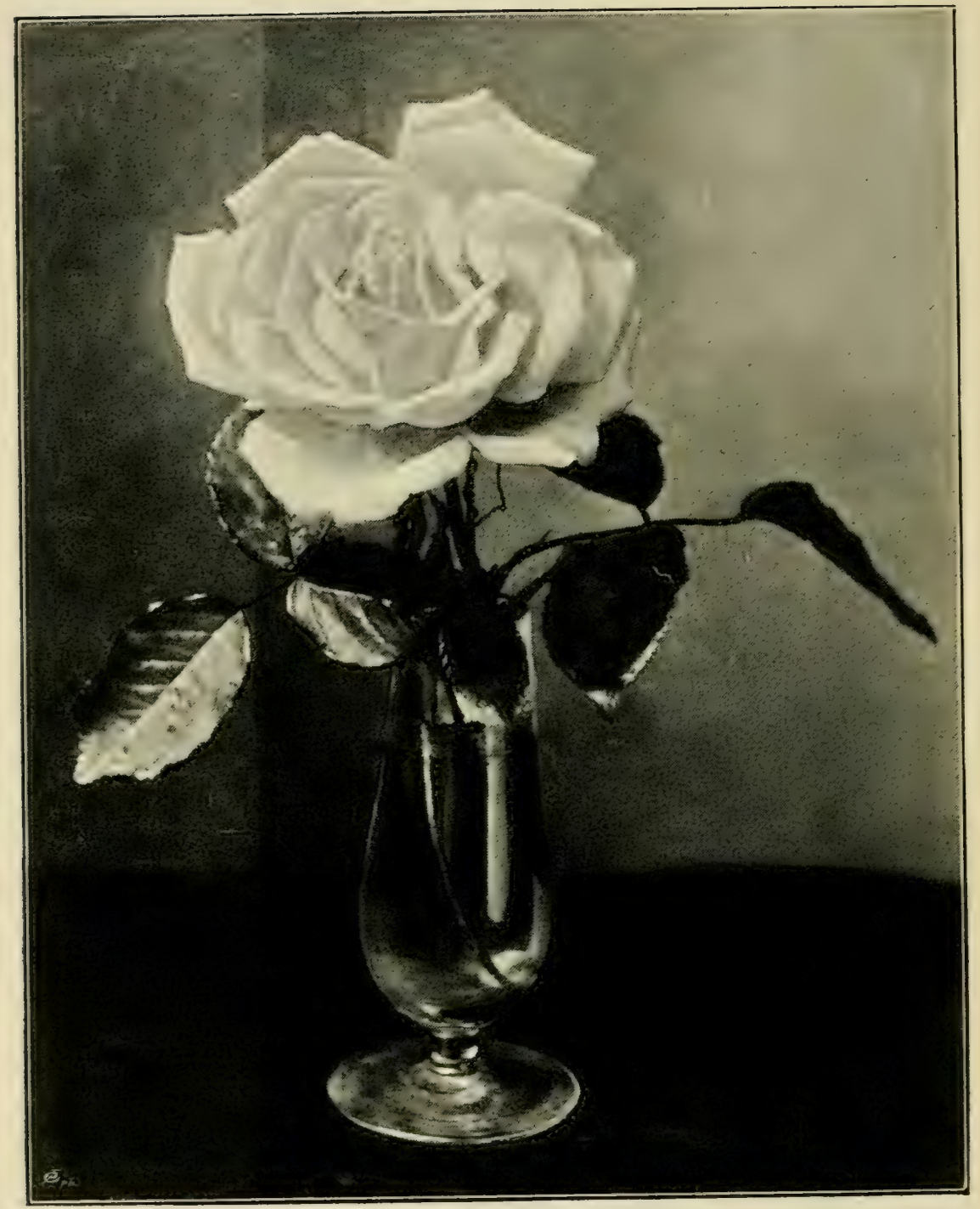

Tea-Rose, The Bride.

To face $p .307$. 
by frost. The blooms require a good deal of heat and to be protected from rain; they are very fine when you get them good, of perfect pointed shape, with very sweet scent, and are capable of reaching a full average size. It is quite good enough to show in any company when grown at its best, but we never see it, and this, the finest shaped of all the Noisettes with the exception of Maréchal Niel, does not appear in the N.R.S. catalogue at all. It is certainly difficult to grow well, and has probably been more often spoken of than seen during its existence of more than half a century.

The Bride (May, 1885).-A pure white sport from Catherine Mermet, of great value. It speedily took a high rank, and gained a great reputation, quite equal to that of the type, and is generally acknowledged as being one of the best half-dozen. It is similar in every respect except colour to C. Mermet, especially in the incomparable form which is common to both. $\Lambda$ slight greenish-lemon tinge sometimes pervades the inner petals, and gives an additional charm. The light colour renders it a little more liable to injury from thrips or rain.

Waban (Wood and Co., 1891).-Another sport from Catherine Mermet, also from America. Not yet sufficiently testerl, but at present it does not often come good. The Bride being so successful, we expect much from the two other American sports from the same Rose, Waban and Bridesmaid, but the one under notice has not hitherto been often seen to advantage.

William Allen Richardson (Ducher, 1878).-A Noisette of good strong growth, but not quite so vigorous a climber as some others of the section. This is a Rose that very soon gained a great reputation purely by its coluur, which is a real orange, a shate till then 
unknown in Roses, and even now only to be found in the centre of two or three others. It is quite small, and only suitable for button-holes and decorative use being more valued and generally grown for the former purpose perhaps than any other Rose. In shape it generally comes well, but it has a disappointing habit, which must often have caused annoyance. The blooms often come practically white, with no trace of orange, except perhaps at the very base of the petals; but about the time that the nurseryman who supplied it has received an indignant letter of complaint, the buyer on passing by the plant sees a bud coming of the true colour. For a while they will all come of deep orange, or orange tipped with white, and then some come perhaps nearly white again. Often the weakest shoots produce the highest coloured flowers, but this does not seem to be a general rule. This lovely and favourite Rose should be grown in quanitity, in the open, against walls, and under glass. It is free-blooming, pretty good as an autumnal, and does well as a dwarf, but should be well treated in rich soil, and requires protection from frost. 


\section{CHAPTER XIII}

\section{SELECTIONS}

This must always be the most unsatisfactory part of a Rose-book, both to the author and the reader. In the first place, the compiler of a selection feels, or ought to, that he has at least one or two favourites which he places in a higher position than most of his brother Rosarians do, and that there are perhaps as many popular sorts that he does not succeed with. His own situation, soil, or climate has probably more to do with this, in most cases, than actual personal predilections.

Next, a certain number of new Roses, issued within the last three years, have to be dealt with; and, their quality and characters being not yet established, it is difficult to know what to do with them. Great mistakes, either way, may be made in attempting to rank them too soon, but on the other hand it seems impossible to ignore notable issues. I have therefore only included varieties sent out later than 1891 where there seems to be a character already established.

And also no one who makes a selection of Roses can shut his eyes to the fact that such a list, especially if given in order of merit, must be of very ephemeral value. New Roses, working their way to the front, not 
only take the places of established favourites, but sometimes entirely supersede them and cause them to drop out altogether. Thus, Madame Lacharme, at one time the best white H.P., was made absolutely useless by the coming of Merveille de Lyon, and will probably soon drop out of the catalogues altogether.

Roses Suitruble for Exhibition. - In these lists it should be noticed that weakness of growth or constitution, or in fact any bad manners, are not taken into account. Chapter XII. should be consulted on such matter's, for in the two following selections the merits of the perfect bloom when once attained are alone taken into consideration.

Forty-eight H.P.s.-I have endeavoured to range these according to order of merit as show Roses, in lots of twelve, thus showing also at the same time the best twelve, twenty-four, and thirty-six. I have included La France, Captain Christy, and Lady Mary Fitzwilliam, which the N.R.S. at present reckon as H.T.s., and Mrs. Paul, Hybrid Bourbon. The list is not entirely according to my own fancy, but considerably influenced by the opinions of others.

1. Horace Vernet

- 2. Mrs. John Laing

3. A. K. Williams

4. Her Majesty

5. Charles Lefebvre

6. Alfred Colomb

- 7. Madame Gabriel Luizet

8. Marie Baumann

9. Gustave Piganeau

10. Susanne M. Rodocanachi

11. La France

12. Ulrich Brunner
13. Etienne Levet

14. Duchess of Bedford

15. Pride of Waltham

16. François Michelon

17. Eugénie Verdier (Marie Finger)

18. Duke of Wellington

19. Dupuy Jamain

20. Merveille de Lyon .

21. Prince Arthur

-22. Duke of Edinburgh

23. Louis van Houtte

24. Earl of Dufferin 
25. Duchesse de Morny

26. Marie Verdier

27. Le Havre

28. Reynolds Hole

29. Xavier Olibo

30. Countess of Oxford

-31. Baroness Rothschild

32. Victor Hugo

33. Camille Bernardin

34. Général Jacqueminot

35. Lady Mary Fitzwilliam.

36. Comte de Raimbaud
-37. Jeannie Dickson

38. Marie Rady

39. Fisher Holmes

40. Madame Victor Verdier

41. Beauty of Waltham

42. Senateur Vaisse

43. Mrs. Paul

44. Captain Christy

45. Marquise de Castellane

46. Maurice Bernardin

47. Madame Eugène Verdier

48. Heinrich Schultheis

Twenty-four Teas and Noisettes, by sixes, in order of merit.

1. Souvenir d'Elise Vardon

2. Catherine Mermet

3. Comtesse de Nadaillae

4. The Bride

ร. Maréchal Niel

6. Marie van Houtte

7. Innocente Pirola

8. Madame de Watteville

9. Cleopatra

10. Anna Olivier

11. Hon. Edith Gifford

12. Ethel Brownlow
13. Ernest Metz

14. Madame Hoste

15. Madame Cusin

16. Souvenir d'un Ami

17. Niphetos

18. Francisca Kruger

1.9. Souvenir de S. A. Prince

20. Princess of Wales

21. La Boule d'Or

22. Madame Hippolyte Jamain

23. Jean Ducher

24. Caroline Kuster

Trepler IIybril Teas.- The subjoined seem to me to be the best of this class at present for exhibition, but I 
must repeat that I think the classification of the N.R.S. on this point is a mistake.

1. La. France

2. Lady Mary Fitzwilliam

3. Viscountess Folkestone

4. Caroline Testout

5. La Fraîcheur

6. Captain Christy
7. Grace Darling

8. Kaiserin Augusta Victoria

9. Augustine Guinoisseau

10. Lady Henry Grosvenor

11. Gloire Lyonnaise

12. Duchess of Albany

Germaine Caillot, a fine show Rose, worthy of a place among the above, seems to me like a Hybrid Tea, but it is not classified as such yet by the N.R.S.

For Midclle Rows. - Where the H.P.s and Teas are grown, as recommended, in long beds with three rows in each, it is adrisable, whether standards or dwarfs be used, to know which will be tall enough in growth to be suitable for the middle row. For such a purpose I recommend of exhibition H.P.s the following thirty of those in the N.R.S. catalogue:-

Thirty H.P.s tall enough in grouth for a middle rove.

Abel Carrière

Alfred Colomb

Annie Wood

Camille Bernardin

Charles Darwin

Charles Lefebvre

Countess of Rosebery

Dr. Andry

Duke of Edinburgh

Duke of Teck

Dupuy Jamain

Ella Gordon
François Michelon

General Jacqueminot

Heinrich Schultheis

Her Majesty

John Stuart Mill

La France

Madame Gabriel Luizet

Madame Isaac Periere

Madame Victor Verdier

Margaret Dickson

Narie Rady

Mrs. John Laing 
Mrs. Paul

Prince Arthur

Reynolds Hole
Thomas Mills

Ulrich Brunner

Violette Bowyer

And of exhibition Teas and Noiscttes, omitting those of Dijon growth, the following twelve:-

Anna Olivier

Caroline Kuster

Jean Ducher

Jules Finger

Madame Hippolyte Jamain

Madame Hoste
Madame Lambard

Madame Margottin

Marie van Houtte

Perle des Jardins

Souvenir de S. A. Prince

Souvenir d'un Ami

Climbing Roses.-These may be required for walls, pillars, arches, rough fences, or even an untidy old treetrunk which it may be desired to hide. There is some difficulty in making a selection for a wall not facing north, because of course all Roses of sufficiently strong growth will do in such a position, while the few that really require a wall are by no means always the best. Thus the Macartneys and Musk Roses will only do on a warm wall, but who, if he had room but for one would have either of them, or even a Banksian, where he could grow a Maréchal Niel? I have tried therefore in the following selection to place climbers for walls in order of merit, that the small grower may have some guide, as well as he who requires a "large order."

Truelve Roses for a wall.

- 1. Maréchal Niel

- 2. Rêve d'Or

3. Turner's

Crimson

Rambler

4. Gloire de Dijon

-5. Reine Marie Henriette.

6. Bouquet d'Or
7. Lamarque

8. Kaiserin Friedrich

9. Madame Berard

10. William Allen Richardson.

11. Waltham Climber (1 or 3)

12. Cheshunt Hybrid 
All the above are very vigorous growers, autumn bloming, with large full flowers. All other climbers, with the exception perhaps of the climbing sports of Niphetos and Perle des Jardins which I have not seen on outside walls, and climbing Devoniensis whose manners are not satisfactory, are deficient either in growth, antumnal qualities, size, or fulness of flowers. In the above list there is much diversity of merit, and Turner's Crimson Rambler, which alone has small flowers though the truss is very large, is not proved, but seems likely to take such a high place. It seems impossible to omit William Allen Richardson from such a list, but it has less vigour than the others mentioned.

Pillar Roses are seldom satisfactory; they are generally half-starved, being often passed over as capable of looking after themselves when the food supplies are being carrierl round. Any of the hardy stiff sorts of climbers will do for this purpose, the Gloire de Dijon race, Rêve d'Or, Reine Marie Henriette, Bouquet d'Or, Waltham Climbers, Cheshunt Hybrid, Gloire de Margottin, and such of the climbing sports of H.P.s as are really extra vigorous in growth. The Hybrid Bourbons, Charles Lawson, Coupe d'Hébé, and others of that class will also serve the purpose of pillar Roses, but I recommend no summer Rose where a perpetual will succeed. Halfclimbers, like William Allen Richardson, L'Idéal, Céline Forestier, and others of a like strength of growth, have not sufficient vigour for pillar Roses, save under exceptionally good treatment.

For arches also one often sees varieties used which are not of sufficiently vigorous growth. The Gloire de Dijon race are rather too stiff for this purpose. Turner's Crimson Rambler may probably be found very effective or this and many other uses; Rêve d'Or and Reine 
Marie Henriette may perhaps succeed, if care and trouble in training and feeding can be given to them: but if the arch is high and wide, recourse must be had to some of the many running summer Roses, the best of which will be found noted under their respective classes in Chapter II.

The same sorts, Ayrshire and Evergreen, Boursault and Multiflora, with the climbing single forms of Polyantha, are the best for hiding rough places. Bennett's Seedling, Dundee Rambler, Félicité Perpetue, Queen of the Belgians, Ruga, and Splendens are among the best known. After giving the leading shoots the right direction for two or three years, no more care will be required; the whole space will become a mass of foliage, most thickly covered with bloom for a while at midsizmmer. At my old home the whole of the roof of a large and lofty summer-house was completely hidden outside a foot or so deep with the growth of some of these Ayrshires, which were planted against and trained up the front pillars. These sorts, with naturally trailing shoots, are also the most suitable for weeping Roses.

For cottage gardens, or any places where some show of Roses is required without much attention being paid to them, choice should be made from the hardiest and most fiec-flowering of those mentioned in Chapter XII. I subjoin, however, a list of

Thelve H.P.s for cottage gardens.
Abel Grand
Alfred Colomb
Lá France
Dupuy Jamain
Madame Isaac Pereire
Edouard Morren
Mrs. John Laing
John Hopper
Paul Neyron
Jules Margottin
Thomas Mills
Ulrich Brunner 
When once established, Roses on the seedling briar stock are best where they are likely to be neglected, but most of those in the above list will do fairly on their own roots.

Only strong growing and thoroughly hardy Teas and Noisettes can be recommended for this purpose, such as Gloire de Dijon, Homère, Rêve d'Or, and Safrano or Madame Charles.

Of these, Gloire de Dijon and Rêve d'Or' would also do as cottage climbers, but the trailing habit of the Ayrshires makes them more suitable than stiff-wooded Roses for situations where they are likely to be left unpruned and untrained.

For the pegging-down system of training, Roses should be free-flowering and strong, yet fairly pliable in growth; but some of the stiffer ones can be bent down if it be done gradually as they grow.

Twelve H.P.s for pegging down.

Camille Bernardin

Duke of Edinburgh

Duke of Teck

Général Jacqueminot

Gloire de Margottin

John Stuart Mill
La France

Mrs. John Laing

Prince Arthur

Prince Camille de Rohan

Thomas Mills

Violette Bowyer

Moss Roses are sometimes trained in this way. Among Teas, the hardiest and most pliable of the Dijon race are suitable, some of the most vigorous among the button-hole varieties such as William Allen Richardson and L'Idéal, and perhaps Marie van Houtte, Caroline Kuster, and Madane Lambard. In choosing sorts with pliable shoots for this mode of culture, it should be remembered that a stiff flower stem is desirable, for 



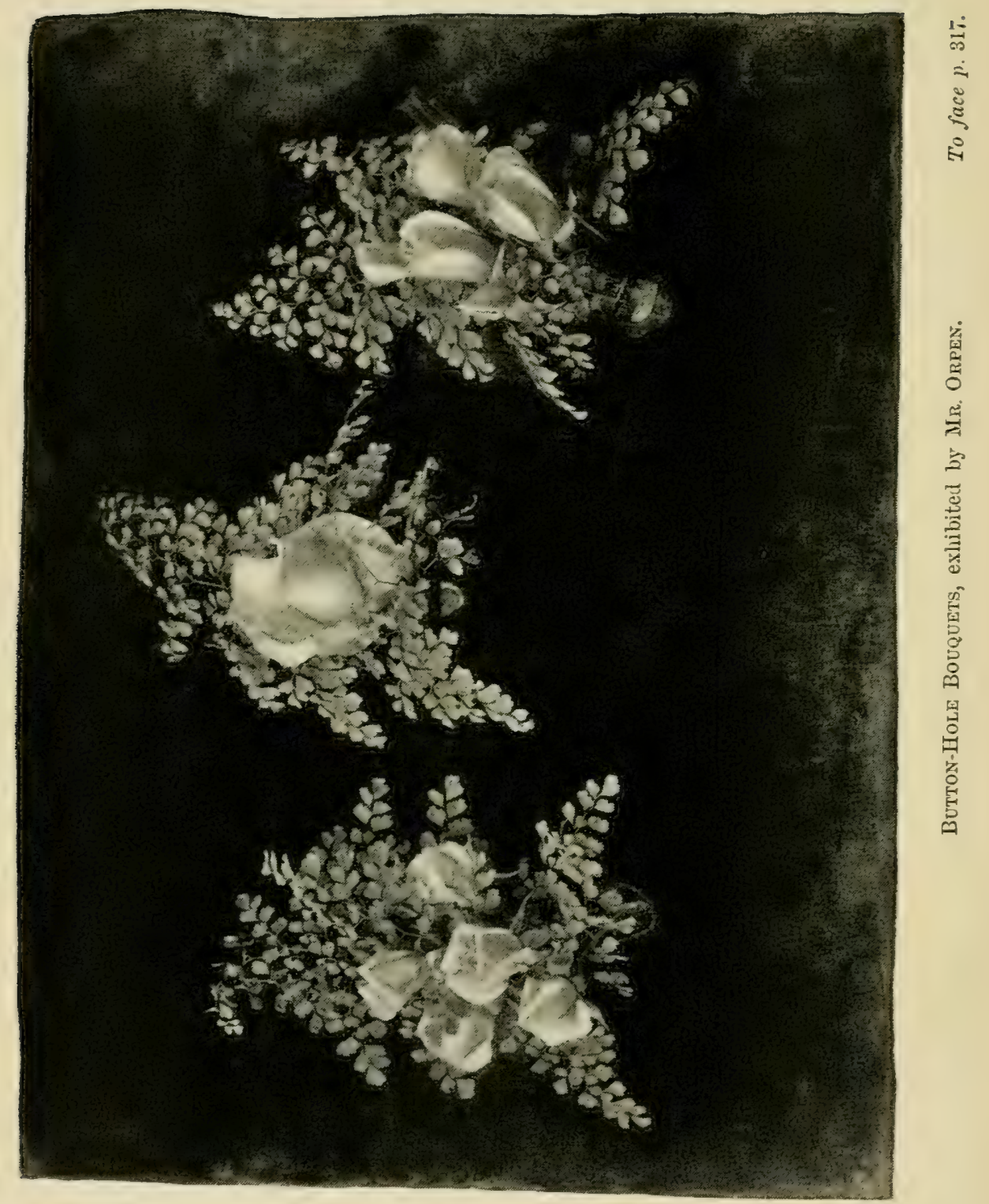


pendent blooms do not display their beauty and are sadly liable to be splashed by heavy showers.

For button-hole Roses, as for exhibition kinds, beauty of form should not be neglected, as it sometimes is, for mere colour, though a combination of both is most desirable. A round fat bud is much less elegant than a long, slender and pointed one. In this respect the Teas have a decided advantage, but if a bright red or really dark bud is desired, the H.P.s must be called upon. The following would be useful as

Six bright or dark H.P.s for button-holes

Duke of Edinburgh

Fisher Holmes

Général Jacqueminot
Gloire de Margottin

Prince Camille de Rohan

Victor Hugo

Twenty-four Teas and Noisettes for button-holes.

Amazone

Anna Olivier

Catherine Mermet

Cleopatra

Dr. Grill

Francisca Kruger

Homère

Innocente Pirola

Isabella Sprunt

L'Idéal

Luciole

Ma Capucine

Madame Charles
Madame Chédane Guinoisseau

Madame de Watteville

Madame Falcot

Madame Hoste

Maréchal Niel

Marie van Houtte

Niphetos

Rubens

Safrano

The Bride

William Allen Richardson

All the above are lovely in the bud, for wearing either singly or together. A choicer selection can be made by referring to their characteristics in Chapter XII. 
Of Moss Roses, the best for wear are the common Moss, which is pink, and Blanche Moreau, which is white. These are summer blooming only, the perpetual forms of the Moss Rose being slightly inferior.

For very delicate, miniature, and artistic buttonholes the Polyanthas are unrivalled.

Six: Polyanthas.

Anne Marie de Montravel

Cécile Brunner

Gloire des Polyantha
Ma Pacquerette

Mignonette

Perle d'Or'

In giving a selection of Roses suitable for pot culture and forcing (see Chap. X.), it should be noticed that "good under glass," or "a good pot Rose," as a catalogue description may sometimes mean simply that the variety will not do out of doors, and it must not necessarily be inferred that it is better for that purpose than others which also do well in the open air.

Twenty-four H.P.s and H.T.s for pots and forcing.

Alfred Colomb

Baroness Rothschild

Beauty of Waltham

Caroline Testout

Charles Lefebvre

Dr. Andry

Duke of Edinburgh

Duke of Teck

Dupuy Jamain

Fisher Holmes

Général Jacqueminot

Gustave Piganeau
Kaiserin AugustaVictoria La France

Lady Mary Fitzwilliam Madame Gabriel Luizet

Merveille de Lyon

Mrs. John Laing

Pride of Waltham

Prince Camille de Rohan

S. M. Rodocanachi

Ulrich Brumner

Viscountess Folkestone

Victor Hugo

The Teas and Noisettes are so specially suited for. 
pot culture and forcing, that I have named an equal number of them.

Twenty-four Teas and Noiscttes for the same murpose.

Anna Olivier

Caroline Kuster

Catherine Mermet

Cleopatra

Comtesse de Nadaillac

Ernest Metz

Ethel Brownlow

Edith Gifford

Innocente Pirola

Madame Falcot

Madane Hoste

Madame Lambard

Madame de Watteville
Maréchal Niel

Marie van Houtte

Medea

Niphetos

Perle des Jardins

Rubens

Souvenir d'un Ami

Souvenir d'Elise Vardon

Souvenir de Gabrielle Drevet

Souvenir de S. A. Prince

The Bride

In making a selection of varieties suitable for culture in a suburban or town garden, there is considerable difficulty without knowing the actual circumstances of the situation. It may vary from that of a small country town, or distant and pure suburb of London, in which case if other matters be favourable the best Roses may be grown, to that of a real town garden in a thoroughly smoky atmosphere, where none can be cultivated to perfection. I have consulted some good suburban growers, but their lists do not at all agree, the probability being that where good Roses can be cultivated at all, most of the best sorts will answer. It seems, however, to be generally admitted that the Austrian briars are as impatient of impure air as any Roses. 
Twenty-four H.P.s suitable for a suburban garden.

Alfred Colomb

A. K. Williams

Baroness Rothschild

Charles Lefebvre

Duke of Edinburgh

Duke of Wellington

Dupuy Jamain

Dr. Andry

Etienne Levet

Eugénie Verdier

Général Jacqueminot

Gustave Piganeau
Her Majesty

La France

Madame Gabriel Luizet

Marie Baumann

Marie Verdier

Mrs. John Laing

Mrs. Paul

Pride of Waltham

Prince Arthur

S. M. Rodocanachi

Ulrich Brunner

Victor Hugo

If any of the delicate Teas can be grown, the list in order of merit should be consulted; and if not, the hardier sorts, as recommended for cottage gardens, should be tried as a commencement. 


\section{CHAPTER XIV}

\section{CALENDAR OF OPERATIONS.}

In the following list of Rosarian work for each month I have not repeated the details of each operation, but merely noted the times when they are to be performed. This is often important, as delay and loss of opportunity will frequently leave a mark on the work throughout the year. A novice should study some such calendar as this, see how much work he has to get through in a given time, and make his arrangements accordingly. It will be seen that a large collection will supply sufficient work to keep a man "out of mischief" pretty nearly all the year round.

October.-By general consent this is considered the first month of the Rosarian's year. Nurserymen's catalogues for the coming season are now to be had, and they are eagerly scanned by ardent amateurs. Orders should be given as soon as possible, and it is better still to visit the nurseries in the early autumn and choose and order the finest specimens. It is rather hard on those who go by the catalogues, but first come first served is a good old rule of trade, and it is right that those who take trouble about a thing should reap some benefit from it. If new beds are to be made, or planting on an extensive scale is to be undertaken, 
preparations should have commenced even in September, in procuring fiesh soil and digging the beds out to the depth of two feet. It should be pushed on at any rate early in October. Pot Roses for growing under glass should now be repotted, and fresh ones purchased if necessary. Many of the firee-blooming 'Teas, now covered with buds, will open them indoors at a time when they will be much appreciated. But beware of too much heat when the amount of daylight is small. This is the month for taking cuttings ont of doors: those of the Roses themselves do better if the leaves have not fallen, and these, if used at all, had better be taken first. Manetti and briar cuttings will do as well without the leaves. All extra long shoots of Roses should now be shortened sufficiently to dininish the wind leverage on the roots; these pieces may be used as cuttings. Towards the end of the month a commencement in planting may be made with those Roses which have simply to be moved from one part of the garden to the other. Such may be planted before their leaves have fallen, much care being taken that their roots are exposed as little as possible; they should be watered and syringed immediately after planting, and will probably do better thus than if moved later. About the middle of the month fresh cuttings may be taken of biar and manetti, and later the rooted cutting and secdling stocks may be planted out, but standard stocks will not bo ready yet. About the middle of the month the wild growth may be removed from those budded stocks wherc the buds look weak.

November.-This is a busy and important month, as it is the time for planting, and the work should be pushed on whenever the soil is fairly dry, for November days are short, and no planting should be done when the 
ground is sticky. Unpack the purchased Roses carefully, and lay them tenderly in the ground when they cannot be planted at once. Be careful in each detail of planting, for much depends upon it. Stocks of all sorts should now be planted also if possible, but there will not be much time yet for getting standards from the hedges. Where seed is saved it should now be gathered. All wild growth is now to be cut away from budded stocks, leaving one or two buds on those laterals of the standards which have been successfully operated on. Roses in pots should be brought into cool shelter before severe weather. In northern districts it may be well to place the winter protection round the Teas before the month is out.

December.-In most English counties it will suffice to apply the winter protection during the first fortnight of this month, but dead leaves should have been collected by the end of the first week in November, and bracken should have been cut and set ready, in sheaves not in heaps, as soon as it began to change colour. It is perhaps best to commence the protection as soon as the Rose planting is finished, even though the setting out of stocks has to be postponed. They will do nearly as well if planted at any dry time during the winter, but a severe early frost coming before the bed-clothes are on the tender Teas may cause much lamentation. Now is the time, on dull damp days, to sally forth with the little stock axe and the Grecian saw in quest of standard stocks. If no winter mulch is applied to the Rose beds, the surfice should still be kept stirred and loose. Roses for the earliest forcing may be pruned and started at the end of the month, and grafting under glass may be commenced about Christmas time.

Senuery. - This is the best month for grafting in heat, Y 2 
CHAP.

though it may be continued in February. In light frosts, strong liquid manure may be put on the Rose beds, when it will sink in rapidly and in quantity. After or during high winds, the Teas may be inspected to see that the protective materials are secure, and standards should be looked to, as they may have broken away from their stakes. Standard stocks may still be got at any time when the weather is open. Even in severe frost work may be found in digging trenches to discover and cut off the invading roots of trees and shrubs Roses being forced under glass will now be starting and requiring much care, and winter grafting will be in full swing.

Fcbruary.-If farmyard manure is used in the soil, now is the time to dig or fork it in, but be sure it is thoroughly decomposed, or in my opinion it will do more harm than good. Still, it supplies the regetable matter of humus, and if the soil in the beds be raw and light-coloured, such an addition is desirable if not necessary, but the upper portion of the beds should originally have been supplied with humus, in old garden mould or the like. If no digging is practised, the soil should be well loosened by the hoe, as some weeds will probably have grown since October. The artificial manure should then be applied, choosing a still day when it can be distributed evenly. If the weather be favourable at the end of the month any arrears of planting may be finished, and stocks of all sorts may still be set out: but Roses planted now may require watering in March and April, if the weather be dry, till they have got a hold. Cuttings should be examined, and those that have been lifted by the frost should be set firm again, either by pushing them down or consolidating the soil around them. Roses on sunny walls may be pruned after the middle 
of the month, and towards the close we may proceed with the summer and hardy garden sorts. Maréchal Niel and other climbing Roses indoors will be starting, and they and all forced Roses should be watched for mildew and insects, and will require much care in the regulation of air and moisture.

March.-This is the month for pruning all outdoor Roses except Teas, but the second week will generally be early enough for H.P.s in northern and midland districts. The Teas should not be pruned yet, but the winter protections should be most carefully removed towards the end of the month. Do not be persuaded to take away the shelter earlier, as the weather is by no means safe yet. It is an error to suppose that the winter protection forces them into precocious growth, for it has just the opposite effect. The same blanket that keeps a man warm will also keep a block of ice cold. It is true, however, that such shoots as are made under the protection grow longer than they would outside simply because they are not stopped by frost, but these premature growths would have to come off in any case. Planting may still be done, with care, but watering will probably be required to follow it. The roots of all plants moved at this time, whether stocks or Roses, should be kept in water as long as they are out of the ground. All budderl stocks should now be staked, and the buds carefully examined, for the grub is sometimes at work before March is out. If it be desired to retard the blooming of Teas, a thick heavy mulch of long wet manure laid on now while the ground is still very cold will keep the roots cool and to a certain extent have the required effect. Be most careful of the ventilation of Maréchal Niel under glass, and attack mildew and aphides when they first appear. With the 
increased light, Roses in pots will bear more heat, but remember that all of them, indoors or out, open their finest and best colomed flowers in a slightly decreased temperature.

April.-In most seasons, in midland districts, the second week will be soon enough for the pruning of Teas. There will be no difficulty in finding Rose grubs now, if the signs indicating their presence in the shoots and young leaves are known. Maiden shoots and buds should be examined the oftenest, as in these cases the life of a whole plant is at stake. Suckers will begin to be troublesome on all plants, especially on maiden standards. Tie up the maiden shoots as soon as possible; if left too long, even though not blown out, they will grow away from the stake, and be troublesome to secure. A regular system of hoeing should now commence on the Rose beds, on which no hard crust must be permitted to form: one of the simpler and smaller forms of pushhoes will generally be found most convenient. If liquid manure is available it may be applied, but cautiously, and not among dwarf maidens. The pushing buds and shoots of pruned H.P.s may now be well thinned; the sooner it is done the better, as rubbing; or even cutting, out a great fat shoot leaves an ugly wound which bleeds a good deal for a time. See that the shoots left are free from pests. Indoors, cut back Maréchal Niel, climbing Niphetos and the like, gradually as the blooms are gathered. The first bloom of the forced Roses will now be over, and liquid manure-not too strong or too cold-may be administered to those intended to flower a second time, by immersing the pots.

May.-This is the month for insect pests of all sorts. The only plan is to go over the whole collection as often as possible: I have sereral times found a large cater- 
pillar or two in the afternoon on a small plant which I had carefully examined in the morning. If a rolled leaf be simply pinched you will probably carefully squeeze the same leaf again half a dozen times: it must therefore either be picked off or unrolled, and the latter plan is best. If several leaf sprays are curled on one shoot the enemy will be found in the topmost one, which probably shows the disfigurement least: he is working upwards towards the bud, and with inherited cumning leaves his past abodes most manifest, and artfully conceals his present one. Be not satisfied with a pinch unless you feel him "go squash." Never" go up and rown without a supply of raffia about you; something is sure to want tying: the maiden plants should be looked over for this pupose very frequently. Do not be satisfied with any shoot till it is firmly and closely tied to a support. Raffia does not keep well in my pockets somehow: there should be supplies of it ready in places close at hand. 'Tea shoots should be thinned; harden your heart if you want good blooms: early trusses will require disbudding before the end of the month. Sucker's should be pulled out or rubbed off as soon as they appear; in fact, there will now be hardly a plant which will not want a little attention pretty frequently. Liquid manure may be applied, particularly to those plants which are already showing flower buds; and hoeing, especially after rain or liquid applications, must on no account be neglected. A further light dressing of artificial manure may be desirable if there has been much heavy rain since February. Towards the end of the month Teas on sunny walls will be in bloom: let them all be cut as wanted, and not remain to seed on the plants. Indoors the Maréchal Niel will have been cut completely back, by slow gradations as the blooms are gathered, to the original 
horizontal old wood. Pot-plants which have bloomed should be hardened off by slow degrees that they may be put out in June.

June-Disbudding will be in progress for a time, of the later sorts. The plague of caterpillar's will be waning, but those that remain will be far more dangerous, as they will now be found attacking the buds themselves. The shoots of all flexible varieties should be staked, the ties being made pretty close to the buds. Watering may be necessary if the weather is very dry, but it is probably better to give none at all if a thorough soaking cannot be managed. Hoe the next day after rain, watering, or liquid manure. Green fly or mildew must be met and combated at once. Where thrips have been prevalent in former years, or at all events in very dry weather, Teas and light-coloured Roses should be syringed in the evening until the petals begin to show. In dry weather Tea buds may be wrapped in paper where intended for exhibition, and the protectorswaterproof cones attached to stakes-should be got out, overhauled, and placed in readiness. Exhibition boxes, tubes, labels, and wires should also be prepared, and moss procured, picked over, and laid on the trays in a shady place in readiness. Constant watchfulness will be required by an exhibitor, as his best bloom may be spoilt by a caterpillar, a gust of wind, or even a shower of rain, in a few hours. Raffia and stakes for tying, and sulphur for mildew, should always be ready where they can be got at once. The new shoots of Maréchal Niel under glass should be thinned and trained up under the wires. Forward stocks may be budded this month with buds from Roses on walls or grafted plants. Roses in pots should have been so hardened off that they can be planted out if desired by the middle of the month It 
is sometimes advisable, to prevent a check, to gently break the pot in the hole made and pick out the pieces rather than turn the plant out. Those plants which are intended for repotting should now be fit and ready for plunging out of doors in their autumnal quarters Many Roses will be in bloom by the end of the month especially the Teas and summer Roses, and the firstfruits, often the best and finest, will gladden our eyes

July.-In many districts this is, in average seasons, the month of Roses, H.P.s being a little later than the old-fashioned Roses of the poets. The last week in June and the first fortnight in July are roughly the general bounds of "the season" for the metropolitan latitude. Rose shows will be in full swing, and exhibitors for a time will have enough to do in cutting their blooms, and rushing about the country night and day to the various shows. Mildew often gets a chance now of establishing itself, and hoeing and aphides are too frequently neglected. It is harvest time, and the details of culture are naturally neglected for a while. Still, even before the show-boxes are put away, budding will have commenced with Tea buds on standard stocks, as these stocks often suffer from a stagnation of sap in August, and Tea buds, which cannot always be got in sufficient quantity, will stand the winter better if they be budded early.

While the Roses are still at their best, it is advisable that notes be made of the colours and good or bad qualities of unfamiliar varieties, as even a good memory may hold a somewhat unreliable picture of certain flowers if they be not accurately judged in comparison with others, and the results of observation committed to writing at once. Now is the time to condemn certain 
sorts for weeding out, and to determine to grow more of others. If it be found that some sort does better in a certain situation or on a particular stock, especial notice should be taken of the fact. The foundations of a good deal of work for the rest of the year may depend upon a few days' observation. All flowers should be cut as soon as they are firded, if not before, as only the rery earliest would be available for seed. Mildew is now likely to be very troublesome, and vigorous efforts should be made to keep it under. Hoeing should not be neglected, or watering if the weather is very dry, but no more liquid manure should be used. Pot Roses should not be neglected, and though they will require but little water, they must be watched for aphides and mildew.

August.-This is the month for budding on all stock: When buds are plentiful and the say of the stocks runs freely, the work should be pushed on as fast as possible, for the sooner it is done the better will be the chance for rebudding in three or four weeks' time the stocks that have failed. Laycring may be rone in this month, and summer cuttings of Roses struck in bottom heat. Watering and hoeing seem the only remedies for rust, the autumn stage of the orange fungus. There is plenty of time for this, and for seeing that aphides do not get a footing anywhere for the man who does not bud his own Roses; but he who does this in any quantity will generally find his hands full, for the mere settling how many, of what varieties, on which stocks, in what situation, he shall bud will require plenty of consideration and arrangement.

September.-Budding on briars should be finished dluring the first week, but manettis may still be budded a little later. Roses for forcing should be kept at rest. 
Maréchal Niel under glass will now probably be growing very fast, and should be kept tied up, and watehed for mildew. Wall Roses may require nailing or otherwise fastening up, as they grow rapidly during this month There will be beautiful Roses in abundance out of doors, among which, if the weather be dry, Teas will be preeminent; but in spite of this I should strongly advise the hard-worked Rosarian now to take a holiday, for if he does not I do not know when he will get one, unless it be during the snows and frosts of Christmas and January. 



\section{INDEX}

Analysis, of soil and Rose ash . . . . . 78 Ants . . . . . . 151

Aphides . . . . . 148

April, work for . . . . 326

Arches, Roses for . . . . 314

Arrangement, of Rose beds . 46

of blooms for

show . . . . 205

Artificial manure . . . . 77

August, work for . . . . 330

Austrian Briars . . . . 18

Ayrshire Rose . . . . . 19

Bariboo stakes . . . . 132

Banksian Rose. . . . . . 21

Bells, shape of . . . . . 45

preparation of . . 48

Black grub . . . . . . 144

Blooms, shapes of . . . 188

faults of . . . 214

Boring insects . . . 147, 148

Bourbon Rose . . . . . 23

Boursault Rose . . . . 20

Boxes for exhibition . . . 195

Bracken, for protection . 58

Briar, Austrian . . . . 18

sweet .... 19

as a stock . . . . 102

seedling , 105118

standard . . 103

cutting . . . 105
Budding . . . . . 106, 119

Burnt clay . . . . . 37

Button-hole Roses . . . 290

selection of 317

Calendar of operations . . 321

Caterpillars . . . . . 145

Chalk soil ....... 40

Chinese Rose . . . . . 23

Christmas, Roses at . . . 180

Classification . . . . 13

Clay soil . . . . . 36 burnt . . . . . 37

Climbing Roses . . . . 313

Colours of Roses . . . . . 212

Cuckoo-spit . . . . . 152

Cultivation . . . . 57,76

Cutting for exhibition . . 196

Cuttings of Roses . . . 136

briar . . . 115

manetti . . 117

DaMask Rose . . . . . 16

December, work for . . . . 323

Depth for planting . . . 52,54

Dijon Teas, pruning of . . 95

Disbudding of shoots . . . 92

for exhibition 93

of buds . . 98, 191

Dog-Rose . . . . . 13, 111

Drainage . . . . . 37,48 
Dressing of blooms for show

Dwarf plants, qualifications of good.

203

50

EARTH, burning of . . . 37 as protection . . . 59

Earwigs . . . . . . 152

Elevation, advantage of . . 30

English Roses . . . . . . 10

grower's . . . 10, 12

Evergreen Rose . . . 20

Exhibiting . . . . . 183

boxes fol . . 195

Fantmies of Roses . . . . 22

Fairy Roses . . . . . . 24

Faults of Roses . . . . 214

Fly, green . . . . . 148

February, work for . . . 324

Forcing Roses . . . . . 176

Form in Roses . . . . . . 188

Fraglance . . . . . 185

French Rose . . . . . . . 16

growers . . . 9

names 11

Friends, insect. . . . . 15j

Frog hoppers . . . . 152

Frost, injury from in May. 167 remerlial measures for 168 protection against, 58,167

Fungus, orange .. . . 163

Gardex Roses.

Glass, culture under . . 171

Grafting . . . . 133

Gravel soil . . . . 39

Gross shoots. . . . . 91

Grecian saw . . . . 109

Habits of Roses . . . . 213

Hoe, use of . . . . 57, 76

Hybrid Bourbon Roses . . 17

China Roses . . . 17
Hybricl Perpetual Roses . . 22 selection of 310

Tea Roses . . . . 22 selection of 312

Hybridisation : . . . 139

ICHNEUMON flies . . 143, 156

Increased culture of Roses . 187

Insects . . . . . . . 142

Iron in soil . . . . . 82

JANUARY, work for . . . 323

Japanese Roses . . . . 26

Josephine, Empress . . . . 9

Juclging . . . . . . 206

July, work for . . . . 329

June, work for . . . . . . 328

LABELS . . . . . . 57

Larvæ of moths . . . . 143

Layering . . . . . . 138

Lawrenciana Roses . . . . 24

Leaves, dead, as protection. $\quad 59$

Liquid manure . . . . . 70

Lime . . . . . 81

Lists of Roses . . . . . 310

Loam . . . . . . 38

Locality . . . . . 30

Macartayey Rose . . . 26

Manetti stock . . . . 102

Manures, natural solid . 65

liquid . . . 70

artificial . . . 77

March, work for . . . . 325

Marl . . . . 41

Maréchal Niel . . . 61, 95

May, work for . . . 326

Middle rows, selections for . 312

Mildew . . . . . . 159

Miniature Roses . . . . 15, 24

Moisture, under glass . . 177 rising in soil . . 56 
Monthly Rose 23

Moss, for exhibition Roses

Moths

195

143

Mulching . . . . 67

Multiflora Rose . . . . 21

Musk Rose _. . . . 25

Names, French _. . . 11

Neglected Roses . . . . 315

Night-soil . . . . . 69

Nitrates . . . . . 80

Noisette Rose . . . . 24, 271

November, work for . . . 322

OCTOBER, work for . . . 321

Odours of Roses . . . . 185

Old-fashioned Roses . . . 183

Operations, calendar of . . 321 manual, by ex-

ample . . . . 38, 123

Orange fungus . . . 163

Otto of Roses . . . . 7

Packing Rose blooms . . . 97

Pegged down Roses . . . . 92

selection of 316

Pests ...... 142

Pillars, Rose . . . . . . 314

Planting . . . . . 43

Polyantha Rose . . . 21, 25 selection of . . 318

Pompon Roses . . . . . . 15

Potash . . . . . . 81

Pot Roses. . . . . . 176 selection of . . 318

Preparation of beds . . . 48

Procuring standard stocks . 108

Propagation . . . . 119

Protection against frost . 58

rain . 193

Provençe Rose . . . . . 14

Pruning . . . . . 84 for exhibition . . 84, 93 roots .... 51
QUEEN of flowers . ... 8

Ratsers, French . . . 9

English . . . 10

Red rust . . . . . 163

Red spider . . . . 173

Remedies for mildew . . . 163 orange fungus 165 late frosts . . 168

Roots of different stocks . 105

Rosarium, pattern or shape of ...... 45

Rose progress . . . . 187

Rose-water . . . . 7

SANDY soil ..... 41

Saw, Grecian _. . . 109

Saw flies . . . 146

Scent of Roses . . . . 185

Scissors . . . . . 197

Scotch Rose . . . . . 18

Seed, Roses from . . . . . 139

Seedlings . . . . . 140

Selections . . . . . 309

September, work for . . 330

Setting up for exhibition . 202

Shading blooms . . . . 194

Shelter . . . . . 32

Site . . . . . 28

Single Roses . . . . . 26

Soils, different . . . . 35

Soot . . . . . 77

Specimen pot plants . . . 181

Sports, climbing . . . . . 271

Stakes for standards . . 31, 132

Standards . . . . . 103 getting the stocks 108

Stocks . . . . . 101

Suckers, to eradicate . . 166 propagation by . . 138

Summer Roses. . . . . 114

Sweet briar . . . . . 19

TALL Standards . . .43, 112

'Tap roots . . . 105, 118 


\section{INDEX}

Tea Roses PAGE PAGE

24 Tying material for . . . 130

pruning of . . 94 Types of Roses . . . . 188 selections of . 311, 313, 317

Thinning shoots . . . . 92 buds . . . 98, 191

Thorns . . . . . 109

Thrips . . . . . . 154

Town gardens . . . . . . 319

Top-dressings . . . . 66

I'railing Roses . . . . . 20

Training Maréchal Niel . 95

specimen pot plants 181

VARIETIES, habits of . . . 211

selections of . . 309

Ventilation . . . . 175

Tying maiden blooms . . . 132

WALLS for Roses . . . . 33, 313

Watering . . . . 76

Weeping Roses . . . . 93

Weevils . . . . 153

Wind, danger from . . . . 31

THE END

RICHARD CLAY AND SONS, LIMITED, LONDON AND BUNGAY. 
in Carefully observe Christian Name.
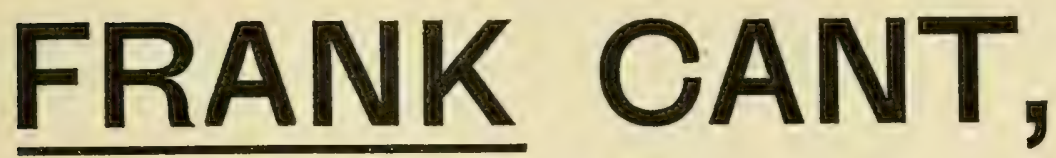

WINNER OF THE

CHAMPION TROPHY of the NATIONAL ROSE SOCIETY FOUR

times, viz.: 1888, 1890, 1892, 1894,

\section{CAN SUPPLY}

\section{STANDARD \& HALF-ST. ROSES,}

\section{DWARF OR BUSH ROSES,}

Roses in pots of all varieties of EXCEPTIONAL QU.ALITI, at Moderate Prices.

ASK FOR IIY ROSE CATALOGUE, THE BEST EVER PUBLISHED.

CAREFULLY ADDRESS-

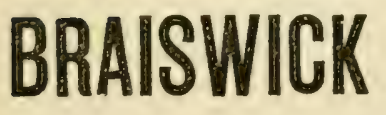

NURSERY,

COLCHESTER. 
KENT. THE GARDEN OF ENGLAND.

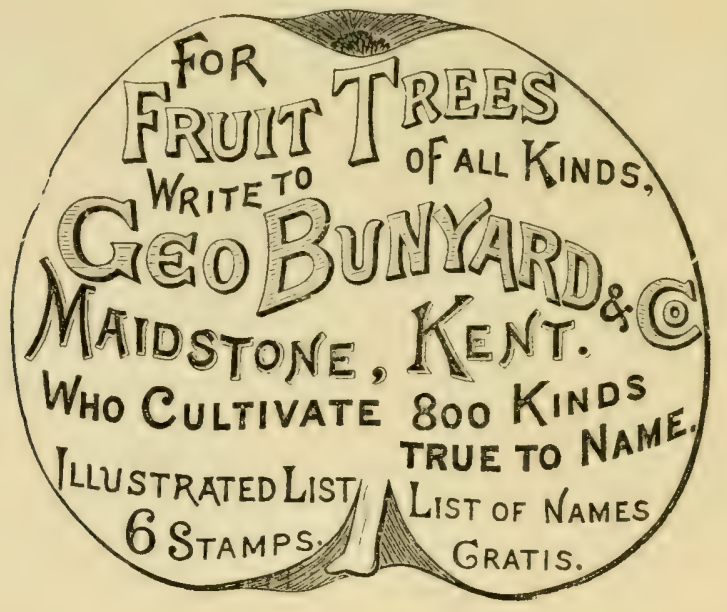

\section{KINDLY ORDER DIRECT. NO AGENTS.}

\section{ROSES. ROSES. ROSES.}

\section{Prior's Colchester Roses}

Have won this Season, 1894,
The Woodbridge Challenge Cup, The St. Osyth Challenge Cup,

1 National Rose Society's Gold Medal, 1 National Rose Society's Silver Mledal, And 43 First and Second Prizes at all the Leading Shows,

D. PRIOR \& SON, Rose Growers and Nurserymen, the best and strongest pleasure in announcing that their Plants are varieties feading and best Stand Perpetuals, Standards, Half Standards, and Dwarfs, which cannot fail to give satisfaction. Catalogues post free on application. 


\section{Rose and Fruit Tree Nurseries,}

\section{BUSH HILL PARK, ENFIELD.}

Where the Rose may truly be said to be "at home," either in open ground or in pots.

\section{HUGH LOW \& CO.}

Cordially invite an inspection.

HeAD OfFICE : CLAP'TON NURSERY, UPPER ClaPTON, N.E.

\section{CELEBRATED IRISH ROSES,}

\section{ALEX. DICKSON \& SONS,}

ROYAL NURSERIES, NEWTOWNARDS, CO. DOWN.

ESTABLISHED 1836.

Raisers of the famous Pedigree Roses, which have been awarded Six Gold Medals, by the National Rose Society, offer strong plants of

MARCHIONESS OF DOWNSHIRE AND

Mrs. R. G. SHARMAN CRAWFORD. The two best Roses of recent years.

A T.SO

A full collection of all the leading roses in cultivation.

Strony Plants at MLderate Prices. 


\section{BENJAMIN R. CANT,}

ROSE GROWER , COLCHESTER,

\section{WINNER OF THE CHAMPION CUP OF THE} NATIONAL ROSE SOCIETY SIX TIMES,

\section{THE JUBILEE CHAMPION CUP TWICE,}

THE CHISWICK CHALLENGE CUP THREE TIMES,

And this now becomes my absolute Property.

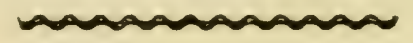

The most successful Grower and Exhibitor for the last 46 Years.

B. R. CANT'S CATALOGUE IS THE BEST PUBLISHED-SENT POST FREE.

The Very Rev. S. REYNOLDS HOLE, Dean of Rochester, President of the National Rose Society, says :-

"No Roses in the World can come up to those of Benjamin R. Cant."

The Rev. H. HONYWOOD DOMBRAIN,

Hon. Sec. National Rose Society, writes:-

"Benjamin R. Cant is still the Champion." 

